\title{
PRICING CARBON EMISSIONS
}

ECONOMIC REALITY AND UTOPIA

Aviel Verbruggen

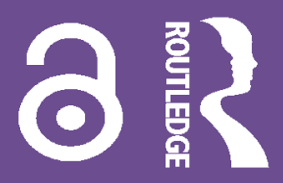




\section{Pricing Carbon Emissions}

Pricing Carbon Emissions provides an economic critique on the utopian idea of a uniform carbon price for addressing rising carbon emissions, exposing the flaws in the economic propositions with a key focus on the EU's Emissions Trading System (ETS).

After an Executive Summary of the contents, the chapters build up understanding of orthodox economics' role in protecting the neoliberal paradigm. A salient case, the ETS is successful in shielding the Business-as-Usual activities of the EU's industry, however this book argues that the system fails in creating innovation for decarbonizing production technologies. A subsequent political economy analysis by the author points to the discursive power of giant fossil fuel and electricity companies keeping up a façade of Cap and Trade utopia and hiding the reality of free permit donations and administrative price control, concealing financial bills mostly paid by household electricity customers. The twilights between reality and utopia in the EU's ETS are exposed, concluding an immediate end of the system is necessary for effective and just climate policy. The work argues that the proposition of shifting to a global uniform carbon tax is equally utopian. In practice, a uniform price applied on heterogeneous cases is not a source of benefits but one of ad-hoc adjustments, exceptions, and exemptions. Carbon pricing does not induce innovation, however assumed by the economic models used by IPCC for advising global climate policy. Thus, it is persuasively demonstrated by the author that these schemes are doomed to failure and room and resources need to be created for more effective and just climate politics. The book's conclusion is based on economic arguments, complementing the critique of political scientists.

This book is written for a broad audience interested in climate policy eager to understand why decarbonizing progress is slow as it is. It marks a significant addition to the literature on climate politics, carbon pricing and the political economy of the environment more broadly.

Aviel Verbruggen is Emeritus Professor at University of Antwerp, Belgium. His experiences and knowledge focus primarily on the subjects of politics, engineering and economics. 


\section{Routledge Explorations in Environmental Economics}

Edited by Nick Hanley, University of Stirling, UK

Economic Diversification Policies in Natural Resource Rich Economies Edited by Sami Mahroum and Yasser Al-Saleh

The Impact of Climate Policy on Environmental and Economic Performance

Evidence from Sweden

Rolf Färe, Shawna Grosskopf, Tommy Lundgren, Per-Olov Marklund and Wenchao Zhou

Economics of International Environmental Agreements

A Critical Approach

Edited by M. Özgür Kayalıa, Selim Çağatay and Hakan Mihçı

Environmental and Economic Impacts of Decarbonization

Input-Output Studies on the Consequences of the 2015 Paris Agreements

Edited by Óscar Dejuán, Manfred Lenzen and María-Ángeles Cadarso

Advances in Fisheries Bioeconomics

Theory and Policy

Edited by Juan Carlos Seijo and Jon G. Sutinen

Redesigning Petroleum Taxation

Aligning Government and Investors in the UK

Emre Üşenmez

National Pathways to Low Carbon Emission Economies

Innovation Policies for Decarbonizing and Unlocking

Edited by Kurt Hübner

The Economics of Renewable Energy in the Gulf

Edited by Hisham M. Akhonbay

Pricing Carbon Emissions

Economic Reality and Utopia

Aviel Verbruggen

For more information about this series, please visit www.routledge.com/ series/REEE. 


\section{Pricing Carbon Emissions Economic Reality and Utopia}

\section{Aviel Verbruggen}

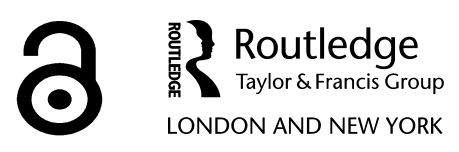


First published 2021

by Routledge

2 Park Square, Milton Park, Abingdon, Oxon OX14 4RN

and by Routledge

605 Third Avenue, New York, NY 10158

Routledge is an imprint of the Taylor \& Francis Group, an informa business

(C) 2021 Aviel Verbruggen

The right of Aviel Verbruggen to be identified as author of this work has been asserted by him in accordance with sections 77 and 78 of the Copyright, Designs and Patents Act 1988.

The Open Access version of this book, available at www.taylorfrancis.com, has been made available under a Creative Commons Attribution-Non Commercial-No Derivatives 4.0 license.

Trademark notice: Product or corporate names may be trademarks or registered trademarks, and are used only for identification and explanation without intent to infringe.

British Library Cataloguing in Publication Data

A catalogue record for this book is available from the British Library

Library of Congress Cataloging-in-Publication Data

Names: Verbruggen, A. (Aviel), author.

Title: Pricing carbon emissions : economic reality and utopia / Aviel Verbruggen.

Description: Abingdon, Oxon ; New York, NY : Routledge, 2021. | Series: Routledge explorations in environmental economics | Includes bibliographical references and index.

Identifiers: LCCN 2021004630 (print) | LCCN 2021004631 (ebook) ISBN 9781032003627 (hardback) | ISBN 9781032003641 (paperback) | ISBN 9781003173816 (ebook)

Subjects: LCSH: Emissions trading. | Carbon taxes. | Carbon dioxide mitigation.

Classification: LCC HC79.P55 V466 2021 (print) | LCC HC79.P55 (ebook) | DDC 363.738/746-dc23

LC record available at https://lccn.loc.gov/2021004630

LC ebook record available at https://lccn.loc.gov/2021004631

ISBN: 978-1-032-00362-7 (hbk)

ISBN: 978-1-032-00364-1 (pbk)

ISBN: 978-1-003-17381-6 (ebk)

DOI: $10.4324 / 9781003173816$

Typeset in Bembo

by Taylor \& Francis Books 
To the memory of my parents: René Verbruggen [†March 20, 1966] and Maria Buyle [†May 1, 1971], who lived honestly, arduously working, a too short life. They left me some financial assets and some intellectual assets, and the choice of which to spend augmenting the other.

My academic motto:

Prefer to speak true words receiving blame, above deceiving advice in soliciting praise. 


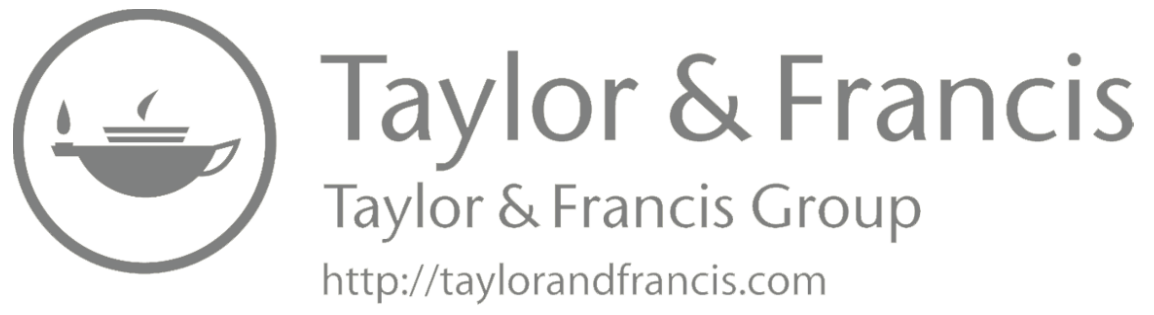




\section{Contents}

List of figures $\quad \mathrm{x}$

List of tables xii

Acknowledgements xiii

About the author xiv

Preface $\quad x$

Executive summary xvii

Roadmap of the book $\quad \mathrm{xxv}$

Acronyms xxvii

1 Introduction 1

1.1 The scene of climate and energy policy, carbon pricing and emissions trading 2

1.2 EU-ETS history in a nutshell 5

1.3 Some economic concepts behind carbon pricing 10

1.4 Equal impact of emitted $\mathrm{CO}_{2}$-eq. molecules is no argument for uniform pricing 14

1.5 Recommendation 16

2 Diversity disqualifies Global Uniform Carbon Pricing for effective climate policy

2.1 Introduction 17

2.2 The concept of diversity and its implications for policy 18

2.3 Amalgamation versus specificity 22

2.4 Global uniform carbon pricing: discourse and performance 24

2.5 Conclusion 28

3 Anatomy of emissions trading systems: What is the EU ETS?

3.1 Introduction 31

3.2 Goals of EU policy (component i) 33 
viii Contents

3.3 Allocation of tradable emissions permits (component iv) 34

3.4 Carbon emissions prices (component iii) 37

3.5 Costs of abatement (component ii) 41

3.6 Linking the four components of ETS 43

3.7 Wrap-up 46

4 What could the EU ETS founders learn from $\mathrm{US} \mathrm{SO}_{2}$ emissions permit trade?

\subsection{Introduction 48}

4.2 Differences between $\mathrm{US} \mathrm{SO}_{2}$ and $\mathrm{EU} \mathrm{CO}_{2}$ emissions permit markets 49

4.3 Salient characteristics of the US acid rain programs 50

4.4 Choices made by the architects of the EU ETS 55

4.5 Concluding reflections 58

5 Early European experience with Tradable Green Certificates neglected by EU ETS architects

5.1 Introduction 60

5.2 Directive $2001 / 77 / E C$ on the promotion of electricity produced from $R E$ sources 62

5.3 Flanders market construct for Tradable Green Certificates 63

5.4 Flanders TGC experiment holds important lessons 65

5.5 The EC's formal evaluation of RE support instruments (EC 2005) 70

5.6 Conclusions 71

6 Critique on price induced technological innovation and on fringe pricing

\subsection{Introduction 73}

6.2 Corporate strategy maximizes financial returns 74

6.3 Pricing carbon emissions and industrial firm's likely reactions 76

6.4 The gap between 'marginal cost pricing' and 'fringe pricing' 79

6.5 The impact of higher EU ETS permit prices 83

6.6 Concluding considerations 84

7 A political economy of the EU ETS

7.1 Introduction 86

7.2 Climate policy in the $3 \mathrm{rd}$ millennium 88

7.3 Actors on the EU ETS scene 111

7.4 The EU ETS policy arena 119 
7.5 Permits trading in artificial markets 137

7.6 Economics critique on the EU ETS 138

7.7 Bewildering EU ETS discourse 140

8 From evaluation to a well thought-out 'Act Now'

8.1 Issues on carbon pricing (CP) 147

8.2 Climate policy and 'Act Now' transformations 154

Annex A: Environmental policy-making and carbon pricing

Annex B: Cost-benefit analysis in the context of climate change $\quad 165$

Annex C: Cost-effectiveness and diversity of emitting sources 173

Annex D: The German feed-in-tariff (FIT): Successful financial incentive 180

Annex E: Ageing electricity economics: Marginal cost pricing $\leftrightarrow$ fringe pricing

References

199

Index

218 


\section{Figures}

0.1 Overview of the book $\quad$ xxv

1.1 The scene of climate and energy policy, carbon pricing and emissions trading

1.2 Posted EU ETS permit prices by the London ICE exchange (2005-2020)

1.3 DPSI frame for global greenhouse warming and climate change $\quad 15$

2.1 Diversity terms and the distinction homogeneous/heterogeneous 20

2.2 Metrics of country performance in applying financial incentive instruments

3.1 Component iv: Allocation of tradable emissions permits 35

3.2 Component iii: Carbon emissions pricing 39

3.3 Component ii: Marginal abatement costs and price-induced innovation

3.4 ETS anatomy consisting of four components and their relations

5.1 Cost coverage, rents and excess profits when three disparate technologies are amalgamated

6.1 Marginal Abatement Cost curves MACi(q) of the aggregate of installations, with innovation shifts over three decades

7.1 OCF quotes clarifying goal and substance of sustainable development

7.2 Dimensions of sustainable development

7.3 The volume of global oil rents (as a \% of GDP) for the period 1970-2017

$\begin{array}{llr}\text { 7.4 Energy efficiency path: opportunity missed } & 99 \\ \text { 7.5 } & \text { Steam electricity generation source and sink flabs } & 102\end{array}$

7.6 Fossil fuel prices and environmental effectiveness 106

7.7 Main actors involved in the EU ETS and in the wider climate debate

7.8 Positions of actors regarding ETS price on carbon emissions 118

7.9 Discursive power masterminded by corporate stakeholders 124

8.1 Energy and technology as substrate of civilizations 146

A.1 Pigouvian tax rate T per unit output $\quad 160$

A.2 Financial incentives are multifaceted 162 
B.1 Simple cost-benefit framing of environmental economics textbooks

B.2 VDPSI@R framework addressing climate change 168

B.3 Cost Benefit Analysis applied to climate change 170

B.4 Valuing impacts on nature and environment: catalog of values 171

B.5 Decision-making context of future time, doubt, and reversibility 172

C.1 Rational polluters reduce emission level from $\mathrm{q}^{\circ}$ to $\mathrm{q} \#$ in reaction to a permit $\mathrm{q}^{\#}$ or an imposed levy $\mathrm{L}$ per ton emitted

C.2 Aggregate MAC of steep $\mathrm{MAC}^{\mathrm{x}}$ and shallow $\mathrm{MAC}^{\mathrm{y}}$

C.3 Minimizing the sum of abatement expenses of three categories of emitters

C. 4 Market of tradable permits

E.1 Marginal cost curves of three generation units: $n^{\circ} 1$ of the merit order; the penultimate loaded $\mathrm{n}^{\circ} \mathrm{k}$ and the marginal loaded unit $\mathrm{n}^{\circ} \mathrm{m}$, visualizing the Lagrange results

E.2 Components and relationships in liberalized electric power supply systems 


\section{Tables}

4.1 Attributes of the US $\mathrm{SO}_{2}$ and $\mathrm{NOx}$ emissions reduction programs (1995-2005) and of the emerging $\mathrm{EU} \mathrm{CO}_{2}$ emissions trading system (2000-2007)

6.1 Juxtaposing Reality and Discourse on carbon pricing

7.1 Observed performance of the EU ETS

A.1 Financial incentives used in environmental policy making

A.2 Criteria (attributes to own, results to obtain) for assessing the performance of policy instruments 


\section{Acknowledgements}

This open access publication is funded by the author's academic credit account, savings of honorarium fees for lectures and advisory studies. Knowledge is a public good, which use is free of rivalry or congestion. Hence, it should be accessible for all and the price should not exclude the millions eager to learn about climate policy and economic instruments.

With thanks to the many colleagues and co-authors, journal editors and reviewers of submitted manuscripts. All of them helped to improve my research work. Most pleasant were the gentle suggestions and critical comments. Also instructive were the academics frantically rejecting my disruptive analysis and propositions, and refusing scientific debate, eventually by lack of arguments. I thank Hanna Brauers for her relevant contributions to the important Chapter 2. Toon Colpaert and, in particular, Pierre Werbrouck pushed me to clarify the first draft manuscript. Pierre, a retired lead economist at the World Bank, helped me with some editing of the book. 


\section{About the author}

Aviel Verbruggen (born 1949) is Emeritus Professor at the University of Antwerp, Belgium. His experiences and knowledge focus primarily on the subjects of politics, engineering, and economics. He has held positions as the Director of research centres and the Chair on institutional advisory councils, and produced numerous publications such as investment appraisals (nuclear power, waste to energy, CHP, renewable power), State-of-the-Environment Reports Flanders, and contributed to reports for the IPCC (TAR, AR4, SRREN). His personal website - www.avielverbruggen.be - holds a repository of around 250 academic contributions in various topics related to sustainable energy transition. 


\section{Preface}

I warmly welcome readers interested in climate policy, policymakers, social scientists and in particular the economists working on carbon pricing. Given your diverse background, the technical aspects in this book are kept to a minimum in the chapters but are covered in annexes.

I wrote this book because facing the climate change challenge requires novel perspectives, practical analysis and disruptive propositions. These are at loggerheads with most literature on carbon pricing and emissions trading. Yet, the valuable elements of economic thinking in climate policymaking are to be maintained. In various gradations we all are economic optimizers in pursuing our goals.

The tension between reality and utopia pervades this book's analysis.

The vaunted economic viewpoint is the supremacy of a 'global uniform carbon price' (GUCP) as either a worldwide, harmonized carbon tax or as the outcome of a global carbon emissions permit trade. This utopian myth is impossible to realize, as the failures in regional or national cases indicate. Global + Uniform do not fit together. The global reality is immensely heterogeneous, and uniformity is only properly applicable in homogeneous cases. This 'global and uniform' economic myth paralyzes climate policy. A myth is scientifically not fully verifiable. It is constructed and lasts by discursive power, exerted by vested interests.

Specific pricing experiments have brought spectacular innovations. For instance, the German and Danish support for harvesting wind and solar electricity developed both technologies to strong maturity in two decades. Uniform price-induced technological innovations did however not materialize, as shown by the EU's emissions trading: the main electrical power companies built large-scale coal plants! Problematic is also the inclusion of the same theoretical mechanism in the models delivering Intergovernmental Panel on Climate Change (IPCC) scenarios for designing climate policy.

Specificity in pricing is an attribute of effective real pricing like in business economics, where all characteristics of goods and services are weighed. In the climate policy debate, vocal voices, like Stiglitz and Stern (2017, p. 4), on the one hand pledge to the uniform pricing idol. On the other hand, they open the window for diversity in activity sectors and adapted policies "to take into account national and local circumstances". 
Hence, the twilights between Reality and Utopia merit investigation to expose the dysfunctional economic myths for ending the climate policy paralysis.

In this book, I advocate for five essential and realistic transformations:

1 To reclaim the substance of Sustainable Development as $3^{\text {rd }}$ millennium paradigm for radical change. Our Common Future (1987) placed Politics central to empower People, bring Prosperity, and respect the Planet.

2 To quit the GUCP utopia and to end the EU Emissions Trading System (EU ETS) chimera. Instead, to apply specific financial incentive schemes respecting the many particularities of heterogeneous cases and to enable fine-tuning of financial incentives, taking into account social realities. Yet, when zero carbon emissions are pursued as nearby goal, the schemes need to be temporary, often short-lived.

3 To end almost all thermal power generation, coal and nuclear first and to trash the deceiving mantra 'renewable energy, nuclear power, carbon capture and storage' as decarbonizing options. The silver bullet of climate policy is $100 \%$ renewable energy supply, mainly harvesting electricity in the ambient environment from wind currents, light waves, and water flows. Industrial processes need to be decarbonized with all tools available by promoting innovation, knowing that uniform price induced innovation will not materialize.

4 To elevate electricity pricing above carbon pricing. A new electricity economic theory is due, because the future power generation systems will no longer deliver power on command [point 3 above]. Electricity prices in many countries are/have been a vehicle for transferring €billions to society projects, such as public transport.

5 Most of the EU ETS expenses are charged to non-ETS electricity customers of the power companies via electricity bills. Public regulation of the electricity sector and pricing is indispensable for installing and guarding the balance between decentralized small-scale generators (households, cooperatives, etc.) and centralized generation.

6 To apply the science, offered by economists like Elinor Ostrom and by other social scientists, for developing self-governance of the commons in global climate policy and at local level (for example cities). Financial incentives are a part of comprehensive and just climate policies. The economics profession can contribute when leaving aside utopian oracles about GUCP.

The main conclusions and recommendations of the book are presented in the Executive Summary and in Chapter 8. 


\section{Executive summary}

Pricing carbon emissions has been endlessly discussed in the centres of climate policymaking. Some pricing of carbon emissions is real and can be judged on criteria of feasibility, effectiveness, efficiency and fairness, for example: excise taxes on car gasoline. To address climate change, economists propose a Global Uniform Carbon Price (GUCP) or a Global Emission Permits Trading System. However, both advertised carbon pricings are utopian, impossible to realize, which makes their decisive evaluation problematic: without the pudding, how to proof the eating?

Yet, the quest for the utopian instruments continues, even intensifies in Europe because EU's policy flagship, the Emissions Trading System (ETS), is not delivering and innovative de-carbonization is obviously absent. The verifiable reality is that under the EU ETS regime, main Western European electric power companies have built coal-fired stations in Germany and in the

Netherlands. Such gaps between 'talk and walk' flourish in the Reality and Utopia twilight zone.

This book clarifies the pricing issues via two scientific channels and then calls to Act Now. The first channel is a critical review of carbon pricing with standard economic analysis as lens and toolbox. The second channel is a political economy analysis of EU ETS, a study of rational decision-making by a kaleidoscope of actors in a context of political and economic institutions, ideas, interests, and infrastructures. Finally, the research and findings are placed in a framework of disruptive and urgent policies to Act Now because Climate Change may turn into irreversible Climate Collapse.

\section{Channel 1: A critique of carbon pricing through standard economic analysis}

When considering the economics of carbon pricing, one has to distinguish between theory and practice. Economists focus on forces of self-interest keeping things ordered in societies. Individuals and communities overcome the forces' permanent myopia in reaching higher goals. Demand for and supply of goods and services are balanced in markets, which are institutions shaped by people. Markets are beneficial institutions when obeying a set of rules. 
Before the neoliberal gulf dazed the minds of most economists, critical follow-up of market functioning was an honourable activity. Neoliberalism, however, has spread market fetishism, which is not a favourable evolution for sound market institutions. All-over, the social science treasure of economics is essential for designing workable climate policies. Yet, failure and contention follow from flawed proposals of implementing economics, with some salient cases documented in this book.

There are three main issues to be considered in standard economic analysis related to carbon pricing:

i Economics' ambivalent treatment of diversity,

ii Price-Induced-Technological-Innovation (PITI), and

iii Assigning to a fringe price the same effectiveness as exerted by an optimal marginal cost price.

The first issue is economics' ambivalent treatment of diversity. The propagation of uniform pricing is harmful for energy-climate policy designs. On the one hand, standard economic analysis neglects diversity or treats it as a cost only. On the other hand, the same economic analysis advocates uniform carbon prices and announces the uniform price will generate benefits proportional to the degree of diversity in the priced emission sources.

This book shows diversity being a gradual property, helpful in cataloguing homogeneous and heterogeneous cases. As Aristotle argued: treat equal cases equally, unequal cases unequally. Unequal treatment of equal cases and equal treatment of unequal cases are unwanted discriminations. Hence, equal (uniform or common) policies fit homogeneous cases. Where heterogeneity prevails, as many specific policies are necessary for the disparate situations.

This knocks out the bottom of the vaunted superiority of uniform carbon pricing proposals.

In practice, diversity is a key element of the real economy. Business is keen in meeting the demands of differentiated actors with a rainbow of technologies, institutions, goods and services, etc. In energy-climate policy, technology and context specific tariffs for electricity from renewable sources pulled wind and photovoltaic technology to maturity in one decade, done by Germany and Denmark.

Market based instruments (inspired by economic theory) did apply uniformly priced green certificates to heterogeneous sources and technologies. This experiment failed and had as main consequence a race to the bottom in technological innovation. Deliberately or unconcernedly, the EU did not learn from the failed market creation in the renewables sector for the set-up of the EU ETS.

The second issue is Price-Induced-Technological-Innovation (PITI). It is an economic rationale to decrease the use of a production factor when its price increases relative to the prices of substitute factors. Technologies needing less of the higher-priced factor are stimulated. As a case in point: applying 
unremitting higher carbon prices are expected to induce the development and deployment of decarbonizing solutions and technologies.

Yet, infinitesimal mathematical evidence of a theory is not automatically converted into broad implementation. The frictions are especially large when the costs of the carbon substitution processes are onerous for companies emitting tens to hundreds million tons of carbon dioxide. Relentless increasing carbon prices on the emissions would cause €millions tax payments by the companies to the treasury and require Emillions company investments in decarbonizing options.

Such transfers are shown optimal in theory, but companies - small to big - are not amused by spending money without financial return. They seal broad anti-tax coalitions, even when the tax would reduce emissions that are harmful for many citizens. Companies want the public treasury to fund decarbonizing innovations.

Anyhow, the EU ETS is not effectively pricing carbon emissions of industrial activities and decarbonizing innovations are not occurring. Effective innovations like wind and photovoltaic power generation have been the result of clever public policy, stimulated by civil organizations, scientists and creative entrepreneurs.

PITI is the theorized innovation engine in market-based instruments, also incorporated in Integrated Assessment Models (IAMs). With the latter, the Intergovernmental Panel on Climate Change (IPCC) generates scenarios for feeding the international debate on climate policy. The gap between hypothesized effectiveness by PITI and factual inertia causes a standstill in global climate policy and in the reduction of carbon emissions.

The third issue is assigning to a fringe price the same effectiveness as exerted by an optimal marginal cost price. Economists advocating emissions trading created confusion between fringe and marginal costs to conceal the free donations of 97\% of the carbon emission permits in Phases 1 and 2 of EU ETS (2005-2012) and of more than 50\% in Phase 3 (2013-2020) and planned for Phase 4 (2021-2030). They refer to a mathematical treatise for supporting the argument that fringe prices will create the necessary incentives for arbitrage among polluters such that the least-cost mitigation solutions are installed.

However, fringe pricing is a tail wags the dog sophism. Leaving theoretical proof to Annex E, will a rational economic agent buy an efficient car when s/ he receives every year free gasoline from January 1 to December 25, but is charged $€ 5 / 1$ for gasoline bought in the last week of the year? Gas-guzzlers love such deals. Similarly, the regulated companies can live with idiosyncratic fringe pricing, additionally sweetened by the tradability of the donated permits, allowing millions of euros in 'windfall' profits (actually rents skimmed on regulatory failure) for major participants in EU ETS.

To clarify the issue, Annex E revisits marginal cost pricing of electric power. Electricity pricing is an interesting case for two reasons: one, clear in showing the fringe-marginal difference; two, electricity pricing is far more relevant than carbon pricing in the transformation to an economy free of carbon emissions, taken up in the final chapter, Chapter 8. 
The studied cases show the utility of mathematical theorems. However, from this utility and formal rigidity one cannot derive practical substance validity. Harsh critique of neoclassical economics in the climate policy arena intends to throw out the water contaminated by utopia, for preserving the baby of sound economic science and practice.

\section{Channel 2: A political economy of EU ETS}

'A political economy of the EU ETS' (Chapter 7, a third of the book's content) is almost a self-contained essay. The context wherein the EU ETS was conceived, set up, and applied is described by major Post World War II bequests. The review of EU ETS actors focuses on the energy companies as the most crucial players. In the crowded EU ETS arena, the real directors prefer secrecy. Footage of the EU ETS play requests the novel perspective of stakeholder masterminding, overstepping captured regulation.

Post-World War II bequests are decidedly relevant for climate policymaking in the $3^{\text {rd }}$ Millennium. The following major distinct bequests are discussed:

- Sustainable Development for Our Common Future, published in 1987. Revisiting the paradigm's substance shows how the Planet-People-Profit mantra erased the actual $4 \mathrm{P}$ of Politics-Planet-People-Prosperity. Without empowering politics, the remaining $3 \mathrm{P}$ mantra is like a wind turbine without generator: it delivers no power, hence no transformative change.

- The 1970s penultimate warning to humankind about its exploitative and destructive interaction with its life-supporting environment was largely denied, often mocked by economists. The positive effects of high-priced fossil fuels beginning 1980s were superseded by anti-tax coalitions. Equating \$billions of rents extorted by oil exporters to $\$$ billions tax revenues of national treasuries, was an intentional blunder, rather supported than exposed by the economics profession. Anti-tax rhetoric matched the upcoming neoliberal paradigm in the 1980s.

Several decades of neoliberal dominance had a significant impact on many institutions for the common good and eroded the public political capability and capacity. It delayed action on deploying substantial sustainable development and on mitigating climate change. Consequently, the world is not well prepared to face the ultimate warning of Climate Change turning into irreversible Climate Collapse.

- Indispensable energy-technology transformations were since Atoms for Peace (1953) expected from the utopia of nuclear power as backstop technology. Notwithstanding unseen scientific, economic, political, and societal support, nuclear technology is decaying. It survives on subsidies and by discursive power masterminded by the International Atomic Energy Agency (IAEA). The IPCC reporting has also been infected by 
the IAEA discourse. It holds up the tripod mantra zero- and low-carbon energy supply from renewables, nuclear energy, and fossil energy with carbon capture and storage (RE, NP, CCS) as juxtaposed low-carbon options, while they are largely conflicting options. This book documents the stories of power exerted by nuclear power advocacy with examples from first-line exposure.

- Incredible progress in future-oriented technologies (microelectronics, data processing Information and Communications Technology, aerodynamics, new materials, biotechnology, etc.) provided the fructuous substrate for energy efficiency and renewable power harvesting from wind currents and light waves. Since 2018, wind and PV generate electricity at lower financial expense than thermal power from fossil or nuclear fuels.

This increases the pace of energy transformations that are delayed and stifled by fossil and nuclear fuel businesses. The latter are helped by established organizations and by people who prefer the status quo or who are dazzled by the revolutionary reversals happening.

Discursive power and false narratives bolster this inertia, for example: "by reducing carbon emissions present generations pledge offers for the well-being of future generations' is a preferred economics framing, while emitting carbon is literally littering the atmosphere. Littering is illegal, and litterers are condemned to stop littering immediately and clean up the mess they created.

The EU ETS arena is filled with a large number of actors. Starring is a triumvirate of clusters of large companies, many operating at a transnational scale: oil and gas, electricity generation and industrial companies (steel, cement, chemicals, etc.).

BP and Shell have broken the ground in the conception and founding phase (1997-2005) of the EU ETS. The European electricity generating companies were at that moment more occupied with the challenges of power sector liberalization. Ever since the start of the ETS in 2005, the electric power companies' role amplified, and after obtaining in 2012 a separate legal status in the ETS, they hold the reins. Among the heterogeneous industrial sectors, some favour the ETS, some are cool lovers and others are reluctant ones. The more climate policy is in the hands of technological problem-solvers in a company, the lower the support for the ETS. With emissions trading, the financial staff has now taken over the climate change mitigation desk.

Although heterogeneous in activities and technologies, companies pursue common goals, such as earning above average returns, avoiding taxes on greenhouse gas (GHG) emissions, delaying deep decarbonizing investments, in summary: preserving 'Business-as-Usual'. Such goals do not match with drastic and urgent reductions in GHG emissions that are necessary to avoid climate collapse. Yet, EU climate politics pretend the EU ETS can reconcile Business-as-Usual profitmaking with climate goals.

The EU ETS is a product of stakeholder masterminding, a participative approach of co-creation and sharing in the governance of public affairs. 


\section{xxii Executive summary}

Official government is complemented by hidden informal power executed by mainly corporate stakeholders according their know-how, networks, money resources, staff, and capability for quick problem solving. Discursive power and narrative setting is crucial in realizing the above-mentioned triumvirate agenda. It is founded on "symbols, and story lines, the provision of effective evidence and compelling arguments in the public debate" (Fuchs 2007).

The EU ETS symbol is the price notation of permits at the exchanges in Leipzig and London. Although volatile, dubious, and unclear what it covers (see fringe pricing), the price attracts most attention and hides money flows, essential for the stakeholders. The Cap and Trade story was instrumental in creating the ETS and is held up as a façade. What happens behind this façade is the opposite of Cap and Trade: the EU administration donates free permits to most emitting activities, and the cap is adapted for obtaining a wanted price range.

There is no evidence that the EU ETS has generated GHG emission reductions or has induced decarbonizing innovations. The arguments for the EU ETS are all derived from abstract neoclassical economic theory and are not compelling. With unconvincing interpretations of economic theory, the arguments continue to be advertised. Chapter 7 details the critique and explains how a flagship with two bows in opposite direction, without a functioning engine and propeller, avoids wrecking.

\section{From evaluation to a well-thought-out 'Act Now'}

The book's raison d'être is disruptive. Urgent reversal not being a choice, it is a necessity. Climate activists' Act Now is not utopian, when rooted in science, evidence and experience. For example, energy systems transformations are precursory for intertwined societal transformations. Removing vested interest barriers and clearly designing the sustainable alternative will incredibly accelerate renewable power deployment. After conclusions on pricing, a well-thought-out Act Now is explored.

Applied carbon pricing's future should be the shortest possible, by keeping in sight the full decarbonizing goal as a nearby one. I recommend ending uniform carbon pricing experiments because they lack efficacy, efficiency, and equity, waste significant resources and occupy the policy arena. Immediate and full stop ending avoids soft remedies, which anyhow would be absorbed and grinded by stakeholder masterminding, as what happened over the last decades.

A hard cure of high $\left(>€ 100 /\right.$ ton $\mathrm{CO}_{2}$-eq) carbon taxes on EU's industrial activities is no proper alternative. Instead, specific subsidies or taxes on goods and services exist and entail climate benefits or burdens, with observable impacts on equity and justice. World and EU politics need to focus on unjustified subsidies for fossil fuels and nuclear power or on profit tax evasions by transnational corporations.

Rubicon crossing from uniform utopia to a more diverse reality dissolves the economics hubris based on neoclassical theory and opens the way to reconnect 
with other social sciences constructing diverse solutions for diverse problems in diverse societies. Economics will become a respected discipline when it contributes to managing peoples' and companies' self-interest for preserving the climate commons.

Electricity pricing is more relevant than carbon pricing in deploying a sustainable decarbonized future. The backbone energy carrier for performing most of human activities will be electric current forthcoming from wind, light and water flows. In 2020 about $90 \%$ of power is generated on command, i.e., the system operator decides at any moment which capacities deliver or stay idle. Electricity supply management is about least-cost reliable power generation and delivery from mainly command-driven plants. This management has to be reverted, because harvested power from nature's flows is only available according to variable, partly stochastic natural phenomena.

The timely revision of electricity economic theory and models should address the new realities and guide the transformations of electricity systems. Challenging issues are inter alia service reliability, islanding of load pockets, and significant momentary redundancy in generated power from natural sources at zero or very low marginal costs. Redundancy leads to curtailing some supply sources, causing conflicts about remunerations and curtailment ranks. Novel solutions, such as 'supply-demand proximity' rules, will supersede conventional merit-order rankings of capacities on command. Principled choices on the prevalence of distributed end-user harvesting or of centralized company projects are guiding future developments of the power systems.

Physical and economic proper cooperation between distributed and centralized power generation is societal optimal, but not evident without excelling public regulation. Electricity pricing research is a better spending than quests for utopian carbon pricing mantras. Understanding electric power engineering essentials seems prerequisite in this multidisciplinary endeavour.

Act Now means breaking inertias in ideas, institutions, interests, infrastructures and energy-technology transformations, for replacements by sustainability options. The extraordinary influence of flawed ideas is stupefying. The investigation of carbon pricing and climate policy encountered dangerous myths, misleading language and images, and stakeholder masterminding via supreme, as well as hermetic and participative EU ETS discourse.

Although the Cap and Trade façade of the ETS is lambasted by critical voices and strong evidence, it continues to daze the minds of economists and politicians and conceal the facts. This book adds an economics critique and a political economy analysis for demolishing the façade and the EU ETS. Because escaping climate collapse demands very effective, efficient and just climate policy.

Progress in Act Now depends on the successful reclaiming of the paradigm of sustainable development with the substance of Our Common Future. Moreover, it depends on the relationship man-nature turned upside down in nature-man, on climate economics reconnecting with classical economics and other social sciences with due respect for diversity, on faster deployment of 
distributed renewable power generation worldwide helped by excellent public regulators, etc.

At presentations of parts of this analysis and results, some have considered my critique severe and desperate. The opposite is true: when we cannot do better than the actual policy over the last decades, then there is no hope. Showing the flaws, failures, and the responsible interests masterminding the utopian mantras, levels the path for opposite policies and deployment of sustainability solutions.

If this book brings you new information and insights, it merits a good score and an excellent one when it spurs you to consider its conclusions and recommendations. 


\section{Roadmap of the book}

The figure below provides an overview of the book's contents, and shows which chapters refer to which annexes. The annexes refresh economic concepts with graphs and mathematics. They support the arguments of the book, mainly in discussion with economists. It is not necessary to study the annexes and understand the mathematics or graphs for reading the book chapters.

Figures and Tables are numbered by chapter/by annex. [Vertical brackets are used for cross-references to sections, figures, and tables].

Chapter 1 first offers a description of my assessment of the societal scene whereon carbon pricing evolves. Then an overview of the EU ETS and some economic concepts underlying carbon pricing are introduced.

\begin{tabular}{|c|c|}
\hline $\begin{array}{c}\text { Preface } \& \text { Executive Summary } \\
+ \text { Roadmap of the book, Table of Contents, Acronyms }\end{array}$ & \\
\hline $\begin{array}{c}\text { Chapter } 1 \\
\text { Introduction }\end{array}$ & $\begin{array}{c}\text { Annex A } \\
\begin{array}{c}\text { Environmental policy-making } \\
\text { and carbon pricing }\end{array}\end{array}$ \\
\hline $\begin{array}{c}\text { Chapter } 2 \\
\text { Diversity disqualifies Global Uniform Carbon Pricing } \\
\text { for effective climate policy }\end{array}$ & $\begin{array}{l}\text { Annex B } \\
\text { Cost-Benefit Analysis in the } \\
\text { context of Climate Change }\end{array}$ \\
\hline $\begin{array}{c}\text { Chapter } 3 \\
\text { Anatomy of Emissions Trading Systems: } \\
\text { What is the EU ETS? }\end{array}$ & $\begin{array}{c}\text { Annex C } \\
\text { Cost-effectiveness and diversity } \\
\text { of emitting sources }\end{array}$ \\
\hline $\begin{array}{l}\text { Chapter } 4 \\
\text { What could the EU ETS founders learn from US } \mathrm{SO}_{2} \text { emission } \\
\text { permit trade? }\end{array}$ & \\
\hline $\begin{array}{c}\text { Chapter } 5 \\
\text { Early European experience with Tradable Green Certificates } \\
\text { neglected by EU ETS architects }\end{array}$ & $\begin{array}{l}\text { Annex D } \\
\text { The German Feed-in-Tariff (FIT): } \\
\text { successful financial incentive }\end{array}$ \\
\hline $\begin{array}{c}\text { Chapter } 6 \\
\text { Critique on Price Induced Technological Innovation } \\
\text { and on Fringe pricing }\end{array}$ & $\begin{array}{c}\text { Annex E } \\
\text { Ageing Electricity Economics: } \\
\text { Marginal Cost pricing } \Leftrightarrow \text { Fringe }\end{array}$ \\
\hline $\begin{array}{l}\text { Chapter } 7 \\
\text { A Political Economy of the EU ETS }\end{array}$ & \\
\hline $\begin{array}{c}\text { Chapter } 8 \\
\text { From evaluation to well thought-out 'Act Now' }\end{array}$ & References \\
\hline
\end{tabular}

Figure 0.1 Overview of the book 
Chapter 2 critiques uniform carbon pricing as neglecting diversity. It argues that specific prices and policies are needed when heterogeneity prevails. The chapter shows that diversity disqualifies the use of GUCP for effective climate policy.

Chapter 3 analyses the conflicting goals of the EU ETS: reducing emissions by price-induced innovation and low expenses for the emitting companies. It also discusses price-induced innovation in abatement technology.

Chapter 4 reviews the lessons the EU ETS could have learned (but did not learn) from the USA Sulphur Dioxide emissions permit trade.

Chapter 5 analyses the early experiences of the Tradable Green Certificates in Flanders (Belgium). Imposing a uniform price on heterogeneous activities is the source of unsuccessful implementation and of exuberant rent skimming.

Chapter 6 reviews issues related to the implementation of price-induced technical innovation (PITI) and deals with the differences between marginal cost and fringe pricing.

Chapter 7 offers a political economy of the EU ETS with a sobering vision on the instrument. This includes climate policy challenges of the $3^{\text {rd }}$ millennium with a focus on indispensable energy-technology transformations. Section 7.4 analyses the corporations' stakeholder masterminding and their discursive power to set the narrative to uphold a façade of carbon pricing, while shielding for diligent policies that could interrupt their Business-as-Usual (BaU) activities and plans.

Chapter 8 summarizes the main findings on pricing carbon emissions. For a sustainable energy future, focusing on electricity pricing is recommended. In a second section, suggestions for more radical policies support a well-thought-out Act Now path for avoiding climate collapse. 


\section{Acronyms}

AC Abatement Costs (for mitigating emissions of GHG)

AR\# Assessment Report \# 1, 2, 3, 4, 5, 6 edited by IPCC

BAT Best Available Technology (applicable at reasonable expense)

$\mathrm{BaU} \quad$ Business as Usual

$\mathrm{CaC} \quad$ Command and Control (regulatory approach)

CAN Climate Action Network

CaT Cap and Trade

CBA Cost-Benefit Analysis

CCEG Control Committee for Electricity and Gas (Belgium, 1955-2003)

CCS Carbon Capture and Storage

CDM Clean Development Mechanism (Kyoto Protocol)

$\mathrm{Ce} \quad$ Carbon emissions; $[\mathrm{Ce}=0]$ is the goal of emissions policy

$[\mathrm{Ce}=0] \quad$ Zero Carbon emissions (as-soon-as-possible)

CHP Combined Heat and Power (use waste heat from a thermal power plant)

CICERO Centre for International Climate and Environmental Research

COP Conference of Parties (of the UNFCCC)

CP Carbon Price/Pricing

CPR Common Pool Resources (Ostrom, 1990); Commons

DC Damage Costs (due to climate change)

DCF Discounted Cash Flow

DNO Distribution Network Operators (of electricity, gas systems)

DoP Donation of Permits (free allocated licenses to emit GHG)

EC European Commission

ECX European Climate Exchange (London)

EEG Erneuerbare Energien Gesetz (Renewable Energy Act)

EEX European Energy Exchange (Leipzig)

EITE Emissions Intensive Trade Exposed (industrial activity/ies)

ETS Emissions Trading System/Scheme (of permits to emit greenhouse gases)

EUA European Union Allowance (licence to emit 1 ton $\mathrm{CO}_{2}$ eq GHG)

EUTL European Union Transaction Log (of emission permits)

FEEM Fondazione Eni Enrico Mattei 
FIT Feed in Tariff (price for electricity delivered to the grid)

GDP Gross Domestic Product

GHG Greenhouse Gases covered by UNFCCC [carbon dioxide $\mathrm{CO}_{2}$,

GUCP Global Uniform Carbon Price/Pricing

IAEA International Atomic Energy Agency

IAM Integrated Assessment Models (IPCC)

IEA International Energy Agency

IEM Internal Energy/Electricity Market (in Europe)

IETA International Emissions Trading Association

IGOP Independent Generator of Own Power (similar to 'prosumer')

IIASA International Institute of Applied Systems Analysis

IPCC Intergovernmental Panel on Climate Change

IRENA International Renewable Energy Agency

ISO Independent System Operator (of electric power system)

LCp Levelized Cost-price [Annex E]

MAC Marginal Abatement Cost

MBI Market-Based Instruments (tradable emission permits, emission taxes)

MC Marginal Cost

MDC Marginal Damage Cost

MER Market Exchange Rates

MRV Monitoring, Reporting, Verification (crucial for cooperation and control)

MS Member State(s) of the EU

MSR Market Stability Reserve (EU ETS price control mechanism since 2019)

NACE European Statistical Classification of Economic Activities

NET Neoclassical Economics Theory

NGO Non-governmental organization

$\mathrm{NP}$

OCF

OECD

PIK

PITI

PPP

PV

RE

Nuclear Power (substitute for the better name Atomic Power)

Our Common Future (publication of WCED, 1987); see SD

RFF

Organization for Economic Cooperation and Development

Potsdam Institute for Climate Impact Research

RGGI Regional Greenhouse Gas Initiative (GHG emissions trading, USA)

$\mathrm{R} / \mathrm{P} \quad$ Reserves/Production (of global crude oil; yearly published by BP)

SCC Social Cost-price of Carbon (when MAC = MDC)

SD Sustainable Development; OCF-SD refers to the full, original substance

SDG Sustainable Development Goal (UN) 
SM

SPM

SRMC

SSREN

TGC

TMI

TSO

UNFCCC

WCED

WG\#

WRI

WWF
Stakeholder Masterminding

Summary for Policy Makers (part of IPCC reports, agreed in plenary meeting)

\section{Short Run Marginal Cost}

Special Report on Renewable Energy (IPCC, 2012)

Tradable Green Certificates (1 per MWh Renewable Electricity generated)

Three Miles Island (USA site of a nuclear melt down in 1979)

Transmission System Operator (see also ISO)

United Nations Framework Convention on Climate Change

World Commission on Environment and Development

Working Group \# 1, 2, or 3 of IPCC (WG3 is on mitigation and policies)

World Resources Institute

World Wildlife Fund 


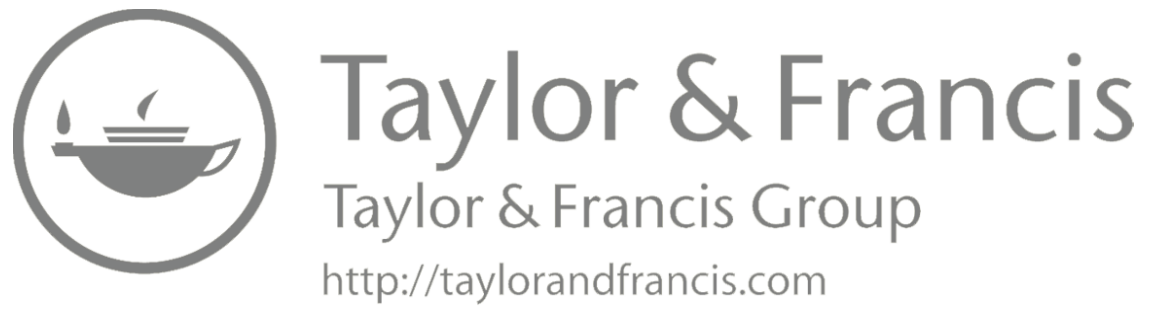




\section{Introduction}

The EU ETS has a troubled history, and the environmental benefits of this economic instrument are contentious. Climate economics is linked to other economic disciplines. Understanding the essentials of economics enhances the debate about its most central climate policy tool, carbon pricing. Self-interest is a strong force in ordering private and public affairs. Financial incentives piggyback on this force to influence decisions and activities of economic actors. The incentives correlate with potential and effective money flows between the private and public sector. In stylized economic theory, based on the adopted assumptions, prices conquer the pole position, although in the real world, price is only an indicator and subordinate to money that people want to own.

Price theory is not easily converted in good pricing practices. Pigou's tax for internalizing externalities is explained in Annex A, but the practical aspects of financial incentives reveal intricacies and pitfalls. Carbon pricing opens the cost-benefit analysis box [Annex B], delivering the concept of the Social Cost of Carbon, with much dispute about its numerical value. The second-choice carbon price $(\mathrm{CP})$ in neoclassical economic theory is a GUCP, which would realize overall least costs for reducing given quota of carbon emissions [Annex $\mathrm{C}$ ]. To obtain fluent and short text in the chapters, Annexes A, B and C document economic concepts of general use in the climate debate, also clarified with basic mathematical formality and graphs.

The discipline of this book is climate economics, at the junction of environmental and energy economics. In the 1960/70s environmental economics emerged as an offspring of welfare economics, itself indebted to microeconomics. Hence, climate economics is rooted in microeconomics. Mainstream neoclassical economics and its derivatives welfare and environmental economics are the main content. However, this chapter and the related Annexes A, B and C are not a copy-paste of content from conventional economics publications. The neoclassical economics material is presented with supplementary comments for broadening the perspective, crossing its narrow scope, and revealing its stylized approach built on many assumptions. In addition, fuzzy language in advocating uniform carbon pricing is exposed.

The purposes of Chapter 1 are

DOI: $10.4324 / 9781003173816-1$ 


\section{Introduction}

$\mathrm{i}$ to describe the scene of climate and energy policy including carbon pricing and emissions trading,

ii to provide an introduction to the EU Emissions Trading System as I see it,

iii to clarify economic concepts used in the debate about carbon pricing,

iv to refute the argument that the global spread of GHG molecules is an argument for global uniform pricing, and

$\mathrm{v}$ to recommend full transparency on the money patches and flows related to particular carbon pricing applications and proposals.

\subsection{The scene of climate and energy policy, carbon pricing and emissions trading}

Why do I add another analysis to the thousands of publications about carbon pricing and emissions trading? The authors of the numerous publications are mostly economists favouring and defending emissions trading in general and the EU ETS in particular as the single largest carbon market and the flagship or cornerstone of the EU's climate policy. The framing and scope adopted by a study determine which concerns about the EU ETS structure, functioning, performance, effects, etc., are considered. The framing and scopes of the studies are diverse, generating a range of positions regarding carbon markets. A classification may encompass following (non-exhaustive) categories:

- Hagiographic, treating the subject with undue reverence (e.g., Ackerman and Stewart 1988; Baranzini et al. 2017).

- Apologetic, constituting a formal defence or justification of the doctrine (e.g., Ellerman et al. 2010; Hahn and Stavins 2011).

- Indulgent, sympathetic and suggesting remedies for the shortcomings (Ellerman and Joskow 2008; Neuhoff 2008; Passey et al. 2012).

- Independent, cautionary in observing and reporting its emergence and setup (Baldwin 2008; Meckling 2011) or functioning (Parry and Pizer 2007; Marcu et al. 2017; 2019).

- Critical about its pretended and actual performance (Toke 2008; CAN 2018; Rabe 2018).

- Rejecting, dismiss as inadequate, unacceptable, or faulty (Spash 2010; Pearse and Böhm 2014; Bryant 2016).

I consulted publications of the entire spectrum because all positions shed different lights on various aspects of the EU ETS. Confirmations of my own critical analysis are found in the cautionary independent and critical literature. By following the ups and downs of the EU ETS since its conception started in 1998, my academic critique evolved into deep concern about two lost decades for developing and deploying adequate policies for decarbonizing human activities.

I do not "take for granted the positive value of carbon markets" (Stephan and Paterson 2012, p. 547), and now I reject the propositions of the EU ETS 
being a good policy instrument, its axiomatic assertion of self-evidently truth, its biased use of mathematical theorems and its cheap slogan 'a good idea sells itself.

Academics with extended critique on carbon markets, and often rejecting the EU ETS, are mostly non-economists, for example Coelho (2015) qualifies carbon trading as ineffective, undemocratic, unjust and unethical, Pearse and Böhm (2014) discuss "Ten reasons why carbon markets will not bring about radical emission reduction”.

Among economists, an overwhelming majority approves the EU ETS, at least in principle. The economics community specialized in climate policy and carbon pricing exhibits strong resistance against investigating and questioning of the established wisdom about the role of prices and markets. My analytical lens for studying the EU ETS is economics: I employ the toolkit of neoclassical economics and its offshoot disciplines, such as welfare, environmental, and energy economics. Technical engineering research on one side and practice in political economy cases on the other side, enlarge the scope of my research lens.

However, this study of carbon pricing respects the essential economic concepts (such as self-interest, demand and supply, market, marginal cost pricing, etc.) and uses the standard mathematical theorems (such as Lagrange optimization). The concept of carbon emissions trading is valid 'in theory' (Tietenberg 2006). However, every implementation is circumstantial and contingent on the subject and context of the intended ETS. For example, for the EU ETS matter the legal, political, economic, social, environmental conditions of the Union, and the role of the European Commission (EC) as political entrepreneur (Skjaerseth and Wettestad 2010).

A study of carbon pricing and carbon trading for addressing climate change is not confined to theoretical theorems in a frictionless vacuum bubble. Design, set-up, and operation of financial incentives are influenced by, and interacting with, other forces active in society (Stiglitz and Stern 2017).

The diverse ranges of societal actors, living on a green Earth encircled by a blue Atmosphere, are driven or uphold by many forces, summarized in five interacting clusters [Figure 1.1]. Actors pursuing their goals manage and endure Ideas, Interests, Institutions, Infrastructures and Indispensable energytechnology transformations (Green 2016; Carlson and Fri 2013; Smil 2017). Climate and energy form an intimate diptych; a scholar neglecting one panel truncates the understanding of the other.

1 Ideas (myths, narratives, discourses, language, paradigms, etc.). Ideas influence the minds of people and purport legitimacy to the actions and positions of societal actors (Lakoff 2010). Biased language imprints faulty beliefs in the minds of people. At several occasions, substitution of appropriate language for flawed or imprecise expressions will be proposed and applied in this book. For example, it is better to say Donations of Permits (to emit volumes of GHG) instead of free allocation of allowances. Often, the essential word 'free' is omitted in publications. 


\section{Introduction}

The neoliberal paradigm has been instrumental in pushing the policy and the public interest to roles subservient to markets and in setting up artificial markets, such as carbon markets. At several occasions, utopian constructions and utopian beliefs are crowding out the link with and the sense of reality. Trained as an engineer-mathematical economist, it took a long time before I started to understand the exceptional power of the cluster Ideas, i.e., discursive power, in the functioning of societies. Masterminding energy companies knew better.

While writing this text (April 3, 2020), my daily paper prints: "under the EU ETS electricity generators, industrial companies and aviation companies must buy emission licenses for every ton of $\mathrm{CO}_{2}$ they emit". This evident error seeds confusion in the heads of politicians and citizens and assigns legitimacy to a system that does not merit it.

2 Interests (positions, power, knowledge, capital, income, etc.). Interests are quantified and monetized in money stocks and flows, when the economic lens is applied. Carbon pricing and trading are evidently focused on money. Societal actors pursue their interests. Some actors (for example climate activists) may prefer non-monetary interests above money, but this is not the case for most actors listed in the centre of Figure 1.1.

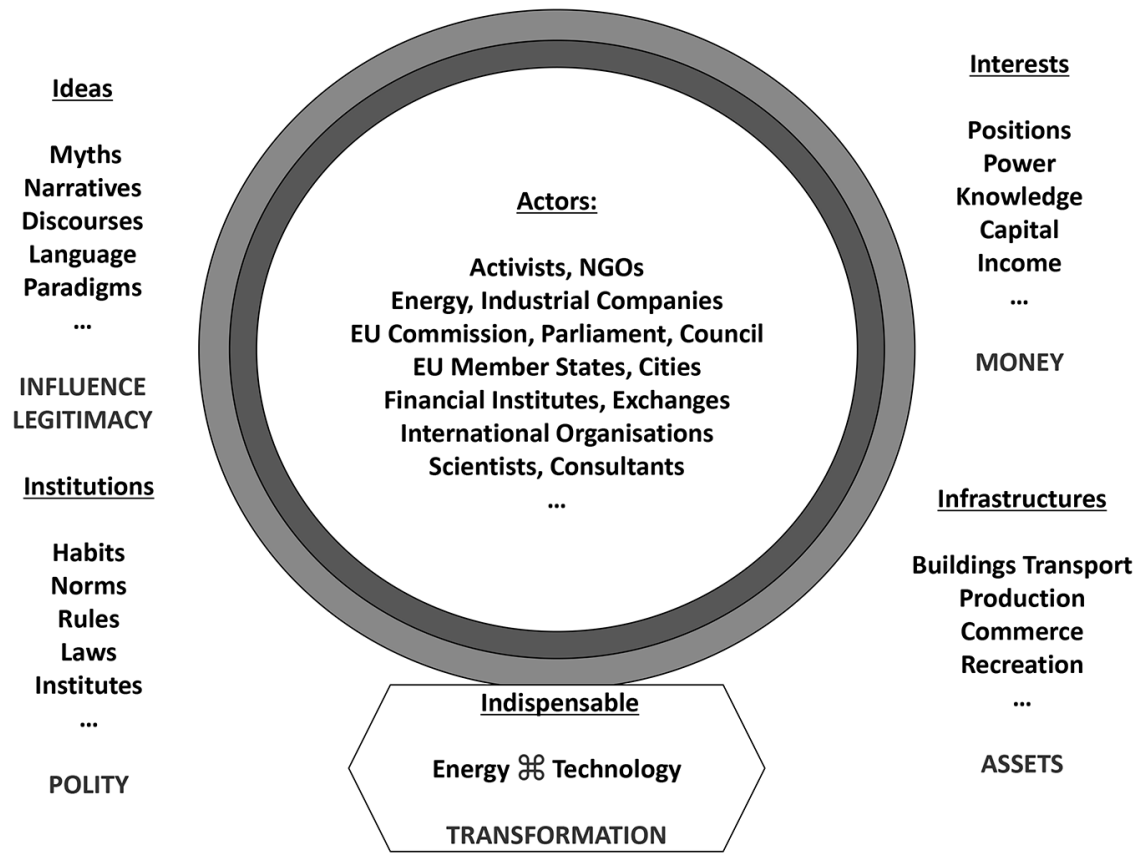

Figure 1.1 The scene of climate and energy policy, carbon pricing and emissions trading 
The cluster Interests is also connected to the Values adhered by people [Annex B]. Even Interests are very diverse, the economics logic reduces all Interests into the single yardstick of money. This reduction holds advantages when numerical precision substitutes for vagueness; the disadvantages are summarized in 'all what owns real value has no price'.

3 Institutions (habits, norms, rules, property relation, laws, institutes, etc.). Institutions structure the polity of society (Vatn 2005; Bromley 2006). A political scientist would specify many institutions and institutes making modern societies, such as governmental, legal, administrative, communicative, social, economic, scientific, and more.

I highlight only the institution market as created and run by people. Generally, markets start spontaneously, either because a supply searches a demand, or a demand triggers a supply. In theory, markets serve mutual interests and guarantee free entry and exit, why they merit the predicament 'free'. Once markets develop and grow, volitional (Bromley 2006) or public authority is needed to provide a regulatory framework to avoid fraud and implosion of the structure.

Carbon markets are top-down artificial constructs. Public authority supplies permits (or licenses) to emit as a commodification of nature and common goods. The demand is the result of coercion by a public authority. Supervision is evidently also the responsibility of public authority. This is a caricature of a sound market institute.

4 Infrastructures (buildings, transport, production, commerce, recreation, etc.). Infrastructures are visible artifacts. They materialize how societies thrive and function. Drastic and urgent change conflicts with lock-in and inertia inherent to large and long-living infrastructures. The energy systems are deeply embedded in all major infrastructures. Dealing with climate change means reducing the GHG emissions of the energy systems to zero, urgently because of the irreversibility of broken ecosystems.

5 Indispensable energy and technology transformations. The special emphasis on energy and technology transformations announces the repetitive attention they receive in this book. They are the substrate of human civilization, and precursors of societal transformations [Figure 8.1]. The scene shown in Figure 1.1 provides structuring elements for analysis and reporting.

\subsection{EU-ETS history in a nutshell}

This open access book is not spending place on copying text from EU ETS advocacy literature. Readers not familiar with that literature, may start with factsheets about the EU ETS available at the Commission's website (https://ec. europa.eu/clima). Also, the International Carbon Action Partnership regularly updates its "ETS Detailed Information" (https://icapcarbonaction.com). 


\section{Introduction}

Academics may further consult Tietenberg (2006), Aldy et al. (2010), Wettestad and Gulbrandsen (2018), or similar.

The overview here describes the EU ETS as I observed it during twenty years follow-up and processing of hundreds of documents on the topic. The nutshell history starts at the preparation period and follows with an account of the major changes in the three phases so far. Also, yearly State of the EU ETS Reports (Marcu et al. 2019) are recommended, while noting their peculiar language and framing.

\subsubsection{Preparation period (1998-2000): assemblage of a Cap and Trade utopia}

After opposing the predominant role in global climate policy for emissions trading, proposed at COP3 in Kyoto (December 1997), in 1998 the EC turned 180 degrees towards adoption of emissions trading as cornerstone mechanism in EU's climate policy. The academic literature is univocal about the precursors of EU's turnabout.

On the one hand the energy and industrial corporations obstructed the EC's prudent energy and carbon tax proposals in the 1990s. The corporations' viewpoint received support from some EU MS who opposed the EC infringing their sovereignty in matters of taxation when EU carbon/energy taxing would happen. On the other hand, the US Clinton administration compelled the delegations at COP3 in Kyoto to accept emissions trading as central policy mechanism, also turning the Clean Development Fund, pursued by India and other developing countries, into a Clean Development Mechanism (CDM).

Both events did shake EU's Climate Change Unit's intentions and visions about governance designed and executed by enlightened public authorities for safeguarding the public good, in case the global climate commons. In the 1990 s other EC directorates had become more lenient to the neoliberal market-oriented ideology, for example in liberalizing the electricity supply industry (EC 1997). Financial incentivizing and market-based instruments (MBIs) were spreading and gaining ground in society and in administrations.

Against this background, with no policy alternatives in the hand in 1998, the EC Climate Change Unit U-turned to occupy the pole position in advocating and experimenting carbon trading, forming the centrepiece of European policy on climate change (Grubb 2007). "European pro-trading business coalition of oil and power companies along with the European Commission moved emissions trading to the top of the agenda in European climate politics" (Meckling 2011, p. 104).

\subsubsection{EC (2000) Green paper sketching a comprehensive Cap and Trade}

Based on the belief that: "Scale effects at the level of the EU will allow for significant cost-savings, while similar regulatory arrangements will allow to keep administrative costs as low as possible" (p. 4), the EC further stated: "The 
wider the scope of the system, the greater will be the variation in the costs of compliance of individual companies, and the greater the potential for lowering costs overall. This argues in favour of a comprehensive trading scheme across different Member States covering all 6 greenhouse gases and sinks, and encompassing all emission sources". However due to "complex technical and administrative issues ... it should initially confine itself to large fixed point sources of carbon dioxide" (p. 10).

The expectations about emissions trading performance were high, for example: "Furthermore, as emissions trading will induce competition between companies to find cost-effective ways to reduce their emissions, an additional boost will be given to environmentally friendly technologies" (p. 8).

The most contentious issue, the allocation of emission allowances to companies, is treated in Section 7.2 of the Green Paper (pp. 17-19). About auctioning, the EC stated: "Periodic auctioning is technically preferable, as it would give an equal and fair chance to all companies to acquire the allowances they want in a transparent manner. Auctioning applies the "polluter pays" principle. The revenues raised by governments could be re-cycled in a variety of ways, even keeping the overall revenue effect neutral.... Auctioning avoids the need to take difficult and potentially delicate decisions about how much to give each company covered by the trading scheme. The complex issues ... about state aid and competition would largely disappear. It would also guarantee fair terms for new entrants to join the system as they, like existing sources, would also have the same opportunity to buy the allowances that they needed" (pp. 18-19).

Another tricky policy issue is the compatibility of emissions trading with other policies (Section 8, pp. 20-24). The EC was firm on this:

A major challenge is to ensure that emissions trading complements and is compatible with other policies and measures. In the international negotiations, the EU insists on the need for the industrialized world to put in place domestic policies and measures as the main means of action. Within the EU many such measures, such as energy taxes, regulatory or technical standards and environmental agreements are already in place. Any Community emissions trading should reinforce, and certainly not weaken, these existing foundations.

Concluding this short reference to the founding edict of EU's emissions trading scheme, the Green Paper also mentions: "The success in compliance terms of the US sulphur trading scheme is largely due to the strictness of the enforcement regime, including stiff penalties for non-compliance" (p. 25). In Annex 1: Economic analysis (pp. 27-28), €1.8 billion gains are assessed by EU-wide trading among energy suppliers, increasing to $€ 2.1$ billion when the energy intensive industries are added, and to $€ 3.0$ billion when all sectors (agriculture, transport, households, services, etc.) participate. 


\section{Introduction}

Not surprisingly, Directive 2003/87/EC, legally regulating the EU ETS, already choked the CaT utopia of the Green paper. The coverage of EU's emission sources was not comprehensive, neither for only the large sources, exempting the chemical and aluminium sectors. Auctions were not applied, rather the worst possible opposite: Free permits, grandfathered on the basis of historical emissions.

\subsection{3 (2005-2019): fifteen years shipyard works at the flagship}

The EU ETS planned consecutive CaT periods of five years, with Caps tightened with every new period. Phase 1 (2005-2007) is known for the oversupply of permits, volatile exchange prices landing at price zero, and €billions in 'windfall' profits cashed mainly by electricity companies (Sijm et al. 2006). The failures were glossed over as teething problems of a fantastic system under construction.

Phase 2 (2008-2012) continued grandfathering of almost all permits, except ca. $3.5 \%$ auctioned by a few countries. The 2008 economic recession and inflow of CDM credits resulted in more than 2 billion surplus permits end 2012. By giving up the closure of the CaT after five years, and accepting the surplus in permits could flood in Phase 3, the dystopian system extended its life and interminable debates continued. The $\mathrm{BaU}$ agenda of the triumvirate of companies was saved.

Phase 3 (2013-2020) started, because of the enormous surplus in permits, with an extensive debate on back-loading auctions of permits from 2014-2016 to 2019-2020 (EC 2012). Differentiation of the electric power generation sector vs. other industrial sectors was codified in legislation (Zapfel 2019), provisioning a special position and role for the electric power companies. The role is familiar to the incumbent, major power companies in Europe, and pivotal in the functioning of the EU ETS [Sections 7.3.1 and 7.4.4].

Gradually increasing auctioning became the default allocation mechanism for only the power generation companies in 2013, with Eastern European power companies partly exempted. Emissions Intensive Trade Exposed (EITE) industrial activities received free permits, moderated by 54 industry specific benchmarks. Via an administrative patchwork, free permits are assigned to specific installations in separate sectors (up to the 4-digit NACE code level, anticipating even to the six- or eight-digit level), with sector-specific benchmarks as buoys (EC 2014a). This way of permit allocation is a twin of the standard environmental permit assignments, referring to Best Available Technologies (BAT). However, this environmental regulation approach was heavily criticized by the early emissions trading advocacy (Ackerman and Stewart 1988).

A significant difference between standard permits and the EU ETS excess permits is that the latter can be sold and permits short of the (once a year) verified emissions must be obtained from own banked/hoarded reserves or purchased at EEX or ICE auctions or exchanges. The monetization of permits offers opportunities for 'windfall profits' (CE Delft 2016; CAN 2018). The 
bills of the ETS money circuit are laid down at the electricity consumers, mostly the captive, non-ETS consumers.

\subsubsection{Preparing Phase 4 with adding price control}

In 2019 a Market Stability Reserve (MSR) mechanism started, after long discussions how it would function (EC 2012; EU 2018a). MSR adjusts the volume of permits in the market (the actual Cap) for controlling the exchange/ auction prices. Since mid-2017, the exchange price went up from around $€ 5 /$ permit to around $€ 25 /$ permit at the beginning of 2020 [Figure 1.2]. Further reforms are planned for Phase 4 (2021-2030) (Löfgren et al. 2018; EU 2018a).

For readers interested in the year-on-year changes and latest reforms, the yearly State of the EU ETS Reports (Marcu et al. 2019) are recommended reading.

Yet, the report is unsatisfactory by its self-constrained framing, for example:

"The EU ETS is important through its role as the 'cornerstone' of EU climate change policy, as well as a 'role model' for other carbon markets" (p. 1) and "The internationalization of the EU ETS, including through linking it to other markets, needs to be part of the continued vision for the EU ETS" (p. 6), i.e., the authors do not test the hagiographic position of the EU ETS against reality, requiring to leave utopia aside.

" $(\mathrm{T})$ he EUA price is far from being able to support the mass deployment of new low-carbon technologies" (p. 2) reveals ex-ante belief in price-induced innovation. "(F)ree allocation has largely covered costs for the industrial sector" (p. 2) is a strange formulation: which costs are covered when no de-carbonization happens? More appropriate language is 'shielded from mitigation expenditures'.

In discussing 'Economic delivery' (Section 5, p. 17) the authors 'cost' vocabulary is also unclear. The authors observe: "direct costs were so far rather

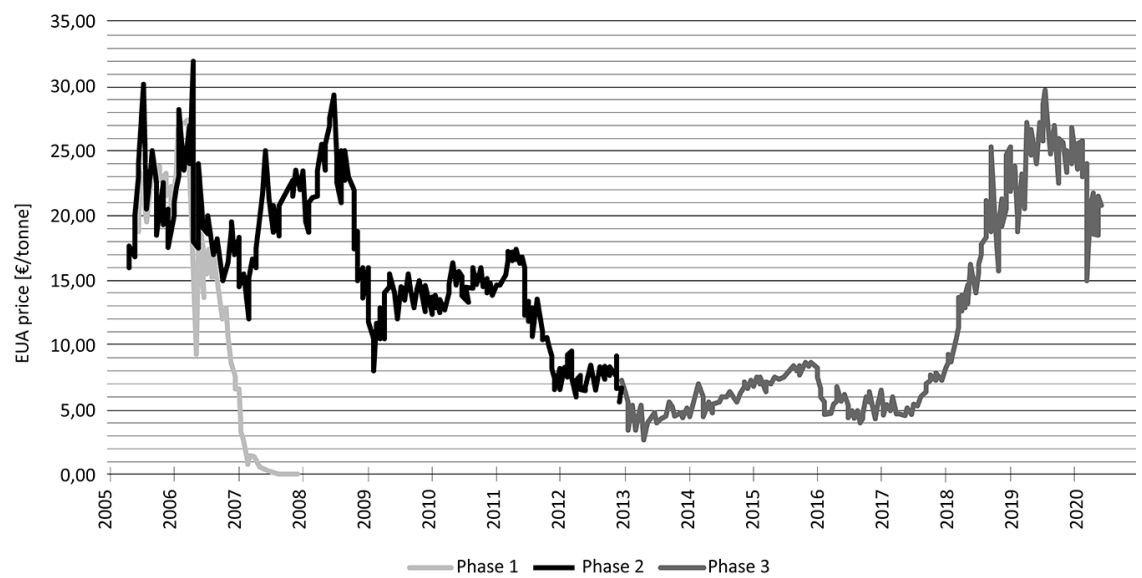

Figure 1.2 Posted EU ETS permit prices by the London ICE exchange (2005-2020) 


\section{Introduction}

negligible or even negative for most industrial activities" (p. 24), without further comment. Similarly, when revealing the compensations of 'indirect costs', they do not ask the question: who finally pays the EU ETS system? The authors complain about "limitations posed on analysts by the lack of publicly accessible data" (p. 5) and equate 'combustion of fuels emissions' to 'electric power generation emissions' (pp. 22-23). Is it not a primary duty of independent academics to investigate why information is limited and the system is opaque?

\subsubsection{Longitudinal view on the EU ETS metamorphosis}

The EU ETS was conceived as CaT (EC 2000). It started with grandfathered DoP for all installations and evolved to benchmark moderated DoP for EITE industrial activities, with auctions gradually mandated for electric power generation since 2013. In 2019, a price control mechanism (MSR) is added to continue the EU ETS until 2030. One cannot deny how the CaT utopia metamorphosed into a DoP per individual emitting installation, congruent to the administrative practice of emission permit allocation by public authorities (EC 1996). The added element is the tradability on exchange platforms of generously donated permits, creating extra revenues (called 'windfall' profits) for many participants.

This means the opposite of the (utopian) talk of industry pays for every ton carbon emitted. The Ebillions in profits are charged on the electricity bills of predominantly non-ETS electricity consumers. In such money circuits EU's electric power oligopolies assume a pivotal role. Another essential service of power generators (as aggregate the largest emitter in the EU ETS) is guaranteeing BaU can continue for the other regulated companies. After Fukushima (2011), the new business model of most power companies means transition to proven, affordable zero-carbon technologies harvesting power from wind, light and water currents (IRENA 2018; 2020). The emissions reductions by growth in renewable electricity generation can satisfy the foreseen system Cap reductions.

Cynically, the RE solutions became available through the FIT financial incentive mechanism, the opposite of MBIs which performance was showcased in the failed Tradable Green Certificate experiments [Chapter 5]. Neoclassical economists condemned FIT to hell as not market-proof, while FIT pulled in the market the most significant decarbonizing technologies for reducing carbon emissions. The pretended price-induced de-carbonization innovations in the ETS did not materialize [Chapter 6].

\subsection{Some economic concepts behind carbon pricing}

\subsubsection{The role of self-interest}

Moral philosopher Adam Smith emphasized the role of self-interest in economic exchanges among people, with exchanges best structured via market 
institutions. Economics Nobel prize-2009 winner Elinor Ostrom mostly studied the governance of common pool resources (CPR) such as the atmosphere and climate, and where markets fall short. The core of her analysis is also a balance of expected benefits and expected costs for participants ('appropriators' in Ostrom language). This balance is essential in winning or losing the engagement of principal participants for a self-governing ruling of the CPR (Ostrom 1990, Chapter 6). One cannot negate the organizing force of selfinterest, neither in markets, nor in public governance institutes, nor in the governance of the commons, the essence of climate policy.

Self-interest is a benign force, not to be confused with malign egoism and greed. Thinking of it as a force, it is comparable to gravity. Both are omnipresent and not fully understood. They are recognizable by their effects. On the one hand, they keep order, things in place. Without gravity, the objects on earth would be flying around. Without self-interest human behaviour would be fully unpredictable, instead of partly unpredictable when self-interest is considered.

By individuals keeping their own affairs ordered, the vast majority of issues in society can be addressed and mostly solved. Only holding objects in place and affairs ordered, means a static situation, which is boring and indecorous without the experience of innovation and progress. In physical life, living beings overcome gravity's inertia by motion (running, lifting, flying, etc.). Motion requires effort, which we spend when we think that the expected benefits are worth the effort.

Immediate self-interest of the status quo situation will be overcome when the expected benefits of change merit the risks of change and the expected costs. This is also valid for engaging people in common endeavours. One of the essential common endeavours waiting for humankind's action is the drastic and fast reduction of GHG emissions.

The economics profession has claimed an influential voice in recommending ways and instruments to address the GHG emissions Hydra. The basic recipe is to charge a payment for every ton emitted GHG, and the invisible hand of self-interest will guide emitters to reduce the quantity of their emissions. Moreover, when a global uniform levy on GHG emissions is applied, the overall reduction will be obtained at least costs, as mathematical theorems confirm [Annex C], however contingent on a set of assumptions. The leastcost or efficiency concern ticks high among economists, blinding many of them for other important aspects, such as equity or political feasibility (Rabe 2018).

\subsubsection{Financial incentives and cash flows}

'Financial incentives' is a generic term, including all measures that could change or do change the financial position of an addressed party (person, household, company, organization, etc.). Mostly, a financial incentive is understood to be a pecuniary reward (subsidy, premium) when executing 


\section{Introduction}

prescribed activities or reaching particular goals, or a pecuniary punishment (charge, levy, tax, penalty) when unwanted actions are undertaken, or unwanted outcomes are obtained by the party. This assumes that a government or authorized public entity is assigning subsidies/cashing taxes: money flows from the public treasury to private actors and vice-versa. Actual or potential money flows from and to the public treasury are incentives for private actors to adjust their decisions and activities.

'Money makes the world go round' is a famous maxim. Money is the general equivalent that allows its owner to obtain everything her/his budget can afford. When the budgetary conditions shift or are affected by governmental measures, households adjust their activities.

Money and budgets play similar roles in firms but in more explicit and managed ways than in households. Shareholder value, financial assets, returns, profits, rents and positive net cash flows are the primordial goal of firms (Volberda et al. 2011). The value of a company depends on its EBITDA (Earnings Before Interest, Taxes, Depreciation, and Amortization). Firms decide about investments based on expected future cash flows (Dixit and Pindyck 1994; Bierman and Smidt 2006). This is also the case for investments in mitigation of and adaptation to climate change. Contrary to neoclassical economics' focus on carbon pricing, firms react to the cash flows occasioned by climate policymaking and by economic instruments.

\subsubsection{Price theory}

Pricing conquered the pole position in the neoclassical economics discourse by the theory of value, with competitive markets maximizing the sum of consumer and producer surplus (Samuelson 1948; Debreu 1959; Henderson and Quandt 1971; Becker 1971; Arrow 1974). The main features of the neoclassical theory are summarized below.

First, producers minimize production costs and maximize profits in competitive markets by offering their goods \& services via their short-run marginal cost supply curves; the aggregate of the latter curves of all producers is the market supply curve.

Second, consumers maximize their utility when allocating their budgets over the purchase of goods and services according to their willingness-to-pay (a pecuniary expression of the marginal utility of goods and services). The aggregate of the individual willingness-to-pay curves is the market demand curve.

Third, in the market, demand and supply curves cross at the competitive market equilibrium price $\mathrm{P}^{\star}$ and equilibrium quantity $\mathrm{Q}^{\star}$ traded, produced and consumed [Annex A, Figure A.1].

The equilibrium price $\mathrm{P}^{\star}$ is the equality of marginal utility with marginal cost, i.e., what society (the aggregate of consumers) is willing to pay equals what it costs to society to produce it. When deviating from the optimal set $\left(\mathrm{Q}^{\star}, \mathrm{P}^{\star}\right)$, society's utility gains of goods and services extra beyond $\mathrm{Q}^{\star}$ would 
be lower than society's extra production costs, and when below $Q^{\star}$ the lost utility is higher than saved production costs. In the friction free, competitive economic framework, optimal prices signal economic actors how to optimize the two essential activities in a private economy: production and consumption.

While the mathematical logic is waterproof, the painted perfect market model belongs to a Utopian world. This is addressed by the economics discipline itself. After the basic theory of the competitive market for optimizing private exchanges, attention is paid to societal organizations (Arrow 1974), the public side of life, welfare economics and to non-competitive market situations. For example:

The reason for the difficulty into which uniform pricing is likely to fall is that real life firms do have at least some monopoly power and can use marketing techniques to keep their markets separate, so that price discrimination is generally possible. [...] Discrimination might be as common in the marketplace as it is rare in economics textbooks.

(Phlips 1983, pp. 1 and 7)

\subsubsection{Challenges in pricing carbon emissions}

Carbon is a shortcut for GHG emitted tons measured in $\mathrm{CO}_{2}$-eq units. As main climate policy instrument, economists propose Carbon Pricing (CP) either as a (global) uniform carbon tax rate applied on all carbon emissions, or as a global emissions trading system (ETS) capping all carbon emission sources (Cramton et al. 2015; Baranzini et al. 2017). Both are called Market Based Instruments (MBIs).

Economists advocate MBIs as the cornerstone of climate policy (Gollier and Tirole 2015; Weitzman 2015; Stiglitz and Stern 2017; CMW 2017; Pindyck 2017a; EU 2018a). The economic policies recommended by environmental and climate economics are based on cost-benefit analysis (CBA). Annex B offers a concise introduction to CBA in the context of climate change. The theoretical CBA frame is widened to address climate change globally.

The inventory, measurement, and monetization of the damages caused by climate change are immensely complicated tasks. Economics stays with stylized quadratic or cubic functional forms and discuss the effects of home-cooked assumptions (Howard and Sterner 2017). Figure B.5 in Annex B shows how the performance of CBA depends on the policy context: the CBA tool evolves from practical over problematic to counter-productive. CBA is counterproductive in the climate policy's context of far-stretching time spans, high degrees of doubt and looming irreversibility.

Nonetheless, in the CP discussion economists continue to refer to the social cost of carbon (SCC) price as "a crucial tool for economic analysis of climate policies" (Pizer et al. 2014, p. 1189). Although Pizer et al. (2014) refer to the usual global CBA and IAMs to obtain a marginal SCC (as result of one ton extra $\mathrm{CO}_{2}$-eq emitted in the USA), the authors mainly recommend a 


\section{Introduction}

regularized administrative process to agree on a beacon $\mathrm{CP}$ numerical value as input for domestic cost-benefit evaluations of considered mitigation activities. Their short article readily turns Utopia into Realism.

Setting aside the never-ending search for the 'right' SCC CP, climate policy practitioners see $\mathrm{CP}$ as a means to obtain cost-effectiveness in reducing carbon emissions. The efficiency ambition level is downgraded from rang 1 (sum of damage + abatement costs minimized) to rang 2 (only minimization of the expenditures on GHG emissions mitigation-abatement efforts, at least necessary to contain the growth of climate change and the accompanying damages).

Annex $\mathrm{C}$ provides an overview of the basic economics of putting a price on carbon emissions, for four cases: an individual emitter, two emitting sources, many emitting sources trimmed by a uniform price (levy, tax), and many sources covered by an ETS. Annex C provides background on the advocacy of economics for the GUCP or for a global emission permits trading system. Chapter 2 discusses the GUCP case; Chapters 3, 6 and 7 consider the EU ETS, as exemplary case of carbon emissions trading.

\subsection{Equal impact of emitted $\mathrm{CO}_{2}$-eq. molecules is no argument for uniform pricing}

Neoclassical economics referring to CP, mostly laud the GUCP version because of the superiority in efficiency when all GHG emissions on Earth are submitted to a uniform tax rate or to an emission permits trading system of global coverage. This Utopian belief is abusively rooted in mathematical theorems [Chapter 2; Annex C]. Additionally, uniform pricing of all $\mathrm{CO}_{2}$-eq tons emitted is argued because well mixed in the atmosphere the $\mathrm{CO}_{2}$-eq molecules occasion an equivalent radiative forcing effect.

The invalid arguments are investigated. First, I illustrate the case of electricity pricing. Next, the DPSI framework shows the huge diversity in Driving forces and Pressures on the one hand and in Impacts on the other hand.

\subsubsection{Physical homogeneous $k W h$ are not priced uniformly}

Physical homogeneity is often transferred in theory onto economic uniformity. Electricity pricing is a clear and interesting example because it has been intensively discussed in the economics literature. Moreover, the future low-carbon economy will mainly run on renewable electric power.

Electric power current is physically homogeneous, even identical. Electric kilowatt hour $(\mathrm{kWh})$ delivered at the grid are instantaneously mixed in wideranging interconnected grids, no longer traceable where generated, nor recognizable as green or brown.

However, economists criticize uniform tariffs for delivered electricity. Because the marginal cost of a delivered $\mathrm{kWh}$ depends on (1) the particular moment in time, earlier distinguished as peak versus off-peak load (Steiner 1957); nowadays hour and quarter-hour load intervals become popular, thanks 
to progress in ICT, on (2) the reliability of delivery (Chao 1983), and on (3) the location of the customers in networks facing congestion (Howard 2008).

An interconnected service area, belonging to a market driven power system, posts a quarter-hourly price of bulk electricity for high-voltage direct customers. The latter are large industrial plants and power traders supplying retail electricity to medium- and low-voltage customers [Annex E]. Prices for retail delivery to end-users vary significantly, with for example two-part tariffs charging capacity and energy separately. In addition, industry gets a range of prices via bilateral contracts, dependent on a booklet of conditions.

In the long-time investment perspective, the 'levelized cost' of electricity price LCp assesses the economics of various electricity generation options. The LCp is derived from equating discounted expected revenues to the discounted net expenses of a planned generation project [Annex E]. Notably, LCp is derived from expected $€$ cash flows. LCp are criticized for the narrow focus on $\mathrm{kWh}$ generated only, not taking into account circumstantial issues of momentary time of $\mathrm{kWh}$ delivery, availability, and location in the network.

The above comments on electricity pricing show that physical identity of the commodity is no solid basis for uniform pricing.

\subsubsection{The atmosphere being global is no argument for Global Uniform Carbon Pricing}

Annex B [Section B.2, Figure B.2] shows the causal sequence Values - Driving Forces - Pressures - State - Impact@ Response (VDPSI@R). This

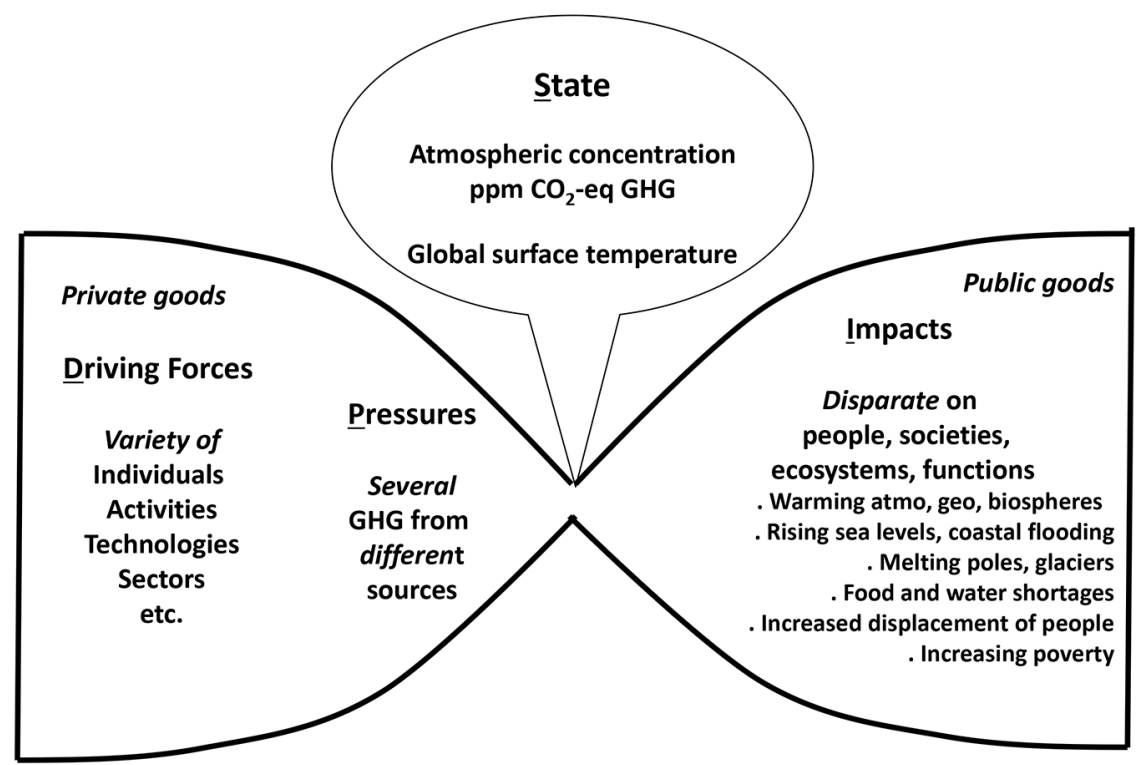

Figure 1.3 DPSI frame for global greenhouse warming and climate change 


\section{Introduction}

framework is generally used for the comprehensive study and assessment of environmental issues. Figure 1.3 is a reduced 'hourglass' format of the climate change DPSI components.

"Equivalent carbon dioxide emission is a standard and useful metric for comparing emissions of different greenhouse gases but does not imply exact equivalence of the corresponding climate change responses" (IPCC 2007, p. 133). The physical attributes of GHG and the use of a metric ${ }^{1}$ are no sufficient basis for a uniform pricing treatment of the emissions. Furthermore, the emission sources (encompassing almost all activities undertaken by people) are very heterogeneous, as are the impacts of climate change, due to geographical, climatic, economic, and other differences in exposure and vulnerability. Hence, the argument for global uniform pricing is technically invalid and economically erroneous.

\subsection{Recommendation}

This chapter documents various aspects of CPs and opens the debate on the utopia of uniform pricing proposals. The danger of deception is significant when the term CP is not well defined in practical contexts. When a particular MBI (CP or ETS) is mentioned, confusion is precluded, or at least reduced, by specifying its design and properties, such as:

- The precise definition of the MBI, answering: Which public instance is organizing the MBI? How is it regulated, including the interactions with stakeholders? Is public access to transparent data about quantities, prices, and money flows guaranteed?

- The scope (covered jurisdictions, emission sources), and: Which actors and parties are involved, in which roles?

- Identification of the goals, objectives of the MBI? E.g., in Chapter 3, the two incompatible goals of the EU ETS are clarified, and other goals of stakeholders are discussed in Chapter 7.

- Yearly (or monthly) quantified money flows created by the MBI, with: Who (ultimately) pays and who (ultimately) receives the money? Transparency about the money flows is a primary condition for assessing the performance of the MBI (CP or ETS).

Analysing and discussing proposals about MBIs request intensive research, with full clarity in actors involved, in language and in financial numbers. The following chapters intend to contribute to clarity.

\section{Note}

1 The $\mathrm{CO}_{2}$-equivalent metric is not a tombstone fact. Researchers discuss and propose improvements to the metric, for example Etminan et al. (2016). 


\section{Diversity disqualifies Global Uniform Carbon Pricing for effective climate policy}

\subsection{Introduction}

Carbon pricing ${ }^{2}(\mathrm{CP})$, both in terms of carbon emission taxes or emissions trading systems, is widely being promoted as the most suitable instrument to lead economies towards a low-carbon future (see e.g. IPCC (2018); Gupta et al. (2007); Stiglitz and Stern (2017); World Bank (2019); Aldy et al. (2010); Cramton et al. (2015); Baranzini et al. (2017)). Rabe (2018) offers a (mainly U.S. and Canada documented) political analysis why CP is appealing, as well as why elected politicians are reluctant to actually tax carbon emissions.

Neoclassical Economics Theory $(\mathrm{NET})^{3}$ supports a "global and uniform carbon price across countries and sectors so that polluters do not simply move operations to so-called 'pollution havens' - countries where a lack of environmental regulation enables them to continue to pollute without restrictions" (LSE 2019). GUCP results from the analysis of the market under conditions of perfect competition, being the cornerstone of NET (Samuelson 1948; Debreu 1959).

This paper confronts the NET position on CP and GUCP with a diverse ${ }^{4}$ world, asking attention for diversity as important factor in real policymaking. We show that in a diverse world, holding numerous heterogeneous, often incompatible constituent parts, the economic logic advising uniform CPs are but valid for sufficiently homogeneous parts. The observed kaleidoscopic, bottom-up CP implementations actually address diversity and heterogeneity.

Our view is that they pose a realistic and effective alternative to global uniform top-down CP intentions. Giving up the global aspect of GUCP, several authors propose CPs tailored to country's characteristics (Stiglitz and Stern 2017; Bataille et al. 2018), climate clubs (Nordhaus 2018), or a social cost of carbon (SCC) price by country (Klenert et al. 2018).

Next to the global attribute, we question also the uniform attribute of GUCP. CPs applied in different parts of the world are not uniform, and signs of convergence are weaker than signs of divergence (Rabe 2018). Wide gaps exist between GUCP advocacy and carbon pricing practices by separate, multi-level authorities (World Bank 2019). We argue that ironing out CP differences to enforce the GUCP is not only counter-productive, but also futile. CPs should be adapted to heterogeneous realities. 
Section 2.2 documents the concept of diversity for use in a policy context [Figure 2.1]. The role of diversity is further explored via opposing amalgamation and requesting specificity [Section 2.3]. The ambivalent attitude of NET toward diversity is exposed. Specific approaches for delineated homogeneous cases accord with the mathematics of economic optimization [Annex C] and match a proper use of economic insights and instruments for climate policy.

Section 2.4 describes the GUCP discourse, and states why the actual performance of GUCP cannot be assessed. We elaborate why uniform recipes for amalgamated heterogeneous cases fail, with the EU ETS as exemplary case. The conclusion [Section 2.5] suggests an alternative indicator for monitoring UNFCCC Parties' implementation of financial instruments to mitigate climate change [Figure 2.2].

Financial incentives influence activities and decision-making of people and organizations. We learned from Arrow (1974, pp. 20 and 23-24) that

under certain very special assumptions ... efficiency can be achieved through a particular kind of social system, the price system... [t]axes are not prices. They are not a voluntary exchange.

$[\ldots]$

The government's role in internalizing externalities is then straightforward in principle, which does not imply that it is easy in practice. The signals it can use to recognize and measure those externalities it can deal with are necessarily imperfect, since these are precisely the areas in which the price system has failed to operate. The government may indeed perform somewhat better than the private sector in realizing social feelings, trust, and empathy, but within limits: power as well as money corrupts.

We are eager to contribute to 'drastic and urgent' policies (Stern 2006) for addressing the challenges of irreversible climate change. Learning from empirics and the application of available economics logic is the basis of the following analysis.

\subsection{The concept of diversity and its implications for policy}

The ethnic, cultural, social, institutional, political, economic, i.e., societal diversity of human communities thrives in kaleidoscopes of geological, biological, geographical, i.e., natural diversity. Section 2.2.1 documents the general concept of diversity. Section 2.2.2 specifies diversity in the context of economics.

\subsubsection{The concept of diversity}

The terms 'diverse' and 'diversity' are well understood in the particular context they are used in. The Shannon entropy index is a metric of the degree of diversity (Shannon 1948). The entropy of a system, which may adopt $\Omega$ different states with probabilities $\mathrm{Pi}$, equals $-\mathrm{k} . \Sigma_{\mathrm{i}=1, \ldots, \Omega} \mathrm{Pi} . \ln \mathrm{Pi}$ (thermodynamic 
formula, $\mathrm{k}$ being the Boltzmann constant). The height of the entropy index reflects uncertainty and disorder. Its maximum value is $\mathrm{k} \cdot \ln \Omega$ when all states are equally likely to occur $(\mathrm{Pi}=1 / \Omega)$; its minimum value is 0 when only 1 state is feasible $(\mathrm{P}=1$ and $\ln 1=0)$.

Every analysis in engineering thermodynamics (Reynolds and Perkins 1977) carefully delineates the system investigated, for accurate monitoring of all energy and matter exchanges between system and its environment. Interconnecting and integrating subsystems to larger systems is the art of engineering, avoiding amalgamation of incompatible systems. Unwarranted mixtures increase the entropy of systems.

This chapter neither pursues a full taxonomy of diversity, nor a metric. It focuses on the meaning of diversity for carbon pricing and climate policy. For political action, Aristotle's rule 'Treat equal cases equally, unequal cases unequally' is the basis to preclude or at least minimize two types of discrimination:

Type I is that equal cases are treated unequally (due to racism, sexism, social status, etc.); mostly this type of discrimination is recognized, rejected, and often prosecuted.

Type II relates to the instances when unequal cases are treated uniformly. Obvious cases, such as sports with participants differing in sex, age, physical fitness, etc., are addressed by stipulating separate homogeneous categories. In less obvious cases, recognizing inequality may fail, causing significant discrimination when applying the first-hand idea 'uniform treatment is fair'. Applying Aristotle's rule implies identification of which cases may be considered equal (homogeneous), and which ones are unequal (heterogeneous). The "common but differentiated responsibilities and respective capabilities" principle (UN 1992, Art. 3.1) is also a reference for designing diverse policies.

A range of terms is connected to diversity, disclosing its gradual character [Figure 2.1]. The arrow on top and the four batched columns represent grades of diversity. Uniformity is the antonym of diversity, the 0-point of the arrow. The terms homo-/heterogeneous are the most useful for a split between equal and unequal states. Adding the adverbs 'strong' and 'weak' to either term forms four columns, each comprising related words to the grades of diversity. The word columns support the connections of homogeneous with 'one category' and of heterogeneous with 'more categories'. The bottom of Figure 2.1 shows recommended policymaking approaches ranging from uniform and common, to specific and individual.

Heterogeneity is addressed by identifying the multiple composing categories and by separating them into homogeneous parts or more disentangled heterogeneous parts.

On the homogeneous parts, specific uniform-common policies are applicable. In addition, subjects or objects may consist of more than one strand, each requesting an own diversity mark. For example, people's basic human rights ask for equal treatment of all human beings on Earth. Other features (age, health, sex, endowed assets, etc.) may ask differentiated treatments. The 


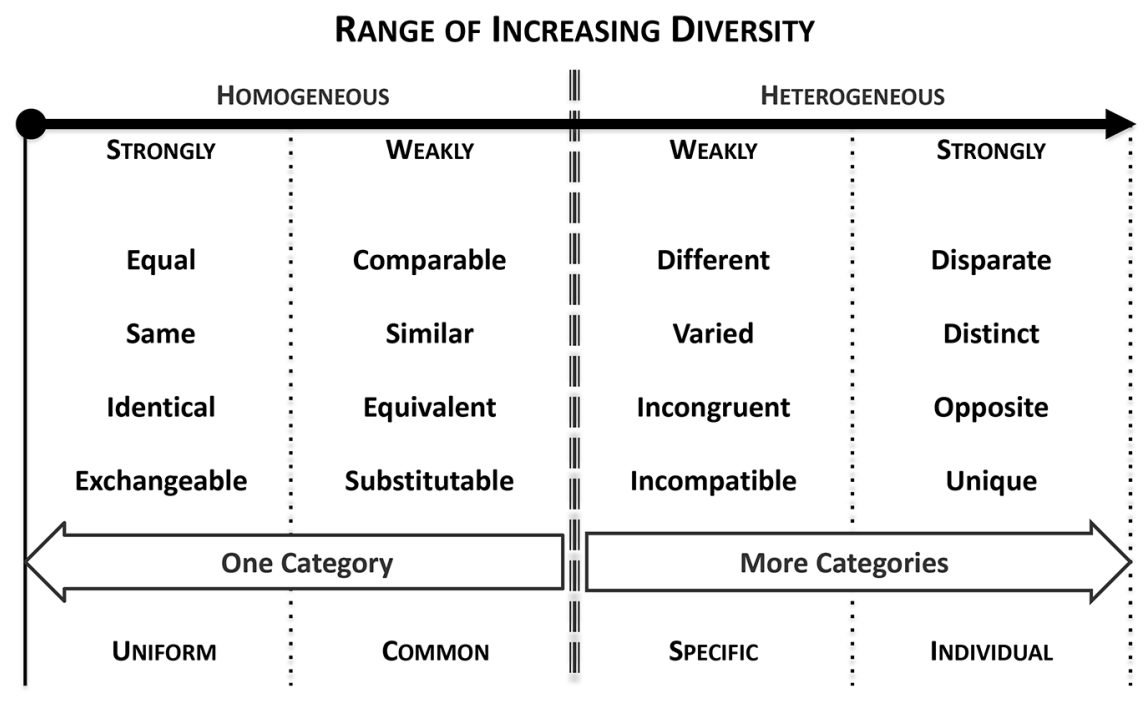

\section{Recommended Policy-Making Approach}

Figure 2.1 Diversity terms and the distinction homogeneous/heterogeneous

presented scheme in Figure 2.1 is applicable on many societal matters. Proper classification of matters is a condition for effective, efficient, fair, and administrative feasible socio-economic policymaking. For example, industrial activities (major emitters of GHG) are classified in nomenclatures along their homogeneity-heterogeneity relationship ${ }^{5}$.

\subsubsection{Economics and diversity}

Applied economics accepts diversity and heterogeneity as natural aspects of life and of economic life, industry, technology and abatement cost functions. Real economies consist of an abundance of product variety, diverse industries and segmented markets (Porter 1985; Tanwar 2013). Multinational corporations pursue diversity in staff, products, marketing, research, etc. as a resilience strategy (Kupers 2018).

Diversity is a crucial factor for firms' sales in a modern economy. Markets are finely segmented to fit the broad range of distinct preferences with a broad range of differentiated products and services. Industries are heterogeneous: Their core technologies, carbon intensity and emissions abatement cost curves are dissimilar (Goulder et al. 1999; Heilmayr and Bradbury 2011). Moreover, competitive positions of companies in the levelled (local to global) markets are ranging from precarious to strong. The mere existence of separate sectors and subsectors is the result of diversity due to specificity of technologies, skills, business models, market coverage, and more.

In academic economics, few authors address diversity: Lancaster (1971; 1979 ) in consumption theory and general economic theory; Weitzman 
(1992, p. 363) affirms that "preservation of diversity in one context can only be accomplished at some real opportunity cost"; Stirling (1998; 2007) presents a diversity framework with three dimensions (variety, balance, and disparity). Institutional diversity is emphasized by Ostrom (2005). van den Bergh (2008, p. 578) sees diversity as an investment rather than a cost in an evolutionary-economic context, with "optimal diversity" resulting from trading-off the evolutionary benefits of more diversity against the loss in returns to scale.

Assigning productive power to diversity, as van den Bergh does, is a contrasting stance to the NET cornerstone paradigm of the market under competitive conditions (Lancaster 1979, p. 62). Schnellenbach (2005) reviews the work by a few economists, modestly opening a window on diversity in economic policy-making, for example Tiebout (1956) on clubs providing specific public goods to its members. Political, economic and fiscal federalism is a frequent answer to actual heterogeneity (Oates 2011; Rabe 2018). It matches polycentric and multi-level governance (Ostrom 2014) and the growing importance of cities in climate policy (Corfee-Morlot et al. 2009). Recent theoretical and applied studies of polycentricity convincingly clarify the role of diversity and heterogeneity (Thiel et al. 2019).

NET obscures the existence of diversity by generic commodification of goods \& services, full monetization for unfettered wide-ranging exchange, while assuming unlimited substitutability and negligible transaction costs. Consumers demand curves and producers supply curves are derived from aggregates and averages. The 'representative consumer' condenses the wide variety of real consumers into one abstract exemplar.

Lancaster (1971) proposed a new consumer demand theory, recognizing that products own characteristics with varying appeal to consumers, also influenced by income level. By integrating differentiation, Lancaster's approach allows to include income distribution functions (Lancaster 1971, pp. 74-75; Verbruggen and Gijsbrechts 1988, pp. 295-296). His theory superseded the reductive microeconomics of the representative consumer, and had the potential to consider income distribution issues and to forge links with other social sciences and with public economics (Bromley 1990; Lawson 1997). In the GUCP discourse, differentiation and diversity are absent as structuring factors.

Our point is that microeconomics is but valid in practice when applied on homogeneous cases, genuinely taking diversity into account. Negating diversity leads to aggregating and averaging incompatible cases, and to address the assumed amalgamation with uniform policy prescriptions, where separate, specific solutions are needed. In the assumptive NET frame, ironing out diversity is a source of benefit, and remaining diversity a loss of benefit, i.e., cost. Aggregation that trespasses categorical boundaries, supposedly benefits from inexhaustible economies of scale, when 'well-behaving' convex cost curve patterns are assumed. This ignores incompatibility of categories, occurrence of diseconomies of scale, limited substitutability, and significant transaction costs. 


\subsection{Amalgamation versus specificity}

This section elaborates further why amalgamation of heterogeneous cases delivers flawed results. Section 2.3.1 highlights the ambivalent attitude of NET toward diversity and observes that actors in the real economy deny NET. After disentangling heterogeneity into homogeneous parts, specific policies are applicable [Section 2.3.2].

\subsubsection{Amalgamation}

Amalgamation is inherent to top-down GUCP, either as a global uniform tax or via a global emissions trading system (Cramton et al. 2015; Baranzini et al. 2017). The Kyoto Protocol (1997) agreed on global carbon trading. The EU ETS set up a regional Cap and Trade initiative (EC 2000), amalgamating all GHG emission intensive industrial activities into a single system. The US Regional Green House Gas Initiative (RGGI) carbon trade is limited to the electricity generation sector in ten North Eastern states, avoiding amalgamation of heterogeneous sources (Rabe 2018, Chapter 5).

The attitude of NET toward diversity is ambivalent, as follows:

1 NET ignores diversity by working with averages, representative consumers, abstract producers, assuming unlimited substitutability, negligible transaction costs, etc. [Section 2.2.2].

2 Without diversity, only its antonym uniformity remains [Figure 2.1]. Uniform policies, uniform CP, etc. is then the most efficient instrument.

3 The efficiency chip of GUCP is widely advertised by numerous academic publications, media, leaflets, etc. Especially emissions trading systems were lauded for the billions dollar savings they would bring (Ellerman et al. 2010). The billions would be the result from equating participants' marginal abatement costs [Annex C]. Or: without prior differences available for being tapped, the assessed profits from trade would be small to zero. Implicitly, diversity is an important component of the neoclassical argument, counting the efficiency profits from treating amalgamated heterogeneous elements with uniform CPs.

4 The assumption of non-existing boundaries stimulates the quest for the largest possible, even global, amalgamation of participants under a GUCP or a single ETS, side-lining concerns about diversity. This step adds 'global' to 'uniform'.

5 In practice, coverage of heterogeneous aggregates many times smaller than the global grand aggregate of 4., face intractable problems with imposing a uniform regime on heterogeneous cases. It ends in unplanned, intricate ad-hoc adaptations, adjustments, exceptions and exemptions (for this the EU ETS history is instructive [Section 2.4.3; Chapter 7]. Heterogeneity in the real world is mostly stronger than the policy trying to make gains on it by uniform pricing. 
This sequence is sobering but throwing out the baby with the bathwater is not advantageous. Economic logic is valid and effectively useful in an approach that respects diversity ex-ante [Section 2.3.2]. In the real economy, actors deny NET in pursuing their economic and financial interests. In academia, few scholars criticize NET, but several add-ons and adaptations are overriding essential assumptions and attributes of NET's core model (Bromley 1990). Climate policy refers to extensions of NET, known as welfare, public and environmental economics (Lesourne 1975; Pearce and Turner 1990), with GUCP remaining anchored in economists' minds. Several economists and practitioners develop plural ${ }^{6}$, alternative economic theories and policy advice (Laybourn-Langton and Jacobs 2017).

\subsubsection{Specificity}

Specificity refers here to differentiated financial incentives for reducing carbon emissions, like shown by the actual variety of CPs and incentivizing financial instruments, such as feed-in-tariffs for promoting innovation in renewable energy technologies [Annex D], (Verbruggen and Lauber 2009), budget reforms (Ekins and Speck 2011), tax \& rebate initiatives (Rabe 2018; World Bank 2019), and many more. GUCP is replaced by a rigorous categorizing of heterogeneity to identify workable homogeneous parts. ${ }^{7}$ With respect for the classifications, economists may implement the economic instruments specifically for each category.

A diverse world is the natural habitat for economics on optimal pricing. It is efficient to equate the marginal carbon emissions abatement costs of every member in a group of comparable emitters to the optimum marginal price $\lambda$ [Annex C]. The latter price $\lambda$ varies with various groups of activities and emission sources and with their available mitigation technology and options. Lagrange optimization logic applied on a group of comparable emitters is plausible, valid and practical for increasing efficiency.

However, the neoclassical economics discourse on GUCP transgresses boundaries of comparability, validity and practicability.

Determining the proper categories for homogeneous treatment holds substantial challenges, exactly the ones politics and companion social scientists face when addressing socio-economic issues. Conceiving diverse bottom-up financial incentives is a relevant contribution of economists. The economic instruments toolkit remains useful. For example, a global ETS by sector covering one specific activity (for example, ocean-borne shipping), are interesting and viable approaches (Verbruggen 2009b; Roelfsema et al. 2018).

Uniform CP is proper and recommendable on levelled fields, meaning homogeneous parcels [Figure 2.1]. A uniform carbon tax or trading system is not suited to match already existing policies in place (Parry and Williams 2012). Specific CP adapts to existing proxy-CP (such as fuel taxes) and to non$\mathrm{CP}$ policies. Specificity breaks unfitting uniformity. By ditching GUCP as the 


\section{Diversity disqualifies Global Uniform CP}

superior instrument, economics would partner with other social sciences in search for realistic, effective, efficient and just climate policies.

\subsection{Global uniform carbon pricing: discourse and performance}

Economists see carbon pricing as the pivotal, crucial game-changer in climate policy, and have remarkable influence on the climate policy debate (for example via IPCC WG3 reports). The principal recipe offered by NET is installing a GUCP [Section 2.4.1]. The performance of the recipe is considered in Section 2.4.2. Section 2.4.3 briefly reminds how the EU ETS, conceived as a uniform pricing experiment, evolved to specific treatment of the heterogeneous activities it covers [Chapter 7]. In Section 2.4.4 we state that ex-ante recognition of diversity is important for good climate policy; this differs from ex-post remedial interventions in failing GUCP experiments.

\subsubsection{The GUCP discourse}

NET advertises GUCP in two versions (Baranzini et al. 2017, p.10). First, as a global uniform levy per unit GHG emitted (Cooper 1998; Nordhaus 2007; Stiglitz 2015; Weitzman 2015; Stiglitz and Stern 2017; Pindyck 2017a; World Bank 2019). Second, as the settled prices in a global carbon emissions trading system (Ackerman and Stewart 1988; EC 2000; Tietenberg 2006; Goulder and Parry 2008; Aldy et al. 2010; Gollier and Tirole 2015; Schmalensee and Stavins 2017; Wettestad and Gulbrandsen 2018).

While debating which of the two versions is preferable, most academic economists subscribe GUCP as superior for saving the climate (Hepburn 2006; Metcalf 2009; Cramton et al. 2015; van den Bergh et al. 2018; LSE 2019).

The performance of economic climate policy instruments is measured on criteria [Annex A, Table A.2] in four categories:

1 Efficacy (physical effectiveness, i.e., reduction in GHG emissions).

2 Efficiency (total costs are minimized, or at least the summed abatement expenses, called cost-effectiveness).

3 Equity (e.g., recycling the cash transferred from polluters to the treasury can buy support of the constituency for GUCP (Carattini et al. 2019)).

4 Administrative feasibility, including political acceptability (Gupta et al. 2007; Rabe 2018).

Efficiency is the economists' most prominent goal (Arrow 1974; Bromley 1990). Cost-effectiveness is a Lagrange minimization of abatement costs for realizing a targeted quota $\mathrm{Q}$ [Annex C], of which we do not question the formal correctness. However, the validity of applying mathematical theorems in decision-making and politics depends on the way it is applied on which problem in which context (Ostrom 2014). 


\subsubsection{The performance of GUCP}

Currently, no global uniform CP exists. Assessing the performance of a nonexisting instrument is a virtual, hypothetical exercise. Hence, the GUCP escapes testing and decisive evaluation. Arguments about it are either theoretical (like NET), or empirical from proxy carbon pricing experiments like the EU ETS [Chapter 7; Section 2.4.3].

The GUCP 'holy grail' (Wagner et al. 2015) is not conquered, and never will. Given the everyday growing evidence of more detrimental climate change and the lack of a workable global climate policy, economists augment the pressure on politicians to adopt and apply a uniform CP, e.g., for Europe (French Council of Economic Analysis \& German Council of Economic Experts 2019).

This perseverance is likely due to the following two reasons: First, the formal mathematical treatise is rigorous, raising respect among scientists, sensitive to formal strictness. One cannot argue against the related mathematical optimization theorems on grounds of them being wrong. Algorithms of computerized general equilibrium models are tested and compared on their capacities in transforming inputs into outputs. Second, the financial interests of major economic actors are not harmed by the NET discourse, because they found shelter in emissions trading safe havens [Chapter 7], securing low emission prices, free permits and even subsidies, to a large part due to successful lobbying (Heiskanen et al. 2018; Johnstone et al. 2017; Kungl 2015; Newell and Johnstone 2018).

This creates complacency for the economic discourse not threatening the incumbent's business interests. Meanwhile, the focus of GUCP on maximizing efficiency omits to acknowledge important global equity and distribution issues. While marginalized actors are often the ones being affected the hardest, they mostly have less political power to influence decision-making.

It is seen as an advantage of the GUCP that it would equalize the financial incentivizing efforts of the countries, effectively tackling free riding in international climate policy (van den Bergh et al. 2018). However, bottom-up accounting is a far more solid approach, which also takes into account subsidies (Coady et al. 2019), the other side of the taxes coin.

Extending an indicator used by EUROSTAT (2010) for gauging the size of environmental taxation in EU's MS would combine the two sides of financial instruments (taxes, subsidies) with negative or positive effects for sustainable climate action [Figure 2.2].

The records in the national accounts of a country are labelled, allowing identification of the four types of money flows, relevant for climate policy: taxes on factors causing negative (TN) or positive effects (TP), and subsidies for factors causing negative ( $\mathrm{SN}$ ) or positive effects (SP). A continuous task is international agreement on clear labels for taxes and subsidies (which continuously emerge), inclusion or rejection of financial flows, and their placement in the four categories (for example: where belong subsidies for nuclear power?) 


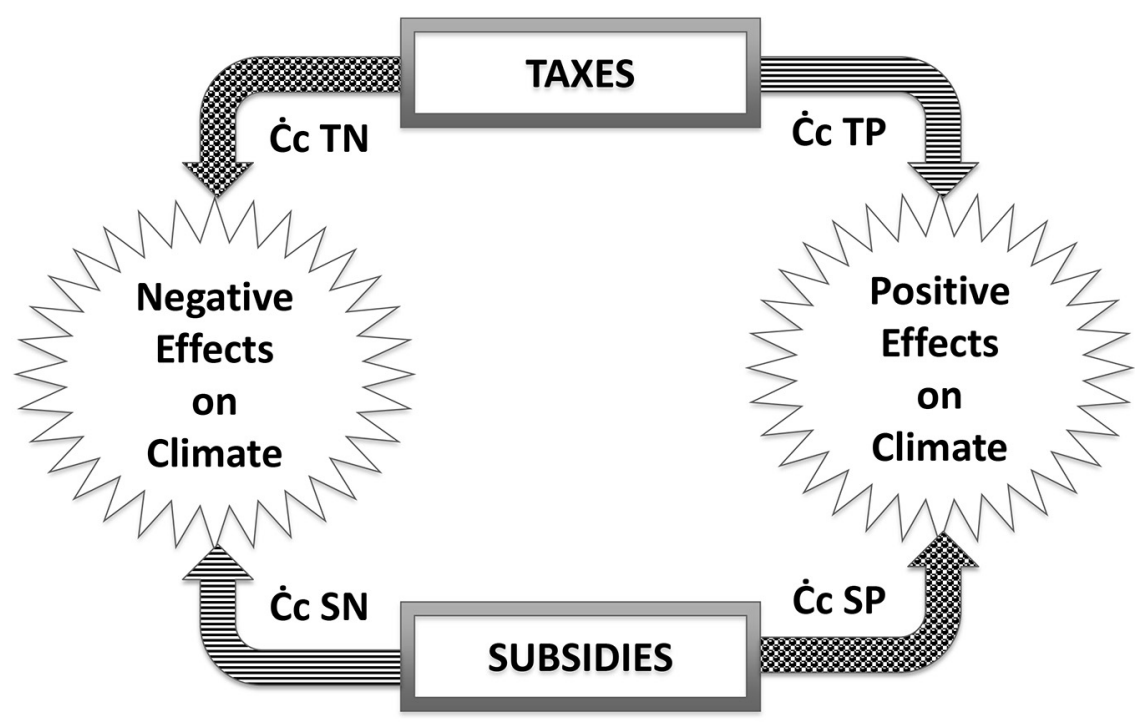

$$
\begin{aligned}
& \text { Ćc Addition: }\{\mathrm{TN}+\mathrm{SP}\}-\{\mathrm{TP}+\mathrm{SN}\} \\
& \text { Ratio }=\dot{\mathrm{C}} \mathrm{c} \text { Addition } / \dot{\mathrm{C}} \mathrm{c} \text { Public budget }
\end{aligned}
$$

Figure 2.2 Metrics of country performance in applying financial incentive instruments Note: $\mathrm{Cc}=$ currency of a country.

The calculation $(\mathrm{TN}+\mathrm{SP})-(\mathrm{TP}+\mathrm{SN})$ is the net result of a country's financial incentives efforts. For international reporting and comparison, the amount in local currency is divided by the total public budget (or another financial variable, e.g., GDP), obtaining a ratio, skipping the pitfall of currency conversions. UNFCCC and the Parties can elaborate the proper indicators, tapping data from the countries' national accounts, which are currently supervised by the International Monetary Fund (IMF). Hereby, bottom-up, specific financial incentives can substitute for top-down, uniform $\mathrm{CP}$, taking diversity into account for climate policymaking.

\subsubsection{The EU ETS}

The EU ETS history illustrates how intended, loudly announced and uniform CP by Cap and Trade (EC 2000) evolved into specific treatments of heterogeneous emitting activities. Chapter 7 provides an analysis and evaluation of the EU ETS from start to present. Here only the uniformity-specificity issue is highlighted, showing:

1 The intention to install a uniform price charged on all capped emission sources failed. Some activities must buy permits, while Emissions Intensive Trade Exposed (EITE) activities receive free permits, with eventual trade at the fringe of their free packages. Some participants may gain money on 
the system, next to receiving free permits for all their emissions, i.e., the $\mathrm{CP}$ they experience is negative or zero. Via electricity bills, the expenditures on permits purchased by power companies are passed on to the electricity customers. Many EU MS use part of their auction revenues for compensating the 'carbon charges' on the electricity bills of EITE companies (Marcu et al. 2019).

2 The posted price of the EU ETS permits is not a uniform CP levied on the emissions of the capped activities, which would theoretically equate their marginal abatement costs. The efficiency trump as argued by NET is therefore absent.

3 Specific free permit assignments to diverse activities, and since 2019 price control via the Market Stability Reserve (MSR), substitute for Cap and Trade announced in the year 2000 .

4 Extended administrations, consultancy and interactions with the emitting industries keep the EU ETS afloat, requiring "a strong demand for skillful government intervention” (Meckling 2011, p. 202).

How to interpret the stranding of intentional uniformity in a myriad of specific measures? Is the ETS instrument as such theoretically flawed? No. Is applying ETS always doomed to fail? No. Sector-specific ETS may function (Verbruggen 2009b), as showcased by the RGGI experiment (Rabe 2018) and by the transition to unleaded gasoline in the USA (Schmalensee and Stavins 2017).

The cause of EU ETS technical failures is the amalgamation of heterogeneous activities under a single umbrella. The unique selling point of GUCP is its Achilles heel.

The top-down almighty scythe shaving disparate activities in distinct contexts is indeed a never-reached 'holy grail' (Wagner et al. 2015). When an endowed jurisdiction like the EU cannot realize a genuine uniform $\mathrm{CP}$ over ca. 11,500 activities, heralding the GUCP is a waste of time, while 'drastic and urgent' action is recommended for avoiding disastrous levels of climate change (Stern 2006; IPCC 2018).

\subsubsection{Good policy designs recognize diversity ex-ante}

An additional problem for the applicability of GUCP is that it cannot account for the diversity of the drastically varying impacts that climate change will have on different states or regions, cultures and practices or ecosystems. GUCP neither accounts for the different capacities of jurisdictions to adapt to climate change. Climate policy will have substantive equality and justice impacts, regardless of the specific policies applied.

Academic concepts such as environmental justice, energy justice and climate justice provide first tools to include distribution and equity aspects in (climate) policymaking (Pellegrini-Masini et al. 2020; Jenkins et al. 2016; Nelson 2013; Walker 2012), while also accounting for power as an influence on ambition 


\section{Diversity disqualifies Global Uniform CP}

levels (Healy et al. 2019; Johnstone et al. 2017). By including local specifics, differences and interdependencies, these approaches do account for diversity.

The literature shows many contributions leaving globalism and uniformity in CP behind, and instead proposing improved financial instruments in climate policy (Rabe 2018). Stiglitz and Stern (2017) recommend CP levels that are tailored to a country's characteristics, including its income level, the quality of its institutions, its endowment in renewable energy and other key resources, its economic structure, its social protection systems, its political situation and many other factors.

Klenert et al. (2018, p. 669) review "real-world pricing regimes" and find that "the reviewed works strongly emphasize the importance of distributional fairness, revenue salience, political trust and policy stability amid partisan changes in government". Bataille et al. (2018, p. 648) find the growing divergence "at odds with basic economic theory, which argues that an equal price for all regions and sectors, whether through a tax or cap-and-trade, is the most effective and efficient tool to reduce emissions".

Recognizing diversity and adapting different $\mathrm{CP}$ proposals to the various heterogeneous situations will reconcile the main criteria for better policy performance. This is not at odds with basic economic theory but corresponding to a proper application of the economics logics in a diverse world.

\subsection{Conclusion}

This chapter added two important aspects to the climate policy debate: First, a clarification of the role of diversity and second, a critique of the 'global and uniform' part of the GUCP mantra. We spell out a scheme how to order diversity terms gradually in four phases [Figure 2.1]. The kink between homogeneous and heterogeneous phases is essential for cataloguing. We extend "diversity as investment" (van den Bergh 2008) to a generic "beneficial role' of diversity. Full recognition of diversity with consideration of transaction costs and diseconomies of scale avoids incompatibility in uniform policies scoping amalgamations of heterogeneous matters. Respecting diversity ex-ante significantly reduces the policy mess caused by announced uniform pricing followed by emergency ad-hoc adaptations and exemptions.

Neoclassical economics' attitude toward diversity is shown to be ambivalent: The unique selling point of GUCP is its Achilles heel. Contrary to the GUCP mantra, applied economics addresses diversity in all branches of socio-economic activities, by specific sectors, segmented markets, and a large variety in goods $\&$ services up to individual customer preferences. This considerably enhanced the utility of consumers' living standard.

Neoclassical economics theory advocates GUCP as superior, top-down policy instrument (LSE 2019, Baranzini et al. 2018). However, actual CPs are distributed, diverse and bottom-up, and proved "remarkably durable" (Rabe 2018, p. 203). Diversity as structuring factor explains the importance and value of specific financial incentives and disincentives. 
The academic discourse on GUCP is rooted in formally solid mathematical theorems, which are not our point of criticism. However, as argued in Annex $\mathrm{C}$, mathematical theorems are impartial for specific or amalgamated coverage. Hence, they do not provide a scientific ground for arguing in favour of amalgamated approaches as the GUCP intends. GUCP is a derailment by its intention to scope global heterogeneity. The hypothetical framework of the market under conditions of perfect competition spreads the carpet for GUCP as the winner on paper.

The non-existence of GUCP makes assessing the performance of GUCP a virtual, hypothetical exercise. Helpful is 'experience based' economic analysis (Saltelli et al. 2020; Tapia Granados and Spash 2019). A lauded experiment of uniform carbon pricing, the EU ETS, is not global, neither uniform over the ca. 11,500 installations included [Section 2.4.3; Chapter 7]. Nevertheless, the quest for GUCP endures.

Our analysis shows that GUCP is unfit and undesirable for climate policymaking. An assumptive, theoretical recipe cannot simultaneously decarbonize steel making in Brazil, electricity production in Belgium, cooking in Bangladesh and the transport sector in Belarus, whilst accounting for substantive equality, distribution and justice implications. A reversal in thinking and discourse on carbon pricing is necessary to stimulate the climate policy debate. The political goal of a GHG neutral economy mandates every industrial sector and company to eliminate all its GHG emissions and erodes the case of uniform carbon pricing (Goulder et al. 1999).

Recognizing diversity and designing ex-ante different CP proposals for the various heterogeneous matters, reconciles the criteria for better policy performance. More effectiveness, efficiency and equity are attainable by implementing a variety of instruments. This is not at odds with basic economic theory but corresponding to a proper application of the economics logics in a diverse world.

Three policy implications are salient:

First, climate policymaking needs to be freed from the GUCP mantra. Economics may play a crucial role on par with other social sciences, developing specific financial incentives, well integrated with other policies to avoid irreversible climate change. A neat example of insight and advice for governing the commons, which keeps the economics essence in central position, is the work by Ostrom $(1990 ; 2005 ; 2014)$.

Second, the Kyoto Protocol and the EU ETS showcase the failing trials of applying top-down GUCP proposals on the world's immense diversity. On the one hand, mainstream economics argues for more efforts to strengthen and multiply GUCP trials. On the other hand, multi-level, polycentric governance in climate politics is winning support and spread (Ostrom 2014; Tormos and Garcia-Lopez 2018; Thiel et al. 2019). Initiatives by citizens in local communities, municipalities and cities are building bottom-up solutions adapted to the diverse contexts.

Third, the performance and resilience of bottom-up solutions are significantly enhanced when matching with the policies at the top of the multi-level 


\section{Diversity disqualifies Global Uniform CP}

governance structures. As countries participating in international climate negotiations remain sovereign, the main role of UNFCCC is coordination. This task can be done more appropriately when the performance of the participants is monitored, reported, and verified in a timely and reliable way (Verbruggen 2009b).

\section{Notes}

1 This chapter is a slightly adapted version of Verbruggen, A., Brauers, H. (2020).

2 Adding the neoclassical favourite attributes 'global uniform' extends CP to GUCP.

3 Neoclassical Economics Theory (NET) is introduced as reference of GUCP and global ETS being superior and ultimate ideals to realize. Other references, such as 'mainstream economics' or 'neoclassical economists' are not precise given many of them defend also non-global and sometimes non-uniform CP as workable options.

4 Dictionaries (Oxford, Merriam-Webster) define diversity as "the state or condition of being diverse"; also as "a range of different things". Diverse is described as "showing a great deal of variety; very different" and "composed of distinct or unlike elements or qualities". Section 2.2 and Figure 2.1 elaborate the concept further.

5 E.g. UN International Standard Industrial Classification (ISIC), or NACE used in the EU.

6 See www.exploring-economics.org/en/.

7 The real economy provides most of the necessary categories, for example the ISIC and NACE classifications of economic activities, the stratification in social groups, etc. 


\title{
3 Anatomy of emissions trading systems
}

\author{
What is the EU ETS? ${ }^{1}$
}

\subsection{Introduction}

The world has seen a substantial increase in the use of carbon emissions trading schemes to mitigate GHG (Rabe 2018; Wettestad and Gulbrandsen 2018). One example is EU ETS, conceived as a Cap and Trade system (EC 2000) and launched in its first phase (2005-2007). Significant adaptations preceded every following phase.

The evaluation of what the EU ETS has become, and its outcome is contentious (Schmalensee and Stavins 2017; Rabe 2018). Opinions about the desirability and functioning of ETS differ among climate policymakers, stakeholders and scholars (Cramton et al. 2015). For example, Gollier and Tirole (2015) are strong proponents. Schmalensee and Stavins (2017), Woerdman and Nentjes (2019) are conditionally in favour of ETS. Pearse and Böhm (2014) reject ETS as a preferred climate policy choice.

Striking a common understanding is difficult for some reasons. Unclear and divergent meanings are assigned to essential concepts, such as 'carbon price', 'emissions cap' and 'efficient emission reductions'. Institutional, political, social, economic and technical realities may conflict with economics textbook assumptions. Interests and agendas vary for participants in the debate [Chapter 7], including politicians, officials, company directors, consultants and NGOs (Meckling 2011). This causes confusion and misunderstanding about the role of ETS in the climate policy debate.

This chapter aims to elucidate the ETS debate by offering an analytical framework with clear definitions of key concepts and referring to empirical findings. This framework is an anatomy of ETS, based on the economic ideas and propositions commonly used by ETS proponents. Anatomy is "the art of separating the parts of an organism in order to ascertain their position, relations, structure and function" (Merriam-Webster's Collegiate Dictionary). For keeping the analysis as transparent and tractable as possible, the leanest version of the ETS anatomy is pursued.

The anatomy of ETS complements recent studies and reports, analysing and evaluating ETS (e.g. Marcu et al. 2017; Schmalensee and Stavins 2017; Narassimhan et al. 2018; Wettestad and Guldbrandsen 2018). The anatomy represents

DOI: $10.4324 / 9781003173816-3$ 
the essential parts and projected functioning of the market-based environmental policy instrument 'emissions trading'. This explains the central position of pricing and the (by economists) announced results of pricing policies, in particular price induced technological innovation (PITI) to attain lower abatement expenses.

Therefore, this analysis belongs to the domain of neoclassical economics and microeconomics as part of the environmental economics literature. By focusing on just the anatomy and on the underlying economic theory and assumptions, actual evaluation of particular tradable permits systems is skipped here and discussed in following chapters.

The value tree methodology (Cummings 2006) is used in the anatomy framework. This involves a philosophically informed analysis to identify and clarify conceptual and technical issues raised by neoclassical economics conceptions of ETS.

A value tree is a hierarchy of high-level (but general, unspecified) moral values at the top, branching into norms, more context-specific prescriptions for or restrictions on particular actions or policy designs, further branching in design requirements embodying the norms in specific designs.

The value tree methodology is applicable when designing products, services or policy strategies (van de Poel 2013). This allows observation of possible value conflicts or mismatches, e.g., between what ethical reasoning based on moral values dictates and the interests of stakeholders. When the ETS anatomy is placed in the context of values and norms, potentially promising results may emerge, for example:

- Facilitating a structured dialogue among actors involved in ETS, resulting in better understanding of each other's arguments. By clarifying the different expectations and involved moral values, contentions become visible.

- Generating new perspectives, opening future deliberations and increasing the solution space beyond prevalent political compromises (Oosterlaken 2015).

- Improving ETS design processes by identifying influential values and value conflicts a priori, before their incorporation in future ETS designs.

The conceptual part of the value tree methodology clarifies the moral values at stake in the design and implementation of ETS. These values count as the evaluative yardstick for the functioning of an ETS organism as a whole. The technical analysis reveals whether (and to what extent) moral values are likely to be met, given a certain internal composition of an ETS exemplar.

Interrelated figures support the description of the anatomy's four constituent components:

i policy goals pursued by the responsible public authority (the EU with the EC as acting administration),

ii costs of abatement to realize intended goals,

iii pricing of carbon emissions, and

iv allocations of tradable emission permits. 
In the leanest version of the ETS anatomy, the four constituent components are necessary and sufficient to explain the essence of this 'market-based' instrument.

For didactic reasons, the aforementioned components (policy goals, abatement costs, pricing, and allowance assignments) are discussed in the seemingly 'odd' sequence i, iv, iii, ii over the Sections 3.2 to 3.5. A comprehensive figure subsequently links the components in 'normal' order for revealing different ETS exemplars in Section 3.6. Section 3.7 concludes this chapter.

\subsection{Goals of EU policy (component i)}

Standard normal distributed opinions about the EU ETS range from 'complete failure' to 'big success', around a critical but complacent, silent majority. The spread is caused by differences in worldviews, interests fostered, and goals pursued. Performance is ultimately gauged by the degree the instrument is meeting clearly specified goals. Often not a single goal, but several goals are pursued. When the several goals are hierarchical, aligned and matching, the ultimate goal is advanced by realizing sub-goals. Different from being aligned, goals may be far apart or even conflicting. Tinbergen's rule (1952) states that one cannot realize far apart or conflicting targets with a single instrument, neither with some kind of 'balanced' application.

Many assume the EU ETS is exceptional, being able to realize the conflicting goals of climate protection and incumbent industrial activity protection ${ }^{2}$. This line of thinking emerges from the hybrid nature of the ETS instrument (component iv) and is covered by the dominant discourse on the superiority of amalgamated emissions trading (Aldy et al. 2010; Gollier and Tirole 2015; Schmalensee and Stavins 2017).

The EU ETS strives to reconcile two different policy goals, which are labelled as:

- A-goal for Atmospheric stability and cleanness.

- $\pi$-goal for Profit-Protection of incumbent companies emitting voluminous amounts of carbon.

The value tree methodology relates policy goals to moral values, norms and design requirements, which will be elaborated below in the context of ETS.

The A-goal can be formulated as follows: 'In all industrial activities, carbon emissions should be brought down to a (almost) zero level by the nearest date (at least $80-95 \%$ emissions reduction by 2050)'. This would contribute to the global mission of reducing carbon emissions to non-dangerous levels (UN 1992; IPCC 2014; EU 2003). Such an A-goal may be seen as the non-negotiable baseline of climate policy (Brown 2010). It is based on the moral value that we should act on climate change now, not because the future costs of inaction exceed those of mitigation, but because the failure to mitigate harms others.

This overarching moral value translates into the norm (or sub-goal) for climate policy designs: 'Induce thorough and disruptive innovations to make 
European industrial activities (almost) carbon-free' (component ii). The ETS community (including economists) generally considers innovation as mainly price induced with the subsequent design requirement for ETS: 'Increase carbon emission permit prices to sufficiently high levels for permanently inducing decarbonizing innovations at a speed and depth as required by the A-goal' (component iii).

The EU's and MS' responsibility for the economic welfare of the region's citizens is expressed in the $\pi$-goal as: 'Maintain (preferably expand) EU's industrial activities, business and employment', with as a subsequent ETS design requirement: 'Protect energy-intensive industries and avoid carbon leakage caused by high permit prices (or tax rates) on voluminous carbon emissions'. In other words, the ETS should not occasion significant financial burdens (compared to other world regions) on Emissions Intensive Trade Exposed (EITE) activities. The $\pi$-goal differs from pursuing 'reductions of GHG emissions in a cost-effective and economically efficient manner' (EU 2003).

'Carbon leakage', mainly seen as an economic-financial question and less as an environmental issue (Marcu et al. 2017, p.18), is of high concern in EU climate policy (Heilmayr and Bradbury 2011; Böhringer et al. 2012; Juergens et al. 2013; Zeng et al. 2018). The absence of carbon leakage in EU's industrial activities (Dechezleprêtre et al. 2014; Marcu et al. 2017; Joltreau and Sommerfeld 2018), witnesses the priority of the wider $\pi$-goal in EU's climate policymaking.

Some industrial activities are moved from the EU to overseas (mainly Asia) due to price differentials in production factors other than fossil fuels and their related emissions. Assessing the extent of this type of displacements is important to identify the actual meaning and proper size of the emissions cap on industrial stationary sources in the EU ETS (which is a design requirement), and to evaluate the environmental effectiveness (or: efficacy) of the instrument (Narassimhan et al. 2018). Emission caps can (and should) be lowered when carbon-intensive material, half-finished, and finished products are imported from outside the EU (Mehling et al. 2018).

\subsection{Allocation of tradable emissions permits (component iv)}

\subsubsection{Theoretical framework}

Starting an artificial market for trading atmospheric pollution space faces creational problems both at the market demand and supply side. One issue is how participants obtain the permits, as they are mandated to yearly deliver an amount equal to the tons of carbon they emitted in the previous year, and to pay a penalty for the number of emissions not covered by permits (Ellerman et al. 2000; Hepburn et al. 2006; Heilmayr and Bradbury 2011).

Figure 3.1 shows the range of available allocation options, some of which have been applied. The light-to-dark box, listing the allocation possibilities of 
permits, reflects the hybrid character of the various allocations as ETS design options, with each option differing also in financial impact on the participants.

A first possibility is a public authority auctioning the yearly total quota of emissions in a competitive bidding among all participants, excluding the opportunity of banking. When the cap is meaningfully lower than the sum of historical non-regulated emissions, the auction would settle at a positive price. Repeating auctions year after year, while reducing the cap and stepping up climate change mitigation exigencies, would create an increasingly stronger CP signal.

The financial burden on emitters would increase when they cannot command the means to reduce their emissions keeping pace with increasing permit prices (component ii). This version of carbon emissions trading is akin to levies (carbon taxes) set by a public authority. This first possibility of starting the EU ETS was unacceptable for the ETS supporting carbon coalition, an anti-taxation alliance of big emitters (Ellerman and Buchner 2007; Meckling 2011).

Descending from top to bottom in Figure 3.1 means passing consecutive levies-permits cocktails. At the bottom the allocation resembles familiar emissions

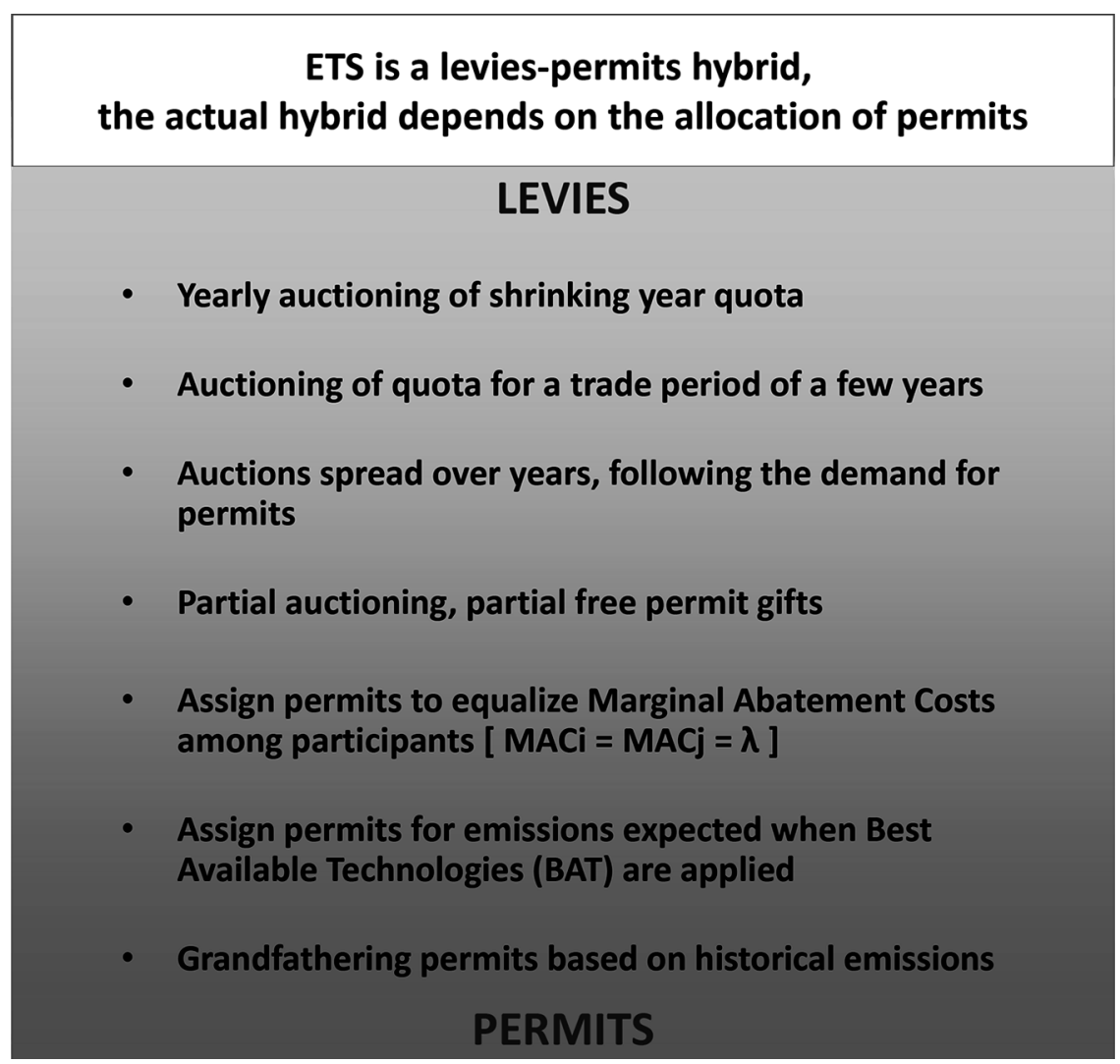

Figure 3.1 Component iv: Allocation of tradable emissions permits 
permit assignment regulation. Public authorities donate free permits to the various sources according to their demands, tempered by standards of Best Available Technologies (BAT).

A performing permits assignment system requests reliable knowledge about emission sources, about actually applied and best available technologies, and about expenses of abatement measures, among other things (Ellerman et al. 2000; Aldy et al. 2010; Juergens et al. 2013). When this information is lacking, 'grandfathering' (free allocation based on historical emissions) is a crude approximation of diligent permit assignment.

In the standard administrative process of permit allocations, companies cannot transfer surplus permits. In an ETS, surplus permits are transferable to others (selling) or in time (hoarding, banking). At the beginning of the EU ETS, the intention was to Cap and Trade emissions within sequential phases of a number of years, without banking across the phases.

Permit trade may reduce the total sum of abatement costs, which is the major selling point of ETS (Stavins 1995; EC 2000). The more exchange is triggered the more the initial permit distribution over the participants was economically inefficient, i.e., when the numbers of permits received by the various participants are not based on the equalization of their marginal abatement costs (Stavins 1995).

For an administrative allocation of permits to installations equalizing their marginal abatement costs, the necessary information and know-how are lacking (Ellerman and Buchner 2007; Juergens et al. 2013).

The implementation of the ideal economic permit allocation principle becomes more illusionary the more diverse the emission sources are. When an ETS is limited to one sector or sub-sector of economic activity with rather homogeneous production and abatement technology (such as electric power generation), a workable proxy of the ideal marginal abatement cost based economic allocation could be attempted.

Another trigger to trading permits is the growth or decline of company activities causing carbon emissions. 'Grandfathering' in permit assignment increases the likelihood of rewarding incumbent laggards at the expense of dynamic business activities. Hence, volumes of trade in an ETS may correspond to the degree of distorted initial allocations. In case of free permit assignment, assessed benefits of trade in the ETS are actually a measure of the extent of economic bias in the initial assignments. Notwithstanding the economic biases caused by free allocation of permits, free permits were the main driver of the carbon trade coalition to advocate emissions trading (Stavins 1995; Markussen and Svendsen 2005; Meckling 2011; Pearse and Böhm 2014).

\subsubsection{The EU-ETS implementation}

In the Phases 1 and 2 (period 2005-2012) more than 97\% of the permits were free gifts to the emitters. In Phase 3 (2013-2020) of the EU ETS, almost half of the permits were auctioned: at the middle of the stack in Figure 3.1, a 
hybrid ETS was created (Woerdman and Nentjes 2019). EITE industrial activities got free permits to preclude carbon leakage. Non-exposed activities, mainly electric power generation, had to obtain their shortfall in permits via allocation auctions or purchase transactions (for instance from excess stocks obtained by EITE industrial companies).

The bills of purchased permits for emissions of electric power plants largely end up on the invoices paid by electricity customers (Gulli 2008). Depending on the market structure and regulatory conditions, power companies may charge significantly higher amounts than their actual bills for obtaining the permits. The differences are generally named 'windfall' profits. However, other labels, such as 'excess' or 'monopoly' profits, better clarify the deliberate construction of the money skimming from mainly non-ETS electricity customers (Point Carbon 2008; CAN 2018).

MS may reimburse EITE companies $75 \%$ to $85 \%$ of the permit-price driven charges on their electricity bills (COM 2012; EU 2018a). This money comes from permit auction revenues obtained by MS, via the EC. The customers outside the ETS receive no rebates, which ultimately means that they pay the ETS to function. This unveils the standard mantra of 'ETS puts a price on industrial carbon emissions'.

Permit allocations relate to the moral value of distributive justice. At the most general level, distributive justice implies that "people should be treated equally unless there are morally relevant reasons for treating people differently" (Brown 2010). In practice, two considerations determine whether an ETS exacerbates or reduces inequality (Caney and Hepburn 2011): the impact of higher emissions costs on different industrial sectors, and the wealth transfers by billing free allocated emissions allowances. When significant windfall (excess, monopoly) profits are observed, ETS designs conflict with baseline expectations on distributive justice.

\subsection{Carbon emissions prices (component iii)}

In the climate policy debate, setting the $\mathrm{CP}$ is the holy grail of economists (Aldy et al. 2010; Cramton et al. 2015; Wagner et al. 2015; Stiglitz and Stern 2017). In climate policy circles, however, the CP is linked to various moral or empirical foundations, origins and meanings, including:

a Welfare-maximizing emissions prices.

b Incentive prices for emitters to reduce their GHG emissions.

c Permit prices observed in ETS (in case the EU ETS).

The kind and amount of information necessary to assess the proper level of actual prices as a design requirement for ETS is unduly complicated and enormous in case a), still very intricate and extended in case b), and rather trivial in case c) because spot and several future prices (derivatives) are daily posted in carbon markets. The significance of the three kinds of CP is different. 


\subsubsection{Welfare-maximizing emissions prices [Annex B]}

Environmental economics propositions about optimal emissions quantities and corresponding emissions prices are based on minimization of the sum of two groups of costs. One group consists of damage costs, rising with higher levels of pollution measured by the GHG concentration in the atmosphere. Damage is a public cost or less damage is a public benefit. The other costs are abatement ${ }^{3}$ or mitigation expenses incurred for reducing emissions. Abatement is a polluter's duty according the polluter pays principle (OECD 1972).

Minimizing the sum of damage costs and abatement expenses indicates the economic optimum level of pollution and emissions. At this level, the marginal damage cost equals the marginal abatement cost. This level is called the 'social optimum price' or the 'social cost of carbon (SCC)'.

The elegance of this logic is of dazzling simplicity, but practically applying the logic is an arduous mess. Implementation starts with the challenge of properly relating the optimal pollution level (in the public sphere of nature and environmental common goods) with the optimal emissions level (in the private sphere of emitters causing the emissions). Abatement expenses are amenable to identify and gauge, because they are mostly immediate, while uncertainties are manageable, and investments are revocable. Scholars (Kolstad 1996; Pindyck 2000) confused irrevocability of investments with intractable irreversibility of losses in unique commons like atmosphere and climate stability (Verbruggen 2013). Incentive prices (case b)) are (or should be) based on evaluations of abatement (mitigation) expenses.

Assessing public damage costs is tricky and its results are highly unreliable when the costs are spread over long periods (sometimes up to millennia or even eternity), with cost drivers that are highly uncertain and moreover poorly or not reversible. They include, for example, the concentration of GHGs in the atmosphere and its direct effects such as temperature and sea-level rising. Reliable estimates of the global and long-term damage costs of climate change are beyond human capability.

However, some scholars and institutes have dared to derive numbers. For example: in 2002, the UK Government Economic Service recommended an illustrative estimate of SCC of $£ 70 /$ ton carbon, within a range of $£ 35$ to $£ 140 /$ ton, for use in policy appraisal across government (Watkiss 2005). The author emphasizes the difficulties to obtain reliable numerical outcomes. Aldy et al. (2010, p. 911) note: "Especially striking is the difference between Stern at $\$ 85$ and Nordhaus at $\$ 8$ per ton of $\mathrm{CO}_{2}-$ a difference largely dependent on discount rate assumptions".

Weitzman (2013) also problematizes the impact of risk-modified discount rates on assessments of the SCC. Pindyck (2017a) observes SCC marginal price ranges in the literature from around $\$ 10$ to well over $\$ 200$ per ton $\mathrm{CO}_{2}$-eq emitted. Notwithstanding huge uncertainties over very long horizons of climate damage, Pindyck estimates an average SCC at around $\$ 100 /$ ton. 
Avoiding the pitfall of spurious quantitative accuracy, only the shape of a 'carbon emissions price stair' is logically deducible from qualitative information about climate change damage costs [Figure 3.2]. The left panel of Figure 3.2 holds a graph with, as driving variable (on the horizontal axis), the atmospheric GHG concentration. Due to yearly emissions of ca. 50 billion tons of $\mathrm{CO}_{2}$-eq the GHG concentration goes up with a few ppm year after year (IPCC 2013).

The vertical axis is a measure of the damage costs in Etrillions. The dashed curve expresses a likely exponential pattern with high uncertainty about actual cost numbers. Two vertical bars placed at a time interval represent two net ppm additions during an earlier and a later year. The consecutive yearly net GHG additions accumulate to the total GHG concentration, a summary indicator of all human-induced drivers causing climate change.

The middle panel of Figure 3.2 shows the flat CP in $€ /$ ton-emitted for all emissions during a given year. This social cost price is derived from the first panel of Figure 3.2 via the slope of the total damage cost curve at the top of the bar in a given year, equalling the marginal damage cost. When total GHG concentration increases, the curvature of the total damage cost function becomes steeper and the derived flat CPs during a year are positioned higher and higher (Richardson and Fraas 2013).

The third panel of Figure 3.2 represents the information of the middle panel, assembled for a sequence of tens of years (the timeline on the horizontal axis). With time passing the SCC goes up. When connected year after year they deliver a stair of CPs, which would drive the carbon emissions in the right direction and would charge the occasioned climate change damage costs on the emitters.

Notwithstanding the huge uncertainty about the real numbers of damage costs, as a corollary about the proper height of the risers and treads of the CP stair, the stair shape as such supports a pattern of unrelenting price increase over time without rebound and without volatility. The multiplicity of parallel stairs in the third panel of Figure 3.2 reflects the huge uncertainty about the numbers (Watkiss 2005; Aldy et al. 2010; Weitzman 2013; Pindyck 2017a).

marginal damage cost $=$ social carbon price

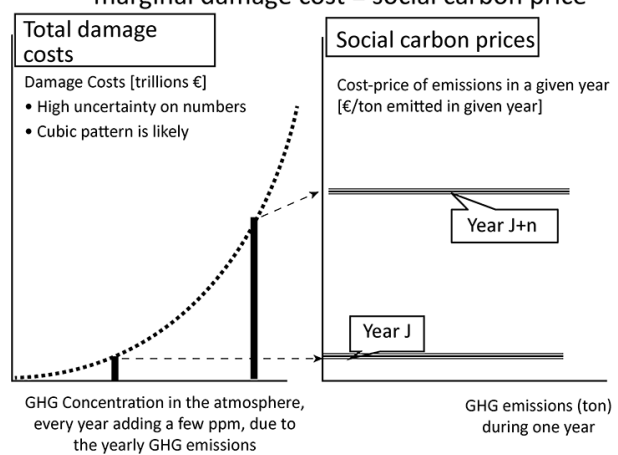

Carbon price stairs evolving over time (specific outcomes depend on start year, height \& gradient)

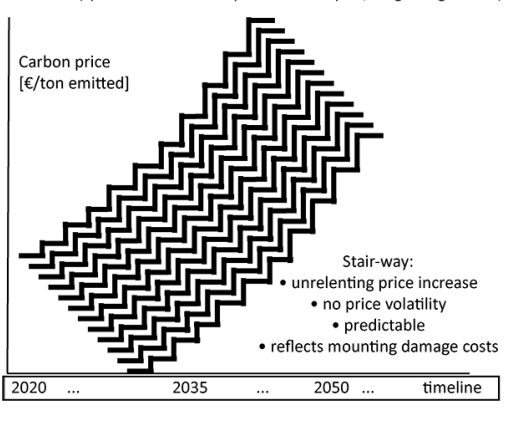

Figure 3.2 Component iii: Carbon emissions pricing 
If year-by-year emissions were charged by levies of the appropriate level, public authorities would collect financial means to compensate undergone damages or to finance adaptation measures. To implement such levies in practice, the policy faces impediments, such as: 1) assigning numerical values to the levies; 2) resistance of most constituencies against levies, alias against paying for the public goods atmosphere and climate stability; and 3) allocation of the damage compensations or adaptation budgets.

\subsubsection{Incentive prices for reducing GHG emissions [Annex C]}

Here the focus is only on the abatement (mitigation) expenses. The purpose is to minimize the total of expenses incurred by polluters when meeting a set of emission reduction targets over a given period. This type of pricing is discussed in Section 3.5 about abatement costs.

\subsubsection{Observed prices of permits in ETS}

In theory, the permit price in a Cap and Trade system results from an equilibrium between the supply of permits and the demand for permits. In the artificial ETS market, administrative rules create supply and demand. The EU planned to establish the artificial markets in consecutive, independent phases, uniformly covering all major emission sources facing the inelastic supply of a single cap [Annex C]. This approach was most congruent with the theoretical model announcing high performance on criteria such as environmental effectiveness, cost-effectiveness and dynamic efficiency through innovation induced by the permit prices.

However, 15 years of experimenting displayed considerable deviations from the theoretical concept. The EU ETS exhibited volatile prices in its first and second phase, and low prices during more than five years in the third phase [Figure 1.2]. Administrative interventions manufactured acceptable permit prices for the participating companies, the MS and the EC. Reforms agreed in November 2017 for Phase 4 (2020-2030) institutionalize a variant of price controls via a quantity-based correction mechanism, called the Market Stability Reserve starting in 2019 (EC 2015; Brink et al. 2016; Hepburn et al. 2016; Perino and Willner 2017; EU 2018a; Wettestad and Gulbrandsen 2018).

An anatomy study cannot address whether the resulting ETS prices are in conformity with welfare-maximizing prices or whether those prices are sufficient to be an incentive for least-cost emissions reduction pathways. However, concerns expressed about the low ETS prices by many scholars (e.g., Edenhofer et al. 2017), policymakers and NGOs (Carbon Market Watch; Sandbag) seem to suggest a significant shortfall of the permit prices posted on the trade boards. After 2017, quoted prices follow a growing trend within a volatile band. The quoted prices differ from the theoretical ones illustrated in Figure 1.2 of Chapter 1: in the EU ETS, the quoted prices are applied on the fringe of industries' emission volumes because most permits are free gifts [Figure 3.1] and the unrelenting price increase is absent. 


\subsection{Costs of abatement (component ii)}

As textbook economics prescribes, emission permit prices should increase to sufficiently high levels for permanently inducing decarbonizing innovations at a speed and depth as required by the $\mathbf{A}$-goal. In this section, we focus on the cost of abatement (mitigation), i.e., on the perspective and interests of private actors causing the GHG emissions. When stricter standards or higher levies on emissions are imposed, extra emission reductions are expected to happen because of legal mandates or because of economic rationality.

Putting a levy on emissions creates economic incentives for the emission sources to reduce the emitted quantities as long as the marginal cost of abating is lower than the permit price or levy rate [Annex C]. Extra reduction means extra abatement spending. Generally, short-term marginal abatement costs (MAC) are running up, from shallow to steep, the higher the reduction percentage of emissions by particular activities becomes [Figure 3.3].

The description in this paper is based on aggregate MAC (the horizontal addition of the MAC curves of all regulated emission sources, i.e., their demand curves for emission permits). The aggregate curve encompasses very different activities under very different conditions.

The top graph in Figure 3.3 shows three 'static' benefit-cost equilibriums in three consecutive $[1,2,3]$ periods (e.g., decades). The marginal abatement cost (MAC) curves start at a point on the horizontal axis (for example $q^{\circ}$ for the period 1 curve). This point corresponds to the amount of emissions without extra abatement effort, avoiding extra abatement spending.

The minimum of the sum of damage and abatement costs is obtained where the marginal damage cost line (the social CP line [Figure 3.2]) cross the MAC curve at point $\mathrm{S}^{1}$, indicating the economic social optimum level of emissions $\mathrm{q}^{1}$.

By accumulating and integrating innovation, technical progress and learning, the MAC curve is expected to shift to the left, showing lower abatement costs. In period 2, a new equilibrium is established. The higher $\mathrm{CP}$ line at $\mathrm{P}^{2}$ and the shifted MAC curve deliver equilibrium $\mathrm{S}^{2}$, at emissions level $\mathrm{q}^{2}$.

Similar logic applies when shifting to period 3. The dynamic efficiency transition from $\mathrm{q}^{1}$ over $\mathrm{q}^{2}$ to $\mathrm{q}^{3}$ (and so on) complements static efficiency in one period, and is key in making low and zero-carbon emission industrial activities feasible and economically affordable.

Realizing dynamic efficiency shifts connect to policies and instruments for promoting inventions and innovations (Jaffe and Stavins 1995; Grübler 1998; Fischer and Newell 2008; Calel and Dechezleprêtre 2016). Within the scope of financial incentives, different visions on economic mechanisms suggest other approaches.

For example, German renewable energy policy was effective in market creation for renewable wind and solar technologies by direct project subsidies (Agora Energiewende 2013). The program was also efficient without excessive rents by careful technology-specific regulations (Verbruggen and Lauber 2009). Despite the incredibly fast and thorough technological success of photovoltaic 


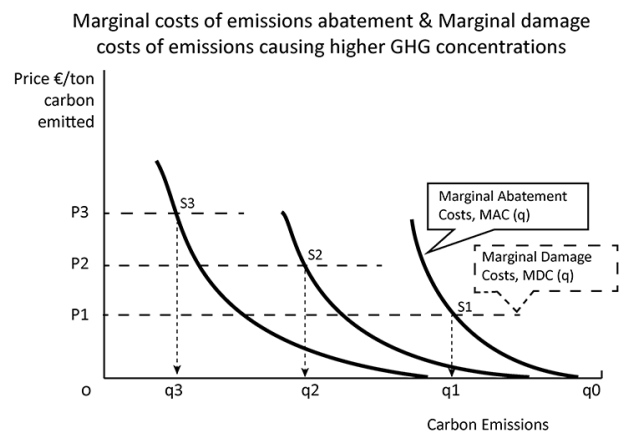

Innovations in abatement, induced by high Carbon prices, shift cost curves and reduce optimal Intensities

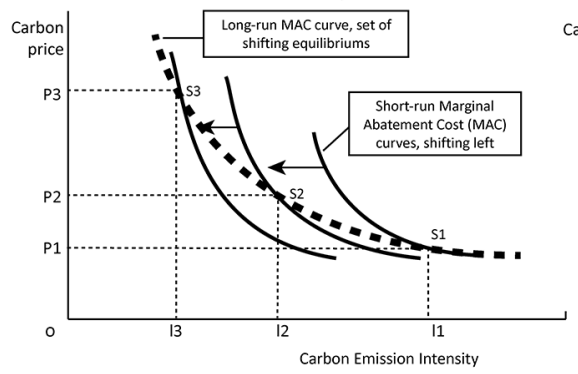

Without inducing carbon prices: autonomous innovations (ceteris paribus, other innovation drivers excluded)

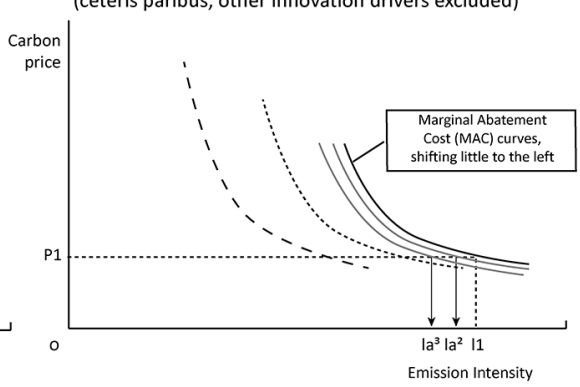

Figure 3.3 Component ii: Marginal abatement costs and price-induced innovation

and wind electricity development and deployment realized in Germany, largely financed by non-ETS electricity consumers, economists complain that it was not market based and thus too costly (Frondel et al. 2010).

In climate policy, economists prefer and advertise price-induced innovation (Fischer and Newell 2008; Aldy et al. 2010; Cramton et al. 2015). This is also inherent in ETS advocacy, expecting innovation success as a result of increasing and high levies on carbon emissions. The foreshadowed effect of price or levy-induced innovation is graphically illustrated in the bottom-left graph of Figure 3.3.

When CPs increase, the financial rationale for polluters is to decrease emissions. At starting (low) CPs, the readily available abatement options are the only way to reduce emissions. When prices increase by multiples and remain at robust heights [Figure 3.2], moving along static short-term MAC curves will result in skyrocketing abatement costs, possibly even leading to bankruptcy or to significant leakages as drastic remedies to reduce emissions.

Hence, polluters will search for inventions and innovations to shift abatement cost curves downwards (e.g., Woerdman 2019), allowing bigger steps in emissions reduction (from $\mathrm{I}^{1}$ over $\mathrm{I}^{2}$ to $\mathrm{I}^{3}$ in the bottom-left graph, resulting from economic cost minimizations at the crossings $S^{1}, S^{2}$ and $S^{3}$ ). When no innovations are feasible, high permit prices would crush the output levels of carbon-intensive products and services supplied by the regulated companies. 
When innovation works and the (short run) MACs are shifting leftward, the dashed curve through the points $\mathrm{S}^{1}, \mathrm{~S}^{2}$ and $\mathrm{S}^{3}$ is the long-term marginal abatement cost curve. In this curve, accumulated learning, innovations and inventions over the foregone years have been incorporated.

By accelerated technological development of mainly wind and solar power (though realized by renewable energy policies outside the ETS), electricity generation is exemplary for a path to full de-carbonization of a crucial industrial, economic and societal activity at affordable and lowering expenses (IRENA 2020).

Other industrial activities may use carbon-intensive technologies that are difficult and expensive to replace by low-carbon technologies (Hepburn et al. 2006; Juergens et al. 2013). Then, high CPs or levies would merely extract high financial transfers from emitting activities without effective inducement of innovations.

This helps to explain why several industrial sectors initially manifested reluctance towards the adoption and implementation of the EU ETS. The reluctance faded when the financial department of the major companies took over from the engineering departments, which were responsible for environmental issues and aware of technological feasibilities.

Company reluctance turned into support by experiencing that the EU ETS offered free permits and that posted CPs were low [Figure 1.2]. Moreover, positive prices offered revenue opportunities when the company was overallocated in permits (CE Delft 2016; CAN 2018), and in the rare cases of under-allocation the prices were only applied on the fringe emissions of these companies. Their carbon emissions bills were low and hardly sufficient as financial inducement to vigorous low-carbon innovation, apart from some minor innovations (Calel and Dechezleprêtre 2016).

By lack of the pressure from high and rising CPs and related bills, only 'autonomous' innovations in reducing carbon emissions emerge. This arguably limited progress is then based on spontaneous improvements in techniques, processes and industrial practices, developed anyhow in modern industrial economies, for instance to reduce fossil fuel bills.

The bottom-right graph in Figure 3.3 illustrates the small shifts of the MAC curves and the little reductions in emissions intensity; the two dashed curves nearer to the ordinate axis are included in the graph as representation of nonrealized technological emissions reduction opportunities. In Chapter 6 the theoretical concept of price induced technological innovation is revisited.

\subsection{Linking the four components of ETS}

The four ETS components are juxtaposed as sewn stacks in Figure 3.4. Different combinations of the various options in the stacks generate different carbon ETS exemplars. However, combinations cannot be assembled arbitrarily. Realistic combinations belong to horizontal bands cutting through the four stacks. Differing GHG abatement costs (stack ii) explain the wide span of 
companies' willingness to reduce their emissions. The aggregated MAC curves cover a range from shallow to sticky-steep curves. Neoclassical economics accepts the aggregate as representative because ETS trade would equalize marginal abatement costs of all companies. Trade also installs maximum cost-effectiveness.

Reducing abatement costs over time by innovation is the result of the uniform price on emitted tons of GHG. Here the link with stack iii is important: the higher the price the more inducement of innovation (= shifting MAC to the left).

In the artificial market of emissions permits, the tightness of the policies determines the height of the price (levy on the emitted ton GHG). Stack iv shows a range of options an ETS exemplar can adopt for setting the prices (stack iii), with decisive impact on innovation and emissions reductions (stack ii), which correspond with the attainment of particular de-carbonization policy goals.

Two combinations, linked to the two major goals described in Section 3.2, are highlighted.

The EU's dominant combination runs over the bottom of Figure 3.4, because the $\pi$-goal has largely overwhelmed the A-goal. Abatement spending for EITE activities is low to zero to preclude carbon leakage. The permit price is only applied on the fringe - if any - of ETS companies' emissions in periods 2005-2007 and 2008-2012, and on a subset of the emissions in period 2013-2020, mainly the carbon emissions of fossil-fired electric power generation plants.

The permits were predominantly grandfathered, and since phase 3 attributed as free emission permits based on product benchmarks for sanctioning growth of the EU based activities of the corporate industry [Chapter 7]. This exemplar of carbon ETS is welcomed and supported by the major corporations (Markussen and Svendsen 2005; Meckling 2011; Verbruggen et al. 2015).

The alternative for the dominant EU exemplar, and favoured by green NGOs (such as Carbon Market Watch; Sandbag), is a combination of green arrows at the top of Figure 3.4, with the A-goal prevailing. Then, industrial activities must fully de-carbonize without delay, requesting a thorough innovation of products, services and technologies.

As economists generally prescribe, carbon pricing should induce the necessary innovations. For activities with 'sticky' technologies the $\mathrm{CP}$ should stay at the highest treads of the carbon emissions price stair, before significant change starts. The allowances quota would be capped severely, with auctions in order to maintain stringent regulation. This alternative ETS exemplar may be the hope of green NGOs, but unlikely to come to life [Chapter 6].

The EU ETS is not up to this challenge, because of the following three factors.

First, EU ETS advocates adopt the mathematical Lagrange principle for ubiquitous coverage to obtain equal marginal abatement costs overall [Annex C]. This supports their claim on superior efficiency for ETS. However, the EU officials are confronted daily with the broad and intense diversity of 


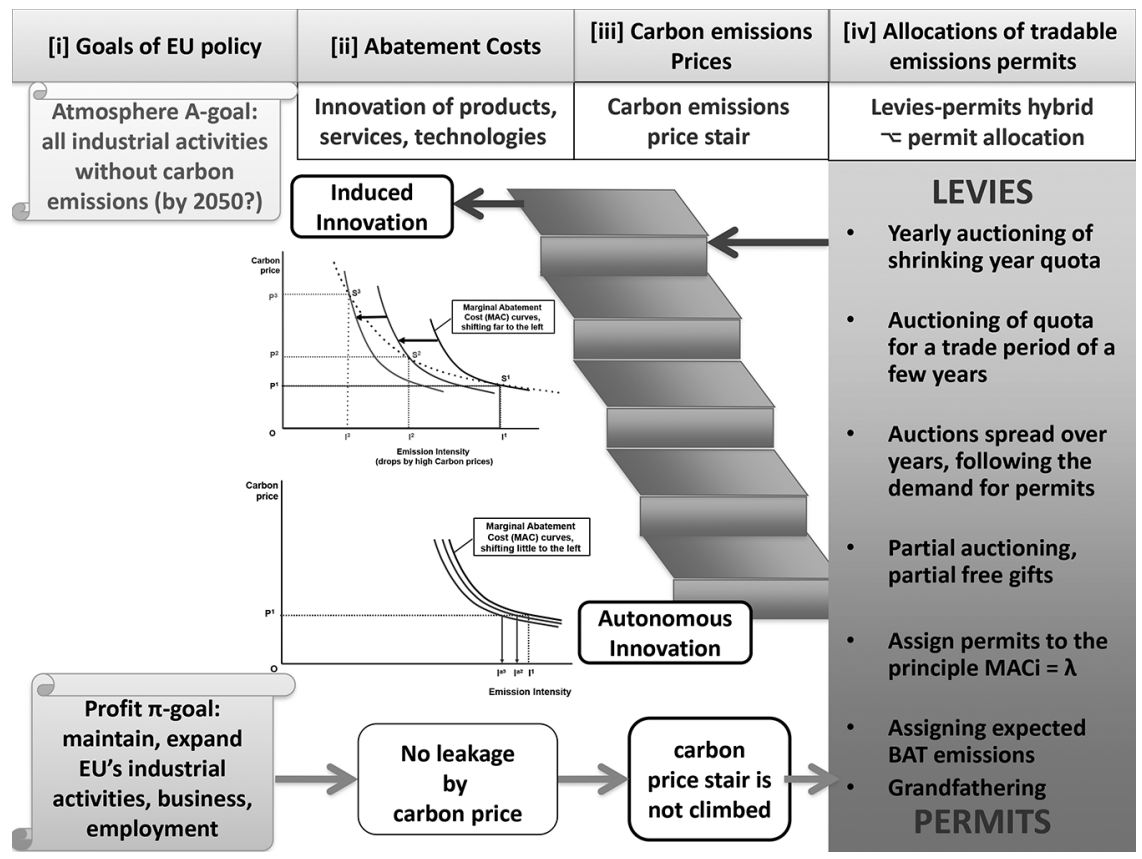

Figure 3.4 ETS anatomy consisting of four components and their relations

activities, technologies, and contexts, which determine essential characteristics of the emission sources, in particular their marginal abatement cost curves. Rather than addressing the diversity, all sources are amalgamated under a single umbrella. However, the equal-marginal cost rule is broken by free assignments of permits to additional emissions from EITE activities, now depending on specific benchmarks (Woerdman and Nentjes 2019; Heilmayr and Bradbury 2011).

Second, by amalgamating all sources, attention for their differences is narrowed down to focusing on trading opportunities, overlooking the discrepancies in real technologies and their capabilities in reducing the carbon intensity of industrial activities. Considering actual technologies is necessary, to measure how sticky they are regarding price-induced innovation, and to find ways for significant reduction or elimination of GHG emissions. "The EU ETS on its own may not provide sufficient incentives for fundamental changes in corporate innovation activities" (Rogge et al. 2011, p. 513).

Third, applying the uniform CP EU-wide or worldwide is a dysfunctional myth [chapter 2]. The social CP is unknown and largely unknowable, but certainly it is several times higher than the past range of $€ 5-€ 25$ per permit in the EU ETS [Chapter 1, Figure 1.2]. The higher price may not be volatile and should be applied on all emitted volumes, not only on the fringes.

A significant increase of the price of carbon emissions permits and of the related bills would create a high financial burden on industrial activities, especially 
the ones with sticky abatement cost curves due to lacking de-carbonization technologies. Leakage due to carbon pricing would then become a more likely reality. A price shock might even lead to devastating economic impacts on the EU industry. The coalition keeping the present EU ETS alive on intensive care would probably walk away from the high permit price ETS exemplar and let it die [Chapter 7].

\subsection{Wrap-up}

The anatomy study is analytical and descriptive of mainstream ETS thinking, hence not a comprehensive evaluation of any ETS. Sections 3.2 to 3.5 describe and comment upon the main components of a carbon ETS. Section 3.6 documents the relations between the components and two carbon ETS exemplars: the $\pi$-goal (profit-protection) pursuing exemplar, which is a clone of the EU ETS; and the A-goal (atmosphere) pursuing exemplar, which, according mainstream ETS thinking, requires high permit prices to induce innovation and is unlikely to be implemented with the present power distribution over the engaged stakeholders. This inconvenient truth tends to be obfuscated by 'pragmatic' ETS experts and academics working within the confines of the 'politically feasible'.

The EU ETS, successful in meeting the $\pi$-goal, is likely to continue because it metamorphosed over time from the initially advertised Cap and Trade quantity-control instrument to a hybrid price-control instrument. The regulated industries are influential via the Brussels negotiation cenacles and also via hoarded permit stocks.

The official EU plans for the future ETS (EU 2018a) confirm the implied price control strategy via the Market Stability Reserve (from 2019 onwards).

Many academic ETS proponents have accepted the metamorphosis and contribute to the discussion about price floors, ceilings, and collars (Wood and Jotzo 2011; Edenhofer et al. 2017). It is unlikely that this will advance the A-goal, because the financial pressure of price-induced innovation remains faint [Chapter 6].

The ETS exemplar unequivocally pursuing the A-goal is conceptual, and not evident to be brought to life. Reaching the A-goal requires policies and instruments forcing technological breakthroughs. Proposals and endeavours to boost the emissions permit prices in the EU ETS are little helpful.

For example, the idea of "[i]ntroducing a carbon price floor can re-affirm the role of the EU ETS as the central pillar in the European effort towards decarbonisation. Such a price floor should start at an economically significant level and rise over time" (Edenhofer et al. 2017, p. 3) confirms the belief in price-induced technological innovation. However, these authors provide no convincing roadmap for realizing their ideas and seem unaware of the real financial-industrial interests influencing the policy arena.

Some propositions may be based on the anatomy study: 
First, the EU ETS exemplar is a hybrid of free permit allocations moderated via specific benchmarks for EITE activities on the one hand and increasing auctioning of permits for the electric power generation sector on the other hand. Renewable power innovations (realized outside, in loggerhead with, the EU ETS) offer affordable and decreasing-cost de-carbonization options for the electricity sector (IRENA 2018). The power sector can pass on the bills of the acquired permits to non-ETS customers.

Second, the two conflicting policy goals pursued by the EU cannot be met with a single ETS exemplar.

Third, a high-cost ETS exemplar is unlikely to substitute for the presently prevailing, industry interests serving exemplar.

The anatomy analytical framework is helpful in situating further research. This research develops in two directions: 'inward' and 'outward' the mainstream neoclassical and business economics paradigms. Inward, reality checks on the actual functioning of price-induced innovation, on the differences between marginal cost pricing and fringe pricing, and on the validity of the 'independence property' (Hahn and Stavins 2011) are discussed in Chapter 6. Outward, the value tree methodology may identify and compare fundamental ETS design choices in the available anatomy framework, as a prerequisite for turning the focus on policies and instruments that design and provide incentives for low-carbon technologies. Finding bridges between inward-outward approaches, which could imply re-thinking the economy-environment relationship, is part of the research challenge.

\section{Notes}

1 This chapter is a slightly adapted version of Verbruggen, et al. (2019).

2 For example, the compromise on ETS reform of November 9, 2017, was commented upon as "striking a delicate balance, seeking to be ambitious on climate while still offering protection for energy-intensive industries that might otherwise relocate abroad to avoid climate legislation" (EURACTIV 2017, November 9).

3 Often, compliance is synonym for abatement/mitigation. For Narassimhan et al. (2018), compliance costs are only the expenses made for MRV (Monitoring, Reporting, Verification) of emissions. The cost terminology in the ETS literature is often ambiguous. 


\section{What could the EU ETS founders learn from US $\mathrm{SO}_{2}$ emissions permit trade?}

\subsection{Introduction}

The UNFCCC COP-3 (Kyoto, December 1997) chronicles are documented history. The Kyoto Protocol included the GHG emissions trading option as part of a package deal between the US and the EU (Meckling 2011). In Kyoto, the reluctance of the EU delegation for accepting emissions trading as a policy instrument for mitigating GHG emissions was strong (Ellerman and Buchner 2007).

Governments, firms, and environmental groups in the EU were the leading skeptics of international GHG emissions trading before Kyoto, and some time after it. The instrument was publicly perceived to be granting a license to pollute to industry and allowing industrialized countries to escape domestic emissions reductions.

$[\ldots]$

UK business and the European Commission led the campaign, which resulted in the import of emissions trading to Europe. BP acted as key broker. (Meckling 2011, pp. 103 and 128)

There is no literature contradicting the above quote about the prevailing opinions on emissions trading in the EU before and following COP3 in Kyoto, and about the role of industry in promoting emissions trading as the alternative for taxing energy use and $\mathrm{CO}_{2}$ emissions. The green paper of the EC (EC 2000) started with: "emissions trading complements and is compatible with other policies and measures", before painting a global horizon for the new market-based instrument. In short time the EC turned into a champion of emissions trading systems (ETS), often labelled the flagship of EU's climate policy (Ellerman et al. 2010; Skjaerseth and Wettestad 2010).

The reversal in the opinions of EC officials and of Commissioner Margot Wallström (1999-2004) was related to several factors, for example: promising stories about emissions trading backed by most neoclassical economists and by some environmental NGOs and strong industry opposition against energycarbon taxing. The EC circumvented the huge barrier of EU MS' sovereignty

DOI: $10.4324 / 9781003173816-4$ 
on tax matters, as Wettestad and Gulbrandsen (2018, p. 35) state: "Moreover, unlike a carbon tax, a carbon market measure could be adopted through the relatively easier procedure of qualified majority vote".

The focus of this chapter is on the years 1995-2007, the EU's period of learning about climate policy instruments, in particular emissions trading. The strong and influential opposition of the European industry and of some MS against energy and $\mathrm{CO}_{2}$ emissions taxing was the outstanding negative argument for the switch at the EC to end the stalemate and adopt the ETS as an environmental policy instrument.

The positive argument was the successful set-up and running of emissions trading experiments in the US (Bryner 1999; Ellerman et al. 2000; Tietenberg 2006; Schmalensee and Stavins 2013; 2017). The main example was the US market for transferable sulphur dioxide $\left(\mathrm{SO}_{2}\right)$ emission permits among electric utilities, established by Title IV of the 1990 Clean Air Act Amendments. By lifting the policy of mandated technology (flue gas scrubbers) and by allowing the power companies high flexibility in reducing the $\mathrm{SO}_{2}$ emissions, the US coal power generating utilities could apply less expensive options, mainly substituting low-sulphur coal for high-sulphur coal (Carlson et al. 2000; Schmalensee and Stavins 2013).

Winning support for EU's emissions trading proposals was frequently argued with reference to the success of the US $\mathrm{SO}_{2}$ Cap and Trade system. This US program can be seen as the starring example for spreading the belief in ETS (Ellerman et al. 2000). Revisiting the program is informative for cataloguing its attributes and for assessing the impact of its exemplary role on the design of the EU ETS, adding to the understanding of the genes planted in the EU ETS. This revisiting exploration delivers important insights not revealed by publications on the guidance role of the $\mathrm{US} \mathrm{SO}_{2}$ program (Carlson et al. 2000; Schmalensee and Stavins 2013; 2017).

In Section 4.2 the differences between the US $\mathrm{SO}_{2}$ and the emerging EU $\mathrm{CO}_{2}$ emissions permit markets are expounded. In Table 4.1 twelve attributes are listed and documented, providing inputs for further argumentation. In Section 4.3, the information of Table 4.1 is used to derive six salient design characteristics of the US program, which were relevant for learning about emissions trading by the EC. In Section 4.4, the EU ETS conditions and implementations on the six salient characteristics are described. Concluding reflections are offered in Section 4.5.

\subsection{Differences between $\mathrm{US} \mathrm{SO}_{2}$ and $\mathrm{EU} \mathrm{CO}_{2}$ emissions permit markets}

Although differences between the functional $\mathrm{US} \mathrm{SO}_{2}$ emissions permit market and the forthcoming $\mathrm{EU} \mathrm{CO} \mathrm{CO}_{2}$ emissions permit market were recognized, they received little attention. Ex-post, a few differences were signalled and commented, e.g., Ellerman and Buchner (2007, pp. 67-69) mention three "significant differences", here summarized as: 
1 The EU ETS is "much larger" than the US $\mathrm{SO}_{2}$ program in number of installations, tons of pollutants and the values of the allowances distributed. "The only dimension in which the US $\mathrm{SO}_{2}$ program exceeds the EU ETS is in required emission reduction - 50 percent - versus the low to mid-single digits for the EU ETS".

2 "The EU ETS has been implemented in a highly decentralized fashion, as might be expected of a multinational system. This is in stark contrast to the highly centralized US $\mathrm{SO}_{2}$ program, which is under one sovereign jurisdiction".

$3 \mathrm{CO}_{2}$ is very different from $\mathrm{SO}_{2}$ "the other a more conventional pollutant that had been long controlled before the emissions trading program started", with "many implications, not the least of which concerns the allocation of allowances".

The above differences are indeed important, but this list of three significant differences is not complete. A thorough comparison between the US and EU contexts and systems merits attention for judging to what degree the US $\mathrm{SO}_{2}$ program could function as a valid example for how the EC switched its climate policy attention almost completely to emissions trading.

In addition, the US markets in $\mathrm{NO}_{\mathrm{x}}$ emissions, set-up in the wake of the $\mathrm{SO}_{2}$ market, provide lessons for designing $\mathrm{CO}_{2}$ emission permits markets (Burtraw and Szambelan 2009). We maintain $\mathrm{SO}_{2}$ trade as the focal program, with some references to the US $\mathrm{NO}_{\mathrm{x}}$ policy experience, or other related policy experiments in the US (Tietenberg 2000, 2006; EPA 2001; Schmalensee and Stavins 2017).

Table 4.1 provides an overview of attributes of the US $\mathrm{SO}_{2}$ and $\mathrm{NOx}$ emissions reduction programs (1995-2005) and of the emerging EU $\mathrm{CO}_{2}$ emissions trading system (2000-2007). The first column shows the four caption attributes, with three additional attributes per caption. The second column provides specification for the $\mathrm{US} \mathrm{SO}_{2}$ and $\mathrm{NOx}$ emissions reduction programs, and the third column for the emerging $\mathrm{EU} \mathrm{CO}_{2}$ emissions trading system. The specifications are readable and understandable in the table, so they are not repeated in this chapter's text.

On the basis of the information summarized in Table 4.1, salient characteristics of the US acid rain programs are discussed in Section 4.3. Important design choices, made by the architects of the EU ETS, are documented in Section 4.4 .

\subsection{Salient characteristics of the US acid rain programs}

Table 4.1 and the underlying publications point to six salient characteristics of the US emissions $\mathrm{SO}_{2}$ and $\mathrm{NO}_{\mathrm{x}}$ trading programs: 1. market segmentation; 2. no leakage; 3. common, well-known production technologies; 4. low-cost abatement options; 5 . rich regulatory bequest at the start of the program; and 6 . emissions permit market instrument subsided to environmental policy-making. 
Table 4.1 Attributes of the US $\mathrm{SO}_{2}$ and NOx emissions reduction programs (1995-2005) and of the emerging EU $\mathrm{CO}_{2}$ emissions trading system (2000-2007)

\begin{tabular}{|c|c|}
\hline & $\begin{array}{l}\text { US } \mathrm{SO}_{2} \text { and } \mathrm{NOx} \text { emissions } \\
\text { reduction programs }(1995-2005)\end{array}$ \\
\hline $\begin{array}{l}\text { 1. Environ- } \\
\text { mental problems } \\
\text { addressed }\end{array}$ & $\begin{array}{l}\text { Acidification by sulphurous } \\
\text { and nitrous acids; particulate } \\
\text { matter (PM 2.5); ground-level } \\
\text { ozone }\end{array}$ \\
\hline $\begin{array}{l}\text { a. Emissions } \\
\text { targeted }\end{array}$ & $\begin{array}{l}\mathrm{SO}_{2}: 16 \text { million tons in } 1990 \\
\text { from coal-fired power plants } \\
\mathrm{NOx} \text { : electricity sector's share } \\
\text { ca. } 22 \% \text { of total US tons } \\
\text { around year } 2000\end{array}$ \\
\hline $\begin{array}{l}\text { b. Impact range } \\
\text { (local - regio- } \\
\text { nal - con- } \\
\text { tinental - global) }\end{array}$ & $\begin{array}{l}\text { Acidification: continental } \\
\text { Particulate matter: local } \\
\text { Ground-level ozone: regional } \\
\text { precursor stocks - local } \\
\text { impacts }\end{array}$ \\
\hline $\begin{array}{l}\text { c. Knowledge } \\
\text { about damage } \\
\text { costs / monetary } \\
\text { evaluations }\end{array}$ & $\begin{array}{l}\text { Extensively studied, with also } \\
\text { monetized damage costs esti- } \\
\text { mates (e.g., nature and build- } \\
\text { ings value loss by acid rain; } \\
\text { human health effects of PM } \\
\text { and ozone) }\end{array}$ \\
\hline $\begin{array}{l}\text { 2. Policies ante- } \\
\text { rior to tradable } \\
\text { permits } \\
\text { programs }\end{array}$ & $\begin{array}{l}20 \text { years policy practice before } \\
\text { the } 1990 \text { Clean Air Act } \\
\text { Amendments }\end{array}$ \\
\hline $\begin{array}{l}\text { a. Regulatory } \\
\text { capability }\end{array}$ & $\begin{array}{l}\text { Knowledgeable, well-staffed } \\
\text { and experienced US Environ- } \\
\text { mental Protection Agency } \\
\text { (EPA); some US States created } \\
\text { similar agencies. }\end{array}$ \\
\hline
\end{tabular}

b. Kind of prior Imposing emissions reductions policies

by legislation, implemented by source specific permits based on BAT. $\mathrm{SO}_{2}$ scrubbers, $\mathrm{NO}_{\mathrm{x}}$ catalysts, mandated techniques for specific sources. Pre-1990 flexibility rules applied: netting, offsets within companies over distributed facilities. Concept of bubbles, caps tested on other environmental issues, e.g. gasoline lead phaseout, or river basin pollution control.
Emerging $\mathrm{EU} \mathrm{CO}_{2}-\mathrm{GHG}$ emissions trading system (2000-2007)

GHG concentration in the atmosphere $\left(\mathrm{CO}_{2}\right.$-eq ppm); ensuing climate change

$\mathrm{CO}_{2}$ : ca. 5 billion tons, mainly from fossil fuel use; nearly $50 \%$ emitted by large industrial installations + other GHG: $\mathrm{CH}_{4}, \mathrm{~N}_{2} \mathrm{O}$, F-gases.

GHG concentration: global Climate change: global - billions of diverse emission sources; varying regional exposure, impacts, risks

Global information and knowhow in IPCC assessment reports Precarious evaluation of various damages, being long-living, highly uncertain, some irreversible

EC proposal for energy-carbon tax rates ramping up yearly during the 1990 decade (failed before COP3)

EU policy via directives, transposed by MS with uneven willingness, capabilities, capacities for design and implementation of climate policy instruments

Regulating GHG emissions: policy matter since 1992 ( ${ }^{\circ} \mathrm{UNFCCC}$ ).

Related: ban on CFC + other ozone depleting substances via Montreal Protocol. Indirectly: fossil fuel taxes and excise duties, energy efficiency measures, and some pollution reduction standards, all with effect on fossil fuel uses, being the principal sources of $\mathrm{CO}_{2}$ emissions. 


$\mathrm{US}_{\mathrm{SO}}$ and NOx emissions
reduction programs (1995-2005)

c. Availability of On all companies in the traddata, information

3. Emissions trade exemplar

a. Vision of the founders

b. Permit allocations

\section{c. Environ- mental effectiveness \\ 4. Regulated
entities}

a. Coverage

b. Technological uniformity/ variety including waste, effluents and emissions.

Pragmatic: The creation of market, labelled Cap and Trade, saw little trade occurring.

Free permits to established and new emitting facilities, based on 1.2 pounds of $\mathrm{SO}_{2}$ per million Btu combusted. EPA auctioned $2.8 \%$ of the total cap for providing a price beacon for traded permits. Auction revenue returned to the buyers. Auctioning not seen for permit allocation. Banking of permits allowed.

$\mathrm{SO}_{2}$ emissions (million ton/ year) decline from 12 in 2000 , to 10 in 2006, down to 5 in 2010 (end of the trade system).
Emerging $\mathrm{EU} \mathrm{CO}_{2}-\mathrm{GHG}$ emissions trading system (2000-2007)

EC mastered little or no information on the ca. 11,500 facilities later covered by the EU ETS. In addition, MS lacked data on GHG emitting installations and actual flows. $\mathrm{CO}_{2}$ emissions assessed with fossil fuel use data, or activity statistics.

$$
\text { Cap and Trade Cap and Trade }
$$
Market credo: "The virtues of $\mathrm{SO}_{2}$ and $\mathrm{NO}_{\mathrm{x}}$ markets evolved the market mechanism are that from gradual flexibility mea- no person, or agency, has to set sures (see 2.b). The $\mathrm{SO}_{2}$ the price - it is set by the competition among buyers and sellers of the rights" (Dales, 1968, p. 801 ).

In Phase 1 and in Phase 2, except a few per-cent, all allowances were free gifts (grandfathering). Permit surplus crashed the Phase 1 price to zero (2007). To avoid zero prices at the end of Phase 2 (2012), banking into Phase 3 was allowed. Auctions in Phase 3, mainly for electric power generation; revenues spent by MS on climate, budget issues, and rebates to ETS companies.

Over allocation of free permits in Phase 1 and in Phase 2 did not spur to extra emissions reductions.

The market bubble includes ca. 11,500 large-scale $\mathrm{CO}_{2}$ emission sources in most of the industrial sectors. EC (2000) planned more sources covered, as tried in UK's initial trading program.

Participants' processes, techniques, equipment, etc. are numerous and activity specific. Their dynamic developments are difficult to cast, poorly known by the EC and MS administrations. 


\begin{tabular}{|c|c|c|}
\hline & $\begin{array}{l}\text { US } \mathrm{SO}_{2} \text { and NOx emissions } \\
\text { reduction programs (1995-2005) }\end{array}$ & $\begin{array}{l}\text { Emerging } \mathrm{EU} \mathrm{CO} \mathrm{CO}_{2}-\mathrm{GHG} \text { emissions } \\
\text { trading system }(2000-2007)\end{array}$ \\
\hline $\begin{array}{l}\text { c. Mitigation } \\
\text { options }\end{array}$ & $\begin{array}{l}\text { Commercially developed low- } \\
\text { cost measures, e.g., improved } \\
\text { combustion processes and fuel } \\
\text { substitution (mainly low-sul- } \\
\text { phur for high-sulphur coal). } \\
\text { Add-on technical solutions } \\
\text { significantly reduce the emis- } \\
\text { sions, e.g., flue gas scrubbing, } \\
\text { catalysts. }\end{array}$ & $\begin{array}{l}\text { Reduction of GHG emissions } \\
\text { requires a broad spectrum of } \\
\text { techniques, some still unknown } \\
\text { or at embryonic stage, best prac- } \\
\text { tices, change in activities, in pro- } \\
\text { ducts, etc. A complete inventory } \\
\text { is difficult to assemble and main- } \\
\text { tain, due to scope, diversity, and } \\
\text { dynamic changes. }\end{array}$ \\
\hline
\end{tabular}

Sources: Dales 1968; Ellerman et al. 2000; 2010; Carlson et al. 2000; EC 2000; EPA 2001; Christiansen and Wettestad 2003; Tietenberg 2006; Ellerman and Buchner 2007; Burtraw and Szambelan 2009; Schmalensee and Stavins 2013; 2017; Wettestad and Gulbrandsen 2018.

1 Market segmentation. The US acidification, particulate matter, and groundlevel ozone precursors $\left(\mathrm{SO}_{2}\right.$ and $\mathrm{NO}_{\mathrm{x}}$ ) emissions markets were separated for $\mathrm{SO}_{2}$ and $\mathrm{NO}_{\mathrm{x}}$. For $\mathrm{SO}_{2}$ fossil fuel $(96 \%$ coal) fired power plants, part of the then intense controlled US power generation sector, were included. For $\mathrm{NO}_{\mathrm{x}}$, different programs were set up for different areas and contexts, including various sources besides power generation plants (Burtraw and Szambelan 2009). Problem and market segmentation have been an important factor of success of the respective programs.

In a market segment, the decision-makers know each other. They speak the same language, being trained in the same discipline and active in the same branch of industry. During their career they meet as members of the same professional organizations and federations. Besides, franchising of service areas in the power generation sector is standard business. Without territorial competition, smoother deals among power companies occur, as could transactions in emissions permits. Nonetheless, the volume of trade remained very modest.

2 No leakage. All relevant, comparable emissions sources were covered in the controlled market segment. The US power generation market is mostly isolated from similar activities abroad. This made that leakage in the $\mathrm{SO}_{2}$ program was of little concern.

3 Common, well-known production technologies. By the specific scope of the $\mathrm{SO}_{2}$ market, the production technologies were common to all sources (mainly thermal coal-fired power generation). They are highly developed, documented and understood by all, including the regulators of the sector. For the more diverse NOx emitting activities and their techniques employed, a less outspoken, similar situation holds.

4 Low-cost abatement options. Reducing $\mathrm{SO}_{2}$ emissions in the US was blessed with low-cost abatement options for meeting the emissions reduction caps, set for 1995-1999 above the actual emissions, and set at 10 million tons/year for the period 2000-2010 (Schmalensee and Stavins 2013, p. 107). Substituting low-sulphur for high-sulphur coal was 
responsible for about $80 \%$ of the decline in marginal abatement costs, while technical change was responsible for about 20\% (Carlson et al. 2000). The Western low-sulphur coal could be mined cheaply; deregulation and innovation in railroad markets significantly reduced coal transportation costs.

In addition to cheap fuel substitution, a mature scrubber technology was available. The indulgent reduction targets side-lined advanced scrubbers, being the high-end of the marginal cost curve allowing above 95\% removal of the $\mathrm{SO}_{2}$ in emitted flue gases. A technical fix for the $\mathrm{SO}_{2}$ emission problem is available. For $\mathrm{NO}_{\mathrm{x}}$ the technical fix is further out, but not impossible, e.g., for large stationary sources in the power generation sector, selective catalytic reduction is available. Small-scale catalysts have been developed and applied in automotive vehicles using internal combustion engines.

5 Rich regulatory bequest at the start of the program. The $\mathrm{SO}_{2}$ and $\mathrm{NO}_{\mathrm{x}}$ emissions market experiments benefited from a rich regulatory bequest. There was a knowledgeable, authoritative regulator: the Environmental Protection Agency (EPA). The emissions permit assignment process was established and streamlined (e.g., 1.2 pounds of $\mathrm{SO}_{2}$ per million Btu combusted). All emission sources included in the starting market bubble owned emission permits. Flexibility practices had been applied by allowing netting and offsetting of emissions. External tradability was a further step in flexible options for meeting environment targets, however of lesser importance than the revoking of strict mandates on the instalment of addon sanitation equipment, like scrubbers. For the efficiency of the program, flexibility was a far more important factor than trade in permits. Banking of permits allowed temporal flexibility as another way to increase efficiency (Schmalensee and Stavins 2013; 2017).

6 Emissions permit market instrument subsided to environmental policy-making. The tradable permit market mechanism was lauded and applauded by the economics profession. However, the regulators kept the head cool. They placed the attainment of set environmental targets higher than the search for exemplary market functioning.

In May 2001, the air quality management district removed the electricity generators from the RECLAIM market and required them to install pollution control technologies. In addition, all sources emitting over 50 tons were required to submit binding compliance plans in 2002 that described how the sources would comply with RECLAIM through 2006.

(Burtraw and Szambelan 2009, p. 19)

This illustrates the directive role of public regulators in the set-up and functioning of the licensed emissions permit markets. It accentuates the necessary availability of public capability and capacity to fulfil the managerial tasks of market set-up, control, and fast intervention when 
problems arise. "It is the paradox of pollution markets that they harness market forces while creating a strong demand for skilful government intervention" (Meckling 2011, p. 202). By 2010, the US government ended the Cap and Trade system.

Although hailed as the guiding star of market-based instruments, the program implied free allocation of permits to the emitters. As such, the observed prices of allowances as determined in the market apply only on a fringe of the emissions.

Prices are volatile $\$ 150 /$ ton $\mathrm{SO}_{2}$ in 1995 , down to $\$ 70$ in 1996 , up to $\$ 200$ in $1999, \$ 150$ in 2000-2003, \$700 end of 2004 due to increase of electricity demand and increase in natural gas prices, spiking $\$ 1600$ in 2006 (after Katrina and Rita hurricanes), down to \$65 in 2009.

(Burtraw and Szambelan 2009, p. 9)

The volatility may be due to speculative interventions, given that the emitting firms were not very active in trading permits across firms that were economically unrelated. In a detailed study, Chan et al. (2017) estimate the abatement cost savings from permit trade at US\$200 million in 2002 before the program had reached the steady state.

Generally, academia and policy makers evaluate the performance of the US acid rain program as positive (Smith 2002). Schmalensee and Stavins (2017) derive five lessons for future designs of emissions trading systems, e.g.:

i put final rules in place well before the beginning of the first compliance period,

ii free allocation of allowances fostered political support,

iii intra-sector emissions leakage can be minimized by including all sources within the sector (above some capacity or emissions level),

iv a cap significantly below business-as-usual emissions, combined with unrestricted trading and banking, and

$\mathrm{v}$ high levels of compliance can be encouraged with the combination of effective monitoring and significant penalties for non-compliance (being the case at $\$ 2000$ per ton $\mathrm{SO}_{2}$ statutory fine for any emissions exceeding allowance holdings).

\subsection{Choices made by the architects of the EU ETS}

The climate policy conditions in the EU at the beginning of the $21^{\text {st }}$ century were almost the opposite of the ones embedding the US acid rain market [Section 4.3, Table 4.1]. In the present section is spelled out which choices have been made by the architects designing the EU ETS. The choices differ on essential points from the US acid rain program regulations. The GHG 
problem and the policy situation in the EU, has given birth to an ETS loaded with challenges, some due to internal contradictions. This opens a future path of protracting corrections and adaptations, with deleterious impacts on the effective reduction of GHG emissions by many industrial activities in the EU.

The six items in this section refer to the six ones in Section 4.3.

1 The design deliberately excluded market segmentation: When designing the EU ETS as a Cap and Trade system, the EC intentionally skipped consideration of problem and market segmentation. The goal was to amalgamate as many $\mathrm{CO}_{2}$ and other GHG emission sources, sectors and countries as possible into a single tradable permit system, to obtain a single $\mathrm{CP}$ for the most emission sources in the widest possible region.

Mainstream economists sanction the practice intended by the EU (Ellerman and Joskow 2008; Gollier and Tirole 2015). Economists' reports and articles show on paper that the more differentiation and the wider the amalgamation reaches, the higher the benefits amass. This theory and the ensuing practice of amalgamation rest on a basic mathematical optimization algorithm [Annex C].

In Chapter 2 it is argued that application of the algorithm is valid and instructive when homogeneous realities are covered. In practice, sources, sectors and countries are heterogeneous differing in many ways, which also hinders informed, transparent and trusted interactions and hence obstructs transactions. Real markets of economic products, goods \& services are organically segmented to maximize utility for customers and minimize expenses for producers.

2 Leakage uproots the ideal emissions trade market. By the inclusion of several industrial activities exposed to competition in the globalized commodity markets, leakage was, and continues to be, one of the major issues of the EU ETS. For precluding effective occurrence of leakage caused by the EU ETS, the EC regulators had to give up the widely praised, announced benefits of amalgamating the maximum of emission sources on a single, levelled playing field.

In the first two phases (2005-2007; 2008-2012) almost all permits were free donations; in the third phase (2013-2020), more than half of the emission sources, labelled as Emissions Intensive Trade Exposed (EITE) industries, got and get free permits for more, all, or almost all of their emissions. As such, the levied price on their emissions is negative, zero, or faint. The electric power generation companies, not exposed to leakage, are since 2013 formally treated separately from the other EU ETS participants. They are mandated to buy their shortage in permits at auctions or from market parties with excess permits. As such, the playing field among participants is not level.

3 Huge variety of sources with various, often little publicly documented, production technologies. The technologies causing GHG emissions in the many industrial (with also transport envisaged) activity sectors are 
numerous and diverse. Some technologies or specific techniques are characterized by complicated technicality, integrated in broader technologies and often patent protected. Generally, public regulators do not command the experts and capability to acquire sufficient knowledge in due time about representative samples of the implied technologies and their dynamic evolution. The diverse sectors and sub-sectors of industrial activities employ diverse specialists. The circles of various specialists have little affinity across the circles' borders.

The EU joint research centres have collected good quality overviews of Best Available Technologies (BAT) to reduce waste, effluents, and emissions of many industrial processes. For allocation of free permits to EITE activities, the EC has worked on benchmarks of the best practices for abating GHG emissions in EITE industrial activities. This cumbersome work requests extensive data and knowledge, and faces many difficulties (Ellerman and Buchner 2007; Heilmayr and Bradbury 2011; Juergens et al. 2013; Stenqvist and Ahman 2014).

4 Low-cost abatement options are not readily available for many industrial activities. The GHG emissions mitigation options, technologies and practices, are related to the many specific production processes, technologies, and their embedment in diverse facilities. Their inventory, detailed description and cost assessment, is not readily available for all European industrial activities.

For some sectors, such as electric power generation, the technologies are rather standard and known. Electric power generation decarbonizing benefits from the spectacular advances in renewable electricity harvesting techniques and their cost decrease, an evolution not seen by the ETS architects of the EC and their advisors. For other sectors (oxygen steel, cement, chemicals, etc.), realizing significant emissions reduction rates requires the invention, development and demonstration of new technologies.

5 Inadequate regulatory bequest. The EU ETS was a green meadow construction. During the founding years (1998-2005) there were no equipped regulatory offices, with decades of experience and contacts with the GHG emitters. At the start of the EU ETS, no GHG emissions permits had ever been allocated to the facilities emitting considerable volumes of GHG. Environmental administrations of the MS were not familiar with flexibility instruments like netting, offsets, bubbles or emissions trading. A handful of academic economists were theoretically aware of flexible environmental policy instruments and tradable permit systems, mostly referring to the US experiences. Intensive and deep exploration of the US systems, their context and particularities, their propensity for transposition to the EU plans on creating the ETS, was not undertaken.

6 The adoration of perfect markets was of little help for addressing the reallive difficulties. The EU officials, commanding scarce regulatory capability, capacity and experience, were happy to find a substitute for the 
failed trial to install a uniform and gradually mounting EU energy-carbon tax in the 1990s. The officials' conversion was outright, with respect for textbook prescriptions on perfect markets. Economics scholars underpinned the new belief by praising the EU's plans and permanent hammering adherence to textbook ideas (Gollier and Tirole 2015; Baranzini et al. 2017 as recent examples).

A reversal of ends and means, as noted by Bryner (1999, p. 20), occurred: 'market functioning' became the end, overshadowing the essential environmental goal of deep decarbonizing (requesting environmental effectiveness and dynamic efficiency by innovations reducing, up to eliminating, GHG emissions), in order to limit the GHG concentration in the atmosphere.

\subsection{Concluding reflections}

Observing real-live experiments in emissions market building offers important insights, not easily detectable at the moment of market design (Smith 2002). Hence, timely and close observation of other endeavours in creating emission permit markets could prove very instructive for learning, also receiving early warnings on likely flaws and their ensuing impacts.

Realizing the neoclassical theoretical ideal GHG ETS for the EU region (intending a later global coverage) is an immense undertaking, actually a 'mission impossible'. For such a project, preparation is essential when pursuing efficient effectiveness. Strategic planning, as taught in business and public administration schools, may frame the efforts. Extensive study of strengths, weaknesses, opportunities and threats provides insight in the own capacities within a complicated, sometimes complex context. Problems can be stated, goals and smart targets formulated. Contingent actions are planned with necessary resources budgeted for staff, data collection and processing, rulemaking, etc. Learning how ongoing ETS programs addressed the issues is instructive (Carlson et al. 2000; Ellerman et al. 2000; Schmalensee and Stavins 2013; 2017).

However, the content and context of the US acid rain program are very different from the content and context of EU's GHG emissions problems and regulatory capacity. Fruitful learning would have adopted the logic that the successful US $\mathrm{SO}_{2}$ program holds several warnings for the planned design of EU's $\mathrm{CO}_{2}$ ETS because the two systems address very different problems in totally different contexts.

At least, the different contents and contexts justified extensive investigation on what kind of GHG emissions trading could be workable in the EU context, and which advantages it could offer, compared to other environmental policies and policy instruments. This discussion still merits attention today.

Opportunistic comparison between the US acid rain program and the intended EU ETS was based on a frothy belief: 'The first is working well, so the second also will'. Shallow comparison and blunt equation were not at all 
justifiable. The recommendable attitude for the EU would have been to learn from the predecessors, while being very keen about the differences in content and in context (Bryner 1999; Tietenberg 2006). Without such attitude, one gets blinded for the fact that the many elements supporting the success of the US acid rain program were missing in the context of EU's GHG emissions reduction program.

Overall, at the turn of the century, the emissions market situation and context of the functional US acid rain program on the one hand, and the intended EU ETS for GHG on the other hand, had little in common [Table 4.1], making referencing unreliable and copy-pasting deleterious.

Recognizing the important differences between the systems is a prerequisite for fruitful learning. Overlooking important differences and gaps, chasing a textbook Cap and Trade market are recipes ascertaining later problems, disparaging rather than helpful in finding fast (given the urgency to mitigate climate change) roads to a low-carbon economy and society. 


\section{Early European experience with Tradable Green Certificates neglected by EU ETS architects ${ }^{1}$}

\subsection{Introduction}

The US Cap and Trade system for reducing sulphur dioxide emissions by mainly coal fired power plants [Chapter 4] is recognized as the guiding star of Europe's GHG emissions trading scheme (Ellerman et al. 2000; Carlson et al. 2000; Burtraw and Szambelan 2009). Mostly overlooked are Europe's early experiments in market creation for trading green-power certificates (TGC), starting in 2002 while the design phase of the $\mathrm{CO}_{2}$ ETS was ongoing. Careful analysis of the TGC experiments delivers important insights for the construction of ETS. This chapter describes the functioning of a TGC experiment during the period 2001-2007, as a learning source for officials then elaborating and testing EU's ETS. Most lessons are still relevant today.

Market prevalence is a common vision in the EC directorate for competition. It is strongly rooted in the directorate striving for a competitive internal electricity market (EC 1997). After UNFCCC COP3 in Kyoto (December 1997), it also permeated the directorate for the environment. This directorate changed camps in accepting emission permits trading as a valid instrument for pursuing climate policy goals (Ellerman et al. 2000; Skjaerseth and Wettestad 2010; Meckling 2011), Soon, EC's environmental directorate became a firm believer and advocate for the application of artificial market constructs (EC 1999; EC 2000; Christiansen and Wettestad 2003; Ellerman and Buchner 2007).

Voss and Simons (2014) attribute the success of the ETS as a policy instrument mainly to the fact that an entire 'instrument constituency' (composed of members of academia, consultancy, public policy, business and civil society) could be enrolled in its support. In turn, this enrolment depended in part on the promised "elegance of an almost self-governing policy instrument that could be operated light-handedly by adjusting an emission cap and leaving the rest to the market" (Voss and Simons 2014, p. 745).

The ETS adopted Cap and Trade, which was mathematically established in environmental economics textbooks by the mid-eighties. The more mundane observation that ETS designs, operations and reparations would create a big demand for consultancy and advisory services explains another part of its

DOI: $10.4324 / 9781003173816-5$ 
success. By the end of the 1990s, the EC was editing a Directive for the promotion of renewable energy (RE) in the EU. It mulled the possibility of supporting renewable electricity development and deployment by applying an artificial market as policy instrument (EC 1999).

At first sight, instruments for reducing GHG emissions have little in common with instruments for increasing renewable electricity generation. However, at the turn of the century, constructing the path of GHG emissions reductions and the path of developing renewable electricity technology faced comparable conditions. Both endeavours were receptive to novel policy ideas and instruments to provide incentives to non-governmental decision-makers (Toke 2008).

Fulfilling the de-carbonization missions requested technological innovations and their broad deployment. In addition to Research and Development (R\&D) pushes, market-pull initiatives had to play a significant role (Fri 2003; Kemp and Pontoglio 2011; Rogge et al. 2011). For stimulating and measuring the market-pull initiatives, quantitative targets for emission reductions and for generated renewable electricity in future years were defined. Minimum targets were - and still are - set in EU's policy-making processes. The EC and the MS administrations had to construct the respective regimes of incentives, control and enforcement to attain country specific targets that would sum up to the EU-wide targets.

In preparing the first directive on RE, the EC (1999) advocated a panEuropean market for TGC. "On paper" such certificates as trading instruments for the promotion of renewable energy "offer clear theoretical advantages ... when compared with command-and-control and targeted subsidies" (Baron and Serret 2002, p. 105).

However, the EC was not capable to submit a clear architecture on how a TGC system would work in practice. Among the MS, mainly Germany opposed the EC proposals. Germany already had implemented its own policy and support mechanism (Lauber and Mez 2006). In addition, the European Parliament delivered a documented critical report (Turmes 2000). This report clearly states that of the three existing types of support systems the feed-in system has proved to be most effective (p. 7) and leads to dynamic market development and considerable reduction of environmental burdens (p. 8).

The EC lacked sufficient influence to impose a TGC market regime on all MS. The majority of MS followed Germany in developing a RE technology specific support mechanism, mostly a feed-in tariffs (FIT) system [Annex D], or a technology specific premium (Meyer 2003; Haas et al. 2004). Following the EC-1999 ideas and proposals, Denmark was elaborating a TGC system (Morthorst 2000), but immediately turned back to FIT support when the RE Directive (EC 2001) allowed the MS to choose their preferred support instrument. A few MS opted for TGC systems, starting their deployment in 2002.

The significance of RE policies for the EU ETS has only been discussed in terms of the interaction between both policy instruments, which was labelled "perverse" by Schmalensee and Stavins (2017, p. 584-585). A thorough study 
of the TGC market architecture and experiments providing valuable insights for the elaboration of the EU ETS in the beginning of the century has not been published so far. The architects of the EU ETS ignored the early lessons available from the TGC experiments.

This chapter holds five sections. In 2001, the EU adopted a directive on the promotion of electricity produced from renewable energy sources [Section 5.2]. The directive let the MS select their preferred policy instruments to realize their indicative quantitative targets on generated renewable electricity by 2010 . A few MS adopted a TGC system. Flanders is an exemplary experiment to learn from [Section 5.3] because it fully followed the artificial certificate market construction recommendation. Moreover, the Flemish region geographically encircles Brussels and its officials could maintain contacts with EC staff that was designing the EU's ETS, i.e., there were no barriers for learning.

Section 5.4 reports salient results delivered by the Flemish TGC system, for example, relatively huge money transfers across groups in the regulated constituency. The excessive transfers are largely due to flawed design, mainly a lack of recognition of RE source and technology heterogeneity and related market segmentation. Poor understanding of the policy matter at hand was neither helpful. Flawed design also impedes technological innovation and environmental effectiveness. Notwithstanding the clear lessons, discussed in scientific reports (Haas et al. 2004; Verbruggen 2004; Held et al. 2006), the EC (2005) adhered to artificially set-up markets [Section 5.5]. Section 5.6 presents some conclusions.

\subsection{Directive $2001 / 77 /$ EC on the promotion of electricity produced from $\mathrm{RE}$ sources}

After the EC launched the liberalization of the electricity sector in 1997 (EC 1997), the realization of the Internal Electricity Market (IEM) as competitive pan-European power market faced considerable defects and delays. Some cures were expected from additional electricity and gas market regulations and updated internal energy market directives $(2003 ; 2009)$ and via supplementary directives for the promotion of Renewable Electricity (EC 2001; 2009a) and of Combined Heat \& Power (CHP) activities (EC 2004).

The prior debates (Turmes 2000) and the compromise in the RE directive of 2001 accentuated essential conditions to respect during implementation, e.g., Article 2 defines a catalogue of energy sources considered as renewable ${ }^{2}$. Article $4 \rrbracket 2$ states that the framework (for support) should "be compatible with the principles of the internal electricity market". It should "take into account the characteristics of different sources of renewable energy, together with the different technologies, and geographical differences". Moreover, it should be "as efficient as possible, particularly in terms of cost" (EC 2001). The RE directive holds a list of the RE generation targets for every MS (then 15 countries), to be met by the year 2010. The indicative targets were expressed as percentages of the MS' electricity consumption. 
The renewables directive (EC 2001) was a compromise. Every MS could choose its preferred support system for the development of renewable electricity supplies and an evaluation of the various systems by 2005 was envisaged. A few MS (Belgium, Italy, Poland, Sweden and United Kingdom (EC 2005)), countries with none or only embryonic RE policies in place, opted for the construction of a TGC market. They were influenced by the EC working paper (EC 1999) and by officials' talk about trading permits and certificates being novel, promising policy instruments.

Implementing the RE directive was urgent for the MS in order to meet the country specific RE targets by 2010. As such, one could observe how artificial market regimes were quickly designed and implemented and how they performed. Section 5.3 presents observations on Flanders' TGC system. Since it started per January 1, 2002, this experiment could provide instructive experience for the EU ETS construction, then on the design table.

\subsection{Flanders market construct for Tradable Green Certificates}

In 1997, domestic RE generation in Belgium was but a slight 1.1\% share of electricity consumption (the lowest percentage of all $15 \mathrm{MS}$ of the EU at that time). Inexperienced in RE policy-making, Flanders embraced the brandnew market creation approach, promoted by the EC and by many academics as superior - sometimes qualified as superior "on paper" (Baron and Serret 2002 , p. 105) - to all previous policy instruments. Belief in simple, assumed superior solutions empowers a freshmen administration. It pursued implementation of the new approach according to the purest textbook blend market creation.

Belgium's regions (Flanders, Wallonia, and Brussels) exert exclusive authority over renewable energy in their territories. While the federal government maintains authority over the Belgian North-Sea area. The regions' authority implies responsibility to apply the RE directives on related matters. Belgium installed four different RE support systems: 3 regional +1 federal. Federal support is related to offshore wind in the North Sea. The Belgian patchwork of authorities in energy policy contributes to deleterious deficiency in capability and capacity at all four regulatory offices (Van de Graaf et al. 2019). Poor coordination among the regions and with the federal level precludes agreement on elementary common standards and rules. The lack of know-how and experience made the Belgian politicians and regulators receptive to premature ideas as brought up by the EC on setting up TGC systems. For discussing how the emerging EU ETS could learn from artificial market constructs. the Flanders TGC case is hiahliahted. based on 
The story (and the regulation built on it) went as follows: First, the regulator assigns to generators one certificate per generated MWh of 'green' electricity, when the output comes from one of the sources labelled as renewable by Article 2 of the RE directive. This creates the supply of certificates in hands of RE generators. Second, sellers of electricity to end-users are mandated to submit yearly to the regulator the number of certificates sufficient to meet the $\mathrm{RE} \%$ targeted in the coming years $(0.8 \%$ in $2002 ; 1.2 \%$ in $2003 ; 2 \%$ in 2004 ; etc.) to meet Belgium's goal of $6 \%$ in 2010 (EC 2001). This creates the demand for certificates.

Naturally, electricity sellers charge the TGC purchase expenses on the bills of their customers. Small, captive customers are more vulnerable than large customers that command more alternatives for obtaining electricity (for example self-generation in combined heat and power units).

When a supplier falls short in submitting the mandated number of certificates, a penalty is applied per missing unit (starting at $€ 75$ per certificate in 2002, $€ 100$ in 2003, and $€ 125$ since 2004). Third, the market mechanisms will function automatically: demand for and supply of certificates will settle their equilibrium price, day-by-day and year-by-year. The regulator only has to fix the yearly quota, monitor and enforce implementation by electricity suppliers, and impose penalties when needed.

The assumed merits of the TGC system were broadcasted, summarized in one-liners, such as: 'set targets guarantee effectiveness in raising the market shares of domestic RE generation'; 'the TGC market guarantees costeffectiveness, because least-cost producers come first'; 'the market, not the bureaucrats, picks the winners and creates stimuli for technological innovation'; 'the financial expenses of TGC support are paid by 'brown' electricity end-users, in accordance with the 'polluter pays' principle' etc.

Following the neoclassical economics theory advice, Flanders TGC system deliberately amalgamated all RE supplies, i.e., all categories of RE supplies were placed on a single playing field and treated uniformly as $1 \mathrm{MWh}$ generated $=1$ TGC. This is contradicting Article $4 \$ 2(\mathrm{c})$ of the directive, saying that any proposal for a (support scheme) framework should take into account the differences in RE sources, technologies and geography. On the one hand, uniform treatment of participating actors in a given market is the theoretical standard, as prescribed by economics textbooks, and what works well when markets are properly segmented. On the other hand, uniform treatment has been the source of major flaws of the TGC system [Section 5.4].

The reckless start of the Flanders TGC system per January 1, 2002, caused significant shortfalls. Most important, there was no deliberation about the goal(s) of the RE support system. Economic theory learns that financial support, i.e., subsidies, are an instrument to correct market failures, such as compensating inventors for free riding by copyists. At the beginning of the $21^{\text {st }}$ century, valid RE policy goals were supporting the invention and development of RE technologies, and growth of related industrial activities. R\&D money delivers technology push support. 
When new technology is promising to deliver low-cost RE in the future, financial support for market pull by pioneer investors is justified. For market pull public authorities count on private investors to install and run novel RE apparatus and equipment forthcoming from the invention-innovation labs and factories. Reaching quantity targets in yearly green $\mathrm{kWh}$ generated should not be the primary goal of RE support policies.

In the initial phase of technology development targets and quota are just means for pulling innovation. A narrow focus on nearby target fulfilment (also called 'target fetishism') works as a barrier to strategic vision on how a growing RE industry and equipment markets may develop and come to mature, robust functioning, outperforming fossil fuelled electricity supplies. Next, assigning TGCs of the same monetary value to all RE MWh delivered by very heterogeneous technologies creates a technological race to the bottom, because the cheapest technologies are receiving the highest support rate. It follows that considerable profits will be cashed by established, often obsolete if not environmentally problematic, electric power generation sources, ultimately paid by captive electricity customers.

\subsection{Flanders TGC experiment holds important lessons}

As a prototype artificial market, Flanders TGC experiment exposed typical attributes of artificial market construction, of direct relevance for the EU ETS conception in the period 2000-2005.

The early TGC systems in a few MS deliberately neglected segmentation of problems and markets (DTI 2000, pp. 25-26). Neoclassical economists prescribe this neglect. However, it turns problematic because it scorns physical and institutional realities. Physically, RE supplies are obviously forthcoming from heterogeneous sources, harvested with different, tailored technologies (for example, a wind turbine is a mechanics device, related to fluid dynamics, new materials, etc.; photovoltaic power is related to electronics, light waves, etc.).

The EU directive (EC 2001) adopts more than ten names to label the various RE supplies. The Renewable Energy and Climate Change special report, edited by IPCC (2012) holds six chapters of classified RE supplies, with additional sub-cataloguing in most chapters, especially in the bioenergy chapter. Institutionally, policy problems are organized by problem category in order to come up with proper solutions. For every public pricing, taxing or subsidizing policy, the devil is in the details. Uniform approaches, applied on heterogeneous realities, are superficial and a source of flawed outcomes [Chapter 2]. Here, three factors are documented: 1. excess profits related to unfair cash transfers, 2. target fetishism, and 3. technological innovation.

\subsubsection{Excess profits as cash transfers from electricity consumers to RE producers}

TGC's deliberate neglect of actual physical and institutional diversities leads to unjustified excess profits and unfair cash transfers. Figure 5.1 illustrates the 


\section{6}

composition of financial flows resulting from a policy installing a uniform price for regulating a diverse reality of different 'bands' of RE sources ('band' is a term introduced in the UK when they experienced the drawbacks of amalgamating all RE sources in one basket). Figure 5.1 shows three different bands of RE sources A, B, C. The marginal cost of the available A-sources is constant and lowest (for example, A may represent incineration of biomass processed in established domestic refuse plants). B and $\mathrm{C}$ show increasing marginal costs (for example, $\mathrm{B}$ may represent the bundle of other biomass conversion processes and $\mathrm{C}$ wind power in the first decade of this century). The area under the three marginal cost curves represents the amount of euros sufficient for covering the real $\operatorname{costs}^{3}$ in producing the RE quota. The payment for the RE quota by electricity users is the full rectangle (quota multiplied by uniform 'market' price per certificate).

The financial flows corresponding to the dashed areas are money transfers from consumers to RE generators on top of cost coverage. The transfers consist of two components: rents and excess profits. Rents ${ }^{4}$ realized within a particular RE source band may result from graduation in natural endowments, from proficiency of the producer, from pioneering inventions and innovation, or from other specific characteristics.

The perspective of earning such rents may stimulate innovation and entrepreneurship, and therefore such rents are mostly considered as reasonable earnings. Excess profits (usually named 'windfalls', an euphemism when regulatory failure is the cause of it), however, result from excessive power of the resource

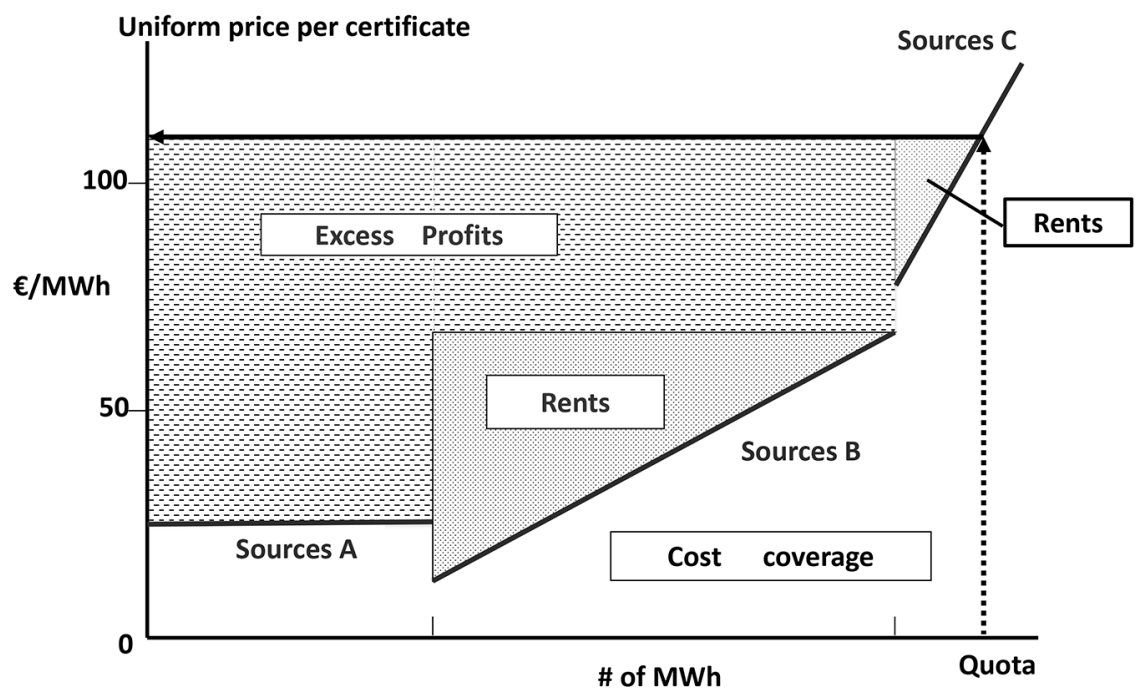

Figure 5.1 Cost coverage, rents and excess profits when three disparate technologies are amalgamated

Note: three disparate technologies, mostly also of unequal maturity, are amalgamated in a TGC regulation imposing a uniform certificate price. 
owners, from flawed regulations, or from other unjustifiable factors. Transfers related to excess profits are unjustifiable and a bitter fruit of failing public policy.

The inbuilt occurrence of excess profits in Flanders' non-segmented TGC market was exposed in 2003, with the warning: "The payments by end-users would grow so high that the system would implode under its own weight" (Verbruggen 2004, p. 175). The extent of the excess profits during the first six years (2002-2007) of the slowly growing Flanders TGC system was quantified in 2008 in a static comparison of the Flemish and the German policies.

The actual $€ 838$ million bill paid for the green certificates in Flanders during the starting years (2002-2007) was compared to the estimated $€ 301$ million bill, if the same amounts of the RE quantities in Flanders would have been remunerated at the rates of the German FIT system. The comparison reveals an estimate of $€ 537$ million excess profits, i.e., 64\% of the money devoted to develop the RE option was squandered. The capture of excess profits was estimated at $57 \%$ by bioenergy in waste processing (not an innovative option), 30\% by other bioenergy sources (neither innovative) and 13\% by new wind-on-land projects (Verbruggen 2009a, p. 1393).

Incumbent electric power and waste incineration companies picked up the predominant share of the excess profits. The independent wind project developers were happy to receive a small piece of the cake, after many years of parsimonious pioneering. Almost all stakeholders at the RE generators side defended the TGC system, although from the very beginning the inherent flaws started to manifest pernicious effects.

Excess profits transferred from electricity consumers' accounts to RE generators were lavish and distributional regressive. The small and less well-off consumers and households carried relatively the highest financial burdens. The high return rates obtained by electric power from bioenergy waste processing corrupted the 'polluter pays principle', and disturbed environmental policies with respect to waste management, built on the ranking: waste prevention, re-use, recycling, processing with materials recovery, incineration with energy recuperation and dumping.

\subsubsection{Target fetishism}

In addition to the structural flaw of negating source and technology diversity came the myopic focus on the RE quota targets. Target fetishism directs all attention on meeting politically agreed numeric targets. Because attainment of a numeric target is easy to measure and reveal, a shortfall exposes politicians in office. It makes that highest priority is adhered to increase in the short run RE output from whatever source or quality. Obsolete and non-sustainable supplies, mostly from bioenergy sources, received extra stimuli in this way. Notwithstanding the lax quality standards applied on what was called 'domestic' RE generation, the numbers of TGC deposited were too low for the target's fulfilment, even with high TGC prices. This allowed significant money transfers from electricity consumers to RE generators. 
RE plants installed before 2002 could obtain certificates, making the regulation instrumental in registering most of the pre-2002 active RE capacities in the region. During the three start-up years (2002-2004), about half of the TGCs were allocated to generated power by pre-2002 plants and by more biomass co-firing in old coal plants. The total RE output did not suffice to meet the year targets. In June 2004, Flanders entitled waste incineration technology for receiving TGC (see Article 2 of the RE directive), neutralizing earlier opposition by green politicians.

The fastest expansion came from biomass co-firing, from converting old coal plants in biomass only plants or from building new medium-scale biomass power plants. Because Flanders' biomass supply is limited, shiploads from overseas (forestry residues from North America, palm oil from South-East Asia) helped to fill the gaps towards the targets. Some companies, which were specialized in recycling wood waste for manufacturing chipboards, did complain about highly subsidized power generation emptying the supplies of wood material for recycling in useful material.

Target fetishism had a high price in environmental costs and in higher bills for electricity consumers. Target fetishism also turns the numeric quota into ceilings on performance and stimulates stop-go policy processes (efforts stop once a nearby target is reached). In Germany, RE development and deployment by yearly adapted FIT support per specific technology were far more successful. The country surpassed its target set in the RE directive (Verbruggen et al. 2015).

\section{Epilogue}

The major lesson of Flanders TGC experiment is that lack of source and technology segmentation leads to ineffective, inefficient, and unfair outcomes. In reaction to the poor outcomes, politicians turned to ready-fix measures to stop the bleeding. The idea of market creation was silently shelved and replaced by ad-hoc rulings per band of RE supplies. This U-turn took place without an official assessment of the failing TGC system. The support dissolved in project-by-project subsidies of larger projects, far too generous compared to all standards, e.g., in 2018 a new investment in a large-scale PV project of the electrical power company ENGIE still receives subsidies. The onerous financial burdens on the small electricity consumers are renamed from time to time. But the consumers keep on being charged.

The once announced and lauded TGC market system has metamorphosed in its opposite. Large-scale RE generation projects set up by influential project promoters receive (on a case-by-case basis) grants of (excessive) financial premiums. In Flanders, not all regulatory failures were directly related to the artificial TGC market trials. The many and persistent failures magnify the dangers of a wrongly designed and implemented artificial market system, when outstanding and alert regulatory and political capability are lacking. This was and is still the case in the Belgian institutional and political patchwork (Van de Graaf et al. 2019). 


\subsubsection{Technological innovation}

Innovation requires strategic vision on the state and future of the renewable energy sector, with separate chapters for each major technology group. A strategic vision is more than the transposition of an EU directive. It is inter alia related with science \& technology policy and industrial policy of the MS and the EU. The neglect of innovation imperatives delays the benefits of better technology and causes higher environmental costs.

In Flanders, the innovation goal was not noteworthy. It was implicitly assumed that the TGC market would automatically care for innovation. However, Flanders TGC had no positive impulse on innovation of RE technologies, neither on the growth of an industrial cluster fostering RE future markets. The poor performance in market pull of innovative technologies is a logical consequence of the amalgamated TGC market construction. It choked the development of promising RE technology by the run to the bottom for mature, cheap (some obsolete and environmental dubious or even negative) RE sources and technologies.

Disruptive technologies were crowded out by easy money on 'mature' options. Fixing the penalty ${ }^{5}$ height (= the certificate ceiling price) faces an innate contradiction. On the one hand, a high penalty pulls the uniform certificate price upwards, further amassing the excess profits on 'mature' options. On the other hand, reasonably low penalty levels exclude high-end new technologies, for example photovoltaic processes (PV) at that time. In 2002, solar power via PV was an immature technology, in need of market deployment. The costing price of PV generation under mid-Europe insolation conditions was above €600/ $\mathrm{MWh}$, far beyond the penalty levels of $€ 75-€ 125 / \mathrm{MWh}$ applied in Flanders' TGC market. When the costing price of a technology is higher than the penalty, mandated electricity suppliers will not buy from the technology because it is cheaper to pay the penalty and charge this on their customers.

Hence, PV got support by assigned premiums (also called 'certificates', defiling the proper terminology) on top of the sales value of generated power. In 2006, the Flemish premium for PV was set at the same value of the then applied German FIT level (€450/MWh). Because at the time, household electricity prices were around $€ 150 / \mathrm{MWh}$ in Flanders, the Flemish premium was too generous. Flemish politicians and regulators did not react appropriately to the spectacular 2008 price drop of solar panels (IPCC 2012; IRENA 2018).

The sales of solar panels in Flanders boomed in the following years. So did the cash drain from small consumers (lacking opportunities to invest in solar panels) to their wealthier co-citizens (obtaining safe, high-return investment deals). This experience emphasizes the importance of continuous regulatory follow-up of every support mechanism. The more dynamic occur technological evolutions, the more alert regulators should react in adapting the support levels. Germany too was overwhelmed by the success of PV cost reductions in 2008. The yearly review and FIT adaptation proved insufficient by the rapid pace of PV cost drops since 2008. Quarterly reviews and adaptations cured the 
follow-up until PV prices became competitive with the electricity tariffs charged by standard suppliers (called 'grid parity').

\subsection{The EC's formal evaluation of RE support instruments (EC 2005)}

Article 4 of the RE directive (EC 2001) states: "not later than 27 October 2005, the Commission shall present a well-documented report on experience gained with the application and coexistence of the different mechanisms". Before the formal report came out, scholars had published evaluations, showing the superior performance of well-designed, properly segmented FIT support and the peculiar functioning of TGC systems (Held et al. 2006; Haas et al. 2004; Verbruggen 2004).

The EC (2005) report does not clearly specify the criteria ${ }^{6}$ and their weights in the evaluation, although essential for executing a proper assessment. At some points the evaluation is circumstantial. It refers to complexities and little experience with TGC mechanisms. The report observes: "The generation cost of renewable energies varies widely. National, regional, and agricultural resources are rather different in MS. Any assessment of support schemes should therefore look at each individual sector" (EC 2005, p. 5).

Apparently, this observation has not thought through the inherent properties of the support schemes: the specificity of FIT versus the amalgamation of TGC. Given the known facts in 2005, the EC report reluctantly acknowledges the better performance of FIT, mainly in developing and deploying wind power and in pursuing solar PV. The report insufficiently discussed the biomass issues and related skimming of excess profits.

The field facts did not at all deliver arguments to the EC for imposing TGC markets on MS, when the 2001 directive was amended, and the 2009 directive (EC 2009) adopted. On the contrary, because of the failures in the TGC concept the few MS that had engaged in TGC systems shifted to FIT or premium systems openly, e.g., UK (DTI 2007) or via covert metamorphosis like in Flanders, continuing the deplorable state of the regulation.

Nonetheless, linkages between RE support systems and the EU ETS remained. They were apparent when in 2014 CEOs of incumbent European energy companies claimed three main points for EU's energy policy: “(1) preference for mature renewables in the regular market; (2) priority to the utilization of existing competitive power capacity rather than subsidizing new constructions; (3) restore the ETS as a flagship climate and energy policy" (Magritte Group Press Conference, March 19, 2014, www.gdfsuez.com).

On April 9, 2014, the then European competition commissioner J. Almunia served the energy corporations, as they liked it. New state aid guidelines significantly constrained the FIT renewable support mechanisms of the MS (EC 2014b). On October 8, 2014, Almunia approved UK's financial support package for the planned nuclear station Hinkley Point C. Critics of the German RE successes joined forces to facilitate the revision of the German 
Renewable Energy Act to rein in "excessively" rapid renewable power deployment (Verbruggen et al. 2015, p. 63). Since the policy break in 2014, the EU lost momentum in RE development, and leadership on the global RE scene, obvious in the later published statistics (Agora Energiewende and Sandbag 2020, Chapter 3).

\subsection{Conclusions}

Observing real-life experiments in artificial market building offers important insights, not easily detectable during the market design stage (Smith 2002; Wettestad and Gulbrandsen 2018). By timely and close observation, one may obtain early warnings on flaws and their ensuing impacts.

The EC (1999) proposals pushed early experiments in the set-up of artificial markets in green certificates. The actual experiments were highly instructive about, e.g., the importance of problem (hence policy and 'market') segmentation, the dangers of target fetishism, the missing focus on technological innovation and the considerable financial transfers from small electricity consumers and households to excess profits cashed by RE generators. The salient failures were evident from analysing the performance of one particular European TGC experiment in Flanders encircling Brussels, being Europe's but also Flanders' capital. Rather than learning from the facts, the EC kept holding up the myth of 'markets solve the problems', illustrating the ideological conversion of means into ends (Bryner 1999).

Due to its failures and to the bursting financial transfers from low-voltage electricity customers to RE generators, Flanders TGC 'market' requested continuous policy interventions, for fixing design failures, e.g., its neglect of problem segmentation. The poor patch-ups, such as crude banding of some RE technologies, did not suffice. Overall, the Flemish TGC quota driven system metamorphosed in direct price support 'à la tête du client', case-by-case for particular projects of particular investors.

Opposite to the failing TGC experiments, technology specific FIT support delivered the diligent development of two most crucial RE power technologies: wind and PV. Economists (Frondel et al. 2010; Marcantonini and Ellerman 2014; Böhringer et al. 2014) commented the success story unfavourably, because it contradicts the Cap and Trade utopia.

For example, the econometric study of patent filings by Böhringer et al. (2014, p. 25) finds that "only the increases/changes in biomass technology subsidies have significant positive effects on renewable patent applications". The "only" hints to no innovation impact on wind turbine and PV technologies. The authors prefer the second-best proxy variable 'patent filings' above the precise metric 'MWh levelized cost price' performance variable [Annex D], continuously updated and published as learning curves (see IRENA (2020) for the latest information).

The learning curves for wind and PV expressed clearly the innovation success of wind and PV year by year on the basis of reliable data. Böhringer et al. 


\section{Experience with Tradable Green Certificates}

(2014) cover the available literature on RE support in a selective way, also skipping to investigate green certificate systems, although "Climate protection as a wide-spread argument for RE promotion has no bite in the German case. The GHG emissions of the power sector together with other energy-intensive industries are capped through an EU-wide emissions trading system" (Böhringer et al. 2014, p. 24).

It should be reminded that the EU's power sector, with the German oligopolies RWE and E.ON in the vanguard, was building coal-fired power plants (Agora Energiewende and Sandbag 2018). The plants were technologically advanced, equipped with supercritical steam cycles, presumably stiffed by patent filings. Remind also that in the year 2014 the Magritte Group and German industrial interests organized their campaign on the EU State aid guidelines and on the German Renewable Energy Act (EEG in German) (Verbruggen et al. 2015).

Problematic attributes of TGC systems are observable in the EU ETS, for example: lack of problem and market segmentation, huge financial transfers, metamorphosis from quota to price controls and no stimulation of decarbonizing technological innovation (Point Carbon 2008; De Cendra De Larragan 2008; Marcu at al. 2017).

There is no evidence the EC has taken advantage of prolific comparative analysis and advanced comprehension of artificially constructed markets, as tested by the TGC predecessors, promoted by the EC (EC 1999). The EC deliberately or unconcernedly - skipped the opportunity of learning from the TGC experiments for the ETS design.

\section{Notes}

1 This chapter is an earlier version of Verbruggen and Laes (2021).

2 (a) 'renewable energy sources' shall mean renewable non-fossil energy sources (wind, solar, geothermal, wave, tidal, hydropower, biomass, landfill gas, sewage treatment plant gas, and biogases); (b) 'biomass' shall mean the biodegradable fraction of products, waste and residues form agriculture (including vegetal and animal substances), forestry and related industries, as well as the biodegradable fraction of industrial and municipal waste (EC 2001).

3 'Cost coverage' includes a normal return on invested capital.

4 'Rent' is not univocally defined in economics. Ricardo is linked to natural diversity of land as rent source; Schumpeter to innovation; royalties captured by oil source owners and monopoly profit skimming are also labelled as rents.

5 The yearly average certificate 'prices observed'/'penalty levels imposed' in Flanders were (in $€$ per MWh/ $€$ per MWh): $74.5 / 75$ in 2002, 94.7/100 in 2003, and 112.8/ 125 in 2004, showing certificate prices hanging nearby the penalty or ceiling price (Verbruggen 2009a).

6 For example: "effectiveness refers to the ability of a support scheme to deliver green electricity", without considering the effectiveness in RE technological innovation; equity aspects are neglected. 


\section{Critique on price induced technological innovation and on fringe pricing}

\subsection{Introduction}

Many economists favour emissions trading (Tietenberg 2006; Aldy et al. 2010; Gollier and Tirole 2015; Schmalensee and Stavins 2017; Wettestad and Gulbrandsen 2018) above a globally harmonized carbon levy (tax), preferred by inter alia Cooper (2007), Nordhaus (2007), Metcalf (2009). The campaign setting up the EU ETS during the first years of this century is qualified as "anti-taxation" (Meckling 2011, p. 128). Since a few years taxing has been considered as the more feasible way for carbon pricing (Stiglitz 2015; Weitzman 2015).

The split among economics scholars is about practical considerations on how to install a uniform $\mathrm{CP}$ for every $\mathrm{CO}_{2}$-eq unit $\mathrm{GHG}$ emitted. Pricing via Market Based Instruments (MBIs) would incentivize economic agents such as individuals, households and companies to reduce their GHG emissions (Stiglitz and Stern 2017; Pindyck 2017a; Baranzini et al. 2017). GHG emissions mitigation policy is readily reduced to estimating and enforcing the 'right price', excluding more direct public regulation (Hache 2019).

Here, only economic arguments are used in reviewing the theory and practice of two keystones of the EU ETS. The ETS is set-up as a market in licensed permits, with a demand side and a supply side. The demand side consists of about 11,500 installations with fewer owners, given that corporate companies control several installations (Bryant 2016). The EC decides the supply of licensed permits, in cooperation with the MS.

In standard markets of goods and services, suppliers tend to attentively observe and investigate the demand side. Section 6.2 explains how corporations build strategy and take positions in economic environments and markets, which remains also valid in emission permit markets.

Section 6.3 follows with industrial firms' reactions to pricing carbon emissions. It reveals why the theoretical proposition of PITI is unlikely to materialize in practice. Actually, business economics is more influential in the design and performance of the EU ETS than is microeconomic theory. The strategic goals of giant corporations are not dissolved or contained by academic analysis, 


\section{Price induced technological innovation and fringe pricing}

ideological arguments or wishful thinking. Explicit and transparent accounting of corporate power and its impacts will clarify the history and performance of EU ETS [Chapter 7].

The EU ETS licensed permits for emitting tons of $\mathrm{CO}_{2}$-eq $\mathrm{GHG}$ are provided by public authorities because controlling the littering of the common good atmosphere is of public interest. Distant from the recipes in economic textbooks and the economics discourse, the uniform 'right price' is not pursued by policy makers, because some permits are auctioned, while others are free allocated to polluters (Marcu et al. 2019). Outside the electricity sector, the EITE industries (EU 2018a) receive free permits for their GHG emissions. The phenomenon of free allocation is the linchpin of the EU ETS, worrying environmental NGOs (CAN 2018) and economic scholars alike. The latter formulated the 'independence property' to save, on paper, the 'efficiency' attribute of the ETS.

In Section 6.4 it is argued that one should not confuse marginal cost pricing with 'fringe pricing' and that the conditions for the 'independence property' are not met by the EU ETS. Section 6.5 takes a brief look at the increase in EU ETS permit exchange prices, from around $€ 5 /$ permit before 2018 to an average $€ 25 /$ permit since the second semester of 2019 . The higher permit exchange prices bring relief to scholars favouring price floors and higher prices (Edenhofer et al. 2017). However, the ETS bills are mainly passed on to nonETS electricity customers, reducing financial pressure on industrial polluters. Conclusions follow in Section 6.6. On crucial items, reality and discourse are juxtaposed in Table 6.1.

\subsection{Corporate strategy maximizes financial returns}

ETS covers the EU's industrial installations emitting significant quantities of GHG (EU 2018a). Most installations belong to large, often giant transnational firms. Fossil fuels fired electricity plants are the major emitters of $\mathrm{CO}_{2}$ (Bryant 2016; Marcu et al. 2017). The ETS 'clients' are businesses. Understanding one's clients is a major factor of success for a supplier. In addition, public policy will succeed more by a rational weighing of the interests, goals, commitments, decisions and actions of the policy clients. Strategic management literature (Volberda et al. 2011; Tanwar 2013) provides good insight in corporate strategy and ensuing behaviour. Two points are highlighted in this section. First, to attain the goal of carbon neutral industrial activities, the visions of firms should include full decarbonizing commitment. Second, financial returns on the firm's resources and activities are the highest goals of businesses.

\subsubsection{Vision of the firm and decarbonizing}

Without strategic management, corporations and firms are unlikely to survive in a globalized competitive environment. 


\section{Vision in the management discourse}

The strategic management process is the full set of commitments, decisions and actions required for a firm to achieve strategic competitiveness and earn above-average returns. Analyzing its external environment and internal organization to determine its resources, capabilities, and core competencies - the sources of its 'strategic inputs' - is the first step the firm takes in this process. With the results of these analyses at hand, the firm develops its vision and mission and formulates its strategy.

(Volberda et al. 2011, p. 9)

A key purpose of vision and mission statements is to inform stakeholders of what the firm is, what it seeks to accomplish, and who it seeks to serve. Vision is a picture of what the firm wants to be and in broad terms, what it wants ultimately to achieve. Thus, a vision statement articulates the ideal description of an organization and gives shape to its intended future. A firm's vision tends to be enduring while its mission can change in light of changing environmental conditions.

(Volberda et al. 2011, p. 22)

The vision of a corporation determines its ultimate goals and future paths. It is stated ahead of specifying the mission and ahead of the numerous commitments, decisions and actions to earn above-average returns. The vision formulation considers the corporate's future identity, resilience (Kupers 2018), even survival. Notwithstanding the central position of financial returns in all corporate activities, vision transcends the "money only' goal. "Grounding the strategic management process in ethical intentions and behaviours increases its effectiveness" (Volberda et al. 2011, p. 38).

When a corporate's vision does not include full decarbonizing of the corporate's core technologies and activities, it is unlikely considerable GHG emissions reductions will take place (Dietz et al. 2018). Realizing deep decarbonizing supersedes the nitty-gritty of financial gains in emissions permits lobbying and trade (Goldstein et al. 2019).

In the real world, there are lists of initiatives by companies and their federations about sustainable development and climate policy (e.g., their presence at the Conferences of Parties, with Paris 2015 as eye-catcher). Adopting and pursuing a decarbonizing vision is feasible for companies operating outside the energy supply and energy intensive businesses. Firms small and large (like Apple, Google) have added full de-carbonization to their vision, maintaining their core activities.

Fossil fuels and atomic power energy companies and energy intensive industry are challenged to re-invent their future role. Electric power 
companies already have split obsolete, decaying generation from future oriented renewable power. Their vision is a full renewable power supply. However, their old assets are delaying urgent decarbonizing (Verbruggen et al. 2015).

\subsubsection{Financial returns are game-changers for firms}

Financial self-interest is an omnipresent strong force directing human decisions and activities, most noticeable in the world of business and finance. What counts in business is financial assets, returns, profits, rents, royalties, cash flow or in one word: money. The financial worth and stock value of a company depends on its EBITDA (Earnings Before Interest, Taxes, Depreciation, and Amortization). Returns are the cashed money flows, visible in the firm's accounts. Their size is assessed compared to the firm's assets, equity, and sales.

For a firm to thrive, a pivotal signpost is average returns "equal to those an investor expects to earn from other investments with a similar amount of risk. In the long run, an inability to earn at least average returns results first in decline and then eventually, failure" (Volberda et al. 2011, p. 8). Successful firms pursue above-average returns, in excess of investors' expectations. "With the capability and flexibility above-average returns provide, a firm can more easily satisfy multiple stakeholders simultaneously" (Volberda et al. 2011, p. 29). Investments depend on their contribution to the firm's profits and are evaluated with capital budgeting methods (Bierman and Smidt 2006; Dixit and Pindyck 1994).

This is also the case for investments in emissions reduction options. Corporations are not inclined to spend Emillions on projects without financial return. For firms, spending on GHG emissions abatement are expenditures without financial return. Trading emissions permits at auctions, on exchanges or with other companies may bring hedging and speculative profits. The size and financial trading experience of the companies, and their position in the ETS (receiving free permits or mandated to buying) are determining the kinds and levels of active participation in transactions.

\subsection{Pricing carbon emissions and industrial firm's likely reactions}

The expenditures made for reducing the volume of emissions are mostly called Abatement Costs [Annexes B and C]. The derivative Marginal Abatement Costs (MAC in $€ /$ ton emitted) are easier to handle in a framework of emission prices (tax rates, permit prices) imposed to provide incentives to emitters to reduce their emissions to levels targeted by public policy and to innovate accordingly (Goulder and Schneider 1999). Figure 6.1 shows three positions of marginal abatement cost (MAC) curves. In microeconomics, the graphs' ordinate shows the driving variable (CP in $€ /$ ton emitted). The abscissa represents the dependent variable (tons of emissions) and the quadrant areas represent €amounts. 


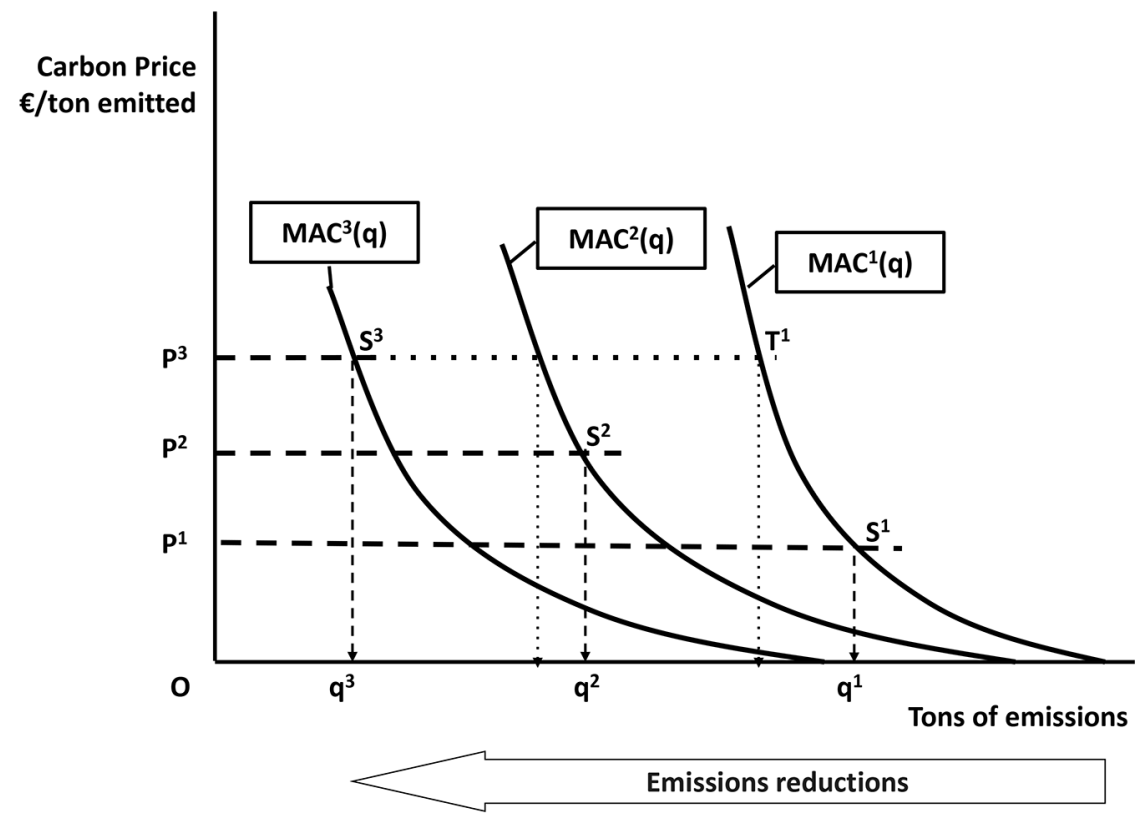

Figure 6.1 Marginal Abatement Cost curves MACi(q) of the aggregate of installations, with innovation shifts over three decades

\subsubsection{Theoretical functioning of price-induced innovation ${ }^{1}$}

With marginal abatement costs (MAC) at $\mathrm{MAC}^{1}$ and emissions priced at $\mathrm{P}^{1}$ $€ /$ ton in decade 1 , 'the rational polluter' reduces the emissions to the level where the horizontal $\mathrm{P}^{1}$ line crosses the $\mathrm{MAC}^{1}$ (point $\mathrm{S}^{1}$ ). Then €expenses are minimal, equal to rectangle with diagonal $\mathrm{O}_{-} \mathrm{S}^{1}\left(=\mathrm{P}^{1} \mathrm{x} \mathrm{q}^{1}\right)$ as transfers to the public treasury, paid on the emitted quantity $\mathrm{q}^{1}$, plus abatement costs the size of the triangular area under the $\mathrm{MAC}^{1}$ curve right from the perpendicular $\mathrm{q}^{1}-\mathrm{S}^{1}$.

The weight of the total €bill is a stimulus for polluters to innovate, i.e. shift the MAC to lower levels, certainly when further CP increase is expected. When, in decade 2, price $\mathrm{P}^{2}$ and the reduced $\mathrm{MAC}^{2}$ materialize, the new least-expenditure emissions level equals $\mathrm{q}^{2}$ tons. $\mathrm{MAC}^{3}$ is the result of further innovation in decade 3 , induced by price $\mathrm{P}^{3}$. When innovation in abatement would have indeed occurred, the pollution €expenses (transfers + abatement expenditures) remain of comparable size over the three decades.

Without innovation, MAC $^{1}$ would remain the emissions reduction cost curve. At the high $\mathrm{P}^{3}$ in the third decade, the expenses would skyrocket to rectangle with diagonal $\mathrm{O}_{-} \mathrm{T}^{1}$ plus the area under $\mathrm{MAC}^{1}$ right from the perpendicular through $\mathrm{T}^{1}$. Stair-wise increasing CPs press polluters to innovate: decreasing abatement cost curves through technological innovation keep the pollution bills affordable. 


\subsubsection{Caveats disturbing the simple theoretical analysis.}

Investigating the innovation effect of EU ETS, most scholars find it is minor or non-existent, for example: Calel and Dechezleprêtre (2016), Joltreau and Sommerfeld (2018). Textbook analysis is not easily transferable to the reality (Kemp and Pontoglio 2011). Several caveats need mentioning.

First, the aggregate or average MAC curves handled by economics scholars and in Integrated Assessment Models cover diverse activities with disparate technology and cost conditions. Knowledge about the numerous and diverse MAC exemplars is difficult to obtain, process and continuously update. Yet it is assumed that the aggregates are sufficiently reliable for policy decisionmaking. Ca.70\% of the EU ETS $\mathrm{CO}_{2}$ emissions comes from combusting fossil fuels (Marcu et al. 2017), most in electric power generation plants.

New renewable power is an increasingly available and cheap substitute for carbon intense power plants (IRENA 2020). Since 2000 the innovations most developed in Denmark and Germany are being pulled by specific and regularly adjusted Feed-in-Tariff support [Annex D].

The giant electric power companies active under ETS did not develop advanced renewable power technology. On the contrary, several major companies (such as RWE, E.ON, ENGIE) invested in new coal plants during the years 2008-2018 built in the Netherlands and Germany.

Bright technological options, similar to wind and PV solar power, are lacking for many industrial processes, some facing steep and sticky MAC curves. Imposing high levies or permits prices on such activities causes considerable yearly $€$ bills, captured by public treasuries. Economists point to double-dividend spending of tax revenues and to rebates to particular societal groups under policy-chosen conditions (Löfgren et al. 2018). However, the bills absorb the companies' investment funds for innovation, which also require considerable €budgets dependent on the stickiness of the specific MAC.

Second, companies in an industrial sector with sticky MAC could buy from sectors with shallow MAC (trading is the theoretical efficiency trump in ETS). However, companies are reluctant to transfer €billions, either to the electricity sector or to companies in other sectors, for obtaining permits. Moreover, transient market transactions do not advance deep de-carbonization of specific industrial activities (DDPP 2015; Waisman et al. 2019). The latter are necessary to realize the due full carbon neutral society. 'Carbon leakage' and 'depletion of innovation funds' are prominent arguments of the refusal by firms to spend significant budgets on obtaining emissions permits.

Third, after Kyoto (1997) the EU ETS was promoted by an anti-tax coalition, led by large companies such as BP and Shell (Meckling 2011). High emissions permit prices are congruent to high tax rates and would crumble ETS' acceptance by industry (Wettestad and Gulbrandsen 2018). Officials and economics scholars recognize the above caveats but cannot overcome the influence that industrial corporations exert for safeguarding their financial interests (Markussen and Svendsen 2005). 


\subsubsection{Corporate management blocks price-induced innovation in practice}

The successful rejection by industry for spending meaningful budgets on emission permits is annoying for the strong belief in the induction power of carbon pricing. PITI as emissions reduction mechanism is embedded in Integrated Assessment Models, at the forefront in global climate policy debates (IPCC 2014; 2018). It is however also criticized on accuracy and scientific robustness by e.g., Ackerman et al. (2009) and by Pindyck (2013, 2017b). Most scholars investigating the innovation impact of the EU ETS find its impact on innovation far weaker than assumed (Kemp and Pontoglio 2011), or limited so far and not sufficient for fundamental changes in corporate innovation (Rogge et al. 2011).

In reality, EITE industrial installations receive benchmark-moderated, free permits. This practice keeps the corporations' €bills of permits around zero. Since Phase 3 (2013-2020), the free allocation of permits for electric power companies is diminishing. The companies can buy permits at auctions, take them from their hoarded permit stocks from Phase 2 free assignments banked into Phase 3 (Marcu et al. 2019) or trade surplus permits with EITE sellers. The electric power companies charge their permit bills on captive customers, often adding excessive rents (Cludius 2018; Joltreau and Sommerfeld 2018; CAN 2018).

Notwithstanding the hints about reimbursement of compliance expenses to industrial companies and academic proposals how to organize it (Helm and Hepburn 2005), industrial companies decline paying considerable bills to public treasuries. They are suspicious of possible skimming by governments and of funding projects beyond industries' direct interest (World Bank 2016).

The prevailing goal of corporate management is the acquirement of aboveaverage returns. In economics publications and in Integrated Assessment Models (IPCC 2014; 2018) price-induced innovation appears easily. But its application in the business sector faces intractable obstacles. Companies deploy "a spectrum of strategic responses to imposed innovation pressures" (Verbeke et al. 2017, p. 684). In microeconomic theory, prices guide the decisions of rational consumers and producers. However, above-average returns and profits (supplemented by rents) are the real incentives for industrial firms (Schoemaker 1990).

\subsection{The gap between 'marginal cost pricing' and 'fringe pricing'}

The EC skips 'setting a price' on most GHG emissions of EITE industries. Following this exemption, ETS economists refer to marginal cost prices as sufficient for encouraging polluters to significantly reduce their emissions and induce innovations (Hepburn et al. 2006; Venmans 2013; Schmalensee and Stavins 2017; Narassimhan et al. 2018; Löfgren et al. 2018; Cludius et al. 2019). 
Reference is made to the 'independence property', as stated by Hahn and Stavins (2011). The independence property is a theoretical concept. Its actual validity is contingent on several conditions, which are not met by the EU ETS anno 2020 (Subsection 6.4.3). There exists confusion between marginal cost (MC) price and the meaning of permit price in the EU ETS. The latter is actually a 'fringe price' (Subsection 6.4.2). For exposing the confusion, the microeconomics concept MC pricing is revisited in Annex E, with electricity generation as practical case, revealing in plain the difference between MC and fringe pricing.

\subsubsection{Short-run marginal cost pricing}

Standard microeconomics and welfare economics recommend short-run marginal cost (SRMC) pricing for maximizing profits (= revenues - expenses) and for maximizing social welfare (= benefits - costs) (Becker 1971; Varian 1978; Lesourne 1975). Although SRMC pricing is a mathematically solid concept, real-life applications are disenchanting few. A main concern of companies is bridging the gap from SRMC price to full cost coverage (Dorward 1987). The clearest SRMC pricing concepts are conceived for the electricity supply industry (Nelson 1964; Turvey 1968; Turvey and Anderson 1977). For electricity generation, practical application of SRMC pricing is feasible, via optimal dispatching of generation capacities in a planned power system or via spot prices in a competitive market for electricity supplies [Annex E].

The mathematical proof of the optimality of SRMC pricing in power generation assumes the fulfilment of several conditions. They include infinitesimal capacities available on command and fully flexible, optimal composition of the total supply system (assuming relatively stable prices of the input factors) and hourly measurement of all sales for billing based on SRMC for all 8760 hours of the year, etc. Although meeting all the conditions is unlikely in reality, the theory has been a guide in pursuing SRMC pricing for signalling consumers the real cost of their use at every moment (hour). The theory is also instructive for understanding the essence of marginal cost pricing, and for exposing the difference between marginal cost pricing and fringe pricing.

\subsubsection{Fringe pricing}

While MC pricing is theoretically solid and practically workable when the system SRMC is applied on all infra marginal generated $\mathrm{kWh}$, fringe pricing is different. Fringe pricing means: all infra-marginal $\mathrm{kWh}$ are given for free and only the marginal $\mathrm{kWh}$ (the tail of the merit order) is charged the SRMC. Fringe pricing abolishes the equilibrium of full cost coverage. Assume the electric power sector would be mandated to fringe price its generated power, obtaining peanut revenues for the power supplied; soon no company would be willing to generate electricity. Continuing the fringe price case, end-users 
would receive all consumed electricity for free, except the negligible payment for the few fringe $\mathrm{kWh}$. The propensity to save electricity would dissolve. In real economies, fringe pricing is hilarious.

However, the EU ETS applies fringe pricing on EITE polluters (EU 2018a). Theoretically, this practice explains the actual lack of significant emission reductions and lack of disruptive low-carbon innovation triggered by the ETS (Löfgren et al. 2013; Marcu et al. 2017). Fringe pricing only stimulates polluters not to exceed their free permits allotment; eventually they reduce a bit of 'low-hanging fruit' emissions to sell permits with profit to other companies short of permits.

Fringing at the margin is not decarbonizing the industrial activities. On the contrary, it permitted and covered up carbon intensive investments, such as the coal-fired plants in the Netherlands and Germany (Agora Energiewende and Sandbag 2018). Some power corporations charged ETS fringe prices on the invoices of captive customers, obtaining Ebillions profits for the stockholders (Hepburn et al. 2006; Sijm et al. 2006; CE Delft 2016; Nazifi 2016; CAN 2018; Löfgren et al. 2018).

EU ETS experts observe 'efficiency and distributional consequences' of the allocation of allowances.

A fundamental decision in any emissions trading program is whether firms should receive allowances for free, and according to what formula, or if they should be distributed through an auction. Basic economic theory states that the emissions outcome, that is, where and when emissions occur, should be independent of this decision (Hahn and Stavins 2011) and that this decision should not affect cost-effectiveness (Montgomery 1972), the 'independence property'.

(Löfgren et al. 2018, p. 285)

Simple reference without further check to the theoretical independence property' deflates concerns about free allocation.

\subsubsection{Concerning the 'independence property'}

In a Debreu-like mathematical treatise, assuming a stylized economic world, Montgomery (1972, pp. 408-410) finds the "somewhat unusual result" that the economic equilibrium in a licensed emissions permit system

is independent of the initial allocation" of licenses, for "reason that the firm's behaviour is independent of its asset position. Any redistribution which preserves totals of each type of license does not change the equilibrium.... A zero-sum trade for all firms taken together may be positive for some individual firms and negative for others.

Hahn and Stavins (2011, p. 270) add: 
such independence follows directly from the notion that by properly defining property rights, participating firms have incentives to exploit all potential gains from trade. This independence property is of central political importance and is an essential reason that cap-and-trade systems have been employed in representative democracies, where distributional issues may be of paramount importance in mustering support for a policy.

The 'independence property', theoretically argued as an only 'cost-effectiveness' issue, is of central political importance in covering paramount distributional political decisions. Alternatively, applied to the EU ETS: the system only mustered support because of free permits assignment to the large GHG emitters, conform the anti-tax coalition agenda (Meckling 2011; Wettestad and Guldbransen 2018). To avoid losers in zero-sum trade and win sufficient support, the assignments were ample for all influential emitters. Economists still may argue the allocations made are cost-effective by equalizing MACs of all emission sources, be it at $€ 0 /$ ton (i.e. the abscissa in Figure 6.1: emitters' best choice is 'no extra abatement efforts'). Environmental effectiveness seems of a lesser urgency for economists.

Hahn and Stavins (2011, pp. 267-268) search validation for free permits in Cap and Trade at Coase's theorem (Coase 1960), a somewhat unusual step. The Coase approach is an alternative for MBIs by focusing on the specificity of environmental cases between two parties: a polluter facing abatement costs and a victim facing damage costs. The interests of the parties are opposite as far as the amount of emissions is concerned. When rigorously defined property rights are assigned - either to the polluter or to the victim - costless negotiation may reach the optimum pollution level (minimum sum of abatement costs + damage costs [Annex B]).

This kind of 'neutral liability' (Bromley 1986) is conditional on major assumptions, e.g., zero transaction costs, no accounting of income (welfare) effects among disputants, no interventions by third parties. Contrary to Coase specificity, MBIs (including Cap and Trade) pursue generality by setting a uniform 'right price' on the emissions of all polluters. Free emissions permits do not advance the setting of such price. There are no two opposing parties, but an alliance of numerous polluters pursuing the same goal: minimize expenditures by obtaining free or low-priced licenses to pollute. It is once more a proof that the protection of the commons or common property resources requests professional, independent public governance, via the political process.

Further, Hahn and Stavins (2011, pp. 271-279) discuss "six conditions under which the independence property may - in principle - break down in a Cap and Trade system: transaction costs, market power, uncertainty, conditional allowance allocations, non-cost-minimizing behaviour by firms and differential regulatory treatment of firms".

Their test in 2011 whether the independence property holds for the EU ETS is scant and based on two scholar articles published in 2007 and 2008. 
Nonetheless, the independence property seems accepted as true in the economics literature (Juergens et al. 2013; Löfgren et al. 2018), without testing its break down conditions in the actual EU ETS. Problematic issues are noted, such as: second-best conditions, differentiated EITE output related free allocations, permit auctions for electric power generators (however with exceptions), unequal treatment across MS and coming up price collar policy via the Market Stability Reserve.

The phenomenon of fringe pricing is also referenced as 'opportunity cost' of free allowances (Joltreau and Sommerfeld 2019; Woerdman and Nentjes 2019). In economics, all cost is opportunity cost as real resources spent on product A cannot be spent on B. However, free and cost do not match. The term 'opportunity' has several meanings. In decision-making under uncertainty, opportunity loss is the difference between expected outcomes from different choices (Jones 1977). Such opportunity losses may also occur in permit trading, yet this is not akin real cost in economic terms.

My presumed conclusion is that the 'independence property' adds little points for assessing the performance of the EU ETS.

\subsection{The impact of higher EU ETS permit prices}

In August 2018 posted prices passed €20/permit and reached around €25/ permit levels in 2019 [Chapter 1, Figure 1.2]. Since then the permit price fluctuates in a band $€ 20-€ 30$ until August 2020 (latest EEX spot price data, not shown in Figure 1.2). The volatile prices are not like the solid stair of mounting prices requested for PITI. They seem speculation driven, although financial companies mostly have given up on the EU ETS market. The transactions occurring are difficult to pinpoint by whom and why (Jong 2018). Because the posted prices on the exchanges reflect fringe prices, they are light to manipulate by giant interests experienced in masterminding regulatory systems where the CP fills an indispensable symbol role [Section 7.4].

The higher prices since 2018 concur with the irrevocable exit of coal-fired power generation in Western Europe. The electricity sector receives less free permits. Eastern European MS may still assign free permits to coal plants, and EITE activities continue to receive free permits in Phase 4 (2021-2030) of EU ETS (EU 2018a). The electric power companies passed through the posted prices in the power sales prices of captive customers in Phases 1 and 2, although they received the permits for free, collecting considerable 'windfall' profits (Point Carbon 2008; Verbruggen 2008; Pearse and Böhm 2014; CE Delft 2016; CAN 2018; Löfgren et al. 2018). The 2018 permit price hike may foreshadow the introduction of the Market Stability Reserve mechanism in 2019 (EU 2018a). Monetizing at $€ 20^{+} /$permit more than 2 billion permits, hoarded via banking free assignments and via auction purchases at ca. $€ 5 /$ permit, is a big deal for corporations in search for rents.

In the future, expanded renewable electricity generation, increased competition in the wholesale power market and reduced electricity demand by 
distributed Independent Generators of Own Power (IGOP), may moderate rent skimming and pass-through of flawed investments in recent-built coal capacity. The moderation of surcharges on the electricity bills depends on effective public regulation.

The EC allows MS to compensate EITE companies for the passed-on charges on electricity invoices (EU 2018a). The reimbursement funds come from ETS permit auction revenues (Löfgren et al. 2018; Marcu et al. 2019). Non-ETS electricity customers are not reimbursed, and largely pay the EU ETS bill. Detail monitoring of the cash flows is practically impossible because of the opacity of permit ownership and their transactions (Bryant 2016; Jong 2018).

Two points merit consideration. First, 'the industry paying for their GHG emissions' is an unfounded statement, because the bill is largely passed on to nonETS electricity customers (Joltreau and Sommerfeld 2019; Cludius 2018). Second, industries' cost pass-on via pricing the goods \& services they sell is standard economic practice. Always the ETS bill was, is and will be passed on to end-users or taxpayers, because this is how the extended market economy functions.

Anchoring climate policy directly at the points where end-users make decisions is the better alternative; it will improve transparency, avoid (at least reduce) 'windfall' profit skimming for stockholders, dissolve the carbon leakage fears and allow fine-tuned distributional adjustments. Because financial selfinterest is a strong force for reshuffling activity levels, changing the weights of spending categories is important. Green Budget Germany (www.foes.de) is an initiative to document the various possibilities of setting a price on emissions. A major aspect is shifting the money volumes across the four main financial levers to maximize the indicator of performance in applying financial incentives [Chapter 2, Figure 2.2]. Such shifts are called environmental budget (tax) reform (Ekins and Speck 2011).

\subsection{Concluding considerations}

The EU ETS is considered from a business economics and microeconomics perspective. The functioning of firms is described, not prescribed or morally judged; wishful thinking and good intentions cannot change the nature of business driven by money. It requires more study to detail industry's diversity and roles in addressing the challenges of drastic and urgent climate policy.

Economics and industry theory and facts deliver insights opposite to the mainstream discourse among economists about the EU ETS. At one point, the novel term 'fringe pricing' is introduced to reveal the erroneous confusion with marginal cost pricing (Annex E clarifies the difference mathematically). Table 6.1 provides an overview of major points in the discussion on climate policy instruments, opposing evidence and deceiving discourse.

Simple, uniform solutions for intricate, diverse and wide-ranging problems irrevocably strand in quagmires, ad-hoc patchwork regulations, exceptions and exemptions. This is also the case in the EU ETS lifecycle. The MBI discourse is not compatible with reality; hence, it is mainly deception. 
Table 6.1 Juxtaposing Reality and Discourse on carbon pricing

\begin{tabular}{|c|c|}
\hline Reality & Discourse \\
\hline $\begin{array}{l}\text { Financial self-interest is a ubiquitous, } \\
\text { permanent force, influencing decisions } \\
\text { and activities, most in rich countries, } \\
\text { corporate industry, and financial } \\
\text { institutes. }\end{array}$ & $\begin{array}{l}\text { Unclear price terms obfuscate the domi- } \\
\text { nant role of money: bills, returns, cash } \\
\text { flows, profits, EBITDA, as processed and } \\
\text { counted by companies. }\end{array}$ \\
\hline $\begin{array}{l}\text { Marginal cost pricing is helpful for effi- } \\
\text { cient allocation, and workable when case- } \\
\text { specific conditions are met. Due is ver- } \\
\text { ification of the theoretical 'independence } \\
\text { property', dependent on many } \\
\text { assumptions. }\end{array}$ & $\begin{array}{l}\text { Fringe pricing is a falsification of marginal } \\
\text { cost pricing [Annex E], and glosses over } \\
\text { the impact of free permits donations in the } \\
\text { EU ETS. The 'independence property' is } \\
\text { assumed to hold unconditionally. }\end{array}$ \\
\hline $\begin{array}{l}\text { The EU ETS did not trigger decarboniz- } \\
\text { ing innovations. Effective wind and solar } \\
\text { PV power technology development was } \\
\text { driven by Danish/German Feed-in-Tariff } \\
\text { support [Annex D]. Firms pursue above- } \\
\text { average returns. To be grounded, dec- } \\
\text { arbonizing must be part of a firm's vision. }\end{array}$ & $\begin{array}{l}\text { Price-induced innovation brings emission } \\
\text { reductions according to the height of set } \\
\text { CPs and assumed MAC curves. By } \\
\text { policy, industry will spend high amounts } \\
\text { for abatement }+ \text { taxes to the treasury } \\
\text { (permit purchases) }+ \text { invention \& inno- } \\
\text { vation outlays in decarbonizing solutions. }\end{array}$ \\
\hline $\begin{array}{l}\text { Non-ETS electricity consumers pay most } \\
\text { of the EU ETS bill, with significant rents } \\
\text { for polluters. }\end{array}$ & $\begin{array}{l}\text { 'By the EU ETS is since } 2005 \text { the Eur- } \\
\text { opean industry paying for their GHG } \\
\text { emissions' is repeated in the media, } \\
\text { although unfounded. }\end{array}$ \\
\hline
\end{tabular}

\section{Note}

1 See also Annex C and Chapter 3. 


\section{A political economy of the EU ETS}

\subsection{Introduction}

This chapter revisits the crooked path of the EU ETS from conception in 1998-2000 until 2020. The six preceding chapters and five annexes on CP and permit trading economics and methods deliver inputs to this seventh chapter. The analysis is extended with history, political economy, live to see, as methods for clarifying how the EU ETS emerged, evolved and performs.

Neoclassical economists limit political economy to the apology of donations of free permits. For example Grubb (2007, p. 17) states that: "Free allocation, in other words, offers from a standpoint of political economy a neat, intrinsic way of buying off political opposition to an efficient market solution". This quote is problematic from an ethical-political perspective: why buying off wealthy polluters? Similarly: "Governments have repeatedly set the overall emissions cap and then left it up to the political process to allocate the available number of allowances among sources to build support for an initiative without reducing the system's environmental performance or driving up its cost" by Hahn and Stavins (2011, p. 289). They find proof for their concluding statement in the neoclassical theoretical constructed 'independence property' [Chapter 6].

Banks and Hanushek (1997, p. 1) paraphrase earlier scholars, stating: "Political economy is the study of rational decisions in a context of political and economic institutions", a workable, succinct definition. Studies of emissions trading, carbon markets with a political economy lens are for example: Newell and Paterson (2010), Pearse and Böhm (2014), Coelho (2015), and Bryant (2016). 'Carbon coalitions' by Meckling (2011) clarifies the emergence of EU ETS. After a theoretical introduction on power, influence, and coalitions as effective institutions, Meckling documents how the oil and gas and electric power giant corporations assembled a coalition that influenced EU climate policies towards Cap and Trade (CaT).

Lane and Newell (2016) revisit the neoliberal political economy of carbon markets, addressing the question: "How can we make sense of these flourishing yet failing markets?" (p. 248), and conclude:

DOI: $10.4324 / 9781003173816-7$ 
In sum, the contemporary characteristics and historical development of carbon markets require a richer, more textured, and nuanced account than afforded by notions of 'zombie' capitalism or either by ascribing to carbon markets the same properties as other processes of commodification or assuming we can 'read off' their complex development from the requirement to create the conditions to (re)produce capital accumulation.

Bryant (2016) delivers a thorough investigation into the main companies with million tons $\mathrm{CO}_{2}$ emission volumes, holding the reins of the EU ETS. The "oligopoly structures where a small number of large corporations are dominant" show that "not idealized market models ... organize the appropriation of carbon" and the operation of carbon markets (Bryant 2016, p. 53).

Meckling and Bryant delve into the details of the EU ETS as an evolving system in a vibrant context. It is recommended to follow their approach. However, the details are not written down in documents or spelled out in discourses readily available for scholars looking for insight and evidence. A political economy investigation faces an iceberg-like reality: $10 \%$ visible and 90\% under the waterline. The 'Methods' section of Meckling (2011, pp. 16-19) clarifies the study's goal is "to explain the influence of business coalitions". Further:

While the concept of influence is intrinsically linked to power, the two differ from each other: power refers to the capabilities to affect political change, while influence refers to the actual effect of an actor on political outcomes.... Whether actor-related forms of power translate into influence depends on a number of variables, such as strategy and the political opportunity structure... Goal attainment, generally speaking, is the indicator for influence.... to assess the influence of advocacy networks we must look at goal attainment at different levels.... While affecting the political outcome is most likely the ultimate goal, agenda setting is also a major political goal of non-state actors.... Advocacy activities, for one, frequently occur in private, hidden behind a veil of secrecy.

Process tracing, correlation, and counterfactual analysis are stuffing understanding as narrative causality: "the outcome flows from the convergence of several conditions, independent variables, or causal chains" (George and Bennett 2004, p. 212, cited by Meckling 2011, p. 18).

Meckling addresses the influence of business coalitions at global climate policy level, with the EU ETS as exemplary case. Bryant (2016, pp. 53-87) identifies the biggest GHG emitting companies covered by the EU ETS and elucidates the crucial role of the electric power oligopolies. His work then focuses on commodification and capitalizing of carbon to address the question "Carbon markets as accumulation strategy?" It ends with "The politics of carbon market design”. 
Chapter 7 adds more paths to the higher referenced political economy studies. By participation and observation in several decision-making processes on energyenvironmental dossiers since the 1970s, I have hit several icebergs and observed how power, secrecy and advocacy function in practice (Verbruggen 2014).

Hence, the chapter's title is 'A political economy' (not 'The political economy'), as the presented acts partly depend on the particularities in my 'live to see'. For staging intricate acts it helps to clarify: scene, context [Section 7.2], and actors [Section 7.3], before entering the policy arena of acts and outcomes [Section 7.4]. The societal scene is constructed with Ideas, Interests, Institutions, Infrastructures, and the Indispensable energy \& technology transformations [Chapter 1, Figure 1.1]. The five constituent components of the scene are repetitively interacting in the political economy analysis.

Chapter 7 holds seven sections, with further subsections.

Section 7.2 provides context to the EU ETS emergence and functioning.

Section 7.3 presents the variety of actors active in the EU ETS play or trying to direct the course of action from outside. Actors pursue ends by using means, in a rational way (political economy addresses indeterminate plots but avoids fairy tales).

The longest section, Section 7.4, casts the EU ETS policy arena. It reveals a metamorphosis of the EU ETS from a CaT utopia to the daily reality of nitty-gritty permit assignments and price controls, i.e., the reverse of CaT. Meanwhile the façade of a carbon market is upheld, part of the surrealist act.

Section 7.5 reviews permit trading in artificial markets. Section 7.6 summarizes the economics critique. The final section, Section 7.7, evaluates the performance of the EU ETS, provides answers about the observed cognitive dissonance, and dissolves enigmas and paradoxes stated by scholars about the EU ETS.

\subsection{Climate policy in the 3rd millennium}

The EU ETS is called the flagship or cornerstone of EU's climate policy. Some background on societal, energy and climate issues is helpful in understanding the context of the EU ETS. First, four main problems and solutions inherited from the $20^{\text {th }}$ century are revisited [Section 7.2.1]. Second, the penultimate warning of the 1970 s stranded in a strong, however flawed, antitax discourse [Section 7.2.2]. Third, the ultimate warning of climate collapse is signalled [Section 7.2.3]. Most focus is on the Indispensable energy-technology transformation [Section 7.2.4], being the spearhead answer on the ultimate warning. Explicit attention is paid to the triptych mantra ' $R E$, nuclear, CCS' diffusing resoluteness in climate policy and protecting $\mathrm{BaU}$ in nuclear power and fossil fuels [Section 7.2.5].

\subsubsection{0th century bequest: problems and solutions}

One should bridge the past to the future to understand the present. In the climate and energy policy nexus, the past, here relevant for review, begins at 
the end of World War II. True that the more decisive energy transformations started much earlier, such as pumping crude oil since the 1860 s (for automotive transport and causing sprawling of human activities) and the generation and distribution of electric power and light since the 1880s. One century earlier, the heat to steam power era took off, industrializing and revolutionizing societies. However, this book is not a regrinding of knowledge on energy history.

Five strands are selected as being the salient ones: three are evaluated as problems (population and material throughput growth; fossil fuels expansion; atomic power), two as solutions (Sustainable Development (WCED 1987), together with the 1992 Rio conventions; science and technology's bursting diversity and accelerating advance over the last 40 years). This classification in problems and solutions is not black versus white. Problems also have silver linings and solutions don't come without risks and need for careful governance.

\section{a) Population and material throughput growth}

When I was born, December 26, 1949, five days before mid-20 th century, the world population was 2.5 billion. The April 2020 population was 7.8 billion, i.e., a tripling within 70 years. In the 1960 s the societal debate about limiting the growth rate of people was vivid. Interestingly, patriarch ecological economist Kenneth Boulding, author of the metaphor 'Spaceship Earth', suggested the transferable birth licenses approach (Boulding 1964). Every woman at fertile age would receive 21 deci-child licenses. Licenses are transferable and tradable. As such a woman could give birth to her preferred number of children within the absolute cap of stabilizing population (2.1 childbirth per woman corresponding to replacement fertility). Boulding considered the proposition more as mind stirring then as a simple implementable solution.

The proposal provoked thinking, and impact on Herman Daly, another ecological economics icon. Daly favoured tradable permits because they may combine 'micro-variability' with 'macro-stability' (Daly 1980, Chapter 21). I guess this pre-history may explain partly why there is little animosity among ecological economists against emissions trading and carbon markets, except for principled critics such as Spash (2010).

Back to the population growth discussion, Ehrlich's 'Population Bomb' shocked the world's intelligentsia, social interest movements, politicians, etc. (Ehrlich 1968). Nonetheless, the scientific warnings fell in deaf political ears. Except for the Chinese 'one child' policy, effective reduction of births resulted from collateral policies.

The growth in population was superseded by a faster growth in commercialized goods and services, globally measured by the addition of the countries' GDPs (Gross Domestic Products). "An almost 3-fold increase of the population multiplied by a 4.4-fold increase in average prosperity means that the global economy has grown 13-fold since 1950", over 1950-2016 (Roser 2020, n.p.). GDP is the widely accepted indicator of wealth, although criticized for 
various reasons from various perspectives. Briefly: GDP adds only registered priced goods and services, neglecting non-priced (hence non-registered) ones. The values of free access commons (such as atmosphere and climate tenderness) are not or but infinitesimally included. The overwhelming share of sunlight, people enjoy and use, is also not registered; billed artificial light is included in the GDP.

Another difficulty is the comparison of GDPs across countries with different currencies. When based on 'Market Exchange Rates (MER)', developing countries weigh less in the world total compared to 'Purchasing Power Parity (PPP)' conversions (Callen 2007). The total world product in PPP statistics (121.2 US\$ trillion in 2018) is almost 50\% higher than the one in MER (82.7 US\$ trillion in 2018), while the numbers also differ whether constant or current prices are assumed. It documents that global calculus, even performed by excelling institutes like IMF and World Bank, is a challenging issue. It may become very tricky when carbon markets would internationalize. Therefore Chapter 2 [Figure 2.2] suggested an indicator not sensitive to currency comparisons for follow-up of countries' performance in carbon pricing.

A critic on GDP growth is that an incomplete GDP is an unreliable compass for showing the proper development path (Daly 1988). GDP growth has been uneven and thoughtless. Fast GDP growth in industrialized countries did not trickle down on developing countries but enlarged the wealth gap. GDP growth depleted, polluted, and destroyed lots of natural resources and environmental amenities (Meadows 1972). In conclusion: fast growth of population and throughput did not (sufficiently) advance development for the global population, conversely caused significant environmental problems. Both requested new Ideas and Institutes, changed Interest priorities, other Infrastructures, with Indispensable energy and technology transformations.

\section{b) Sustainable Development (WCED 1987), Annex the 1992 Rio conventions}

In 1983, the World Commission on Environment and Development (WCED) was established and it delivered 'Our Common Future' (OCF) in 1987. For a future, common to all world citizens, the world leaders should adopt Sustainable Development (SD) as the new socio-economic paradigm. The SD message resonated through all layers of societies from East to West and from South to North. It was a clear, strongly grounded and equilibrated message, confronting its opposite: neoliberalism serving vested interests (Baker 2012, p. 266) with growing adherence and impact since the 1980s. How could this confrontation evolve, and which side would win, and how?

With hindsight in 2020, the evolution is discoverable and the outcome is known. The world lived through three decades of neoliberalism (Wolin 2008). About the how, visions are diverse and contentious. The focus here is on the 'how' question. For this, I build on observations of changing tactics of the corporations (in case: the Belgian electric power sector) in 'how' they influence societal processes. In the Belgian post-war period, one can distinguish 
three phases of giant companies influencing politics: technocracy, controversial debate and acquisition ('Stakeholder Masterminding' is an active version of acquisition in the EU ETS Policy Arena [Section 7.4.2]).

- In the 1950-70s, the technocratic power of corporations was sufficient to obtain the government's rubberstamp on licenses to construct seven nuclear reactors in Belgium. However, the 1970s brought anti-nuclear protests and political initiatives to enhance public knowledge about energy issues, including decision-making.

- Controversial debate substituted for hegemonic technocratic autonomy. In 1981-1984, the private power companies failed in obtaining approval for building two $1300 \mathrm{MW}$ nuclear reactors, after hearings with inputs from non-sector scientists and social organizations. Presumably, this event accelerated the shift from public controversial debate to more emphasis on hidden influencing. Ideas or Institutions that challenged the companies' vested interests were no longer confronted head-on. A spectrum of indirect interventions emerged to legitimize the companies' plans and policies. One intervention was the ending of all federal funding of research on alternative energy (efficiency, renewables, modelling, policy studies), by lobbying the then minister of budget, Guy Verhofstadt.

- The acquisition phase followed the debate phase. The corporations formally embraced the challengers in some type of self-pronounced partnership to hollow out the challenge from inside. The remaining façade is a welcome cover for concealing truncation, transformation, adaptation of the substance, choking its force and killing its essence. This type of acquisition happened also to Our Common Future - Sustainable Development $\left(\mathrm{OCF}_{-} \mathrm{SD}^{2}\right)$ at the global level in order to safeguard the neoliberal growth model (Nemetz 2015).

It started with flattening OCF-SD's radical mission by adjusting the contents of concepts and words and by truncating the substance (Jacques et al. 2008). $\mathrm{SD}$ is framed as a vague, multi-interpretable concept. Everyone can find in it what $\mathrm{s}$ /he likes, making it unfit for providing guidance. This framing thrashes the radical OCF-SD goals, substance, and limits (Meadowcroft 2012). However, OCF-SD is not an indefinite concept. Like 'democracy', it is characterized by explicit goals and constraints, needing historical, anthropological, philosophical, political implementation in diverse contexts. Such constructive duty exposes OCF-SD to falsification and abuse, something more democracy can help to minimize or prevent. However, as society should never give up democracy, it neither should dump OCF-SD.

The one-liner 'SD is a development that meets the needs of the present generations without compromising the ability of future generations to meet their own needs', is a quote from OCF. It is widely propagated as the sufficient definition of SD. However, it is only a goal statement, hence not complete because it lacks the substance of SD [Figure 7.1]. 


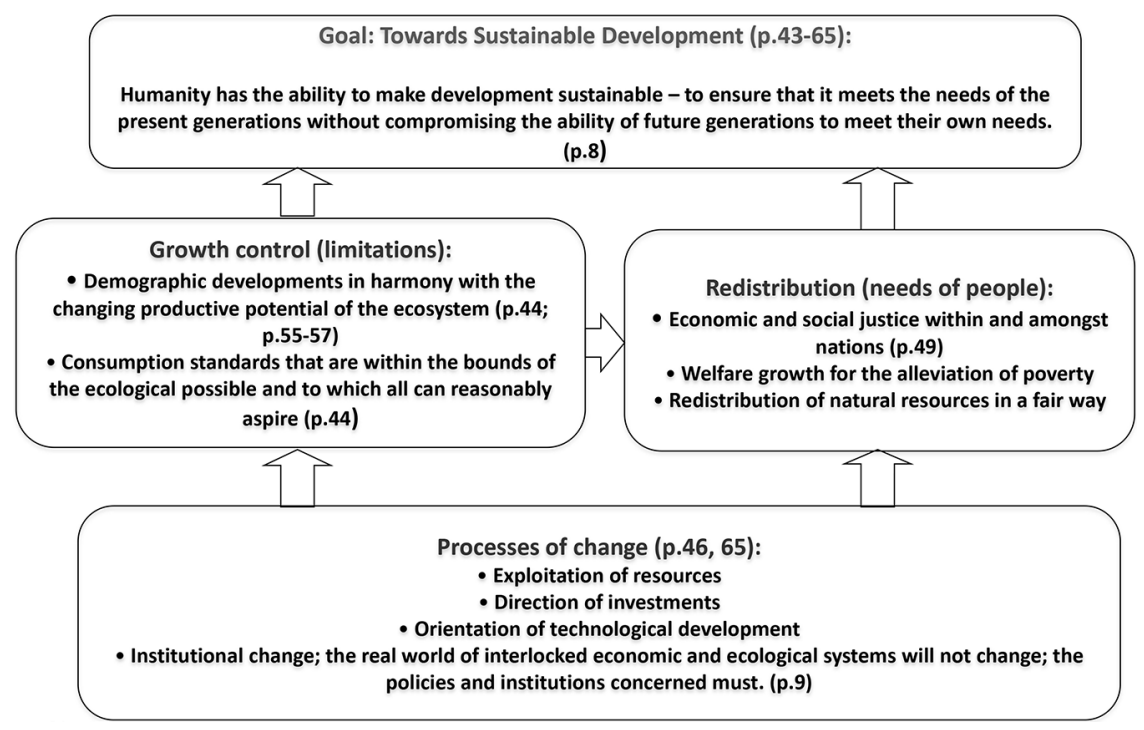

Figure 7.1 OCF quotes clarifying goal and substance of sustainable development

Three substantial components are growth control, redistribution and processes of change. Or to quote WCED (1987, p. 46):

In essence, $\mathrm{SD}$ is a process of change in which the exploitation of resources, the direction of investments, the orientation of technological development, and institutional change are all in harmony and enhance both current and future potential to meet human needs and aspirations.

The flawed narrative emphasizes other aspects: Sustainability allows economic growth, with environmental, social, and economic concerns, reduced to $3 \mathrm{P}$ language of Planet, People, and Profit (Munasinghe 1993). Companies comply with SD when respecting the 3P bottom line. Society complies with SD when pursuing the voluntary SD Goals (SDGs). Here economic growth is covering neoliberal, uneven and thoughtless, material accumulation, the opposite of OCF's 'welfare growth for the alleviation of poverty'. The mix of neoliberal and SD agendas safeguards vested interests (Green 2016), while legitimizing their operations.

Our Common Future is a radical change program, crafted on four core dimensions [Figure 7.2]: People (in communities), Planet (not only climate), Prosperity (instead of profit), and Politics (public policies) in the centre for energizing the other dimensions. The $3 \mathrm{P}$ representation is like the blades of a windmill without a dynamo: it delivers no power. This fits the neoliberal hype of 'markets solve the problems'. OCF-SD places institutional change, politics, central (Meadowcroft 2012), because the public dynamo is crucial for generating the change. The $3 \mathrm{P}$ mantra is a falsification: it truncates the essential 


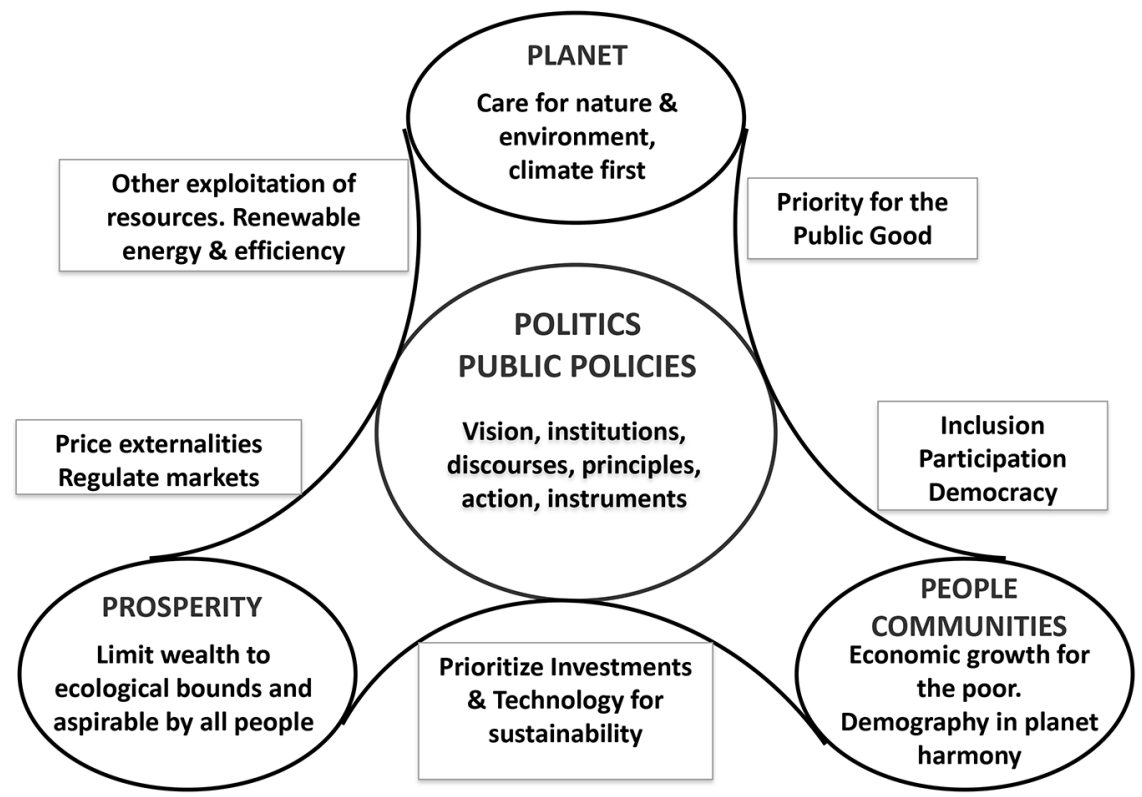

Figure 7.2 Dimensions of sustainable development

political responsibility, now displaced by voluntary SDGs being "periodic global updates issued in New York, which have little impact on how governments treat their citizens" (Green 2016, p. 147).

The 1992 World Summit on Environment and Development in Rio de Janeiro did accept the first inroads on the OCF-SD essence (Zaccai 2012). However, it also delivered the UNFCCC, and other conventions for building global policies for life-support global commons. This is a necessary bequest the $3^{\text {rd }}$ millennium needs.

\section{c) Fossil fuels expansion and nuclear power}

Energy use and GHG emissions are narrowly related. The main source of $\mathrm{CO}_{2}$ emissions is the combustion/gasification of carbon in fuels, predominantly fossil fuels. Since the $18^{\text {th }}$ century, industrializing societies expand infrastructures in energy, manufacturing, transport, buildings, ... with fossil fuels as main energy source, putting the energy sector "at the heart of the climate change challenge" (IEA 2019a, n.p.). Since World War II, the growth in fossil fuel use has been significant, notwithstanding the improving energy efficiency in almost all economic activities (BP 2019; IEA 2019b). Cleaner ${ }^{3}$ hydrocarbons (first petroleum, next natural gas) entered the market without driving out the dirtier ones (coal, lignite). Neither the 'Atoms for Peace' were able to replace coal in thermal power generation.

Common wisdoms during the fossil fuel growth period were: 'Fossil fuels are cheap; reducing their use is very costly, their elimination would end 
civilization; the growth in their use parallels the growth in GDP, and vice versa; oil depletion is the main menace (the 'peak oil supply' doomsday)'. The discourse prisoned open-minded thinking, except for a few, such as Lovins (1976), Freeman et al. (1974).

The 'wisdoms' are flawed in several aspects:

As historically saved solar energy, fossil fuels are a free gift of nature. Winning and processing fuels request significant economic resources (capital, labour, energy). However, the immense costs of their use are damages to nature and environment, human health, risks of irreversible climate change. Hence, taking into account these externalities, fossil fuel use is incredibly costly. The use is low-priced, because external costs and risks are not or little incorporated in the price. On the contrary, they are heavily subsidized (Coady et al. 2019). The full economic costs of using fossil fuels are extremely high. Therefore, eliminating fossil fuels from societal activities is a net win, though $100 \%$ transition to renewable energy will bring much societal turmoil because of the shifts in economic activities, in employment and its consequences [Section 7.2.4].

Energy is indispensable for all human activities. The interrelatedness between energy and economic production and consumption is strong, though not a proof of a 1-to-1 coupling of GDP and fossil fuel use. Breakthrough energy efficiency and the successful development and deployment of renewable energy will fully decouple energy-GDP on the one hand and carbon fuels on the other hand.

The hoax of oil depletion has stupefied the majority of the constituency, including ecological oriented scientists, including myself at younger age. Evidently, the Earth is limited to a sphere with radius $6,371 \mathrm{~km}$ and the mass is finite. Fossil fuels are but a tiny share of that mass. Extracting ever-increasing volumes during centuries would dry up the reserves and resources (Verbruggen and Al Marchohi 2010).

Yet, there are problems related to fossil fuels at the source and at the sink side of the so-called industrial metabolism (Ayres and Ayres 2002). The sources may fall dry due to exhaustion. Overloading the sinks precludes the yearly discarding of Giga tons of $\mathrm{CO}_{2}$. Climate change is the evident sink bottleneck, and fossil fuel reserves must remain underground. The ensuing geopolitical conflicts are discussed in Section 7.2.4.

In 1953 the Atoms for Peace heralded 'too cheap to meter' electricity from nuclear power plants. The announced technocratic energy Eden on Earth has since then metamorphosed in a blend of utopian plans and a reality of risks, accidents, unsolved waste, and weapons proliferation. The only application of nuclear energy is boiling water to medium pressure steam, 1/3 converted in electricity and $2 / 3$ discarded as waste heat in the environment. The transition from coal to nuclear in global electricity generation failed. As a result, the share of nuclear energy in global electricity generation is decreasing (BP 2019; Schneider 2019).

The history of nuclear power can be studied from various perspectives. Within the limits of this book, I disclose Utopia-Reality contradictions. I 
question for example: How do strongly vested Interests survive self-inflicted, devastating calamities, when no good reasons for their survival exist? Answering this question of 'deep incumbency' (Cox et al. 2016) unveils a patchwork of imaginary narratives, advocacy, and discourse (Gamson and Modigliani 1989). I highlight here two patches (and some more in Section 7.2.4): First, the unbearable lightness of precautionary safety in nuclear power generation. Second, the nuclear renaissance narrative building and advertising.

\section{PRECAUTIONARY SAFETY}

In 1979, a reactor core melting happened in the USA Three Miles Island (TMI) nuclear plant. In a melting plant, temperature goes up which causes a chemical reaction of high-temperature steam with the zirconium cladding of the fuel rods. That sets free highly explosive hydrogen. The TMI incident revealed that the formation of hydrogen was ten times higher than the values predicted by reactor scientists (Gillon 1986). At all occasions and in contacts with his nuclear proponent colleagues, nuclear science patriarch Gillon pointed to hydrogen formation as significant explosion risk. He insisted to install at least hydrogen re-combiners to reduce the risks. The warnings by a highly esteemed colleague were neglected and insufficient precautionary measures were taken. On the contrary, nuclear plant operators stored zirconium cladded spent fuel rods in the reactor buildings.

The hydrogen explosions in Fukushima in March 2011 multiplied the catastrophic impacts of the loss-of-coolant accident. The Fukushima disaster demonstrates the risks of unexpected chain failures, (such as the destruction of the entire site's emergency diesel power generators, seawater cooling pumps and external power supply) incurred by locating the emergency facilities within the 'paralysis radius' of a reactor accident and multiplied by installing several reactors on one site (Verbruggen et al. 2014). This is highly relevant to the existing reactor fleet and to future nuclear programs dependent on constructing new reactors on existing sites, e.g., UK Hinkley Point site. However, after 2011 no precautionary measures followed to move disaster prevention and emergency, outside the paralysis radius of operated nuclear plants. The disastrous impacts of nuclear accidents do not trigger a precautionary policy but seem to strengthen the ostrich attitude of 'accidents will not happen here'. This is the case for the hard-core nuclear interests negating the reality. Many countries and power companies have evaluated the nuclear case. They stop flogging the nuclear dead horse by phasing out active plants (Schneider 2019).

\section{NUCLEAR RENAISSANCE NARRATIVE}

Nonetheless, hard-core nuclear interests do not dismount the dead horse and spin a discourse around 'nuclear renaissance', orchestrated by For-Atom and Nuclear Forums in several EU MS. 
The new pro-nuclear narrative. In Brussels, July 2007, Saatchi \& Saatchi (and similar consultancies) received lavish contracts to design the advocacy plan, with as main elements:

1 Confuse the minds of people. Do not put forward a clear position about the attributes of nuclear power, but create doubt, opacity, to install a feeling of 'nobody seems to know well all technicalities and effects of nuclear power; it is all complex'. We, the experts, do not know well, so do you? Or is there anyone who could know? It seems there is no real case, so why should we have 'so-called independent' experts? Waste money? When you don't know well what nuclear power implies, it is a bit stupid to be 'anti' nuclear, isn't it? You are right: being 'pro or anti' depends on personal preferences, something like two supporter groups watching a soccer game.

2 Adopt a modest slogan. Dispose the arrogant hubris of the 1950-80s. The new catchphrase is: 'Nuclear power is not the solution, but there is no solution without'.

3 Lime a virtual support. Revert the counting: in the 1950-80s every person daring to say a critical word or ask a pinching question about nuclear, was marked as opponent. Saatchi \& Saatchi advised: every person not being an informed, fierce critic of nuclear, the nuclear sector counts as proponent, i.e., the silent majority is included as proponents, so obtaining the majority aura.

4 Informed opponents must be silenced, eliminated from the public forum. In July 2007, it was explicitly stated to avoid every meaningful debate about nuclear power. Lavish advertising in the media occupies the space for the nuclear topic. Influencing journalists continues as it went on for decades.

5 Mobilize vocal 'neutral' experts, expressing the necessity of nuclear power. J. Hansen, J. Lovelock, S. Pinker, etc. speak out about the necessity of nuclear power for addressing the climate problem, although the vocal voices lack knowledge about electricity systems, nuclear technology, nuclear facts, etc. For all neo-modernist people I have met, inanity is a virtue.

6 Obscure the facts about the nuclear history, failures, hazards, etc. Talk about illusionary GEN4 and GEN5 technologies, small modular reactors, thorium, fusion, etc. without serious feasibility assessment. IAEA's sustainability assessment of nuclear power is flawed (Verbruggen and Laes 2015), and the sustainability assessment of nuclear fission power exposes the technology as unsustainable (Verbruggen et al. 2014). The attribute of low carbon emission is not sufficient to claim sustainability.

7 Sell nuclear power as ideal matching partner of renewable electricity. Actually, nuclear is antagonistic to wind and solar [Section 7.2.4]. 
The resurrection of nuclear power is anyhow failing (Schneider 2019). Yet, the advocacy goes on, as does the waste of capital, time, human resources, etc. squandered in the few building projects going on. The IAEA, EURATOM, OECD-NEA, play an important role in the life extension of the nuclear option (Lehtonen 2019).

\section{d) Science and technology}

Fossil fuels and nuclear did command huge financial resources for developing and investing in the technologies of the steam era. In the 1970s modest R\&D budgets were allocated to research about energy efficiency and renewable energy technologies. Even specific budgets were small.

The remarkable progress in efficiency and renewables is the result of the spill overs of revolutionary science \& technology developments on future oriented lines. To name a few: microelectronics, ICT (Information and Communication Technology), life sciences and biotechnology, new materials, etc. The new sciences \& technologies were the surfboards for the World Wide Web and the globalization, for the new media, for blossoming development of many scientific hot spot areas, now spread over industrialized and industrializing areas.

On the issue of climate change, climate science received many more data, which it could process to improve the understanding of climate change and its impacts (IPCC, WG1 and WG2). The new renewable energy technologies (mainly wind and PV) fully benefited and benefit (Belton 2020; IRENA 2020) from the boost in science \& technology. They are natural partners in the progressive development of a sustainable future.

\subsubsection{Penultimate warning of the $1970 \mathrm{~s}$}

$\mathrm{CP}$ is an option to be considered for climate mitigation policy. The mission of the policy is to end as-soon-as-possible all GHG emissions, with as spearhead the elimination of energy-related carbon $\left(\mathrm{CO}_{2}\right.$ and $\left.\mathrm{CH}_{4}\right)$. "Dealing with climate change means changing the energy system with a speed that has rarely been seen in the past" (Fri 2013, p. 6). Carbon-free energy supplies are the solution. Two supply technologies are carbon-free: renewables and nuclear. Even with enormous public, political, scientific, and financial support, the nuclear technology failed, and is in regress (Schneider 2019).

The most evident technologies (energy efficiency and renewable energy) got lukewarm treatment in the previous century, except for some modest support in the 1970s when energy depletion and energy security were high on the agenda, and oil price hikes occurred in 1973 and 1979 (BP 2019). Vested fossil fuel and nuclear interests continued to thwart efficiency, and certainly renewable energy, as peanuts, not worth their attention and money.

In the mid-1980s, plummeting crude oil prices nipped the tender budding of modern energy efficiency and renewable energy technologies and applications. 
Appraisal studies based on high fossil fuel prices had recommended investments in energy efficiency with a good financial return. Since mid-1980s, the high financial savings from energy efficiency equipment did no longer materialize. This frustrated energy efficiency and renewable energy inventors, developers, and investors. Several inventions were classified. The mega tons of carbon, that could have saved by a wide application of such efficient solutions, are now littering the atmosphere and changing the climate.

While building a passive solar house end of the 1990s, I found a leaflet of a company (Van Beveren Alu) advertising window frames with internal PUR insulation. After unsuccessful trials to find such frames in the market, I contacted the company, and got as answer: 'the leaflet dates from the mid1980 s, our company was ready to manufacture the advanced frames, but the demand for high efficiency windows crashed, so we did not produce the efficient frames'.

Proposals to maintain the price signal for fossil fuel end-use energy at a reasonably level (i.e., substitute increasing fossil fuel taxing for the decreasing rent skimming by crude oil exporters), were rejected with as shallow argument the economic woos during the high-priced energy period 1973-1985. However, the distress to the fossil fuel intensive economies by oil price hikes in 1973 and 1979, was a result of the \$billions pocketed by oil exporting countries. The World Bank documents the yearly size of the global oil rent skimming as a percentage of the world GDP [Figure 7.3].

Extrapolating the situation of the 1973-1985 period beyond the post-1985 years is erroneous, because it ignores the distinction between bleeding \$billions

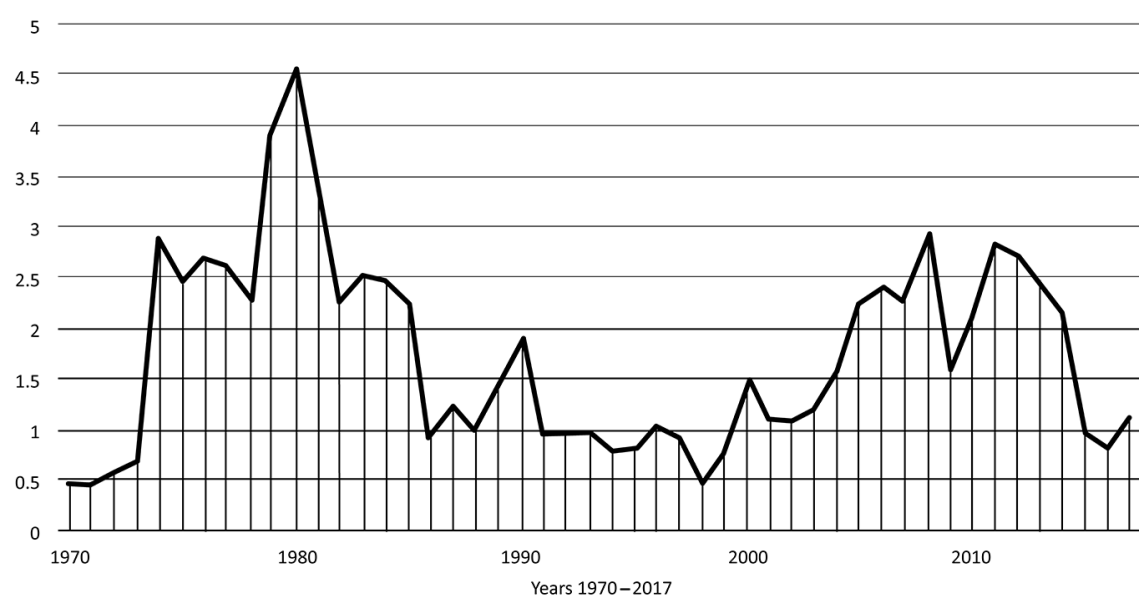

Figure 7.3 The volume of global oil rents (as a \% of GDP) for the period 1970-2017 Source: World Bank. 
rent payments cashed by oil exporting countries on the one hand, and recycling \$billions tax revenues on the other hand. The latter have a positive effect when they correct an environmental negative externality by taxing it. Tax revenues can be used to correct, for example, $R \& D$ positive externalities by subsidizing invention and innovation (double dividend). As far as I know, only Denmark has then experimented with taxing energy for supporting energy efficiency and renewable energy.

The anti-tax narrative spread like a viral infection, paralyzing most politicians in applying pricing instruments for the common good (Rabe 2018, Chapter 2). Nonetheless, taxing the bad things and subsidizing the good things are elementary components of good policymaking [Chapter 2, Figure 2.1]. In particular, technological inventions and innovations for energy efficiency and renewable energy merit full attention and support, a task taken seriously by Denmark and Germany, and accelerated in response to the 1992 UNFCCC [Annex D].

The penultimate warning to the global world community and to political leaders in particular, has been largely neglected and rejected. A strong mood against taxing energy and environmental pressures gained track and paved the way for more neoliberalism and globalization, causing further growth in GHG emissions. If the penultimate warning had been taken seriously, the hazards of climate change would have been less onerous today. Figure 7.4 illustrates the policy process after the second crude oil price hike in 1979 (as it was followed in Belgium, similarly to most other industrialized nations).

The actual energy use pattern is bumpy since 1973. Nonetheless, the official predictions of energy demand show mounting scenarios only, summarized in

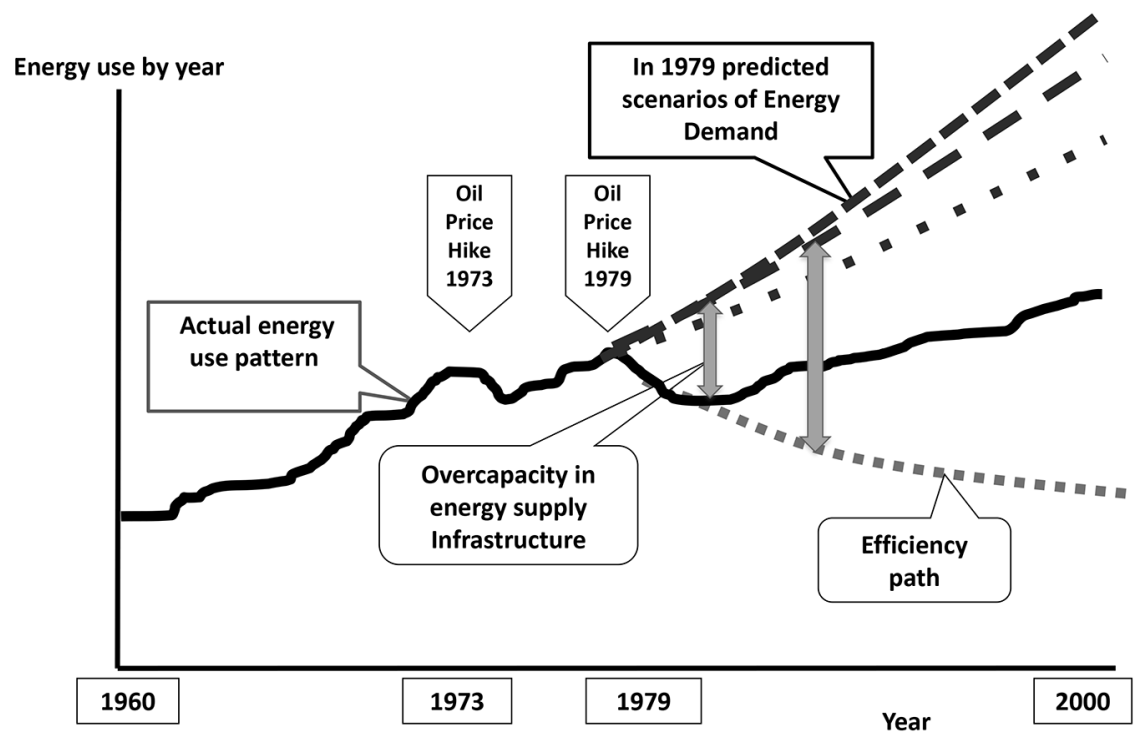

Figure 7.4 Energy efficiency path: opportunity missed 
High, Medium, and Low versions (with the warning that preparing for the Low scenario is perilous). The governments' answer on the 1973 oil crisis consisted in expanding supply capacities of coal, natural gas, and nuclear power. Following the 1979 oil price hike, the actual energy use pattern turned downwards.

Two factors explained the decrease: less economic activity and more energy efficiency measures. Differently with the 1970s, there were several efficiency techniques, products, practices, etc. available in the 1980s and many more in the pipeline. Following a soft energy efficiency path (Lovins 1976) was a real possibility, however blocked by economic Interests, owning considerable overcapacity in energy supply Infrastructures (with mega projects under construction).

No one can change the past, however one can learn from it:

- Future scenario projections that are fenced in economic growth tunnels obscure and close sustainability pathways.

- Flawed economic analysis neglects the accurate meaning of \$billions money flows, which blocks proper design and use of financial instruments.

- Anti-tax advocacy is very influential, also without transparent scientific arguments.

\subsubsection{Climate change: the ultimate warning}

Climate change is why this manuscript is written. Only few words are spent on the phenomenon and its impacts, because IPCC WG1 and WG2 reports provide the knowledge and are free access (www.ipcc.ch). The special report on the impacts of global warming of $1.5^{\circ} \mathrm{C}$ above pre-industrial levels and related global GHG emission pathways (IPCC, 2018) is an ultimate warning that drastic mitigation of the emissions is due, now. Urgency is necessary because many of the impacts and all-over climate collapse are irreversible, in the full meaning of the concept irreversibility (Verbruggen 2013). Every day delay is one too many. 'Drastic' means go to zero carbon emissions, especially energy-related carbon emissions $\mathrm{CO}_{2}$ and $\mathrm{CH}_{4}$, or: Carbon emitted $=0$ $[\mathrm{Ce}=0]$. Hence, the climate policy mission is clear: $[\mathrm{Ce}=0]$ as-soon-aspossible, answering (in a pondered way) the ' $A C T$ NOW' request of climate activists.

Policy room in the context space of future time, doubt and reversibility [Annex B, Figure B.5] is identified. The policy horizon to accomplish $[\mathrm{Ce}=0]$ is 10 to 20 years. There is little doubt what to do first and immediately: eliminate the energy-related emissions. The human survival duty is: restore and maintain flexible reversibility. In discussing the EU ETS in this chapter, $[\mathrm{Ce}=0]$ is pinned on the four walls of the room to remind us that as-soon-as-possible the carbon market should vanish by lack of carbon emissions. Actually, it has to vanish much earlier, because the EU ETS is the mechanism maintaining Business as Usual $(\mathrm{BaU})$ with the corresponding emissions [Section 7.4]. 
Advance to the $[\mathrm{Ce}=0]$ policy mission will be too slow without spearheads that break the walls of $\mathrm{BaU}$ resistance. Indispensable energy-technology transformation is the spearhead of the mitigation efforts. Industrialized countries are responsible for the development and deployment of technologies and practices, implementable by all countries, in particular the least developed countries having to grow economically (WCED 1987).

\subsubsection{Indispensable energy-technology transformation}

The term 'transition' came before 'transformation'; today, 'revolution' and 'reversal' is also used to emphasize the U-turn character of the changes. As climate change is linked to energy, so is energy linked to technology. Energy transformations are of all times in the human history, and mostly occurred spontaneously, voluntary, first pursued by some people and communities, later adopted by all. Early transformations are documented as controlling fire, domesticating animals, inventing tools. The link with technology is evident, from levers, wheels, sails, to electronics, new materials, biotechnology. Energy transformations did revolutionize societies and civilizations. Well documented is the $18^{\text {th }}$ century start of the steam era, based on thermodynamics and derived technologies, such as thermal power generation, internal combustion engines, cooling cycles, etc.

The $3^{\text {rd }}$ millennium revolutionizing transformation is the direct harvesting of renewable power from the environment, with advanced mechanics and aerodynamics (wind), electronics (PV), chemistry (fuel cells, batteries), ICT, etc. already applied by some and ready to be adopted by all. Different from earlier voluntary transformations, the $3^{\text {rd }}$ millennium one is also compelled by climate change, degradation of nature and environment, rising risks and irreversible loss of vital life-support systems. The transformation matches the OCF-SD paradigm, however impeded by Inertias (lock-in) in vested Ideas, Interests, Institutions, and Infrastructures.

The on-going Indispensable energy-technology transformation deploys over four strands, named with an adjective:

a Technical: electricity (and in assisting order: hydrogen) becomes the backbone energy vector.

b Ecological: all energy, driving societal activities, is harvested from renewable sources provided by the environment, accompanied by rational improvements in energy efficiency.

c Vicious: keeping the fossil fuel reserves and resources in the ground.

d Overdue: phasing-out nuclear power.

The Technical and Ecological interrelated strands are positive, futureoriented endeavours that will flourish at exponential pace. The faster politicians dissolve the last two strands, the faster the first two strands will rise. What is slowing down the transformations is not the lack of low-carbon solutions 
but the vested Interests and $\mathrm{BaU}$ of the fossil fuel companies, with the EU ETS playing a major role in shielding the $\mathrm{BaU}$ against effective climate policy [Section 7.4].

\section{a) Technical}

Most technical infrastructures built for long-time service need adaptation to the exigencies of low-carbon societies, with thermal power generation as the central case. De-carbonization is linked to electrification of activities, conditional on sourcing electricity from renewable energy currents (light, wind, water). Already since the 1970s, mainly Danish and German citizens and politicians (Hennicke et al. 1985; Scheer 1993) stimulated the development and deployment of wind and solar (photovoltaic) electricity with cleverly designed financial incentives [Annex D]. Around 2008, wind and PV started to compete with established power generation. Since 2018, wind and PV undercut any other technology in power generation expenses (IRENA 2018; 2020). Remind that expenses do not cover the significant external costs caused by all types of thermal power generation cycles. Energy systems' transformation to the use of RE currents will irrevocably revolutionize societies more thoroughly than the steam era did during industrialization. Not only fossil fuelbased electricity will be driven out. With the exception of clean geothermal steam sources, most steam cycle electricity will dwindle because of its cumbersome and costly flabs for sourcing steam and for sinking the residues thereby spoiling scarce water resources [Figure 7.5].

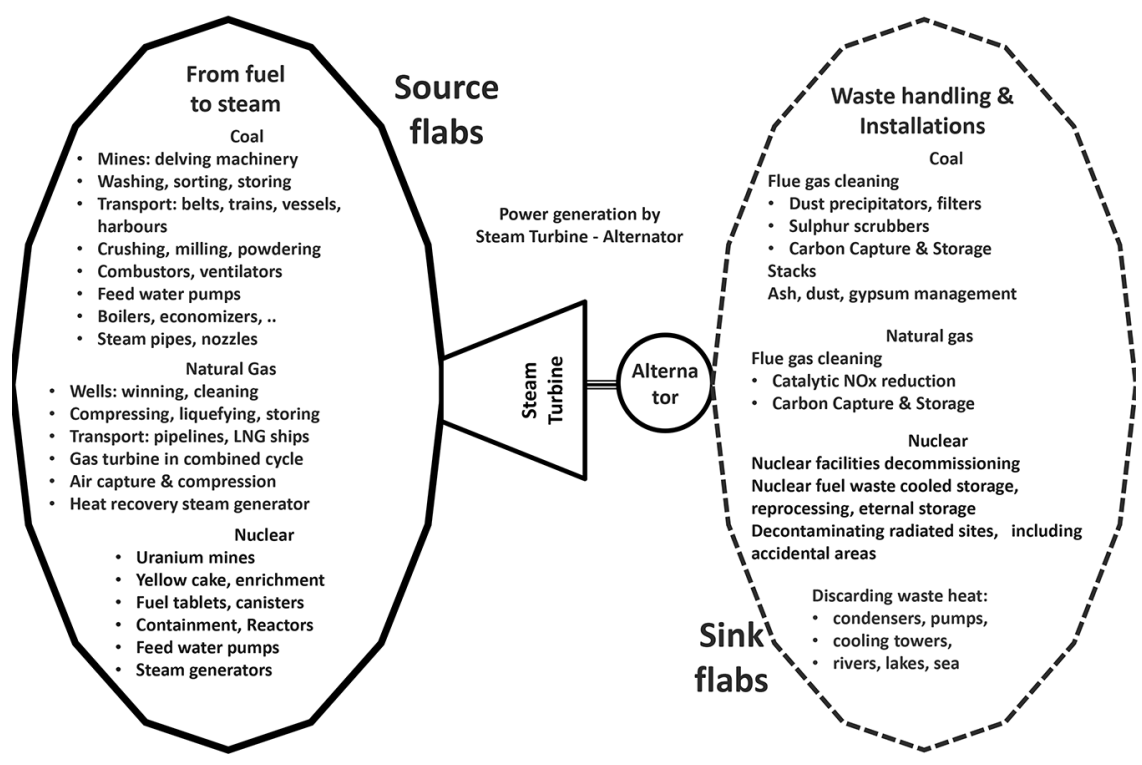

Figure 7.5 Steam electricity generation source and sink flabs 
The core of a large-scale thermal power plant consists of a turbine and an alternator. The latter converts the torque of a spinning axis in electric current. The turbine is driven by kinetic energy delivered by high-pressure, hightemperature gas flows (steam or combusted gas). Obtaining the gas flows requests fuels and wide-ranging infrastructures, as does discarding the workedout flows. The (non-exhaustive) enumeration in Figure 7.5 of the various devices, equipment, resources, etc., linked to thermal power plants, provides an impression of the tremendous impact they have on the planet, people and prosperity. It announces the incredible political and economic challenging tasks in scratching all such source and sink flabs. This riddles throughout the entire neoliberal economy, affecting the jobs of many, the financial and most industrial sectors. Yet, the transformation is essential for escaping climate collapse because thermal power generation stands for 40 to $50 \%$ of the global $\mathrm{CO}_{2}$ emissions, and the related flab activities for another 15 to $20 \%$.

Very differently, wind and PV harvest wind currents and light waves from the ambient environment, both without source and sink flabs. This is why renewable power is structurally and significantly cheaper than thermal power, also when considering the related financial expenses only, omitting to take in account the risks and environmental externalities of thermal power.

\section{b) Ecological}

The pace of substituting renewable for steam-sourced power is decisive for decarbonization success. The language: 'Integrating renewable power in the established electric systems' is implicitly maintaining the control position of power plants on command [Annex E] and delays the 100\% renewable electricity deployment. Energy corporations now fully invest in large-scale wind and solar projects, a welcome turn in their investment policy. Yet, delivery priority for power from large-scale plants endangers the profitability and future of community and household owned installations. The contentious issues of delivery priority request proper public regulation (EU 2018b).

Affordable and performing small-scale renewable power generation is less vital for countries with dense power grids than it is for developing countries now causing the growth in carbon dioxide emissions. For saving the global commons, priority for decentralized renewable power is necessary. Largescale systems should complement small-scale generation, not crowd them out as the business strategy of the giant electric power companies implies [Section 7.4.4].

\section{c) Vicious}

The industrial society is built on fossil fuels, first coal, later complemented by oil (petroleum) and natural gas. Restricting and phasing out fossil fuels are imposed by climate change and are inevitable. The restrictions will be exerted via precautionary mitigation of energy-related emissions or via irreversible 
impacts on ecosystems and on human habitats. The dismantlement of the three main fossil fuel groups has been started for coal and is discussed for oil.

Although the phase-out of natural gas is not widely discussed yet, as its combustion is ca. $40 \%$ less carbon intensive than the combustion of coal, substantial amounts of methane are emitted over the lifecycle of natural gas use. Therefore, also natural gas contributes to short-term and long-term GHG emission growth. There exists more indulgence for natural gas, because its substitution for coal and oil is seen as a mitigation option in EU ETS circles. Oil and gas are also used as raw materials in industrial processes (petrochemicals, fertilizers, and more). Oil is most versatile, dense, easy to store and ship, refined to several fuels, most applied for automotive vehicles, aviation and shipping.

The focus here is on oil as leader of the hydrocarbons band, with the price of crude oil influencing the economic and political state of the world. Oil has made the USA to the nation it is, 'addicted to oil'. The eye-catching discourse item is 'Peak oil (supply)', the famous moment of oil use turning from growth into decline, due to the depletion of oil wells. There are strong advocates (mostly geologists) and strong opponents (mostly economists) of the peak oil supply theory (Verbruggen and Al Marchohi 2010). Ecologists and critical social scientists adopt peak oil as a doom of industrial (capitalist) economies (Heinberg 2011; Meadowcroft 2012, p. 281).

The yearly published R/P indicator (ratio of oil Reserves/ Production) functions as discourse symbol of quantitative confirmation. The global oil R/P oscillates between 40 to 50 years sufficiency of oil reserves, since it was first published, also after the first 50 years were passed and in the meantime the use of oil had doubled. Still, the R/P is a number between 40 and 50 years (BP 2019, p. 15). This shows that $\mathrm{R} / \mathrm{P}$ is a deceiving indicator of scarcity. It only confirms the preparedness of oil producers for $\mathrm{BaU}$ during the coming 40 to 50 years.

From a holistic sources-sinks perspective (Ayres and Ayres 2002) limited carrying capacity of atmospheric sinks, not absolute scarcity in oil resources, is imposing constraints on oil use. Observing some year that oil production peaked in a preceding year is the result of socio-economic shifts and of politically imposed limits on carbon emissions. ${ }^{4}$ The peak will not be caused by physical lack of oil resources. Two salient political questions are: First, how to keep oil \& gas in the ground? Second, which role can oil pricing play?

\section{HOW TO KEEP OIL IN THE GROUND?}

First, keeping oil and gas in the ground is the booty of geopolitical conflicts on oil and gas, most severe in Middle Eastern and African countries, also spreading to South America and Russia (Verbruggen and Van de Graaf 2013). Many observers interpret the geopolitical conflicts as part of a global struggle to obtain cheap oil resources, with countries addicted to oil in the vanguard. They often expect more militarized conflicts or 'resource wars' in the future as 
a result of dwindling reserves, with peak-oil supplies allegedly dooming on the horizon (Homer-Dixon 1991; Peters 2004; Friedrichs 2010; Klare 2004; 2008; 2012). Oil reserves indeed have a significant potential to stir or shape geopolitical tensions and conflict, yet not because of their scarcity but because of their abundance.

Oil markets are bound to incur drastic shrinking. Concern over peak oil supply will crumble when the irrevocable peak oil demand is created. Replacing oil in the world's energy economies requires redirected market forces too, notably concerning the height and stability of oil end-use prices. Thus far, crude oil prices obeyed oligopolistic market and pricing mechanisms, causing faster or slower growth in the demand for oil. A horizontal hockey stick with upwards handle pattern of the global oil supply curve supports high sales prices, providing \$billion rents to ample sub-marginal sources. Cutting oil demand and maintaining high prices implies reducing the supply hockey stick's length by curtailing some oil producers. In this global oil market context, the alliances, goals, and tactics of oil geopolitics change (Verbruggen and Van de Graaf 2013).

For explaining the embargos, invasions and instigated civil wars, three groups of oil exporting countries are identified: friendly, hostile and countries drifting between the two sides. Since several years the axis US (with NATO allies) - Arab Gulf States (united in the Gulf Cooperation Council, shaken by the Qatar-Saudi Arabia diplomatic conflict in 2017) represent Western Interests 'friendly' oil. 'Hostile' oil is centred in Iran, followed by a few committed allies (e.g. Venezuela). Conflicts and warfare are less aimed at conquering oil fields for exploitation than at paralyzing hostile oil production capabilities of opponents or of unreliable transient sources (Wolin 2008, pp. 47, 49, 93). Covert warfare and instigated civil wars are likely tactics to exhaust hostile opponents. Since our publication 'Peak oil supply or oil not for sale' in 2013, antagonist cracks in the oil and gas market multiplied. For example, the 'Nordstream2' Russia-Germany gas connection project incidents provide an open book on extortion by Trump, coercing Europe to buy USA 'freedom gas'. Moreover, the embargos on Iran and on Venezuela have been intensified. Yet, this is not sufficient: in April 2020, hockey stick pricing crumbled because the oil glut is too large.

\section{WHICH ROLE CAN OIL PRICING PLAY?}

Belief in peak-oil by dwindling oil supplies may induce a lax attitude on mitigating carbon-dioxide emissions (Verbruggen and Al Marchohi 2010). Active policies for reducing emissions from fossil fuels encompass higher, by preference carbon intensity related, end-use prices on fossil fuels. The crucial issues are: Who is going to set the higher prices and how will the revenues (rents) be collected and appropriated? When pricing is left over to the major oil producers, most rents will be private and available for bringing more and dirtier fossil fuels into use. Producers can pump more oil for many decades, 


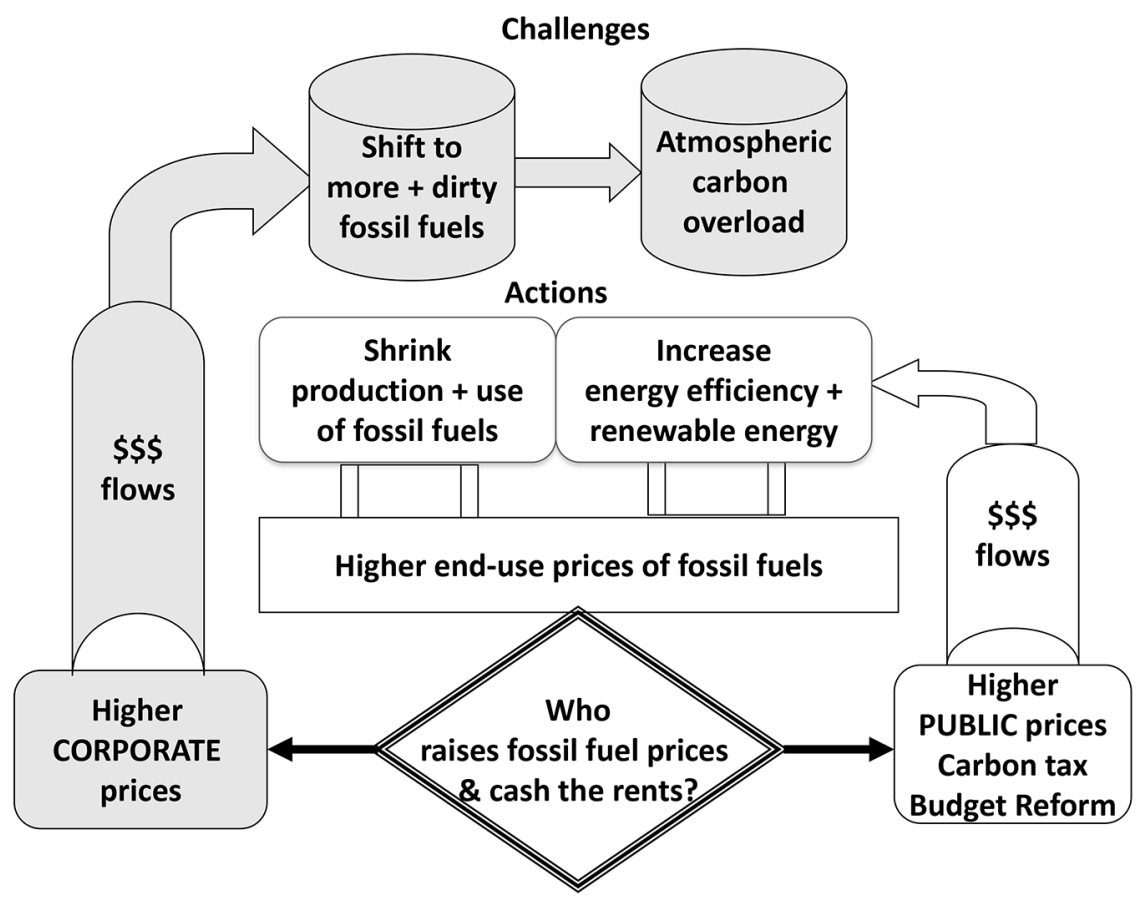

Figure 7.6 Fossil fuel prices and environmental effectiveness

postponing peak oil demand to occur while extending carbon lock-in. For avoiding this risky climate future, revenues from higher fossil fuel prices (taxes) must be directed to stimulating energy efficiency and renewable energy sources [Figure 7.6].

\section{d) Overdue}

The phasing out of nuclear power (NP) is long overdue. Presumably, the link with weaponry is a lifeline for civil nuclear activity, called 'deep incumbency' by Cox et al. (2016). Some countries rejected NP at the right time, for example Austria in 1978 and Denmark definitely in 1985, following countries like Australia and Norway that precluded NP. Countries deciding to quit NP after considerable engagement are for example Belgium in 2003, Germany in 2011, South Korea in 2017.

The USA is officially favouring NP, but in practice no new NPs come on line in the country with the world's largest (but aged) nuclear fleet (Schneider 2019). The partial core melt in breeder reactor Fermi 1 (1966), the fire in Browns Ferry (1975), the Three Miles Island accident (1979), and huge cost overruns in plant constructions (Komanoff 1981), informed investors about the high, non-insurable, risks of NP. In 2017, the bankruptcy of reactor builder Westinghouse drove its new owner Toshiba in stormy financial weather. The 
Fukushima disaster (2011) awakened Japan's population, locking down almost the full NP pack in Japan. Russia is a stubborn nuclear adept, although many of the announced projects are dubious and the USSR nuclear contamination bequest is considerable.

China fosters now the most expansive nuclear program, but signals of more caution arise (Schneider 2019). EDF and France's obdurate blindness for the shortcomings of nuclear technology is costing the country Ebillions (e.g., the bankruptcy of reactor builder AREVA); the nuclear Interests preclude the country's preparation for a 100\% renewable electricity future. This short overview of facts may spur nuclear advocates (A. Berger, J. Hansen, J. Lovelock, S. Pinter, etc.) to first study the history of their pretended solution, before speaking out about NP's 'promises'.

There are many arguments to redirect all nuclear expertise and resources from new plant construction and life extensions, to a thought-out "Act Now" on global phase-outs, decommissioning, restoration of contaminated sites, handling nuclear waste, etc. (Haas et al. 2019). This redirection is supported by a clarification of the position of nuclear power in the sustainable low-carbon energy transition. Comprehensive sustainability assessment of the today's employed nuclear technology (fission power plants) reveals it fails on all relevant criteria, except one: the low-carbon attribute (Verbruggen et al. 2014). When circumventing SD imperatives and sustainability assessment results, and only weighing the low-carbon attribute, nuclear power is neither part of the Indispensable energy-technology transformation, because:

- The most sustainable renewable electricity supplies are harvested from variable ambient energy currents wind and light. When significant wind and solar capacities are built in an electricity service area, they collide with inflexible nuclear power supplies. The operator of the integrated power system can assign supply priority to only one of the options, and priority for one ruins the financial accounts of the other (Verbruggen and Yurchenko 2017; 2019). Nuclear power is not compatible with renewable power harvested from wind, light, and water currents.

- Europe has to invest €billions in modernizing and extending the power grids. Distributed renewable power generators are served by local smart grids, knit together and connected to a transport grid intended for exchanges of renewable power over the continent. Giant nuclear reactors need a pyramid-like grid, directed from the top where at one point several Giga Watt High-Voltage power is pushed in the network. Smart and Giga collide.

- Even in narrow economic terms (i.e. only considering expenses, excluding the full costs of risks and externalities) new buildings of NPs are a financial trap, for example Olkiluoto, Finland and Flamanville, France (Haas et al. 2019).

The actual technical and economic performance of NP is such that, in democratic societies, the logical decision is a fast, total stop of nuclear power. 
However, vested Interests, located in IAEA, EURATOM (Fouquet 2019), OECD-NEA (Lehtonen 2019), and similar hides, defend their personal statutes and privileges. The unimpeachable status of IAEA, webs of contacts, luxurious budgets, shielding from evaluation, allows nuclear technocrats to continue a fantasy discourse about the 'necessity' of NP for the climate case, backed-up by mirages about promising nuclear technologies at the horizon (for example, fast neutrons, small modular reactors, fusion). This is deceit beyond Utopia, concealed by narratives and manipulation at crucial nodes of societal influencing and decision-making processes.

Verbruggen and Laes (2015) describe how the WG3 contribution to the fifth assessment report of IPCC (2014) was manipulated on the depiction of NP. One falsification is the systematic exclusion of peer-reviewed publications that are not in line with the nuclear advocacy discourse. This is the gravest infliction on the 'Principles Governing IPCC Work, Section 4.3.3' (www.ip cc.ch), requesting the assessment of all peer-reviewed literature, and "clearly identify disparate views for which there is significant scientific or technical support, together with the relevant arguments". There was ample referencing to IAEA and other nuclear institutes' non peer-reviewed reports. The significant infliction went seemingly unnoticed by vested interests controlling large swatches of the media.

The author of the nuclear pieces in the AR5 report was H-H. Rogner (life career at IAEA, after retirement at IIASA), appointed as Contributing Author to Chapter 7 (Energy Systems) of WG3 (IPCC 2014). In Berlin, April 7-11, 2014, the approval of the SPM (Summary for Policy Makers) of the WG3 contribution took place. I was attending as member of the Belgian delegation. In the evening of Thursday 10 April, Chapter 7 issues were discussed, with the Coordinating Lead authors taking the chair (in case: T. Bruckner). The SPM draft text proposed:

Nuclear energy is a mature low GHG emission technology but its share of global electricity generation is declining since 1993 (robust evidence, high agreement). Barriers to an increasing use of nuclear energy include concerns about operational safety, (nuclear weapon) proliferation risks, waste management security as well as financial and regulatory risks (robust evidence, high agreement). New fuel cycles and reactor technologies addressing some of these issues are under development.

(SPM draft of March 2014, p. 18)

This formulation is not shocking, what helps to get its flawed messages pass the approval by the meeting delegates. For example: "Barriers to an increasing use of nuclear energy include concerns about operational safety", is veiling language of the IEA statement "to reach nuclear goals, countries need to make significant efforts to convince an increasingly sceptical public that nuclear power should continue to be part of the future energy mix" (IEA 2012, p. 73). In plain language, IAEA and IEA state: not the risks of NP are the problem, 
but peoples' concerns about the risks. In reality, the peoples' rejection of NP risks is at the same footing of the global reinsuring companies' refusal to assume nuclear liabilities.

My intervention in the plenary about the above argument was causing upheaval, an intense discussion with the USA delegation, followed by an interruption of the meeting to find a better wording. When resumed, the meeting chair became Contributing author H-H. Rogner. Yet, IPCC practice is that Contributing authors are not present at SPM approval meetings, a fortiori not chair the plenary meeting. His presence was via IAEA-IIASA network connections. ${ }^{5}$

The compromise text resets the reverse risks/concerns language, yet the real status and performance of NP remains concealed:

Nuclear energy is a mature low-GHG emission source of baseload power, but its share of global electricity generation has been declining (since 1993). Nuclear energy could make an increasing contribution to low-carbon energy supply, but a variety of barriers and risks exist(robust evidence, high agreement). Those include: operational risks, and the associated concerns, uranium mining risks, financial and regulatory risks, unresolved waste management issues, nuclear weapon proliferation concerns, and adverse public opinion (robust evidence, high agreement).

New fuel cycles and reactor technologies addressing some of these issues are being investigated and progress in research and development has been made concerning safety and waste disposal.

(IPCC 2014, pp. 20-21)

The Special Report $1.5^{\circ} \mathrm{C}$ holds a section "4.3.1.3 Nuclear energy" (IPCC 2018, p. 325). Now reference is made to literature of independent experts (e.g., A. Gruebler, M. Schneider), whose work is mentioned in a poor, deceiving way. The half page text is below scientific standard. The SPM of the Special Report $1.5^{\circ} \mathrm{C}$ mentions only nuclear power in reporting results of modelling studies. The stealthy pro-nuclear interventions intend to cover-up reality and conserve 'Atoms for Peace' Utopia.

\subsubsection{Triptych 'renewables, nuclear, carbon capture and storage' mantra}

The last pages of Section 7.2.4 dealt with the lobbying by nuclear Interests, via a biased discourse for protecting the nuclear technology from independent evaluations, hereby protracting its risky and cumbersome activities. One of the tactics is silencing or misrepresenting valuable information in superficial and biased contributions to IPCC $(2014 ; 2018)$. It is high time to reform IAEA, taking out its role as nuclear promotion and advocacy centre.

Simple slogans serve a widespread and deep impact of flawed and deceiving viewpoints. A most successful slogan of the nuclear and fossil energy Interests is 
the triptych mantra 'renewables, nuclear and carbon capture and storage (CCS)', presenting the three options juxtaposed, seemingly equivalent, to mitigate energy-related $\mathrm{CO}_{2}$ emissions. Its full description is: "zero- and low-carbon energy supply from renewables, nuclear energy and fossil energy with CCS" (IPCC 2014, p. 16).

The mantra is rotten, yet it is a critical lifeline for the vicious and the overdue energy options, in providing a safeguard for legitimacy and political support, thus protecting $\mathrm{BaU}$, life extension of non-sustainable energy. This contradicts the necessity of drastic and urgent change, for avoiding climate collapse. Nevertheless, the mantra is everywhere in the literature, media, policy debate, ...

One type of framing to support the triptych mantra is shallow talk: 'there is no silver bullet' but 'need for all available options to face the challenges'. Sometimes option diversification and redundancy are strategically valid, though not a general rule. It is particularly not the case in the Indispensable energy-technology transformation.

The transformation means 100\% renewable power from wind, light and water currents, ending most thermal power of the steam era, with clean geothermal power as exception. IPCC (2018, p. 315) finds:

The political, economic, social and technical feasibility of solar energy, wind energy and electricity storage technologies has improved dramatically over the past few years, while that of nuclear energy and CCS in the electricity sector has not shown similar improvements.

The juxtaposition of the three options is apparently misleading.

The juxtaposition is scientifically problematic because it obscures the incompatibility of nuclear power with renewable power from ambient currents (wind, light, water). Nevertheless, juxtaposition is current practice in the Integrated Assessment Models (IAM), calculating the mitigation pathways of the IPCC reports. By their global and multi-sector scope the IAMs are broad, but shallow.

The crucial economic activity of transformative pathways is electricity generation, maximum electrification also being the first strand of the Indispensable energy-technology transformation. Electricity is a current, it is a transient phenomenon, physical impossible to store. Hence, the resolution of the chronology is fine (seconds, minutes, quarter hours, maximum by hour), with the sequence of the time intervals relevant when (up and down) load ramping by thermal generation units is constrained and costly. Proper modelling of power generation in one service area requires lots of data, computing capacity and time, and specialized staff.

The growing share of renewable electricity harvested from variable, stochastic natural currents wind, light and water, has multiplied the intricacy of the modelling task. The advanced models take interrelatedness and interaction of the generation plants into account. They observe the incompatibility of 
base-load nuclear power with power from light, wind, and water offered at zero-marginal cost, and thus deserving the first position in the merit-order, being the base-load.

The IAMs are coarse, juxtaposing yearly quantities of generated power of selected technologies, up to the total quantity of electricity fitting the model's equations. The results from the IAMs in the IPCC reports repeat the triptych mantra. For example, in the SPM of the Special report $1.5^{\circ} \mathrm{C}$ (IPCC 2018), nuclear power is only mentioned via IAM results, as part of the triptych mantra. IPCC does not question the problematical juxtaposition of nuclear and renewable power supplies (Verbruggen and Yurchenko 2017; 2019).

The deceiving discourse, advocacy and manipulations on NP are instructive for the study of the EU ETS political economy.

\subsection{Actors on the EU ETS scene}

For deconstructing the carbon economy, political scientists may use ActorNetwork Theory frameworks (Stephan and Paterson 2012). This section starts with an overview of actors very active on the EU ETS up to more distant actors with interest in or affecting the course of the EU ETS from outside [Section 7.3.1]. Then the focus is on the energy companies [Section 7.3.2], followed by an exemplary case of an electric power company [Section 7.3.3]. The characteristics of large companies are described in Section 7.3.4, to finish with an example of rent skimming by implied companies [Section 7.3.5]. The presentation of the actors is limited to aspects of relevance for a political economy study of EU ETS.

\subsubsection{Overview of the actors}

The central axis of Figure 7.7 shows two main actors: on top, the energy industry; below, the most implied bodies of EU governance: the EC, the Parliament and the Council of Ministers. The third main actors are shown at the top-left: the industrial companies and interfering agents from the financial sector, some structural such as the auction and exchange platforms EEX and ICE-ECX, others voluntary such as banks holding climate trade desks, or specialized data analysts (such as Point Carbon).

Bottom-left refers to the scientific and advocacy actors. IPCC takes the central position by its mission to assess all available knowledge about climate change (WG1), impacts and adaptation (WG2), and mitigation (WG3). In WG3, policy instruments are considered, including carbon pricing and emissions trading. Contributions to IPCC come from all sides. Concerning economic instruments, the English language literature, a significant share Anglo-Saxon, calls the tune.

The neoclassical economics paradigm prevails and neoliberal worldviews are but sporadically contested. Representatives from the major oil companies played active roles in IPCC, for example: M. Jefferson (Shell) as review editor 


\section{A political economy of the EU ETS}

in AR3 (TAR), B. Flannery (Exxon Mobile) as lead author in AR4. Research centres focusing on climate change and policy (such as RFF, WRI, FEEM, Cicero, PIK), university departments, and think tanks, favour carbon pricing and many prefer emissions trading above taxing emissions.

The right side of Figure 7.7 lists a variety of actors, some playing a direct role (for example, EU MS) or an umbrella role. For instance, UNFCCC COP3 in 1997 backed the turnabout of the EC from tax to emissions trading proponent. Outspoken ETS supporters are international organizations (World Bank; OECD). Business federations range from warm, over lukewarm, to cold acceptance of the EU ETS, depending on their membership.

A similar distribution applies for climate NGOs: Friends of the Earth (2013) and Corporate Europe Observatory (CEO 2013) reject the EU ETS as being a valid climate policy instrument. Most NGOs try to convert the EU ETS in an effective policy instrument. In 1997, the US NGO Environmental Defense became a partner in the global pro-trading coalition assembled by multinational corporations (Meckling 2011, p. 81).

Climate activists seem not interested in the EU ETS. They have, however, a significant impact by pushing for immediate effective measures such as 'Coal Phase-out'.
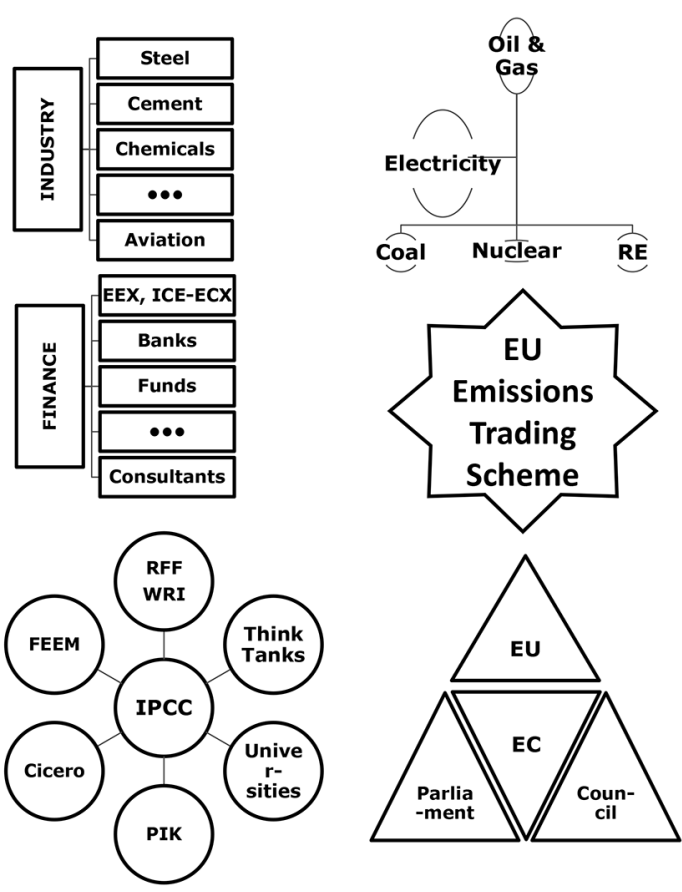

World Bank, OECD, IEA, IAEA, •.•

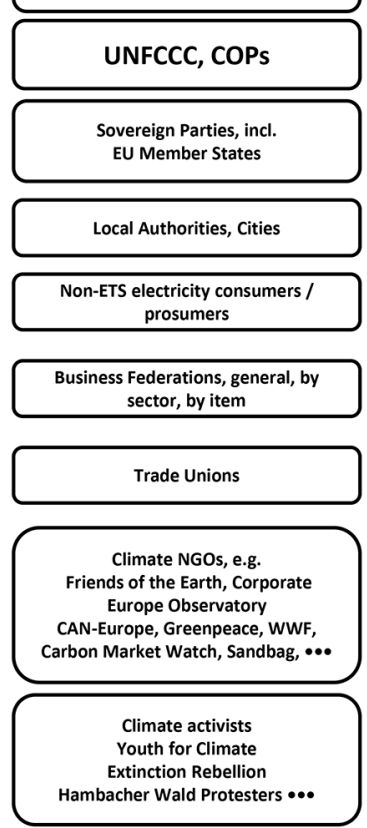

Figure 7.7 Main actors involved in the EU ETS and in the wider climate debate 


\subsubsection{Energy companies are prominent actors in the EU ETS}

Energy companies (oil majors and large electricity companies) did and do play a prominent role in the formation and continuation of the EU ETS. In the industrialized world, firms and corporations protect and promote their activities also by influencing public policy (Fuchs 2007; Wolin 2008). "Scholars characterized this political support base as a 'iron triangle' of sorts, reflecting a steadfast coalition between industry, legislators, and executive agencies" (Rabe 2018 , p. 1). "To some industries, such as the oil, electricity and energyintensive manufacturing ones, engagement with climate policy is about managing and containing regulatory risk" (Meckling 2011, p. 23).

Corporate pioneers thus leveraged action at the European level. Oil majors BP and Shell as well as the European electric utilities found a powerful ally in the EC. Together these actors successfully introduced emissions trading to Europe, ultimately resulting in the creation of the EU ETS.

(Meckling 2011, p. 24)

This identification of the architects of the EU ETS is clear, and the energy sector continues to exert a prominent role in the EU ETS.

Oil and gas and electricity have distinct interests in the set-up and operations of the EU ETS.

First, there is the physical fact that $\mathrm{CO}_{2}$ emission is linearly connected to the combustion of fossil fuels. Emission reduction is a life-challenge for fossil fuel companies. Electricity is a carbon-free energy transmitter, with a central role in the urgently due transformation to a [Ce $=0$ ] society [Section 7.2.4]. Nonetheless, because most electric power generation still is generated in fossilfired thermal power plants, EU's large power companies are the largest emitters. Bryant (2016, Chapter 3 'Capital and carbon in the EU ETS') documents this for the period (2005-2012).

Second, oil \& gas companies are global multinationals. The few 'special' links with EU MS are not intense (BP-UK, Shell-UK and the Netherlands, TotalFrance) except when they were public controlled (ENI-Italy; Statoil-Norway; Dong-Denmark). Electric power supply is the backbone of every MS economy, with fixed Infrastructures (power plants, transmission stations and lines), connecting all households, facilities, industrial companies, public services, etc.

Third, oil and gas companies in industrialized market economies have seldom been exposed to nationalization and tight regulation. The European electricity supply industry was largely public owned before the 1980's liberalization gulf (Joskow and Schmalensee 1985). The few private electric power companies experienced a type of regulation within the 'iron triangle' cooperation between industry, legislators and executive agencies.

The three distinctions point to the electric power companies having more and other stakes than the multinational oil majors in EU ETS. Yet, this is not saying that EU ETS is of minor importance for the oil majors. Elucidating the 
stakes and the roles of the electric power companies clarifies what the EU ETS is and how it functions. This elucidation starts with revisiting past experiences.

\subsubsection{Exemplary case: private electric power companies in Belgium}

The history of the Belgian private electric power sector reveals that for the sector's interests, captured regulation is more beneficial than no regulation. The private sector created itself a regulatory shield for bouncing back overly diligent politicians with anti-monopolist agendas.

After World War II, several European countries nationalized their power sector (for example France EDF 1946; UK CEGB 1947; Italy ENEL 1962). In 1955, the Belgian private electricity producers defused nationalization proposals by creating their Control Committee for Electricity (CCE), adding gas in 1964 (CCEG). Controlled are the companies for production, transport, and distribution of electricity/gas.

The controllers are the Belgian Business Federation (with private power and affiliated companies as important members, i.e., a circular reference in the control links) and the three official Trade Unions (connected to the then most significant political parties: Christian-Democrats, Socialists, and Liberals). The government was assigned a role of observer, allowed to be present at the official meetings and suggest agenda issues (Verbruggen et al. 2001). The power companies were committed to increasing productivity, innovation, and reliable services, what they did successfully.

Institutionally, this control committee is hilarious. Practically, it has functioned during 45 years, formally ending in 2003 after Belgium's implementation of the Internal Energy Market directive (EC 1997; Verbruggen and Vanderstappen 1999). The strength of the CCEG was in providing benefits for controlled and controller participants, acquiescence from federal and local politicians, with the bill diffused across the low and medium voltage customers and across the tax-paying constituency.

Belgian high voltage industrial tariffs were among the lowest in Europe. These low tariffs silenced the business federation controllers and minimized on-site power generation by energy-intensive companies. Low and medium voltage tariffs were among the highest. For example, in the 1990s low and medium voltage consumption (60\% of total) generated $94 \%$ of ELECTRABEL's net revenue, while the industrial high voltage consumption ( $40 \%$ of total) only $6 \%$.

The electric sector staff enjoyed the best salaries and working conditions in the country, silencing the Trade Union controllers, who also accepted the argument that low tariffs for industry attract more investment and more employment. The controlled companies voluntarily upgraded the position and salaries of CCEG staff from the civil servant level to the more luxurious level of electricity sector staff. Moreover, the CCEG was housed in the headquarters of TRACTEBEL (the strategic head engineering company of the sector).

By creative application of tax rules, the power companies escaped high taxes on their significant profits. However, the evasion mechanism was combined 
with commensurate transfers to municipal and provincial treasuries (solidifying an immovable political support, while diffusing the bill in the federal tax labyrinth). The power company as money collector shielded the local politicians from their voters' critique about higher taxes.

In 1989, the experience and know-how on dealing with stakeholders and public authorities was taken over by SUEZ, later transmuted to ENGIE. Telling the full story needs many more pages. Other countries have experienced similar situations, with electric utilities that were keen in 'capturing' their regulators (Stigler 1971). Peltzman (1976, p. 211) added to Stigler's theory of capturing that "regulatory agencies will not exclusively serve a single economic interest". The Belgian case goes beyond 'capturing' because the controlled parties self-organized the regulatory system and understood that a spectrum of economic and political interests had to be suitably served.

Why these experiences are relevant in our study on carbon pricing and EU ETS? As shown in Annex A [Figure A.2], surcharges on electricity bills may equal quasi taxes, which are (mostly opaquely) processed by utility companies. The mechanism is also active in EU's ETS [Section 7.4.4]. Overall, the case shows how formal regulation may be a perfect cover for concealing profit making with the bill paid by captive customers via prices including private rents and quasi taxes on indispensable utilities. When such regulatory constructions could function successfully for the Belgian electricity companies during 45 years, why should the companies not try similar set-ups in the context of EU ETS regulatory intricacy?

\subsubsection{Characteristics of EU's electric power giants and of corporations}

Evidently, a giant power company is large in scope and in scale. With the opening of the internal energy market in the 1990s, their scope enlarged to the entire EU. Most of them obtained assets in several countries, with some competitive frictions among the oligopolies. The level of influencing political decision-making moved up from MS capitals to the EU capital Brussels.

Co-authoring of EU's directives is the most effective and efficient influencing, evidently hidden, path. In Brussels, EURELECTRIC looks after the sector's common interests and manages the variety of its members, sometimes with side-lining some of them on some issue, for safeguarding the higher interests of the club. The preservation of the EU ETS is a major concern for EURELECTRIC, also because not all its members understand its functionality as a shield bouncing back stringent regulation.

Maintaining good contacts in the MS capitals is worthwhile for connections to the EU Councils and the EU Parliament. Some of the giant power companies are still intensively linked to its national government, administration and power equipment industry. EDF is the most evident example, trying to keep the nuclear power generation and the French engineering-contractors alive. Stranded assets are significant barriers against speedy transformation of power generation technology [Section 7.2.4]. 
Large power generation companies are generally established institutes, with a respected record, able to address intricate organizational challenges. The companies command considerable financial resources, competent and committed staff, and broad and deep networks. They aim at good, long-term relations with energy-intensive industries, and avoid conflicts, for example about climate policy preferences. On shaping the EU ETS, the power generation sector and several industries (e.g., steel, chemicals) differed in vision, which emerged again about auction back loading in Phase 3 of the EU ETS.

In the period 2000-2007, most techno-economic environmental experts of large companies, including energy-intensive ones, rejected ETS as a proper instrument to address the problem of carbon emissions. For example, at a conference (December 4, 2008) of Dutch and Flemish chemical industry environmental staff, in a vote by the ca. 120 attendants, more than 95\% approved following statements: 'EU ETS is leaking, flawed, no teeth, shadowboxing', and 'Saving EU ETS is a mirage, on global coverage, efficiency, impact'.

High approval of the statements confirms a growing separation of the engineering technology problem solvers in industrial companies from the financial departments that follow emissions trading. Tradable permits are classified as financial products in review of EU financial market rules, supervised by the European Securities and Markets Authority (ESMA), and submitted to the Markets in Financial Instruments Directive (MiFID) and the Market Abuse Regulations (MAR). This classification was necessary after the significant carbon market fraud in the years 2008-2010 (assessed at €10 to €20 billion; EurActiv, July 18, 2016), which prompted France to indefinitely close the BlueNext spot exchange office.

The finance industry was welcomed by the EC to make the permits market more liquid and dynamic, what it also did in 2005 until the evidence in March 2006 of the oversupply of free permits by the MS. The permits market developed further, most on futures. Several market analysts offered their services (Point Carbon, Independent Commodity Intelligence Services, Bloomberg New Energy Finance, Markets Insider) and investment banks opened climate desks.

It is unlikely that large electric power companies were generous buyers of new financial services. They could build on a long tradition of trading experience in their fuel purchase divisions, in the 1990s complemented by operations at the new electric power exchanges. They were familiar with trade over the counter, bilateral contracts, spot, futures, hedging, etc., before emissions trading started.

\subsubsection{Rent skimming under a CP umbrella}

Moreover, electric power companies are known as wealthy, profitable enterprises, well aware that above average money returns are needed to finance a manifold of projects inventoried and budgeted. The interests of the power 
companies are most guaranteed by financial solidity. The basic money circuit in the electricity business is fed via (relatively) small monthly amounts from millions of customers.

Because of the limited price elasticity of the demand for electricity by captive customers, their bills may include monopoly rents. Notwithstanding the liberalization of the EU electricity sector to pursue competition among the electricity producers, oligopoly companies charged significant rents under the cover of high prices posted at the exchange of EU ETS permits in Phase 1. Sijm et al. (2006) labelled the rents as 'windfall profits'. This euphemistic language is dubious: Keynes coined the term 'windfall profit' for cases of truly exceptional luck, when no other explanations of the profits are possible. It would be better practice to label the Ebillions as 'monopoly rents', feasible by deficient public regulation (Verbruggen 2008).

A company obtains above average returns by increasing its revenues, boosted by rent skimming (Schoemaker 1990), and by lowering or avoiding expenses (skipping payment for emitted carbon in case of climate policy). Economic agents are particularly reluctant to give up vested privileges. Such reluctance is observed when public authorities (plan to) charge money for the utilization of commons good, so far free open access.

Framing the narrative and language are again important. Endorsing current privileges and visions is the formulation 'When mitigating carbon dioxide emissions, the present generations bring offers for the well-being of future generations' (Aldy and Stavins 2007; Prins and Rayner 2007; Hahn and Ulph 2012). It glosses over the appropriation of privileges and rights (Bromley 1986) on the atmosphere and on the climate by the minority, affluent part of humans living in the fossil fuel era. Flawed language paves the road to lenient treatment of polluters: "the rationale for a policy allowing some free allocation of allowances based on historic emissions is based on the desire to compensate incumbent installations that are affected by regulation" (IPCC 2007, p. 758).

Proper framing and language, 'Carbon dioxide emitting is gaseous littering of the atmosphere', reorder legal positions. Littering is illegal: the duty of the litterer is to stop littering immediately, and to clean the mess s/he made. Language, discourse, and narratives are significant in legitimizing and in disguising actual handling and distribution of wealth and opportunities.

What for economic actors, especially for businesses, really counts is money, but the talk deviated to carbon pricing, alias the volatile prices of an EU ETS permit. To conclude the presentation of the main actors on the EU ETS scene, Figure 7.8 is a rudimentary representation of the positions of actors regarding the ETS price. The positions range from 'high price on all carbon emissions' (similar to a carbon tax), over 'medium price on some emissions' (the situation created during Phase 3 of the EU ETS), to 'no price on carbon emissions' (as was the case in Phases 1 and 2 of the EU ETS, and wanted by fossil fuel supply companies and by carbon-intensive industrial sectors like steel, cement, chemicals). 
Most climate NGOs got entangled in the EU ETS shadowboxing, and deliver advices to cure the system, for example: Carbon Market Watch (CMW 2019): 'Avoiding A Carbon Crash. How to phase out coal and strengthen the EU ETS?' A noticeable exception is Friends of the Earth (2013), calling the EU ETS "uncertain, ineffective, and unfair" and "no amount of fiddling with the ETS will make the system fit for the challenge of tackling the climate crisis". The position of Corporate Europe Observatory (CEO 2013) is similar.

The positions of the electric power industry and the EU Commission are similar in defending 'what exists': a medium price on some emissions. One caveat: the Polish electric power industry, mainly coal-based, was for long at position 11, joining the fossil fuel industry and emission-intensive industrial sectors. Business federations are placed at position 10 because they mostly criticize taxes; however, particular business organizations may climb higher in the ranking (with growing awareness of irreversible climate change, more companies - mostly not in the energy business - have eye for $[\mathrm{Ce}=0])$.

The EU Council favours lower prices than the Commission does, and EU's Parliament (at least its Environmental Commission) favours higher prices, but, internal and triumvirate compromising rings in centre-fugal forces. Figure 7.8 is tentative, showing that positions on EU ETS CP diverge significantly [Chapter 3; Figures 3.1 and 3.5].

\section{Positions beyond the EU ETS: Friends of the Earth; Climate activists; non climate NGOs; Corporate Europe Observatory}

1. CAN-Europe, Greenpeace

High Price on all carbon emissions

2. WWF

3. Carbon Market Watch, Sandbag

4. Non energy-intensive industries, open for change

5. Finance sector

6. EU Parliament

7. Electric power industry, EU Commision,

Medium price on some emissions

8. EU Council

9. ETS industries with shallow abatement costs

10. Business federations

11. Oil \& Gas, Coal industry, Steel, Cement, ...

No Price on carbon emissions

Figure 7.8 Positions of actors regarding ETS price on carbon emissions 


\subsection{The EU ETS policy arena}

The Policy Arena deals with the conception and design of the EU ETS forthcoming from "rational decisions in a context of political and economic institutions" (Banks and Hanushek 1997). The conception period started after COP3 (December 1997) and was finished by the EC's green paper on ETS (March 2000). At that time, most literature on emissions trading refers to the USA $\mathrm{SO}_{2}$ policy for the electricity sector (Tietenberg 2000) [Chapter 4], with a few papers on $\mathrm{CO}_{2}$ reduction, such as Goulder and Schneider (1999).

$[\mathrm{Ce}=0]$ is dawning at the horizon because climate collapse is a path of nonnegligible likelihood (IPCC, WG1 reports; Weitzman 2013). It is understood that $[\mathrm{Ce}=0]$ means the end of the fossil fuel industry, a life-threatening challenge for carbon intensive industrial activities and for giant electric power generation companies, heavily dependent on thermal power from fossil fuels or nuclear power reactors. In 1997-2000, none of the three groups had answers ready. They only had common goals: 'earn above average returns, maintain $\mathrm{BaU}$, avoid taxes on $\mathrm{CO}_{2}$ emissions, postpone decarbonizing investments'. Delay effective climate mitigation policy is the kernel of the strategy followed by the triumvirate of company clusters. However, for the common good, accelerating $\mathrm{CO}_{2}$ emission reductions is crucial: the question is no longer IF $[\mathrm{Ce}=0]$, but WHEN.

The controlled companies are the major players in the EU ETS act [Section 7.4.1], exerting discursive power via 'Stakeholder Masterminding' [Section 7.4.2]. It is shown that evidence on the Symbol and Narrative about Cap and Trade (CaT) is contentious, not effective [Section 7.4.3]. The Europe's electricity companies' role in the EU ETS is clarified [Section 7.4.4].

\subsubsection{Controlled companies as major players}

The overview of actors [Figure 7.7] shows on top the triumvirate of economic actors: oil \& gas companies, electricity companies, and other energy-intensive companies (steel, cement, chemicals, and similar). They represent the dominant Interests, and did take the rational decisions to protect and advance their Interests.

As corporations behave, they pursue Ebillion profits (Volberda et al. 2011), in case by minimizing the expenses of the coming up climate mitigation policy (and when occurring the opportunity, cash extra revenues from it). This behaviour is a salient component of the neoclassical economics doctrine, as motor for the functioning of carbon markets. However, giant companies evidently prefer Ebillion returns from their core business activities above scanty €millions from fringe emission permits trading.

A common concern of the companies in the triumvirate is safeguarding the company's business model, i.e., $\mathrm{BaU}$ continuation of activities and realization of the next-years plans as approved in the latest company board sessions. "Trans National Corporations' default mode is to defend status quo or at least 
delay change as long as possible" (Green 2016, p. 165). Part of BaU is: delay de-carbonization and avoid meaningful pricing (taxing) of carbon emissions.

By the end of the 1990s, the signals about climate change were publicly not as alarming as they are in 2020. Nevertheless, the UNFCCC was adopted in May 1992 and entered into force on March 211994 (www.unfccc.int). Giant companies investing in equipment lasting 40 years or longer, adopt a strategic horizon of around 40 years in the future; in the 1990s they understood what $[\mathrm{Ce}=0]$ means to their $\mathrm{BaU}$. The impact of $[\mathrm{Ce}=0]$ differs for every economic sector (Goulder and Schneider 1999).

For the fossil fuel companies, $[\mathrm{Ce}=0]$ equals the end of usual business, at least a drastic decline when activities shrink to delivering coal, oil and gas as materials only. Count the $\$$ billions losses of $[\mathrm{Ce}=0]$ scenarios, to weigh the related Interests. BP, Shell and other oil and gas majors have explored the RE sector, but did not stay for long; seemingly RE is not their cup of tea. Hence, their rational behaviour is engagement in the climate policy debate and conception for delaying de-carbonization and precluding carbon pricing (taxes) on all end-uses of fossil fuels. The effort for an overall ban on taxing fossil fuels is for saving their vending markets and for remaining the sole absorber of the rents [Section 7.2.4, Figure 7.6].

For electric power generation companies, $[\mathrm{Ce}=0]$ holds challenges and opportunities. Part of the Indispensable energy-technology transformation is maximum electrification, resonating the 'everything electric for everybody' sector slogan of the $1950 \mathrm{~s} / 60 \mathrm{~s}$, related to the 'too cheap to meter' nuclear power slogan. However, by some efficiency lasting from the begin 1980 years [Section 7.2.2] and the Internal Electricity Market starting in the 1990s, power generation capacities were in excess.

Sunk investment in large-scale nuclear and fossil fuel (coal, natural gas) fired plants was the main concern of most giant companies in Europe (EDF, RWE, E.ON). Defending the own position in liberalizing markets was a primary goal, and attention for de-carbonization was low. On carbon pricing, the Interests of the giant power companies diverged, depending on the composition of their generation park. The hydro \& nuclear capacity owners were rather in favour or indifferent; the coal and gas plant owners in Germany, Poland, UK, Spain were fiercely or modestly against carbon taxes. Electric power companies adopted a soft anti-tax position, without voicing it loudly.

Given their habit of meddling in political life at home, and widening their territory to Europe through plant acquisitions, electric power companies were eager to be involved in the conception of new EU energy and climate policy instruments, as of support mechanisms for any option generating power (renewables, CHP). Section 7.4.4 highlights the rollercoaster path of the electric power sector, ending in a starring role for continuing the EU ETS play in its Phase 3 and planned Phase 4.

The manufacturing sectors (iron and steel, cement, chemicals, non-ferrous metals, minerals, pulp and paper, etc.) are sui generis heterogeneous, organized in various sectors and subsectors. Since the 1970s, manufacturing companies with 
significant solid, liquid and gaseous waste flows experienced regulation by emission permits. Large emitters could develop a dialogue with regulatory agencies to increase flexibility for obtaining higher efficiency in the abatement efforts.

During the years of the EU ETS conception, most industrial companies were not in favour of the ETS, indifferent or opposing. The engineeringtechnological staff, generally running the environmental departments for developing abatement solutions, opposed the trade for a long time [Section 7.3.4]. Soon, it became obvious that ETS had little to do with abatement technology and innovation. Consequently, handling the EU ETS shifted to the financial and legal departments of the corporations. BaU could continue, with an additional area for the financial managers pursuing maximum revenues and minimum expenses in permits trading. The companies' focus was to avoid overly diligent regulators loading the company with decarbonizing obligations or charging carbon taxes on emitted volumes of GHG.

The danger of 'carbon leakage' is the main shield. Some NGOs consider this as a fake argument. However, the argument is valid, but the danger of carbon leakage did not materialize, because the industrial companies did face neither diligent regulators, nor carbon taxes. On the contrary, by obtaining lavish donations of free permits, some companies could cash extra profits at the exchanges with dealing the fringe of their permit stocks.

Like the other members of the triumvirate, also the energy-intensive industrial sectors were pursuing $\mathrm{BaU}$ and undated delay in deep decarbonizing transformations. In the period 1997-2000, companies oriented on low-carbon goods and services were few, not endowed with ample financial resources and missing political leverage. The mid-1980s carnage [Section 7.2.2] had driven efficiency and renewable options in small pioneer niches, with policy declarations showing more talk than walk.

The leading corporations had to create an instrument, painless for their $\mathrm{BaU}$ activities and plans, under a flag of superior climate policy for addressing UNFCCC commitments. Experienced policy influencers know that holding the pen of the initial concept is far more effective and efficient than amending launched drafts. ${ }^{6}$

The table was ready for the design of a flagship: the captain should be a high-ranked EU official - the visible proof that the final word was with a public office. Once the flagship was launched, many experts and advisors, pointing to all directions, manned its bridge. Since the launch, crew in the machine room has been busy with continuous adjustments and adaptations. As is the case in the maritime sector, shipping companies (not on board) hold the command, decide the routes, and capture the profits.

A high ranked Ph.D. in economics was available and converted to emissions trading after the EC proposals on energy-carbon taxing were blocked by the triumvirate corporations in the mid-1990s, and after COP3 (Kyoto 1997): "Jos Delbeke, Head of the Climate Change Unit, EC (DG ENV), Brussels" (EC 2000, p. 5). He was the ideal front captain-caretaker of the flagship and became a vocal advocate for the EU ETS. 


\subsubsection{Stakeholder masterminding (SM)}

In the 75 years since World War II, powerful companies changed roles and outfits for sharing in the governance of public affairs [Section 7.2.1]. The evolution in most countries of the EU (limited to Western Europe until 2004, year of accessing by Eastern European countries) may be typified as 'technocratic rule' during 1945-1980, 'controversial debate' during 1970-1995, and after 1985, transition to 'stakeholder masterminding'. Periods overlap with the three types co-existing within and across countries. Depending on the alertness of the constituency and the vitality of democratic institutions, controversial debates occur with the visible power of 'technocratic rule' and with the hidden power of 'stakeholder masterminding'.

Stakeholder masterminding (SM) is a new term to describe how powerful interests occupy the nerve centre in a regulatory policy process, such as the EU ETS. SM adopts the outfit of partnership in addressing a particular case of high societal interest. The various interest groups of relevance for the case may participate in the partnership as stakeholders, although some in the inner circle, others in the outer circle. The society's formal rules for decision-making are complemented with informal rules based on the partners' inputs (know-how about the case; extent and weight of their networks; resources in money, staff, capability in quick problem-solving, assuming opportunities, etc.). As far as I know, SM is not named as such for exercising discursive power. Fuchs (2007, pp. 146-153) reviews several attributes of discursive power characteristic for SM, which offers most clarification on the positions, events, and results in the conception, launch and life of the EU ETS. Her analysis is most helpful in understanding the power play making the EU ETS to what it is.

SM offers significant advantages for the major players described in Section 7.4.1:

- Stakeholders are invited to the 'comitology' meetings of "experts that, among other things, decide on detailed implementing measures for EU legislation" (EC 2003, Article 23; Peeters 2008; Lundy 2017, p. 27).

- The corporations can silently take over where and when politicians 'fail' in matters of high interest for the corporations (Vatn 2018).

- Such takeover is provisory ruling without formal investiture, hence no responsibility, nor liabilities.

- The Emillions lobbying budget made up of "financial resources - and the organizational, technical, and human resources that come with it" (Meckling 2011, p. 37) are used in an efficient way.

- SM executes invisible power, and secrecy is a major factor of success in protecting the Janus function of the ETS (on the one hand, shielding the triumvirate of companies from effective regulations; on the other hand, a showcase of supreme GHG emissions reduction instrument [Chapter 3]).

Conceiving a policy instrument reconciling water and fire is like squaring the circle. Additionally, every-growing evidence of irreversible climate change 
contracts action freedom for $\mathrm{BaU}$, with $[\mathrm{Ce}=0]$ as the inevitable end of using fossil fuels for conversion in thermal energy. A large part of civil society is attentive for climate change and for the policies addressing it. Policies must appear (if they can't be) trustworthy to acquire and preserve sufficient legitimacy.

The challenge for the ETS promoting corporations was to deploy and maintain a perfect hermetic discourse, meanwhile avoiding sterile dogmatism and remaining open for deliberative imagination. Meckling (2011) offers theory and empirical evidence about the crafted carbon coalition supporting and advancing the agenda. However, his analysis needs complements of deviating insights and inferences. For example: Meckling (2011, pp. 195-196) typifies the EU ETS as a

normative compromise instead of regulatory capture [because] Governments and a few NGOs equally acted as policy entrepreneurs for emissions trading with their own interests in mind [although] there is strong evidence that the design process of cap-and-trade schemes has to some extent fallen prey to regulatory capture.

SM assigns different interpretations to what happened and is happening in the EU since COP3 (1997). For instance: the non-corporate members of the carbon coalition were the minimum necessary to make the emissions trading CaT discourse sellable and the stealth realization of the corporates' anti-tax and $\mathrm{BaU}$ agenda feasible. The few NGOs can be seen as Baptists (Yandle 1999). The EC is indispensable as the formal public regulator.

Designating the corporations as Bootleggers falls short in covering their real role. SM sets up informal participative coalitions, with many participants [Figure 7.7]. In such Noah's Arks, the corporations play elephant. Mice are partners for obtaining the societal stamp of diversity. This means: the power balance in participative coalitions is very uneven, and the elephant/mice power ratio is worth keeping in mind during evaluation.

Assembling the various pieces of the EU ETS game delivers Figure 7.9, helpful as map for the following explicative text in this section and in Section 7.4.3. The assemblage has benefited from Fuch's book about business power in global governance. As foundations of discursive power, Fuchs (2007, p. 139) identifies "symbols, and story lines, the provision of effective evidence and compelling arguments in the public debate". The four elements helped in ordering my analysis, however putting her adjectives 'effective' and 'compelling' in brackets. Even without effective evidence and compelling arguments, discursive power via SM can uphold the façade and create fuzziness for concealing the climate policy failure of the CaT utopia and of the EU ETS overall.

The eight-pointed star in Figure 7.9 highlights Stakeholder Masterminding as a central node in the discursive neural system. The symbol of the EU ETS is 'Carbon Price', notwithstanding the fuzzy content of CP [Chapters 1 and 2]. The CP symbol conceals 'money', the €billions reason of EU ETS's existence. 


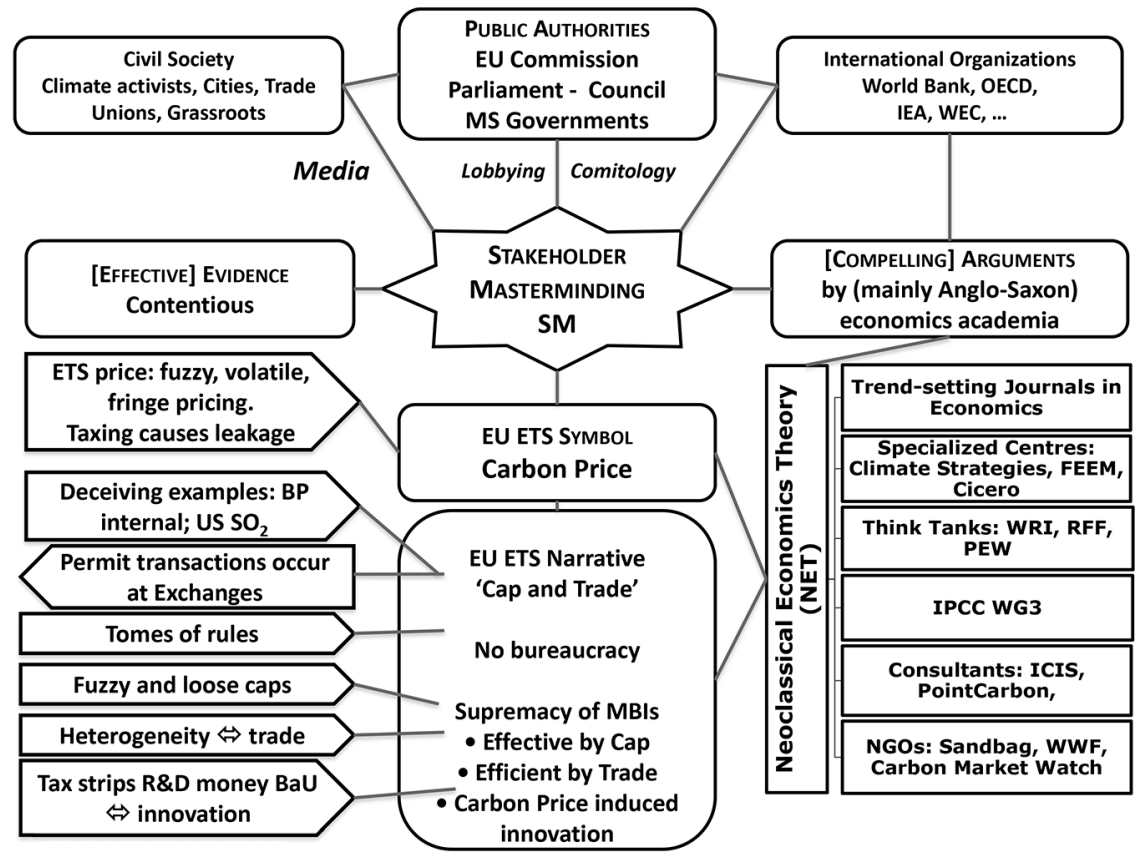

Figure 7.9 Discursive power masterminded by corporate stakeholders

[In the stack EVIDENCE Contentious: arrow pointing left shows valid evidence; arrows pointing right refer to disputed evidence discussed in Section 7.4.3].

The hiding was successful. The CP is continuously in the spotlight of economists and media, without clarity what the price effectively covers and what its impact is.

Deviating from the main ETS literature is the 'State of the EU ETS Report' (Marku et al. 2019) by "The report will not judge the success or failure of the EU ETS based on price levels" (p. 6), by "EU ETS prices have, as yet, been far from these levels" [for the EU ETS being a driver of change] (p. 20), and by assessing "monetary impacts" (pp. 22-25).

The narrative (Fuchs uses the term 'storyline') of the EU ETS at its conception was 'Cap and Trade' (EC 2000). On paper, CaT is a wealth of supreme properties for a policy instrument, evaluated on the criteria: environmental effectiveness, economic efficiency, equity and administrative feasibility (IPCC 2007 WG3, Chapter 13) [Table A.2].

- Environmental effectiveness. On paper, an imposed Cap on the summed emissions of a group of emitters guarantees a limit on the volume emitted, i.e., effective reduction of emissions would occur. This assumes the Cap is sufficiently strict for constraining emissions, and is never and nowhere porous (leaking emissions outside Europe to carbon-intensive plants, owned by EU ETS transnational companies). 
- Efficiency. On paper, arbitrage in CaT trading equalizes the marginal abatement expenses, so minimizes total expenses [Figures C.3 and C.4], i.e., reductions are made in the most efficient way. Further, 'dynamic efficiency' is assumed to be the result of innovation in mitigation technologies, what increasing, non-volatile CPs should induce [Chapters 3 and 6].

- Equity is mostly absent in the argument or treated in a poor and flawed way (for instance: polluters should be compensated for accepting regulation). COP3 global emissions trading installed the Clean Development Mechanism (Kyoto 1997) as mechanism to engage developing countries and transfer project funding. Next to salient abuses (Wara 2007), the overall system did not perform well (Lohmann 2006), and activity is now minuscule. Art. 6 of the Paris Agreement intends to revive such mechanisms, by 2020 without success.

- Administrative feasibility. On paper, CaT is free from bureaucracy, simple and light for politicians: they only have to set the cap, and then see how trade processes and solves the rest, such as setting a price on all carbon emissions administered under the cap. Market's invisible hand takes over. Inexperienced (slightly naïe) politicians were charmed by this fairy tale, also freeing them from tedious tasks, such as the nasty nearby task of opposing powerful companies wanting and advocating CaT. EU's official public authority turned servile to the emissions trading narrative as exponent of the MBIs supremacy in general.

'Compelling Arguments' for the EU ETS are based on neoclassical economics theory (NET), seemingly enough for obtaining the attribute 'compelling'. NET is the dominating paradigm in economics for longer than a century, guarded and extended by the (mainly Anglo-Saxon) economics academia. MBIs, emissions trading, CaT, and the GUCP [Chapter 2], root in 'value theory' (Debreu 1959), 'price theory' (Becker 1971), microeconomics, and derived welfare economics, environmental economics, ... (Samuelson 1948; Lesourne 1975; Pearce and Turner 1990). Theory is the cradle of MBIs, not the practice of economics. NET is a highly abstract processing of many assumptions with important ones that are clearly imaginary (Arrow 1974; Bromley 1990).

The EU ETS discourse hinges on the arguments of NET. The number and weight of NET's dependents [Figure 7.9] is impressive and frightening. Although many scholars deliver outstanding insightful studies on emissions trading (to name a few: Dallas Burtraw, Lawrence Goulder, Ian Parry, William Pizer, Tom Tietenberg), they do not question the constructed discourses' impact on delayed climate policy.

The trend-setting (also called 'top') journals in economics are bound by the neoclassical paradigm, and reject analysis that transgresses the paradigm's boundaries or that questions the validity of assumptions and dubious logics constituting the paradigm. As in other silly situations, whistle blowers are blamed, not the wrongdoers exposed. The NET commandments penetrated to all levels and corners of the industrialized capitalist societies. As a corollary the 
acceptance of MBIs and CaT is widespread and unquestioned (in the technocratic worldview of the 1950s, the acceptance of nuclear power was also overwhelming).

'Effective evidence' on lethal flaws in the discourse is discussed in Section 7.4.3. Here two short examples illustrate verbal expressions of discourse acceptance: one by IPCC, the other by Sandbag. ${ }^{7}$ IPCCs mission is to assess all available knowledge [Section 7.2.4]. The 2007 AR4 WG3 report was covering the literature up to 2005-2006. The SPM firmly states: "Tradable permits will establish a carbon price" (by discussion, source Chapter 13 formulated more prudent "Tradable permits can establish a carbon price") (IPCC 2007, p. 19; p. 747). The conviction was stronger than the evidence, and what the price covered was not mentioned. It illustrates the symbolic value of $\mathrm{CP}$ and its poorly defined content.

Sandbag describes its position as follows (my underlining):

Sandbag's take-away message: The ETS is a powerful policy instrument to help the EU make a meaningful contribution to fight climate change, but its current design features are limiting its effectiveness. Europe needs a single, unified policy instrument on climate.... A homogenous regulatory environment minimizes the impact on businesses. Emissions trading is the most workable policy option: It avoids prescriptive command-and-control regulations, and provides an incentive for continuous innovation. $\underline{A}$ carbon price set a priori does not ensure an agreed-upon target is achieved.

(Luta 2014)

With such a credo, it is difficult to test the foundations, limitations, and real performance of the system.

The NET paradigm is spread wider than the institutions shown in the stack [Figure 7.9]. Via academic curricula, every graduated economist is 'infected' by the doctrine, not at least the economics staff of International Organizations. Their adherence to emissions trading resonates globally, reaching the EU's Public Authorities and Civil Society. This resonance considerably lightens SM's tasks: support for or acceptance of emissions trading abounds. However, this abundance is no sufficient guarantee that the specific EU ETS Janus version fostered by SM will smoothly succeed or, in case unveiled, would last for long.

Successful advertising of 'Symbol and Narrative' requires continuous repetition, refreshment to preclude dogmatism, and proper reaction when adverse events occur. The media play an important role in settling and sinking beliefs in civil society. Important for SM is, for example, repetition of the flawed 'the EU ETS giant companies pay a price for every ton GHG emitted'. An acquiescent civil society is a necessary (although not sufficient) condition for bringing public authorities in line with SM's plans. 
Public authorities are a kaleidoscope of ideologies, constituencies, and relations with particular interest groups. Baron (1997) offers a comprehensive description of the regulatory issues, such as multiple principals, hierarchies, uncertain commitment, unforeseen contingencies, varied information, and more. SM approaches the EU and MS authorities via appropriate lobbying canals. For the EU ETS the legally created procedure of 'comitology' (Peeters 2008, p. 35; EC 2003, Article 23) is especially effective and efficient: the stakeholder experts co-create the expanding rulebooks of a 'simple' CaT utopia, steadily metamorphosing in a reality of complicated Donations of Permits and price fabrication via manipulated mechanisms. "Emissions trading may be viewed as 'regulation lite' by critics because it frequently involves controls and allocations that are designed not to frighten the horses of the incumbents" (Baldwin 2008, p. 27). It is realpolitik of accepting ETS because it can be implemented, because it allows the $\mathrm{BaU}$ and de-carbonization deferral agenda of the masterminding stakeholders.

A meritocracy of ETS experts flourish in the EU institutions, international consultancy companies, legal firms, specialized NGOs, academia, ... assembling faithful supporters of the EU ETS, which evidently are unconcerned about the opaque intricacies of the system (Voss and Simons 2014). They have grown to an extended, vocal group - seemingly independent - advocating the EU ETS without apparent links to the SM triumvirate of companies.

The last, but not least, part of discursive power analysis is investigating the evidence, a cumbersome task worth a separate section.

\subsubsection{Evidence on conformity of discourse with facts and theory}

For Fuchs (2007) discursive power is based on effective evidence. One may limit the evidence check to the performance of the object of the discourse, in case EU ETS. In this section evidence is tested on the validity of the Symbol and the Narrative. After placing 'effective' in brackets, the adjective 'contentious' is added [Figure 7.9]. Seven items are considered: one is in line with the CaT narrative; six are contradicting the EU ETS Symbol and Narrative. They reveal the deception in the discourse masterminded by the triumvirate of companies. The items are treated one by one, also referring to preceding chapters and sections.

1 Is the EU ETS price holding up the Symbol 'Carbon Price'? Chapter 1 introduces the economics behind CP with Sections 1.5 and 1.6 clarifying a number of different meanings assigned to CP. The NET's holy grail GUCP is utopian [Chapter 2]. The EU ETS discourse about pursuing two diverging goals with one instrument reveals its Janus character: one side free Donations of Permits (DoP); the other side ever increasing CP inducing innovation, an illusory wish [Chapters 3 and 6; bullet 7 below]. The Exchanges for trading permits daily post a price (spot or future delivery of permits) ${ }^{8}$. The prices were volatile, following the booms and 
bursts in the economy [Figure 1.2]. Since 2019, the MSR is intended to stabilize the CP within a price collar by administrative adjustments of the volume of permits in reserve via pacing the auctions, i.e., adjusting the Cap. So doing, Cap setting moves from the head to the tail of the CaT instrument.

The connection between the posted price and the financial incentive for abatement and innovation is ambiguous. It is weak or broken when the price only applies to the fringe of the industries' emissions [Chapter 6]. The lauded Ebillion market seems an addition of speculative, mainly shady intra-trade, activities. Whatever the posted exchange prices may be said to cover, in reality they only touch the fringes of the million tons of emissions of the EITE companies. In their trial to square the circle of DoP and CaT efficiency, neoclassical economists equate fringe pricing with marginal cost pricing [Chapter 6]. The EU ETS fringe price has crashed to zero in 2007 and was going to crash in 2012; this triggered bureaucratic interventions for price control to avoid recurrent denuding of the CP Symbol.

The principal purpose of CP as Symbol is to distract the attention from the Ebillions $\mathrm{BaU}$ booty the companies obtain by being shielded from diligent climate policy striving for timely $[\mathrm{Ce}=0]$. The observed discursive power of SM is amazingly effective in attracting attention towards the CP Symbol.

The danger of 'carbon leakage' is invoked for making the EU ETS cheap or profitable for the triumvirate companies. Hence, carbon leakage is not occurring so far (Ferguson and Sanctuary 2018). This observation is no valid argument for ignoring the danger of heavy taxing carbon emissions of EU's industrial activities causing leakage [Chapter 8]. No leakage so far only proofs that 'the industry does not have to pay a price on every ton of GHG emitted'. Bullet 5 argues that the EU ETS Cap is leaking by other pinches than CP.

2 CaT Narrative built on deceiving examples. As at COP3 in 1997, the US $\mathrm{SO}_{2}$ trade program was touted as the effective evidence of the supremacy of emissions trading. The experience available from the program was indeed an opportunity for learning. An extensive and intensive investigation without ideological bias would have revealed the particularities of the $\mathrm{SO}_{2} \mathrm{CaT}$ experiment, and the huge differences with the EU-wide carbon emissions CaT concept. Selling the CaT concept to the public and defying sceptics, made ample reference to the $\mathrm{SO}_{2}$ trade program, deliberately or unconcernedly skipping the learning opportunity [Chapter 4].

In 1999, BP launched internal carbon trading among $\mathrm{CO}_{2}$ emitting activities in its facilities: $8 \%$ of the emissions were cut with profit, i.e., implementing low-hanging abatement options dissolved X-inefficiency. The BP case levered the UK emissions trading system, transferring $\mathcal{E}_{111}$ millions from the treasury to the participating companies, and attracting interest from the City of London (CEO 2009). It boosted the dissemination of the CaT narrative, concealing the 
huge differences between an internal company system and the EC's ambition for a wide, encompassing scheme (EC 2000).

3 Transactions in permits occur at Exchanges. Daily prices of emissions permits posted by the EEX and ICE-ECX Exchanges are effective evidence of some exchange activity occurring. The official information source about transactions is the EUTL (EU Transactions Log). It seems an interesting field for PhD researchers. With referencing to other authors, Jong (2018, p. 20) confirms "three deficiencies: (i) power sector installations cannot be precisely separated from the EUTL industry category 'Combustion of fuels' category, (ii) EUTL allocations do not reflect New Entrant Reserve allowances or other allocation adjustments, and (iii) the EUTL-specific industry categorization can attribute installations to industries different than those of their parent companies". Transactions are not specifying price, neither type of contract (spot, OTC, or derivatives). The parties executing a transaction mention a code and freely chosen name, not necessarily linked to specific companies. "The energy sector has the largest share of inter-firm trade in the EU ETS", and "trades were systematic repurchases and resales (...) responsive to market arbitrage opportunities” (Jong 2018, p. 80, p. 115). Independent monitoring of the transactions is made almost impossible. The opacity, fuzziness, and loopholes of the database are not convincing of a healthy permits exchange by companies equalizing marginal abatement costs, to install overall efficiency, as NET assumes.

4 Tomes of rules for keeping the EU ETS flagship afloat. The announced stunning simplicity of CaT was related to the neoliberal shift in power toward transnational companies advertising markets as the panacea solution for governance problems (Wolin 2008). However, the EU ETS manifests a growing bureaucracy, puzzling scholars dazed by the CaT narrative. When it is understood that the permits market is but a façade, spontaneous market forces are missing and the invisible hand is lame. The visible hand of public authority must take over in metamorphosing the CaT utopia into something more realistic, such as messy permit assignments and messy price controls, while upholding the artificial market façade.

Since 2002, I have spent numerous research days (adding up to a few years) for processing EC Directives, regulations, presentations, and reports, of the EC, stakeholders, NGOs, think tanks, and hundreds of academic publications on ETS. This topic is a black hole swallowing scarce public staff and resources specialized in economic policy instruments. Voss and Simons (2014) coined the term 'instrument constituency' for the many and diverse actors in the sludge stream of the ETS. Squandering valuable human, organizational and financial resources is a negative externality of the EU ETS. The resources are needed for developing decarbonizing technologies and organizing effective mitigation activities. 
5 Caps are more fuzzy and porous than $\mathrm{CaT}$ one-liners pretend. The CaT narrative had and has a disproportional impact on environmental NGOs by the tale of the firm, immovable Cap on the summed emissions of the EU ETS participants. Guaranteed environmental effectiveness would indeed be a strong selling point. And the hope on emissions trading for also install global fairness created proposals on distributing equal permit packages over all world citizens (Meyer 1998; Bode 2004). Although phantasies about a global ETS persist (Baranzini et al. 2017), the EU ETS is limited to a parcel of not half of EU's assessed volume of GHG emissions.

The relevance of a Cap depends on what is covered and on how impenetrable the cover is. With all attention focused on eventual CP induced leakage, non-CP motivated leakage went largely unnoticed and unmonitored. The deindustrialization of Europe implied a move of carbon-intensive activities. Standard 'comparative advantage' by lower wages in developing countries is the main driver, with precaution against tighter climate policies in Europe as additional windfall profit. The share of China's total GHG emissions in 2004 related to production for export to Europe, and other rich countries, was assessed at 23\% (Wang and Watson 2007).

The EU ETS Cap setting corresponds to the created volume of permits. By lavish DoP the Cap did not cap emissions since the start of the EU ETS in 2005 until 2020. The generous Cap has perverse effects, as the 'waterbed' metaphor reveals: single emitters or emitting countries do not care about the own emissions, because the Cap keeps the total emissions volume under control. For example: 'flying across Europe makes no difference with taking the train, given both are covered by the EU ETS and the only thing that counts is the total emissions cap'.

6 Heterogeneity and transaction costs limit the range of trade. Arbitrage by trading emission permits for equalizing marginal abatement costs is the key of the announced efficiency trump of CaT. Bullet 3 documents the lack of reliable, verifiable data on permit trade in the EU ETS, and points to mostly financial speculative transactions. There is no evidence of exchange of permits obeying the textbook prescriptions of NET establishing the Lagrange optimum [Annex C]. Heterogeneity of the participating sectors makes trade with impact on the physical processes unlikely (confirmed by oral information from experts in steel and chemical companies). The disconnection of permit trade and physical emissions parallels the shift of responsibility for ETS affairs from the engineering-technological departments to the financial offices in large companies.

7 Business interests impede 'CP Induced Innovation'. Presumably the least contentious statement among all parties concerned about climate change, is the crucial role of innovation in mitigating $\mathrm{GHG}$ emissions to [Ce $=0]$. Therefore, the acceptability of a policy instrument is related to its force for 
pushing or pulling innovation. In the infinitesimal logic of NET, lowerpriced production factors substitute for higher-priced ones. This economic rational, plausible effect is also valid when pricing carbon emissions.

On paper is shown that stair-wise increasing CPs create a dynamic efficiency effect, implying innovations in abatement technologies and practices. The bottleneck of price-induced innovation is the €millions taxes stripped from polluters, which are expected to also spend €millions on R\&D and innovation. In theory, the 'doubling' bottleneck may be dissolved when the tax transfers (expenses for the companies; revenues for the treasury) are returned to the taxpayers as R\&D and innovation subsidies. However, companies distrust public authorities for cycling their Emillions. They also expect plain subsidies for R\&D and innovation in carbon mitigating technologies [Chapter 6]. The overall goal of the companies to continue $\mathrm{BaU}$ and postpone deep de-carbonization is not stimulating innovation in mitigation technologies and practices.

The seven points support that the evidence on the Symbol and the Narrative of $\mathrm{CaT}$ is more contentious than effective.

\subsubsection{Europe's electricity companies' rollercoaster paths and the EU ETS}

Describing a rollercoaster path is puzzling for the writer and for the reader. The fuzz multiplies when paths crisscross by the diversity of the European electric power companies, headquartered in different MS. With a bird's-eye view over the period 1997-2020, and the EU's territory expanding eastwards, only headlines are pictured.

In preceding sections, common characteristics of large companies were noted as pursuing above average returns, minimizing payment of carbon taxes, continuing business $(\mathrm{BaU})$, and delaying de-carbonization of their activities. This applies also to electric power companies, which are territorial anchored: their customers live in a spatial service area within the home country, within Europe. The companies are more exposed to scrutiny by the civil society; as utility providers they are also committed to that society. Significant shares of their assets are in infrastructure; their goods and services do not face international competition; power generation is the largest source of EU's carbon emissions (Bryant 2016). The EU ETS differentiated between the power sector and other sectors, codified in legislation for Phase 3 (Zapfel 2019).

In the post-war decades, the electricity supply business model was monopolistic, centralized top-down, based on large-scale power plants on command for reliably supplying mushrooming sales volumes. They were not amused with Independent Generators of Own Power (IGOP), mostly Combined Heat and Power (CHP) units on-site in industrial or service facilities and in cities with district heating. IGOPs decrease sales of the monopoly and disturb the top-down operational model. To minimize IGOP activity, power monopolies raised barriers for IGOP's grid access, technical and by peculiar electricity tariffs (Verbruggen 1990). Partnerships or joint ventures were an alternative for 
IGOP plants of medium size in oil refineries, chemical facilities, and similar. Over the period 1997-2020, CHP-IGOPs were complemented and superseded by RE-IGOPs, increasing the importance of public regulation, fair grid access and fair electricity pricing rules [Chapter 8].

Since the 1990s, the Internal Energy Market (IEM) enlarges the territory of European electricity companies. Then deeply divided about the why and how of the IEM, they could not stop the USA-UK driven liberalization gulf (Joskow and Schmalensee 1985). Once the dike broken (EC 1997), the oligopolies fostered expansion beyond the own territory, retarded 'unbundling', requested compensation for 'stranded assets', mocked fair 'reciprocity' in economic relations, etc. (Verbruggen 1997). In the years 1997-2005, IEM challenges and opportunities dominated EU power companies' agendas.

Mitigating carbon emissions was left to public authorities and their local utilities, which pioneered energy efficiency and renewable energy projects. At the end of the 1990s, most giant electric power companies favoured a nuclear renaissance, looking with disdain at infant RE technologies ("we do not deal with peanuts capacities less than $20 \mathrm{MW}$ ", a power company manager once answered me).

Although IEM hagiography pretended that the market suffices to address all energy issues, 'ancillary' Directives designed policies on promoting energy efficiency and services, CHP, buildings energy efficiency, and, as discussed in Chapter 5: renewable energy (EC 1999; 2001; 2009; EU 2018b). The electric power oligopolies were present during the law-giving processes, for example very influential on the CHP directive (EC 2004), however missed the RE boat launching wind and PV technology. The small RE boat developed to a numerous flotilla, this mainly thanks to the market creation with FIT financial support mechanism adopted in Denmark and Germany [Annex D]. The EC (1999) wanted a market in tradable green certificates (TGC) to promote RE, and economists at the front line of CaT advocacy heavily opposed FIT. Danish and German citizens and politicians applying FIT have pulled wind and PV technologies over the innovation 'valley of death' to maturity in a decade. It placed the EU at the head of RE's technology and industry until 2015 (see below). These laudable achievements are still today negated or criticized by ETS advocates.

The EU ETS did not challenge $\mathrm{BaU}$ and did not induce decarbonizing innovations. During Phase 2 of the EU ETS, European power companies ordered large-scale coal-fired power station construction in Germany and in the Netherlands specifically: ENGIE $800 \mathrm{MW}$ in Rotterdam; RWE 1560 MW in Eemshaven; E.ON (later UNIPER) 1070 MW near Rotterdam; commissioned in 2015 and 2016. EDF stuck to its nuclear option. Building coal plants corresponded to the low or no interest of big power companies in peanuts wind and PV. They were cashing significant excess profits on the RE TGC systems enacted in a few jurisdictions of the EU [Chapter 5], as well Ebillions excess profits on DoP in the first years of EU ETS (Sijm et al. 2006; Verbruggen 2008). 
Take-away points: First, the power companies pursue above average returns and cash €billions when they can. Second, power companies can skim Ebillions per year from their customers, mostly from the captive medium- and low-voltage customers. Similar skimming is not feasible for industrial companies without a captive clientele and submitted to international competition. Hence, the electric power companies are interesting partners in squaring the ETS circle on financial transactions. They obtain €billions by charging the fringe price of the permit exchanges on the electricity consumers.

A part of the Ebillions is spent at permit auctions providing 'auction income' for MS. The MS may use part of this income for rebating EITE companies the carbon charges (indirect costs) on their electricity bills (a practice observed in Phase 3 of the EU ETS). Via these money circuits, the non-ETS electricity consumers are the ones paying the expenses of the EU ETS. Exponential growth of RE supply will dry up the circuits in the future. Nonetheless, the EU ETS Phase 4 (2021-2030) is arranged, similar to Phase 3, with additional price control via the Market Stability Reserve (MSR).

In the period 2008-2012 (Phase 2 of the EU ETS), important events changed the landscape. First, wind and PV technology were developing incredibly fast, for example in 2008 a downward kink in the declining investment costs of PV amazed foe and friend. Without urgent decreases in FIT support, free riding mushroomed. The once called RE peanuts turned into millions of IGOP nuts hard to crack by incumbent power companies. Second, the disaster in Fukushima Daiichi (March 2011) exposed again the calamities of failing nuclear technology. Germany phasing out NP, nuclear renaissance evaporating, the business models of most incumbents turned obsolete.

Third, too generous DoP, economic recession in 2008, and inflow of CDM credits caused a flood of excess EU ETS permits in Phase 2: the CP crash to zero in 2012 was certain without administrative intervention of its curators. The ETS Directive of 2003 (EC 2003) drew five-year CaT periods, for pondered tightening of the sequential emissions caps. In 2012, the fence for closing Phase 2 was removed for the unhindered flow into Phase 3 of the banked surplus of more than 2 billion permits. This circumvented the dooming zero price crash end 2012 but loaded Phase 3 with the curse of surplus permits (a pretext of endless proposals, reports, discussions, etc. keeping the EU ETS meritocracy busy and the corporations at their ease).

More challenging for the giant power companies is the invention and deployment of a business model adapted to the realities of the $3^{\text {rd }}$ millennium. Compared to the fossil and nuclear fuel companies, they live on a bed of roses, nonetheless with some prickles. The roses are the Indispensable energy and technology transformation with electric power the backbone and dominating energy carrier of the future [Section 7.2.4], and the fast-growing availability of wind and PV electricity supplies at ever decreasing expenses (IRENA 2020). 
The prickles are the ineradicable IGOPs generating (a significant share of) their own demand for electricity. Citizens, communities, grassroots initiatives, and cooperatives trigger new societal preferences. At that time in Germany, citizens own about half the installed renewable capacity and a growing share of renewable electricity generation is forthcoming from small-scale projects (Schleicher-Tappeser 2012; Haas et al. 2013).

The progressive aisle of the power company band understood that the future electricity supplies would become exclusively renewable, mostly harvested from ambient currents wind, light and water. For saving their centralized, topdown and financially privileged business, clipping grassroots blooming was due. The lobbying machinery worked in overdrive.

In 2014, Germany's Renewable Energy Act (EEG ${ }^{9}$ 2014) was adapted in deliberation with the EC to rein in 'excessively' rapid renewable power deployment and accelerated growth. This suited the agenda of major power companies and the striving by German industrial companies to minimize their contribution in covering the FIT support.

The CEOs of the largest European energy companies defend their core assets. On March 19, 2014 under the aegis of the Magritte Group (www. gdfsuez.com), they issued a "call for government and state heads to implement immediate and drastic measures to safeguard Europe's energy future. Nine recommendations to reform Europe's energy and climate policy so as to achieve the three key objectives of competitiveness, sustainability and security of supply". These are complemented by three proposals.

The proposals are:

i preference for "mature renewables in the regular market",

ii "priority to the utilization of existing competitive power capacity rather than subsidizing new constructions", and

iii "restore the ETS as a flagship climate and energy policy".

The proposals slowed down the deployment of, mainly decentralized, renewable power, and of the further development of so far non-mature technologies. Agora Energiewende and Sandbag (2020 p. 13, Figure 3-1) show EU's RE growth curve halted in 2015-16.

On April 9, 2014, the EU adopted new "Environmental and Energy State Aid Guidelines for 2014-2020" (EC 2014). The Guidelines make bidding systems the central support instrument for renewable power in the future and ban feed-in tariffs for most situations, thus truncating a key instrument. They consider exemptions from renewable energy surcharges for industrial companies as state aid and require that these companies make a contribution, which however may be limited to a fraction of the rates small customers pay. 
On July 23, 2014 the EC accepted a compromise German EEG 2014. The overall goal of these guidelines is to reduce the supposed burden from renewable power support in the name of European competitiveness and affordability of the electricity bills. The likely intention is to contain renewable power growth to lower levels than so far, and to give big corporate operators a better position to replace IGOPs as chief generators of renewable electricity.

On April 9, European Commissioner Joaquín Almunia, then responsible for competition policy, stated: "Many renewable energy sources have reached a scale and a level of maturity that allows them to compete with other sources". This statement would undoubtedly hold if 'other sources' were priced at total costs, including externalities and risks, and if the available energy infrastructures and institutions suited renewable energy. However, this is not the case and something that hinders the establishment of a level playing field. Renewables are on the way to competitiveness even so, but in Europe their progress was slowed. Since the policy break in 2014, the EU lost momentum in RE development and leadership on the global RE scene.

To take away all doubt about electric power companies' lobbyism: on 8 October 2014, Almunia approved intended loan guarantees and price commitments for UK's nuclear power project Hinkley Point C. A level playing field does not seem to be required for new construction of nuclear fission power, clearly not mature after 65 years of generous subsidies.

In 2015, 12 colleagues published the above analysis in the International Journal of Sustainable Energy Planning and Management (Verbruggen et al. 2015). Already in summer 2014 a Viewpoint was submitted at Elsevier's Journal Energy Policy addressing the scheming under way. Editor Nicky France, who over decades developed Energy Policy to an open scientific platform, was however fired and replaced by two industry friendly editors (one ex Shell). The corporates' putsch, swarming and intrigues then experienced, merit a separate political economy analysis. ${ }^{10}$

What often happens with dinosaur companies, they reacted too late. Wind and PV passed the 'innovation valley of death' since 2008 and the technologies surf on most new inventions and innovations happening in the dynamic technological era of the $3^{\text {rd }}$ millennium (Belton 2020). The only future of energy is harvesting renewable sources. Except EDF, entangled in the nuclear labyrinth, all EU power generation companies are now only investing in the large-scale versions of wind and solar, and envision their control over system integration and balancing (via storage, back up, load management), consumer services, grid access and pricing issues, and more.

The outfit of the strategy to let centralized interests prevail over distributed IGOPs, will differ along the aggressiveness of the giant company. However, electric sector liberalization unbundled system control and operation from the 
other functions, such as generation. In this way, the responsibility for reliable (and sustainable) power supplies is with the independent system and network operators. The rearrangement of the electric power landscape is not finished; politics and high-quality, independent regulation play an even more important role than ever before [Chapter 8].

In the EU ETS, the situation of the triumvirate companies is quite comfortable. The inflow of more than 2 billion permits in Phase 3 (2013-2020) could be processed by the various industrial sectors (Marcu et al. 2019). The power companies' hoarded stocks could be valorised via electricity bills at prices posted at the exchanges in the range $€ 20-€ 25$ per permit after mid2018. In 2020, the ETS companies end Phase 3 with surplus permits augmented by the Coronavirus crisis. In principle the cards for Phase 4 are dealt (EU 2018a), with comitology tackling later operational problems.

The power companies hold the reins. Financially, they operate the money circuit related to the permit transactions: power companies purchase permits at the auctions; the auction bills are charged on the, primarily non-ETS, electricity consumers. By lack of transparent, verified data it is difficult to assess the volumes of rents (windfall profits) extra extracted from the captive electricity consumers. Physically, the decarbonized RE technologies in power generation are available and affordable, steadily improving in efficiency and decreasing in cost (IRENA 2020).

After their failing coal plant investments during Phases 2 and 3 of the ETS, the giant power companies switched to large-scale RE (offshore wind, MegaWatt PV fields, and similar), some adventuring in nuclear power (EPR reactor construction in Finland, France and UK; life extension of old stations). Given power generation stands for the largest chunk of ETS emissions, RE relieves the planned linear shrinking of the announced emissions cap, promising industry and fossil fuels sectors a third decade of $\mathrm{BaU}$ without deep decarbonizing.

There is one scenario problematic for the incumbent power companies: popular rebellion of more millions of captive electricity consumers investing in solar roofs and cooperative wind turbines nearby their communities. This likely scenario makes the giant electricity companies less relevant for generating power. Then the sources of fresh cash from the non-ETS electricity users would dry up, the money circuit could jam, and the deceiving CaT discourse denuded to what it actually is: DoP, free donation of permits.

The gone decades of precious time for addressing irreversible climate change by decarbonizing industrial activities, however, are lost forever.

An additional look at financial policy instruments: FIT financial incentives pulled wind and PV technology over the 'valley of death' to maturity in the first decade of this century [Annex D; Chapter 5]. In the second decade, the new era of energy harvesting from the ambient environment opened definitely; it is irresistible and irrevocable and substitutes for fossil and nuclear thermal power generation, because it is least-cost in all meanings: investments, risks, environmental, health, etc. (IRENA 2020). 
Neoclassical economists criticized FIT like hell (Frondel et al. 2010; Böhringer et al. 2014) because FIT disturbed the CaT utopia. The neoliberal interests could maintain a CaT façade for hiding their extension of a $\mathrm{BaU}$ reality. Now and in the future, the real conflict is about which RE reality will prevail: either centralized, top-down revitalizing the giant corporations, or distributed, bottom-up community owned. Only the latter is in conformity with global OCF-SD. Financial and other policy instruments play a central role in building the future reality.

\subsection{Permits trading in artificial markets}

A few aspects of the financial and market aspects of EU ETS are briefly considered in three subsections.

\subsubsection{Nature of the EU ETS permits}

This book uses the clear word 'permit' to emit a ton of GHG above 'allowance'. Also 'Donations of Permits' (DoP) signals clearer the unpaid character of the gifts, above 'allocations' with non-payment remaining unclear. Regulation by DoP was, and still is, the usual way to obtain free but moderated access by economic actors to commons such as land, water, and atmosphere.

All effective policies protecting open-access resources must limit use in some manner. Any limitations on use, however, create winners and losers: people who get more access versus those who get less, or people who pay more for their use versus people who pay less. This is true regardless of the mechanism- public or private, Command and Control or market-based - by which access is restricted.

(Raymond 2003, pp. 18-19)

Standard permit donations provide 'licenses to pollute' restricted in time and cancelled, if not been used. For tradable permits, Raymond (2003) introduces the term 'licensed property' as a not fully vested legal property right. The EU ETS assigned to the licensed property the status of 'financial product', traded on Exchanges and a source of moneymaking when DoPs are generous.

\subsubsection{Purpose of the EU ETS for EU's corporations}

Eluding the philosophical, legal, and economic debates about commodification of the commons (Page 2012), the ETS is not "a regime of accumulation under neoliberalism” (Lane and Newell 2016, p. 254). The few Ebillions 'windfall' profits, rent skimming, on too generous donated permits, are pocketed but are not the primary goal of the founding and fostering of EU ETS. The goals of the companies masterminding the EU ETS are very down to earth: continuing their $\mathrm{BaU}$ for the coming decade, next decade, following decade, meaning: no 
taxing of emissions, delaying real efforts in de-carbonization, above average returns in their core business.

There is neither evidence for Matthew Paterson's framing of "Emissions trading as a project has been, and continues to be propelled by the realization by powerful financial actors that here was a new commodity to be sold, new profits to be made" (quoted by Lane and Newell 2016, p. 254). Actually, the energy and industrial companies were keen to safeguard their own agenda. Financial actors have been active in Phase 1 and 2, but the interest of the City of London and investment banks faded (Meckling 2014, p. 571). The likelihood is high that financial departments of the energy (in particular power generation) industries control the financial affairs of the EU ETS.

\subsubsection{Shady EU ETS market}

The market (if any exist) is artificial. There is no natural demand, only a forced one by governmental regulation (Dales 1968, p. 803). When the rules (Cap) are lousy, so is demand. In theory, auctions would face the aggregate of the participants MAC curves [Annex C] for distributing the 'licensed property' rights according the willingness to pay of participants. However, by DoPs to the industrial activities, remain non-EITE industries or electric power companies as only buyers, flanked by speculative transactions.

Because of the significant extent of fraud and theft of tradable permits, the EC converted the permits' status to that of a financial product, supervised by the European Securities and Markets Authority (ESMA), and submitted to the Markets in Financial Instruments Directive (MiFID) and the Market Abuse Regulations (MAR).

In large companies, the EU ETS shifted responsibilities on climate matters from techno-economic, environment departments to financial departments.

\subsection{Economics critique on the EU ETS}

In preceding chapters, theoretical issues were addressed, such as: diversity and heterogeneity request specific approaches [Chapters 2, 4 and 5]; one cannot realize two divergent goals with one ETS exemplar [Chapter 3], price induced technological innovation does not materialize in the EU ETS; fringe pricing is not equal to marginal cost pricing [Chapter 6, Annex E]. All these findings affect EU ETS functioning and performance, as revisited here.

\subsubsection{Diversity and heterogeneity}

NET is ambivalent towards the reality of diversity and heterogeneity. On the one hand, they are the necessary factors for announcing huge profits when uniform carbon pricing is proposed on an amalgamation of heterogeneous emission sources. On the other hand, NET ignores diversity and heterogeneity ex-ante for silencing that uniform pricing of the intended amalgamations does 
not work or implies perverse effects (such as a race to the bottom of obsolete, non-sustainable technologies). Similarly, for the EU ETS: the conceived CaT [Section 1.2] intends a utopian inclusion of the most heterogeneous emission sources, but, in reality, ends in specific treatment of the installations one-byone or by homogeneous industrial sector activity. Moving from utopia to reality, the sacrosanct supreme efficiency by uniform pricing has been destroyed underway but remains on top as discursive symbol [Sections 7.4.2/3].

\subsubsection{Janus structure of EU ETS}

Chapter 3 presents the bare anatomy of ETS, including explicitness of the goals pursued by assemblages of particular ETS exemplars. The EU ETS strives to reconcile two diverging policy goals. On the one hand, atmospheric stability and cleanness by urgent and drastic reduction of carbon emissions by regulated companies, incentivized by high uniform permit prices. On the other hand, profit-protection of incumbent companies, emitting voluminous amounts of carbon. Such disparate goals cannot be realized with one consistent ETS exemplar.

Actually, masterminding stakeholders, being the vested corporations, have moulded the EU ETS as a shield against diligent climate policy initiatives, while protecting their goals: continue $\mathrm{BaU}$, no taxing of emissions, delay deep decarbonizing, earn money (this is reality). The other head of the ETS Janus is a façade created and hold-up by bewildering discourse [Section 7.7], on essential points telling the opposite of what is happening. It is discursive power holding diligent policymakers at bay, and paralyzing academics entangled in neoclassical assumptive utopia.

\subsubsection{Price-induced technological innovation (PITI) not materialized in EU ETS}

In first order, PITI evidently did not materialize, because the posted CPs in the EU ETS were volatile, low, and moreover not applied on the industries' emissions. In second order, arises the question why no innovation inducing $\mathrm{CP}$ is applied? The answer is related to the first goal of every corporation or firm: 'earn above-average returns' (Volberda et al. 2011).

The PITI theory assumes that corporations would be willing to pay €millions in taxes to some public treasury and spend Emillions on inventions and innovations for decarbonizing their activities (decarbonizing being a non-core activity). Such double bill is a no-go for corporations.

On paper, there are propositions to recycle the carbon tax payments to the private agents who paid the taxes, reducing the Emillions to the ones spent on the decarbonizing itself. Corporations are suspicious about the recycling mechanisms on paper, and find the Emillions in decarbonizing lost money. They actually demand subsidies for $\mathrm{R} \& \mathrm{D}$, innovations and investments in decarbonizing, next to free permits in emissions trading (https://www.iea. org/articles/the-challenge-of-reaching-zero-emissions-in-heavy-industry). 


\subsubsection{Fringe pricing is an emperor without clothes}

Chapter 6 and Annex E explain the powerlessness of fringe pricing. Leaving theoretical fuzz aside: will a rational economic agent buy an efficient car when $\mathrm{s} /$ he receives free gasoline from January 1 to December 25, but is charged $€ 5 / 1$ for gasoline bought in the last week of the year? Every gas-guzzler will accept such deal. The regulated companies can live with such idiosyncratic pricing, additionally sweetened by the tradability of the permits, allowing Emillions 'windfall' profits for the dominating participants.

The above elements ask for immediate action on the EU ETS, leading to its end. However, the critique is not aiming at throwing the baby out with the bathwater: financial incentives are important levers in transforming activities and societies, and in particular sufficiently homogeneous circumstances permit trading may be a workable instrument.

Moreover, in the case of carbon emissions, there are pockets of emissions where global emissions trading may function, for example global civil aviation, or ocean-going shipping. The final end $[\mathrm{Ce}=0]$ should be included in the conception and design of any specific ETS system. In EU ETS, $[\mathrm{Ce}=0]$ is still nebulous after two decades, maintaining 2050 as the year to finally deliver.

\subsection{Bewildering EU ETS discourse}

By hegemonic and hermetic discursive power, stakeholder masterminding upheld and upholds the façade of the EU ETS as carbon market. A volatile, fuzzy, and ineffective CP is the Symbol that blinds the believers. The evidence of the CP Symbol and of the CaT Narrative is not effective as elaborated in Section 7.4.3 and also observed by other scholars, such as Spash (2010), Baldwin (2008), Lane and Newell (2016).

\subsubsection{Poor performance of the EU ETS}

By looking behind the façade, the actual performance of the EU ETS becomes visible. A check of the performance on main criteria [Table A.2] is summarized in Table 7.1.

The poor performance of the EU ETS seems no hinder for its advocates, quite remarkable for the many academic advocates. A reversal of means and ends is embedded in the EU ETS and is visible: the main concern is the instrument itself, proof that the imagined carbon market functions, at least does not collapses again. Thousands, having invested in the EU ETS as academic or as professional advisor, pursue the survival and continuation of the flagship they boarded.

In reaction to "Virus and solar cause record fall in $\mathrm{CO}_{2}$ " in April 2020 "some analysts are now calling for urgent measures to prevent the EU carbon market from collapsing" (EurActiv 2020, April 30). This points to shortcomings: the system is not robust when carbon emissions suddenly decline. 
Table 7.1 Observed performance of the EU ETS

\begin{tabular}{|c|c|c|}
\hline Criterion & Performance & Score \\
\hline $\begin{array}{l}\text { Mitigation } \\
\text { effectiveness }\end{array}$ & $\begin{array}{l}\text { Oversized and permeable Caps. Companies continue } \\
\mathrm{BaU} \text {; deferral of deep decarbonizing. No urgent and } \\
\text { drastic reductions of carbon emissions in sight: }[\mathrm{Ce}=0] \\
\text { is not embedded in the EU ETS. The } 2008 \text { economic } \\
\text { shock revealed fragility, not robustness. }\end{array}$ & 0 \\
\hline $\begin{array}{l}\text { Efficiency, cost } \\
\text { effectiveness }\end{array}$ & $\begin{array}{l}\text { No Cost-Benefit optimization; damage costs out of } \\
\text { scope and control. Equalization of Marginal Abatement } \\
\text { Costs at the various installations is not realized in a case- } \\
\text { by-case treatment. Fuzzy price signal; some transactions } \\
\text { in financial 'licensed property', without clear link to } \\
\text { physical emissions. }\end{array}$ & 0 \\
\hline $\begin{array}{l}\text { Innovation, } \\
\text { dynamic } \\
\text { efficiency }\end{array}$ & $\begin{array}{l}\text { Price-induced innovation is not observed; on the con- } \\
\text { trary, power companies were building coal plants during } \\
\text { Phase } 2 \text { and Phase } 3 \text { of the EU ETS. Influential new } \\
\text { technology coming from RE, developed outside the EU } \\
\text { ETS by FIT financial incentives (the tried TGC market } \\
\text { failed) [Annex D; Chapter 5]. }\end{array}$ & 0 \\
\hline $\begin{array}{l}\text { Administrative } \\
\text { feasibility }\end{array}$ & $\begin{array}{l}\text { Incredible bureaucratic mess. Lack of transparency in } \\
\text { permit ownership, trade, money sources and sinks. } \\
\text { Metamorphosis of CaT in its opposite: DoT and price } \\
\text { control via MSR. Opaque 'comitology' and lobbyism. }\end{array}$ & 0 \\
\hline Equity & $\begin{array}{l}\text { Controlled companies gain 'windfall' profits via lavish } \\
\text { DoT and rent skimming. Non-ETS electricity con- } \\
\text { sumers, households, SMEs and institutions like schools, } \\
\text { hospitals, and so on, pay €billions lubricating the system } \\
\text { that saves a CP façade hiding BaU activities. This is a } \\
\text { case of reverse redistribution. }\end{array}$ & 0 \\
\hline
\end{tabular}

Note: Score goes from 0 (minimum) to 5 (maximum).

While declining carbon emissions should be an element of satisfaction, it is a pinch of sorrow. EU ETS curators are mainly concerned about the CP Symbol of the inadequate instrument. The Symbol is doing well in reaching almost $€ 40 /$ permit in February 2021: captive non-ETS electricity consumers may experience the impact.

\subsubsection{Explanations for cognitive dissonance}

Cognitive dissonance (Spash 2010) is a psychological explanation (beyond my engineering-economic training). Prins and Rayner (2007, p. 22) point to "many obstacles, ranging from administrative inconvenience, to psychological and emotional barriers. It is difficult to abandon profound investments not just of capital, but also of effort and conviction, or of reputation and status". Instructive are other sophisticatedly constructed advocacies, like the nuclear power case (Gamson and Modigliani 1989; Verbruggen and Laes 2015) [Sections 7.2.1/4/5]. 
Nonetheless, the EU ETS advocacy outstrips all. Its exceptional success in setting up the EU ETS, keeping its façade upright for sixteen years, while its performance is deplorable, requires reflection and deliberation. Following list of explanatory factors may be a start of understanding:

1 The major players (the triumvirate of companies [Sections 7.3.2, 7.4.1]) signify an aggregate of enormous power, influence, and interests. They are the champions of the industrialized steam era, based on fossil fuels and thermal power with huge flabs [Figure 7.5], standing for jobs and GDP in the globalized, neoliberal societies governing the world today.

2 The major share of global GHG emissions is due to activities of the major players, in delivering and using fossil or nuclear fuels. The energy transition of the $3^{\text {rd }}$ millennium [Section 7.2.4] extinguish the major players' businesses. For the fuel companies, adaptation means ending the incumbent business and creating another one; for the others deep decarbonizing is challenging too. The stakes for the major players are incredibly pertinent and weighty.

3 The 'Zeitgeist' (mood) of neoliberal prevalence and "contraction of the public domain due to the expansion of the market domain" (Fuchs 2007, p. 141; Wolin 2008; Vatn 2018) were levelling the entry for MBIs. In the 1990s, I observed once creative, proud public servants crumble to market servile valets. Neoclassical economics theory revived, politically coupled to the neoliberal agenda. Emissions trading received broad, unreserved and lasting support of the dominant economics colleges, foundations, publishers, etc. It is a steep uphill fight to substitute Reality for Utopia, once Utopia inhabits the minds of people.

4 The UNFCCC COPs were not secluded from the neoliberal, neoclassical gulf; neither was IPCC WG3. At COP3 (Kyoto 1997) Al Gore himself praised the MBIs and the USA would accept no Protocol if not built around the flexible mechanisms. After COP3 and EC's prudent energytax proposal of beginning 1990s was torpedoed by the players under bullet 1, EC's Climate Unit was deprived of a policy alternative, so very receptive for the ETS adventure (EC 2000). Distraught people are an easy prey for masterminding stakeholders.

5 Stakeholder Masterminding [Sections 7.4.2/3] succeeded in creating an effective, efficient, and robust discourse for maintaining the façade intact, with the major players hiding in the role of controlled parties. The details of the EU ETS adaptations are arranged via comitology (where corporate stakeholders or concurrent consultant experts set the tune). Policing public opinion was left over to the media, repeating lies like 'industry paying for its carbon emissions'. The neoclassical economics gatekeepers backed up the Symbol and Narratives on the EU ETS. Next to manning comitology meetings, the companies maintain their lobbyism networks with MS and EU-institutes. Sporadically, a tip of the veil over SM is lifted, like the Magritte Group's press conference in March 2014, ensuing the interventions by EC Commissioner J. Almunia (April and October 2014) [Section 7.4.4]. 


\subsubsection{Dissolving enigmas and paradoxes}

The economics critique and a political economic view answer the enigmas and paradoxes of the Janus EU ETS. For example, Meckling (2011, p. 202):

It is the paradox of pollution markets that they harness market forces while creating a strong demand for skillful government intervention. This requires the ability to mobilize business forces, on the one hand, and partly insulate decision-making on the design of carbon market from corporate influence, on the other.

Some comments are due.

1 Which market forces are harnessed? The minimum requirements to call an interchange among economic agents a 'market' are not fulfilled (Dales 1968, p. 803).

2 "Skilful government intervention" is a euphemism for bureaucracy, being a natural corollary of regulation by case and exemption, because the clients are very heterogeneous [Chapters 2 and 5].

3 The business forces mobilize the officials, academics, and media, practical for their agenda and discourse.

4 The stakeholder status opens many doors for masterminding, comitology being a prominent example.

Meckling (2014, p. 570) is more outspoken about "existing markets have performed rather slow in mitigating GHG emissions and incentivizing lowcarbon investments". However, he continues: "The major caveat is, of course, that carbon markets are going through the early phase of the learning curve". How many decades more can mankind lose in the face of irreversible climate collapse? Time is the critical factor in reaching [ $\mathrm{Ce}=0$ ], the real goal. This criticism on Meckling is friendly: his 2011 book on Carbon Coalitions is a rich documented analysis for understanding the EU ETS up to 2010 .

Lane and Newell (2016, p. 248) put as central question: "How can we make sense of these flourishing yet failing markets?" Flourishing is evident when the construction serves the interests of the triumvirate of corporations. This is also why business interest groups in other regions want to be shielded by similar 'carbon markets'. The EU ETS failing is by design and construction. The permit trading cases that were successful cover a limited number of emission sources in one homogeneous sector (Rabe 2018). The EU ETS is not a grand new capitalist experiment of the finance sector, but a shameful case of private corporations overruling the public interest. Their goal is staying shielded from diligent decarbonizing obligations.

Since 1997, more than two decades, 20 precious years, have been lost, by spending scarce public climate policy-making resources on a system 
which has bought time for the fossil fuel and EITE industries. This is the opposite of the urgent and drastic action needed for escaping irreversible climate collapse. Get rid of the EU ETS as soon as possible (Pearse and Böhm 2014).

Chapter 8 offers analysis and suggestions about climate economics for the future.

\section{Notes}

1 Comitology is a term conceived and used in EU's bureaucracy (even mentioned in the 2003 EU ETS Directive). It is a process of deliberation/cooperation of EC officials with third parties, mostly influential stakeholders, on the implementation of legislation.

2 Full-substance OCF-SD is distinct from the reduced contents of SD favoured by companies.

3 The carbon emission intensity of hydrocarbons ( $\mathrm{H}-\mathrm{C}$ molecules) depends on the share of carbon vs. the combustible $\mathrm{H}$, being 0.25 for methane $\mathrm{CH}_{4}$, up to nearly 0.5 for oil $\left(\mathrm{C}_{\mathrm{n}} \mathrm{H}_{2 \mathrm{n}+2}\right)$, and 1 for coal $\left(\mathrm{no} \mathrm{H}_{2}\right)$. Hydrogen $\left(\mathrm{H}_{2}\right)$ is a carbon free fuel, abundant in the universe but not freely available on Earth.

4 The year 2019 is likely to be the Peak Oil moment, due to the Corona-virus in 2020 and the growing awareness of irreversible climate collapse building up.

5 The Paris Agreement (COP21, 2015) Art.16.8 adopts the participation of IAEA and its member States at the sessions of the COPs as observers. This is one of the exceptionally few specific regulations of the Paris Agreement.

6 It would ask excessive place to document an experienced case about EU Directive 2004/8/EC on the promotion of cogeneration (EC 2004). Essential circular logic flaws persist in today's legislation EU (2012) (Verbruggen 2008b; Verbruggen et al. 2016).

7 A well-informed NGO "working to reform and improve the EU carbon market". The main staff of Sandbag (founded in 2008) changed in 2019 to Ember "to accelerate the global electricity transition from coal to clean". A reduced Sandbag team is now based in Brussels.

8 Ember provides a dynamic price viewer at https://ember-climate.org/data/ca rbon-price-viewer/.

9 EEG = Erneuerbare Energien Gesetz (Renewable Energy Act).

10 Documentation available at www.avielverbruggen.be (check: Transversal Issues). 


\section{From evaluation to a well thought-out 'Act Now'}

This books raison d'être is the CC acronym's content shifting from Climate Change to Climate Collapse. Some aspects of Climate Change could be assessed as beneficial and manageable, although on a slippery slope. The slope has been far more slippery than most of us thought in the 1980s. Climate Collapse is whereto we are gliding. Climate Collapse is irreversible and likely ending human civilization. For these reasons, drastic and urgent change, transformation, reversal is not a choice, but a must. I subscribe to the 'Act Now' of climate activists: not utopian, but a realistic and well thought-out Act Now rooted in science, evidence and experience.

The scope of this book's analysis is outlined in its Introduction [Figure 1.1]. There, energy and technology are shown as the substrate, the circulatory system, for societies' functioning, for human civilization (White 1943; Smil 2017). Fossil fuels were the substrate of the industrializing era; renewable energies are the substrate of the sustainability epoch, opening the perspective on a qualitative leap in human civilization. Civilization is multi-faceted, constructed by a broad diversity of people with various disciplines, impossible to enumerate here.

Figure 8.1 is an image of two main transformations, one in the substrate and one in the societal superstructure. On the left there is the present (soon to be replaced for evading Climate Collapse). Neoliberal regimes still rest on the fossil and nuclear fuels substrate. Neoliberal regimes cause divisive and deeply unequal societies, one of the main problems to be addressed by Our Common Future Sustainable Development (OCF-SD) as a new societal paradigm, fed by renewable and efficient energy provision. The transformations are conditioning one another and interact intensively, with the energy transformation in a precursory role.

There is no contradiction between assigning priority to decarbonizing all economic activities and creating ethical politics. False prophets cause cracks between both, in preaching the Utopia of the 'be-good minded climate man' as more important than the engineer developing better sustainability technology.

Energy as substrate of civilization unveils two phases in the transformation from fossil fuel-based neoliberalism to renewable power based OCF-SD. The

DOI: $10.4324 / 9781003173816-8$ 


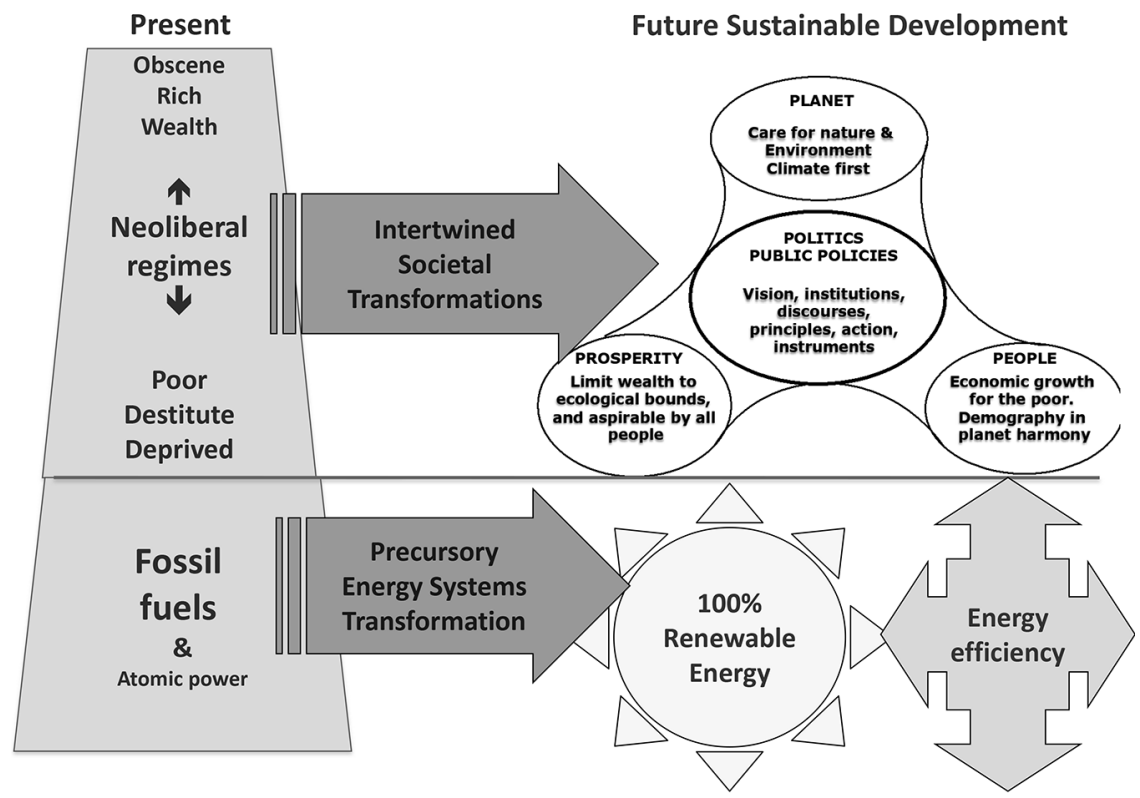

Figure 8.1 Energy and technology as substrate of civilizations

substrate of energy uses is composed of numerous combinations of 'energy sources X technology' to win, convert, and transmit the energy. The transformation is from 'obsolete exhausted technology requiring stocks of dense fossil and nuclear fuels' to 'vibrant progressing technologies (such as PV, wind turbines) that harvest diffuse and variable currents'.

Out of the 1970s development, environment, energy, economic, and societal crises, neoliberalism continued the unlimited GDP growth path, with a high approval rate. The penultimate warning about the wrong relationship man-nature was ignored [Section 7.2.2]. Vested financial, economic, and military Interests addressed 'limits to growth' (Meadows et al. 1972) with more conventional Institutes and Infrastructures temporarily crushing the limits. Unmatched growth in throughput implies more natural sources obliterated and depleted, more scarce sinks polluted and filled, and the most dangerous: more essential life-support systems havocked. Fossil fuel winning and combustion, yearly litter the atmosphere with billion tons of $\mathrm{CO}_{2}$, ensuing irreversible CC.

This chapter is organized in two parts. Section 8.1 deals with Carbon Pricing issues, the main topic of the book. Then the issues of climate policy and 'Act Now' transformation are discussed [Section 8.2]. Both parts are interrelated, for example: the essential proof of Carbon Pricing (and other financial incentivizing instruments) is reducing carbon emissions, not 'on paper' but 'in the field and in the air'. Climate politics, with as major theme reducing GHG emissions, is responsible for designing financial incentive instruments that perform well. 


\subsection{Issues on carbon pricing (CP)}

$\mathrm{CP}$ is more than an economic mechanism. As shown in Chapter 7, the EU ETS permit price is mainly a symbol, stifling urgent and drastic de-carbonization. In this section, results from the book chapters are summarized as sobering observations on CP [Section 8.1.1]. The future of CP is weighed, arguing it should be short because of the urgency for full de-carbonization [Ce $=0$ ]. Deceiving systems (such as the EU ETS and the quest for the GUCP) are to stop immediately [Section 8.1.2]. Electricity pricing being far more relevant than carbon pricing results from envisioning future energy and societal dependence on electric power supplies [Section 8.1.3].

\subsubsection{Sobering observations on carbon price/pricing}

$\mathrm{CP}$ is a panacea term with symbolic resonance, while actual contents and effects of items presented under the CP label are dubious (for instance the permit price uphold in the EU ETS). On most occasions, the CP symbol is disconnected from the basis it is said to cover. Hence, the so-called CP does not exert money pressure ${ }^{1}$ to reduce carbon emissions. The attractiveness of making money or the fear for losing money is an incentive to act for economic agents. The incentive may pull (subsidies) or push (taxes) to action. Several characteristics need to be specified before a particular CP is valid for application [Chapter 1] such as a precise definition specifying the relevant details including the responsible authority, the scope (covered jurisdictions, emission sources), the goals, transparency and the Monitoring, Reporting and Verification (MRV) of the money patches and flows.

One often meets confusing and superficial CP language. Chapter 2 addresses the GUCP as a Utopian fairy tale. It denies the diversity and the heterogeneity inherent to economic actors and activities. The treatment of heterogeneous emission activities with uniform CP promises attractive efficiency results on paper, which is seemingly 'proven' by mathematical optimization methods [Annexes B and C]. However, the accuracy of a formal method like Lagrange optimization over a range of assumed substitutable activities is insufficient to validate its application over disparate, non-interacting cases. Ex-ante denial of heterogeneity is also an explicit design factor in Tradable Green Certificate market regulations [Chapter 5] and in Cap and Trade like EU ETS [Chapter 7]. Both artificial market trials deteriorated to the reverse of the qualities promised on paper (EC 1999; 2000).

The lasting utopian quest for the GUCP 'holy grail is astonishing. It is however supported by a vast majority of environmental and ecological economists (exceptions are, for example Bromley (1990), Spash (2010), Vatn (2005)). Elements that help to explain the widespread cognitive dissonance are:

- Neoclassical mathematics value theory, full of unrealistic assumptions, does blind academic economists, who overlook that procedural proof mathematics does not guarantee substance proof in practice. 
- The economics profession got entangled with the neoliberal paradigm and its focus on capital accumulation hided in market fetishism. The tunnel view on theoretical efficiency obscured the inequalities paired to accumulation and concentration of wealth and power.

- A triumvirate of Interest clusters (fossil fuel corporations, electric power generation oligopolies and industrial companies) has exerted supreme discursive power in setting and holding up EU ETS narrative. The economics profession has been intensely compromised and delivers the theoretical arguments and spearheads the discourse.

- Financial incentives are a crucial mechanism to produce activity changes, but good practice is not related to GUCP.

In summary, below are five researched positions of energy and climate economics on CP:

1 On diversity and heterogeneity. The economics profession adopts an ambivalent, erroneous attitude regarding diversity and heterogeneity. This attitude upholds GUCP narratives, while the experiments that have been tried show flaws and failures. For example, the few carbon markets set up in the world are fenced in limited jurisdictions, full of particularities. They jeopardize even the idea of joining the few experimental systems and are far from approaching 'global'. The announced 'uniform' treatment of sources covered by the EU ETS has stranded in an opaque mess of exceptions and exemptions 'à la tête du client'.

2 There is confusion between foreign oil rents extortion and domestic revenues from energy taxes. Modestly budding energy efficiency and renewable energy technology resulted from the 1970's hikes in oil prices [Section 7.2.2]. In the 1980s, when rent skimming by oil exporting countries came down [Figure 7.3], neoliberal anti-tax narratives paralyzed politicians to financially incentivize sustainability options. Equating oil rents cashed by oil exporters to tax revenues of domestic treasuries confused economic analyses and fueled anti-tax narratives. Danish policy was one of the few nonconfused and salvaged in the 1980s some budding results in efficiency and wind power.

3 Price Induced Technological Innovation (PITI): unverified assumption. PITI is an issue of high relevance for climate policy based on IPCC WG3 reports. IPCC WG3 scenarios are delivered by Integrated Assessment Models that incorporate PITI as core mechanism for projecting carbon emission reductions dependent on future CP settings. Hence, farfetched significance is assigned to the level of the GUCP narrative.

The functioning of PITI in real carbon emissions abatement programs needs verification. Likely, it is an unfounded extrapolation of the microeconomics logic that changing the relative prices of production factors shifts the optimal technology on production isoquants. However, in the real world, corporations are not paying €billions in carbon taxes (or 
emissions permits) plus €billions in low-carbon technological innovations. On the contrary, corporations expect public support for R\&D and innovative undertakings.

4 'Independence Property'. The EC with MS administrations distribute free emission permits to EU's Emissions Intensive Trade Exposed (EITE) activities for avoiding carbon leakage. The donations are moderated by sector specific benchmarks. Free permits mean that EITE industry pays a $\mathrm{CP}$ zero, slightly positive (in case of shortfall in free donations) or negative (in case of excess donations).

Hahn and Stavins (2011) call on a mathematical treatise by Montgomery (1972) to establish the 'independence property', declaring that the efficiency of the EU ETS is not affected by free donations of permits when a set of conditions is fulfilled [Section 6.4]. The executed check on conditions fulfilment is very weak and outdated. In essence, the argument equates the effects of fringe pricing with the effects of marginal cost pricing, best described as 'the tail wags the dog' sophism [Annex E].

5 Feed-in-Tariffs (FIT). Since the 1990s, Denmark and Germany supported the development and deployment of Renewable Electricity (RE) technologies by Feed-in-Tariffs (FIT). This financial incentive mechanism lifted two crucial technologies (wind turbines and PV) over their innovation 'valley of death' in the first decade of the $3^{\text {rd }}$ millennium, creating a lifeline for future mankind.

Most economists denied this success story. Frondel et al. (2010) fiercely criticized FIT as too expensive. Böhringer et al. (2014) negated the plain evidence of wind and PV learning curves. Schmalensee and Stavins (2017) called it perverse for the EU ETS.

FIT treats each RE technology separately on the own merits, i.e., the opposite of what GUCP believers propose. The evaluation of FIT on the standard set of criteria, used by economists, shows its good performance [Annex D]. Progressive politics interacting with civil society, grassroots, municipalities, entrepreneurs, and more, realized FIT, against the will of energy and industrial corporations and neoclassical economists (Haas 2019). This ranking: first society and politics, second markets, is no appetite for neoliberal interests and their economics supporters.

Nonetheless, FIT was the one that delivered in reality and prepared the road for sustainable, decentralized power generation as substrate for the transformation to societies organized along the OCF-SD paradigm.

\subsubsection{Has carbon pricing a future?}

If CP would have a future, it should be the shortest possible future because of the as-soon-as-possible to be realized goal [ $\mathrm{Ce}=0]$. In fact, it should have been realized yesterday. Using utopian CP symbols, vested interests related to the use of fossil fuels have blocked the path to [Ce $=0]$, and the obstruction will continue by shielding those interests from due diligent policies [Section 7.5]. 
Scholars concerned about slow decarbonizing progress, suggest alternatives and cures. Rosenbloom et al. (2020, p. 4) offer "sustainability transition policy" as an alternative. Vailles and Berghmans (2020, p. 1) propose "reshaping the EU ETS as a safety net". In the case of GUCP and EU ETS 'gentle healers cause stinking wounds'. Digging for the root causes of failing instruments and slow emissions reduction, shows radical change, reversals, U-turns are inevitable for escaping Climate Collapse (Prins and Rayner 2007).

I recommend ending the Utopian GUCP and EU ETS carbon pricing symbols for several reasons: they lack effectiveness, efficiency, fairness, and they waste significant human capital and administrative resources. The political economy analysis of Chapter 7 shows that proposals of help, reshape, or any other soft remedy are insufficient, easily absorbed and grinded by stakeholder masterminding. Problematic with all good-intended proposals and cures is their deflation of the urgency imperative in today's climate policy.

Is then the solution found in a hard cure of high ( $>€ 100 /$ ton $\mathrm{CO}_{2}$-eq) carbon taxes on every ton of GHG emitted by companies covered by the EU ETS? No, because brutal carbon pricing on industrial emissions is also Utopian when the low-carbon alternatives are absent. It is unlikely that PITI would bring deep decarbonizing innovations. When brutal carbon taxes are only applied on industrial activities covered by the EU ETS, carbon leakage is very likely for activities that cannot pass on the carbon bill to customers.

In the EU ETS, the spending by electricity companies for obtaining permits at auctions or via purchases from industrial companies with excess donated permits is charged mainly on non-ETS electricity customers, being 'surcharges' on the bills of captive customers (households, communities, SMEs, and similar).

In a market-based political system, politicians are reluctant to impose fuel or carbon taxes on their constituency (Rabe 2018). The triumvirate of corporations masterminding the EU ETS can deploy enough power to smother proposals about high CPs on their Business-as-Usual activities. It would be a protracted uphill battle to approve EU legislation on carbon pricing, while time and urgency are precious and perilous in climate policy. Besides, a EUCP (European Uniform CP) is as ineffective as a GUCP by ignoring heterogeneity.

Rather than taxing industrial activities of corporations (many of them functioning in transnational contexts), public authorities should subsidize or tax goods and services according to the climate burden they entail, in detailed specificity and caring about equity and justice. Fiscal federalism (Oates 2011) and polycentricity (Thiel et al. 2019) take a significant place for assigning more financial incentive policy tools to cities and local authorities, the leading centres of future climate policy. World and regional (EU) politics better focuses on eliminating unjustified subsidies for fossil fuels and nuclear power, and, beyond the scope of this book, on profit tax evasions by global corporations. 
Disqualifying GUCP, EU ETS and brutally taxing of GHG emissions of industrial activities will not end the crucial role of financial incentives. In Chapter 1, human self-interest is compared with gravity in physics: it is always there, and it must be constantly overcome. Annex D documents how crucial and effective the financial incentives of FIT were to develop and deploy wind, PV and other RE technologies. Chapter 2 refers to Aristotle's policy principle 'treat equal cases equally, unequal ones unequally', implying discrimination when either part of the principle is broken.

To become effective, efficient, fair, and administratively feasible, CP should leave its triumphal pillar and become a financial environmental policy instrument like applied in waste management, water use and pollution, traffic control, etc. Good CP is specific for every single homogeneous category and case. Most CP can be executed at the city-municipal level, with respect for the lessons and experience of fiscal federalism. All CP must keep in sight the full de-carbonization goal $[\mathrm{Ce}=0$ ] as a short-term one, i.e., it should abolish itself as-soon-as-possible. Eliminating the use of fossil fuels and a full transformation of the energy system to maximum distributed RE (such as wind, PV solar power) is the main road to [Ce $=0]$.

Decarbonizing industrial activities implies sector-specific approaches. Allowing sufficient flexibility in designing and implementing solutions facilitates industry's decarbonizing. In some cases, permit trading may provide appropriate flexibility. For example, permit trade offered the USA refineries high flexibility in their conversion to deliver unleaded gasoline (Schmalensee and Stavins 2017). Specific sectors functioning on a global scale (for example ocean-going shipping; international civil aviation) may apply permit trading, when politically framed, supervised and enforced for a near term $[\mathrm{Ce}=0]$. A public controlled, transparent and specific application of financial incentives makes use of the best fitting instruments. A mechanism or instrument not functional in fast realizing $[\mathrm{Ce}=0]$ is a barrier. The EU ETS is a significant barrier for urgent and drastic climate policy, because it offers the fossil fuel and industrial concerns another decade (2021-2030) of Business-as-Usual.

Rubicon crossing from uniform Utopia to diverse Reality will dissolve GUCP and the hubris based on assumptive neoclassical economics. It is a big step from being an oracle to becoming a partner of the myriad of social sciences, and reconnecting with the own roots of economics: Adam Smith (moral philosopher) and classical economics. Social sciences, and economics is a social science, fabricate diverse solutions for diverse problems in diverse societies. Economics will be a respected discipline, when it contributes to managing self-interest for the common good (Ostrom 1990; Ostrom 1992).

\subsubsection{Electricity pricing is more relevant than carbon pricing}

Carbon emissions will decline and vanish when reaching $[\mathrm{Ce}=0]$. Development and deployment of non-carbon emitting sustainable technology is due by strategic public policy with the support of economically effective and efficient 
financial instruments. This happened for wind and PV power generation [Annex D], now ready substitutes for cumbersome thermal power [Figure 7.5].

In 2010 , electricity globally was generated $80 \%$ in fossil and nuclear thermal plants, and 20\% from renewable sources; in the first quarter of 2020 (with the Covid-19 impacts) the respective shares where $72 \%$ and $28 \%$ (IEA 2020, p. 27). After a first decade of growth, wind and solar power realised $9 \%$ of the supplies. Bringing this share to above $80 \%$ in the coming decade is a technological, industrial, financial, political, and social challenge at local, regional, and global levels (IPCC 2012; Connolly and Mathiesen 2014; IRENA 2019). Turning the challenges in opportunities is the way to escape climate collapse.

Electricity is the backbone energy carrier of the coming $[\mathrm{Ce}=0]$ societies. Who controls the electricity systems, controls important arteries of society. For future electricity systems, two versions of deployment and control are feasible. The first version assigns priority to bottom-up, distributed, consumer-owned generation. In the second version, top-down, centralized, company-owned generation prevails. Physical and economic proper balance and cooperation between distributed and centralized power generation is optimal. It demands strong, independent public interest regulation for setting and enforcing the effective and just rules for dispatching and pricing, rewarding the investments and delivery of power by both sides. Exceptional, independent regulation is the prerequisite for equilibrating informational, organizational and monetary asset asymmetries between the few centralized and the numerous widely distributed actors (Verbruggen 2017).

Understanding the phenomenon electricity and the related generation and transmission systems, requests attention and time. Follow-up of power systems is a full-time expert job, applying models and various practices under ever-changing circumstances. Distinctive variables fluctuate permanently (Stoft 2002). As a corollary, most non-expert parties (small businesses, households) lack knowledge and time to comprehend sufficiently electric power systems to benefit from its erratic intricacies. The revenue/expense ratio of their muddling in dynamic electricity system balancing is very low. Societal optimal is transparent public regulation shielding small power producers and end-users from this awkward duty.

In the $[\mathrm{Ce}=0]$ future, most electricity (distributed and centralized) will be tapped from free for use, variable, and stochastic natural currents (Twidell and Weir 2006). The electricity economics theory of power systems based on generation units on command is growing obsolete with every new wind turbine or PV panel coming online [Annex E]. Incumbent basic theory assumes:

i all generation capacities available on command (= deliver/not deliver on demand of ISO),

ii convex marginal cost curves,

iii generation systems optimally composed (at given factor prices, mainly of fuel and capital), and

iv systems are optimally operating (in the short run by unit commitment and merit order loading). 
With the above assumptions, the equality between short and long run marginal costs holds, and optimal prices equal Short-run Marginal Cost (SRMC). There are many caveats to this stylized model [Annex E]. In addition, SRMC are dependent on spatial and temporal specifications. The out-dated theory still dominates electric power discourse and management, with conflicts between RE power and incumbent thermal power units causing aberrant negative electricity prices on power exchanges (not in the bills of customers). Timely revision of electricity economics theory and models should address the new realities and guide the transformation of existing electricity systems.

Natural currents are weather dependent, not at command, variably and stochastically available (Twidell and Weir 2006; IPCC 2012). 'They have to be integrated in the existing power systems' is so far the dominant discourse, and hindering urgent, full RE deployment as spearhead policy to $[\mathrm{Ce}=0]$.

Proper framing is: 'RE must grow at maximum rate, with immediate removal of all barriers to this growth'. IPCC (2012) states 100\% RE as feasible, contingent on changes in policy and societal adaptations.

In a future of $100 \%$ RE supplies, maximum $1 / 5^{\text {th }}$ may be on command (dam hydro; thermal power from geothermal, biogas and biomass residues). Minimum $4 / 5^{\text {th }}$ will be harvested from wind currents, light waves, or water flows. PV and wind technology is increasing in efficiency with investment and operation costs decreasing (IRENA 2020). The environmental costs are minimal and manageable.

For brevity, this treatise is limited to three major issues in 100\% RE supplies: reliability of service, redundancy of capacities, islanding by local storage.

1 Reliability in power supply by variable and stochastic RE sources has gained lots of attention. Can power sources not on command be reliable? They can when the necessary provisions are taken. Reliability in fully commanded power systems also requires particular provisions (such as spinning reserves to meet the outage of the largest plant in the system, quick start units, contracts with neighbouring service areas for emergency support, interruptible loads). Some of the existing provisions apply as well in 100\% RE systems, complemented by a diverse range of RE supplies, interaction with the heat and transport sectors, extra energy efficiency, load management, interconnection, and storage facilities (IPCC 2012).

2 Redundancy will be the result of incredibly cheap PV today and cheaper the coming years. Solar roofs and solar buildings everywhere are at the doorstep. In addition, wind turbines come down in price. Redundancy is a major issue in power supply: a brown out or black out may cause annoying hindrance, however transgressing voltage thresholds devastates end-use equipment. When the aggregate of non-commanded RE supplies 
exceeds the loads at given nodes of the grid, extra loads must be created (for example in storage) or supplies must be curtailed.

When the marginal costs of the redundant RE supplies are zero, there is no standard merit order telling which sources to curtail. Shall one curtail the offshore wind turbines owned by corporations, or the wind turbine of the cooperative, or the PV of households? Here the centralized and distributed versions of a 100\% RE future are clashing, when no clear regulatory rules apply, consistent with transparent principles, e.g.: the 'proximity principle,, a likely substitute for the 'SRMC merit order' ranking.

3 Islanding based on local storage is likely to develop, coupled to redundancy. Islanding may start with financially endowed households, gated housing estates, campuses, local communities, and similar. PV becoming incredibly cheap, the owner of an (energy efficient) house allowing the installation of ten or more kilowatt, can store power in a battery for the coming nights loads, and electrolyse water to hydrogen stored for generating fuel cell power in the coming winter season. The significance of islanding is difficult to assess and depends on further technological development of batteries and fuel cells. Islanding may be embedded in smart grids maintaining exchanges with the interconnected grid, which, however, may be stripped from economies of scale and economies of density.

The number of Independent Generators of Own Power (IGOP) is constantly rising. In countries where early and high-remuneration FIT contracts end after 20 years, large batches IGOP will enter the electricity market with amortized installations. Also recent RE installations without FIT can deliver power at low prices, however not on command, while needing complementary and back-up power from the grid. The interactions IGOP-Grid are contentious, and the regulation thereof demands transparent, fair and principled policy. The prevalence of either distributed or centralized RE is a principled choice in guiding future development of the power systems.

Economists, proficient in optimization, pricing theory, regulation, etc. are welcome to address the issues. A good understanding of technical aspects of power systems is a prerequisite, as is cooperation with scientists in law and other social disciplines. Electricity pricing is more relevant to spend public resources on than funding repeating of utopian carbon pricing mantras.

\subsection{Climate policy and 'Act Now' transformations}

Since World War II, relentless growing emissions of GHG, mainly fossil fuel related $\mathrm{CO}_{2}$, accumulated the atmospheric concentration irrevocably for centuries. Climate change is worsening with irreversible impacts on life-support systems and approaching the abyss of climate collapse.

The $14^{\text {th }}$ edition of the Global Risks report by the World Economic Forum ranks "Extreme Weather events" first, and "Failure of Climate Change 
Mitigation and Adaptation" second of 30 major global risks, combining impact and likelihood (WEF 2019).

Since 1992, the danger of climate change is undeniable known by the captains of industry and governments in the world when adopting the United Nations Framework Convention on Climate Change (UNFCCC). Also known was fossil fuel combustion as the predominant culprit, and the necessity of the new paradigm Sustainable Development (WCED 1987). In 1992, the ultimate warning was posted for the world community, with conventions and intentions as response. Climate change urged change in politics, societies, economies, and in their interaction with nature and the environment. However, the force of neoliberalism and unlimited GDP growth overpowered the fragile efforts for sustainability change (Jacques et al. 2008).

Yet, in the cracks of bursting globalism, a few European countries and maverick states in de US stimulated energy efficiency and distributed renewable power generation. In 2018, the cliff in energy systems transformation is passed because harvesting electricity from wind currents and light waves became structurally cheaper than any kind of power from thermal plants (IRENA 2020). A new epoch irrevocably is arraying. It allows a sigh of relief, but no rest due to needed urgency because of looming irreversible climate collapse.

Climate change urges 'Act Now', overcoming the numerous inertias in ideas, interests, institutes, infrastructures, and indispensable energy-technology transformation [Figure 1.1]. It all starts with ideas: myths, narratives, discourses, language, and paradigms. Civilizations are legitimated with ideas via elaborated paradigms accepted, partly endured, by a significant majority of the people.

Agreeing on a proper paradigm for a fundamental new epoch is a work of years. Luckily, this work was done in the 1980s by the authors of Our Common Future (WCED 1987). The comprehensive, radical paradigm of Sustainable Development (OCF-SD) was an answer to the environmental and development curses of the $20^{\text {th }}$ century. Yet, neoliberal interests, pursuing the opposite of OCF-SD, conquered the symbol, eroded the substance, and occupy the discourse.

Sustainable Development Goals (SDG) is no valid substitute (Green 2016, p. 147). Policy is the central and empowering dimension in OCF-SD (yet, obscured by 3P distortion [Section 7.2.1]). As policy tool, sustainability assessments on all major technologies, programs, projects would shed light on suitable OCF-SD pathways. For example, they would expose nuclear power and fossil fuels as non-sustainable, smashing the deceiving official decarbonizing triptych 'Renewables, Nuclear Power, Carbon Capture \& Storage'.

Reclaim Our Common Future Sustainable Development as $3^{\text {rd }}$ millennium paradigm is an indispensable priority of the 'Act Now' pathway. Adjust or replace biased and misleading Ideas to make them match the OCF-SD paradigm. The following challenges are exemplary: 
- Dangerous myths: 'change is possible without changing'; 'incumbent interests in finance, economy, administration, military, media and science are the institutes responsible for change'; 'the thinking for solving problems is the same as the thinking that caused the problems'; 'persuasion, goodwill and intentions are sufficient for preserving the commons'.

- Misleading language and images: 'reducing carbon emissions means present generations bring offers for future generations' ( $\leftrightarrow$ emitting carbon is gaseous littering); '3P Planet-Profit-People dimensions of SD' ( $\leftrightarrow 4 \mathrm{P}$ Politics-People-Prosperity-Planet); 'cheap fossil fuels" ( $\leftrightarrow$ extremely expensive when costs of climate collapse are included); 'integrating renewable power in the established power systems based on generation capacities on command' $(\leftrightarrow 100 \%$ renewable power is the future, to be taken as the reference, and the established systems have to adapt or vanish).

- Masterminding discursive power by powerful stakeholders: the EU ETS as flagship, cornerstone of EU's climate policy ( $\leftrightarrow$ no evidence of effectiveness, efficiency, innovation; evidence of regressive distribution impacts); IPCC WG3 adhering neoclassical economics, neoliberal worldview, broadcasting $3 \mathrm{P}$ and the decarbonizing triptych by being manipulated in the assessment of nuclear power; directing social science research via swaying approval committees of research proposals, with the argument that research needs valorisation by society (meaning vested interests in society), via influencing editorial boards of journals (Elsevier's Energy Policy in 2014; the IAEE journals given the constitution of the association), via creation of forums linking academic scientific units to society, creating common understanding (yet, stifling critical thinking).

It seems high time to reformulate, rewrite common wisdom and framings of the passing fossil fuel-based era: myths, language, images, narratives, and discourses all need screening and correction where needed (Lakoff 2010). Transversal approaches such as 'volitional pragmatism' (Bromley 2006) may contribute to the creation of proper institutions of the new epoch. The importance of clarity in Ideas is significant because transformations in energy systems and in society are not hindered by lack of sustainability options, solutions, technologies, but by constraining weight of vested Interests.

New images are welcome. Some pictures in the book aim to imprint crucial concepts in people's mind, for example: Introduction Figure 1.1, actors and five main Inertias to address; Figure 2.2, four categories of financial incentives; Figure 3.1, tax - free permit hybrid emissions trading; Figure 7.2 tetrahedral, dynamic 4P sustainability driven by politics (substitute for the flat 3P Venn diagram); Figure 7.5 flabs of thermal power generation (showing that thermal power generation is an anomaly); Figure 8.1 linked transformations of energy substrate and societal civilization.

Among the many creative transformations necessary, some are generic like following two examples. First, the relationship 'man-nature' is turned upside 
down to 'nature-man': man is not master, but part of nature with respectful stewardship as substitute for destructive exploitation (Simmons 1989). Second, renewable distributed energy winning and supply becomes a major cornerstone of local activities and politics prevailing over centralized accumulation and power.

Defenestration of bureaucratic top-down policy, such as GUCP and EU ETS, paves the road for effective, efficient, fair and transparent policies that are diverse and locally anchored (Thiel et al. eds 2019). The integration of the numerous bottom-up initiatives is based on principles of coordination, substitute for top-down imperatives that lost contact with reality and hide behind utopian symbols (like the panacea GUCP). Nonetheless, financial incentives play an important role in successful transformations and in future societies organized via self-government for preserving vital common pool resources (Ostrom 1990; Ostrom 1992).

In the coming radical transformations rationality is to reign rather than emotion, ephemeral goodwill, or be-good mindsets. Hardin (1968) visionary and Ostrom (1990) meticulously showed how to govern the commons, while self-interest of people works like gravity force. Their scientific contributions inspire to assemble numerous ideas and propositions about climate policy (Aldy and Stavins 2007) in a self-governance framework for global climate policy (Verbruggen 2015). Who has to make society fly to a better future, takes gravity forces in account for finding forces and devices to overcome inertias in ideas, interests, institutes and infrastructures.

By linking up with classical economics, political economy sees actors as embedded in society and pursuing varieties of different interests. Revealing how realities are constructed in whirlpools of interests is like observing icebergs: $90 \%$ happens below the waterline. All participants foster their interests first and most, as do academics, bureaucrats (international organizations, administrations, local authorities), citizens, companies (from transnational corporations to Adam Smith's local bakery), consultants, politicians (at all levels, of all colours), publishers, scientists, and more. In the gravity fields of interests, the societal airship of the common good interest is constructed, operated and protected.

At earlier presentations of parts of this book's analysis on failing policies (like the EU ETS), part of the audience is often shocked by "merciless critique, seeming cynical, without hope".

Once more, the opposite is true: when the present policies would be the best possible, though resulting in growing GHG emissions, no deep decarbonizing in industry, protracting Business as Usual, no urgency, etc. analysis revealing the fully flawed policies is especially hopeful. Society can do much better by substituting proper policies for flawed policies, the right way to escape climate collapse.

As a Western educated scholar, I find support for radical policy proposals in the historical precedent of the slaves' cross substituting for the Roman imperial eagle (Edict of Milan AD 313). This radical and necessary reversal founded European civilization. 


\section{Notes}

1 Pressure $=$ Force $/$ Area. The art of financial incentivizing is applying adjusted forces to the diversity of areas, in order to obtain the proper pressures for changing activities. Specific financial incentives can adapt pressures according ability-to-pay, not only willingness-to-pay.

2 Proximity principle: the appropriate RE supply source nearest to the demand sink gets priority for delivering its generated power to the end-use. Big data are needed to implement the principle, also attending the frequency standards. 


\section{Annex A: Environmental policy-making and carbon pricing}

Carbon pricing (CP) is an application of environmental policy instruments (Gupta et al. 2007). The literature on such policy instruments started before climate change became a salient issue (Coase 1960; Dales 1968; Weitzman 1974; Baumol and Oates 1975; Fisher 1981; Pearce and Turner 1990). More than a century ago, Pigou first addressed the problem of environmental externalities disturbing optimum market functioning and proposed a levy on the measured externality to correct the failure, known as the Pigouvian tax. Coase (1960, p. 28) calls Pigou's work "the fountainhead for the modern economic analysis". It aims to pursue and safeguard perfect market functioning.

\section{A.1 The Pigouvian tax}

The Pigouvian tax is linked to the strong belief in perfect markets, reducing environmental problems to the status of 'externalities' disturbing the perfection. Taxing the externality is the remedial recipe for returning to the real optimum. This way of logic is built in the prevailing 'general equilibrium modelling', mostly the economics panel of the IAMs, feeding the Assessment Reports of IPCC WG3. Figure A.1 clarifies how a tax can internalize environmental external costs.

When the externality is proportional to the output generated by producers, a tax rate proportional to the output is applied (for example: a coal fired electric power plant emits $1 \mathrm{~kg} \mathrm{CO}_{2}$ per $\mathrm{kWh}$ generated). The curve $\mathrm{OS}^{\circ}$ is the supply curve without tax, and TF is the supply curve including the tax rate $\mathrm{T}$. The demand curve remains.

The equilibrium shifts from $S^{\circ}$ to $S^{\star}$, with economic and financial effects, as follows:

- $\quad € \mathrm{~S}^{\circ}-\mathrm{F}-\mathrm{S}^{\star}$ welfare loss is avoided, because $\mathrm{Q}^{\star}$ units are produced and consumed rather than $\mathrm{Q}^{\circ}$ when the externality remained unpaid.

- The consumers surplus is reduced from $€ \mathrm{P}^{\circ}-\mathrm{D}_{-} \mathrm{S}^{\circ}$ to $€ \mathrm{P}^{\star}-\mathrm{D}_{-} \mathrm{S}^{\star}$.

- The producer surplus is reduced from $€ \mathrm{O}-\mathrm{P}^{\circ}-\mathrm{S}^{\circ}$ to $€ \mathrm{~T}-\mathrm{P}^{\star}-\mathrm{S}^{\star}$.

- The $€ \mathrm{O}-\mathrm{P}^{\star}-\mathrm{S}^{\star} \mathrm{Q}^{\star} \mathrm{Q}^{\star}$ revenues the producers receive consist of: $€ \mathrm{~T}-\mathrm{P}^{\star} \mathrm{S}^{\star}$ producer surplus $+€ \mathrm{O}-\mathrm{Q}^{\star}-\mathrm{G}$ cost coverage for supplying $\mathrm{Q}^{\star}$ units $+€$ $\mathrm{O}-\mathrm{T}-\mathrm{S}^{\star}{ }_{-} \mathrm{G}$ tax transfers to the public treasury. 


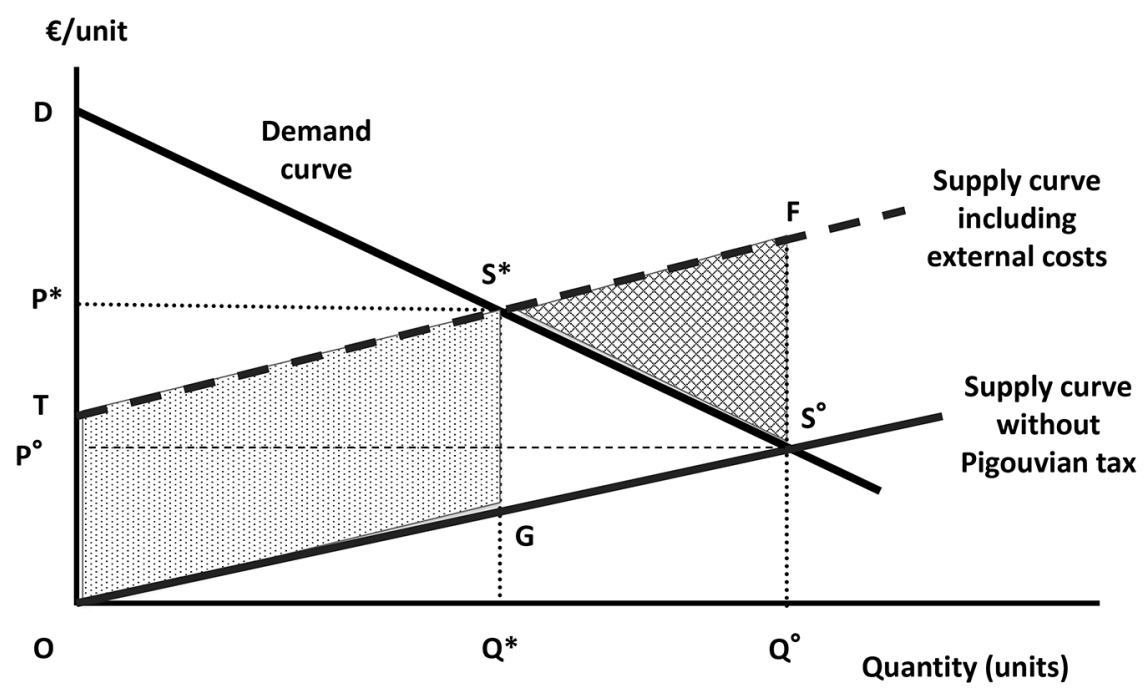

Figure A.1 Pigouvian tax rate T per unit output

When the externality is fully or largely rolled off on third parties, i.e. parties not implied in the shown market, the involved market parties (consumers and producers) do oppose the tax, because their surpluses are reduced (from O-D-S ${ }^{\circ}$ to T-D-S ). The emission of carbon dioxide is a typical example of burden roll-off to the global atmosphere, leading to low tax rates $\mathrm{T}$ on emitted carbon, with the effect of insufficient mitigation of the related externality.

\section{A.2 Environmental taxes/incentives}

Environmental taxes have been labelled as 'financing' taxes or 'incentive' taxes. However, actual money flows mostly confuse this intentional split. It is recommended to identify the purpose(s) of a financial incentive, its effects (aimed and finally obtained), and design guidelines for better reaching the intended effects.

Table A.1 provides an overview of common financial incentives in environmental policymaking. In addition to the descriptions in the table, the many arrows in the Links column express that the relation between Purpose and Effect is not simply linear. Pursuing an effect will generally trigger not intended effects, some even harmful for the intended effects.

A real-life example is instructive: A jurisdiction enacted a comprehensive (and capital intensive) plan for building water sanitation infrastructure. Industries were responsible for about $2 / 3^{\text {rd }}$ of the polluting effluents and should pay $2 / 3^{\text {rd }}$ of the investments through a tax on effluents. However, the tax on the effluents had as effect that the industries reduced their effluents by more than $95 \%$ by building on-site sanitation equipment. This eroded the tax basis and the tax revenue was largely insufficient to finance the public sanitation investments. 
Table A.1 Financial incentives used in environmental policy making

\begin{tabular}{|c|c|c|c|c|}
\hline $\begin{array}{l}\text { Suitable } \\
\text { name }\end{array}$ & Purposes & Links & $\begin{array}{l}\text { Effects } \\
\quad(\text { seen, obtained })\end{array}$ & Design guidelines \\
\hline $\operatorname{Tax}$ & $\begin{array}{l}\text { Financing for } \\
\text { the treasury }\end{array}$ & $\vec{\searrow}$ & $\begin{array}{l}\text { Obtain financial } \\
\text { assets }(€)\end{array}$ & $\begin{array}{l}\text { Maximize } \\
\text { financial flows, } \\
\text { while minimiz- } \\
\text { ing physical } \\
\text { changes }\end{array}$ \\
\hline Levy & $\begin{array}{l}\text { Incentivize } \\
\text { economic } \\
\text { actors to } \\
\text { change }\end{array}$ & $\begin{array}{l}\longrightarrow \\
\searrow\end{array}$ & $\begin{array}{l}\text { Reduce/eliminate } \\
\text { harmful emissions, } \\
\text { activities, techniques, } \\
\text { etc. }\end{array}$ & $\begin{array}{l}\text { Maximize phy- } \\
\text { sical changes, } \\
\text { while minimiz- } \\
\text { ing financial } \\
\text { impacts }\end{array}$ \\
\hline Price & $\begin{array}{l}\text { Charge for } \\
\text { public services }\end{array}$ & $\vec{\nearrow}$ & $\begin{array}{l}\text { Compensation, } \\
\text { proper use of public } \\
\text { goods, commons }\end{array}$ & $\begin{array}{l}\text { Beware of fair- } \\
\text { ness, afford- } \\
\text { ability for all } \\
\text { citizens }\end{array}$ \\
\hline Subsidy & $\begin{array}{l}\text { Support parti- } \\
\text { cular actors for } \\
\text { particular } \\
\text { activities, } \\
\text { projects, } \\
\text { technologies, }\end{array}$ & $\vec{\nearrow}$ & $\begin{array}{l}\text { New solutions for } \\
\text { environmental pro- } \\
\text { blems. Inventions, } \\
\text { innovations }\end{array}$ & $\begin{array}{l}\text { Fine-tune } \\
\text { support for } \\
\text { maximum out- } \\
\text { comes. Adapt } \\
\text { and reduce } \\
\text { support over } \\
\text { time }\end{array}$ \\
\hline Penalty & $\begin{array}{l}\text { Punish excess } \\
\text { emissions } \\
\text { beyond } \\
\text { allowed } \\
\text { standards }\end{array}$ & $\vec{\nearrow}$ & $\begin{array}{l}\text { Enforce laws, rules, } \\
\text { conventions, etc. }\end{array}$ & $\begin{array}{l}\text { Replace } \\
\text { penalties by } \\
\text { pro-active and } \\
\text { preventive } \\
\text { instruments }\end{array}$ \\
\hline
\end{tabular}

Introducing levies to create incentives for emissions reductions will cause transfer payments to the treasury. The example shown in Figure A.1 illustrates such case: while the Pigouvian tax aims in principle only at a shift in market equilibriums, it also causes financial transfers. The few design guidelines in the last column of Table A.1 reveal that good policymaking on financial incentives is a challenging task. The various financial instruments cannot be handled as separable, due to the many interactions.

\section{A.3 Multifaceted financial incentives}

The policy-making task is even more intricate when including instruments beyond explicitly designated financial incentives. Figure A.2 enlarges the scope. The figure originally served to highlight the difficulties in comparing the burden of explicit environmental levies across countries. Counting the returns versed in an environmental (here carbon) fund is not a sufficient metric for gauging the environmental tax pressure. Private actors are approached in several ways to pay for environmental goods or to receive support for reducing their emissions. 


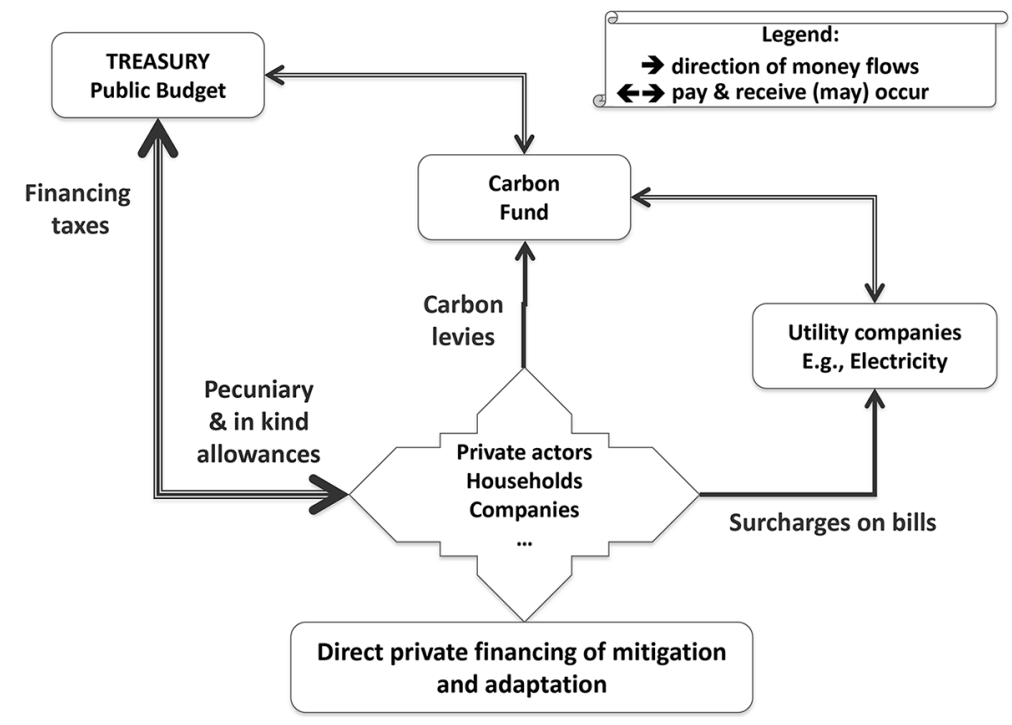

Figure A.2 Financial incentives are multifaceted

Some countries may finance the climate policy efforts without specific climate fund, but via several accounts in the general budget, some not purely environmental or carbon specific (energy excise duties are an obvious example). Other countries may impose significant obligations on the constituency to engage in environment preserving investments and activities.

Direct 'in-house' financing of environmental mitigation and adaptation by private actors may not be recognized as financial contributions to environmental goals. Private initiatives, such as investments in energy efficiency, are intertwined with non-environmental targets and actions.

Companies apply the environmental label generously when the environmental share is regulated (and often subsidized), biasing the metrics in assessing policy performance. The fourth channel in Figure A.2 shows surcharges (also called quasi taxes) on utility (mostly electricity) bills [Annex D]. This common practice in several EU countries had and has a significant impact on investments in energy supply and other public services, and on climate policy. Chapter 5 and Annex D document market pull initiatives in the development of wind, photovoltaic and other renewable energy technologies. Chapter 7 clarifies the quasi-taxing role of electric power companies in the EU ETS.

\section{A.4 Criteria for gauging the performance of economic policy instruments}

For brevity, the criteria and sub-criteria are summarized in Table A.2. The 3E triptych 'Effectiveness - Efficiency - Equity' is the core of performance evaluation (Bohm and Russell 1985). Neoclassical economics focuses on 
efficiency, almost forgetting that environmental effectiveness precedes efficiency, the latter being 'result over effort', or: zero result = zero efficiency. Besides, economists use 'cost-effectiveness' as term for measuring efficiency in performing mitigation-abatement activities, a bit confusing terminology for laypersons.

Cost effectiveness is used when benefits or cost benefit ratios are hard to measure such as in education, health, environment, in case climate change [Annex B]. If not fully ignored, equity is anyhow the Cinderella of economics, with the argument: 'first you need to be efficient in obtaining the wealth for being fair later'. The 'later' is mostly left over to other social sciences and politics.

This artificial division of labour is not helpful in designing and implementing workable climate policies. For overcoming the resistance against carbon taxing, recycling the tax receipts for buying support of constituencies is proposed and tested (Marten and van Dender 2019; Carattini et al. 2019). Canada (British Columbia) and Switzerland apply 'Fee \& Dividend' substitutes for Taxes. The latter schemes address limited jurisdictions.

Table A.2 Criteria (attributes to own, results to obtain) for assessing the performance of policy instruments

1 Environmental effectiveness - Efficacy (measurable change and results)

a Private actors take mitigation / adaptation measures

b No or little leakage erodes obtained results

c The measures are robust, not halted by circumstantial events

d Rebound effects can be contained

2 Efficiency (results are obtained at least costs)

a The sum of abatement and damage costs are minimized

b Cost-effectiveness in abating carbon emissions

c Dynamic efficiency: declining abatement costs by technological innovation

d Macroeconomic efficiency through co-benefits

3 Equity (fairness, outcome and procedural ethics)

a The 'Polluter Pays Principle' is implemented, incl. residual and historical damage

b Specific policies, treating equal cases equally, unequal cases unequally

c Account for distributional effects when designing financial instruments

d Contribute to ethical behaviour towards nature and environment

\section{Administrative and political feasibility}

a For starting, operationalizing, and maintaining the instrument

b Functional in polycentric, multi-level governance

c Monitoring, Reporting and Verifying (MRV) of instrument functioning and results

d Transparent and enforceable 
164 Annex A: Environmental policy-making and carbon pricing

Proposals about 'international per capita dividends' from revenues collected by a global uniform CP resound the pledges of the Clean Development Mechanism of COP3 in Kyoto (1997). Equity progresses more by transparent measures included in commitments and rules decided during the design and approval of specific policies. For example, one may design progressive carbon taxing schemes requesting more contributions from the rich than from the poor.

In addition to the $3 \mathrm{E}$ triptych for measuring performance, one may add three climate policy design criteria (coherence, comprehensiveness, specificity) and four policy process criteria (urgent and drastic, flexible and adaptable, responsible and accountable, administrative and political feasible). In Table A.2, administrative and political feasibility is included, given its importance for getting any policy started and running (Gupta et al. 2007; Rabe 2018). 


\section{Annex B: Cost-benefit analysis in the context of climate change}

In Environmental and Natural Resource Economics Cost-Benefit Analysis (CBA) occupies a central place (Fisher 1981; Turner et al. 1994; Tietenberg and Lewis 2015). CBA is the cradle of the most ideal of all CPs in welfare economics: the 'Social Cost of Carbon (SCC)'. Hence, CBA is described here, with attention for some salient problems when applied in the context of climate change and the design of climate policy.

Section B.1 introduces the CBA scheme as mostly presented in environmental economics textbooks. Section B.2 presents the broader Values $\Xi$ Driving Forces $\Xi$ Pressures $\Xi$ State $\Xi$ Impact@Response (VDPSI@R) framework for a comprehensive view on climate change (CC), encompassing a diptych of private and public issues. Section B.3 specifies a more appropriate framing of CBA for explicit consideration of the private-public diptych. The pivot of the diptych is a reliable conversion of private tons of GHG emissions in public GHG atmospheric concentration ( $\mathrm{ppm}$ ). Section B.4 presents an overview of environmental values to be considered when the impacts of CC are assessed in preparing the necessary policy responses. Section B.5 illustrates the context wherein climate change CBA is conceived. The context space is divided in three parts distinguishing the usefulness of CBA, from practical, over problematic, to counter-productive.

CBA is a tool of welfare and public economics. It may be seen as an extended and public version of private capital budgeting. The latter tool estimates future financial revenues and expenses (cash flows) for appraising the profitability of intended investments (Dixit and Pindyck 1994; Bierman and Smidt 2006). Including only financial revenues and expenses of a private entity skips the essential issues of societal decision-making.

For obtaining social relevant benefits and costs, monetary revenues and expenses have to be augmented with related public benefits (like spill-over effects of inventions) and public costs (by air pollution, climate deterioration, loss of biodiversity, etc.). The identification, quantification, and monetizing of public benefits and costs are linchpins of CBA, but all extremely challenging in obtaining meaningful, reliable numbers.

For CBA studies to deliver practical answers, scholars proposed specific methods beyond and besides neoclassical economics theory (Lesourne 1975; 
Turner et al. 1994). For example, while neoclassical theory eschews interpersonal utility comparison, CBA is based on aggregated willingness-to-pay of large groups of people, although who is included in the CBA constituency is often unclear (Tietenberg and Lewis 2015).

For treating distributional effects, compensation rules are discussed, and some CBA may assign weights to identified groups of citizens. Being aware of the many unsolved issues, partial methods and approximate assessments, are common when using CBA in climate change decision-making. Nonetheless, CBA is highly influential in societal discourses, calling in the argument 'there is no better alternative'.

\section{B.1 CBA schemes as used in economics publications}

CBA occupies a central position in climate policy, dominantly argued in economic terms. Abatement (often called: mitigation, compliance) costs are private expenditures for reducing GHG emissions. For economists the present level of an aggregate of emissions $\left(\mathrm{Q}^{\circ}\right)$ is the least-cost mitigation position, because polluters always minimize their spending.

Benefits are the result of diminishing the damages for societies caused by climate change being an effect of GHG emissions. Welfare is maximized when the sum of abatement costs and damage costs is minimized.

The mathematical logic is summarized as:

Let: $Q=$ variable quantity of emissions (tons)

$\mathrm{Q}^{\circ}=$ emissions quantity without policy triggering (more) reduction efforts

Thus: $\left[\mathrm{Q}^{\circ}-\mathrm{Q}\right]>0$ is the reduction effort variable

$\mathrm{Q}^{\star}=$ welfare maximizing (= minimizing abatement + damage costs $)$ quantity Let: $\mathrm{DC}(\mathrm{Q})=$ damage costs increasing with higher levels of emissions $\mathrm{Q}$ $\mathrm{AC}\left(\mathrm{Q}^{\circ}-\mathrm{Q}\right)=$ abatement costs increasing with reduction efforts $\left(\mathrm{Q}^{\circ}-\mathrm{Q}\right)$

The sum of costs $\left\{\mathrm{DC}(\mathrm{Q})+\mathrm{AC}\left(\mathrm{Q}^{\circ}-\mathrm{Q}\right)\right\}$ is minimum for the 'optimum' quantity $\mathrm{Q}^{\star}$, meeting the first order condition $\left\{\mathrm{MDC}(\mathrm{Q})+\mathrm{MAC}\left(\mathrm{Q}^{\circ}-\mathrm{Q}\right)\right.$. $(-1)\}=0$

Or: $\mathrm{MAC}\left(\mathrm{Q}^{\star}\right)=\operatorname{MDC}\left(\mathrm{Q}^{\star}\right)$

The logic is illustrated in Figure B.1. The top panel shows the total cost curves, both mounting more than proportionally when their driving variables increase. The bottom panel shows the marginal cost curves: the ordinate shows marginal costs in $€ /$ ton (like a price or tax rate); total costs are areas under the marginal curves: area $\mathrm{OQ}^{\star} \mathrm{S}$ are total damage costs at $Q^{\star}$ ton emissions, and area $Q^{\circ} Q^{\star} S$ are total abatement costs for reducing $\left[\mathrm{Q}^{\circ}-\mathrm{Q}^{\star}\right]$ tons. The price at the height of point $\mathrm{S}$ is named the 'Social Cost of Carbon' (SCC) when the CBA scheme is applied on carbon or $\mathrm{CO}_{2}$-eq GHG emissions.

Formally, the logic is correct. Problems start with the logic's practical applications, requesting accurate determination of: 
Annex B: Cost-benefit analysis in the context of climate change 167

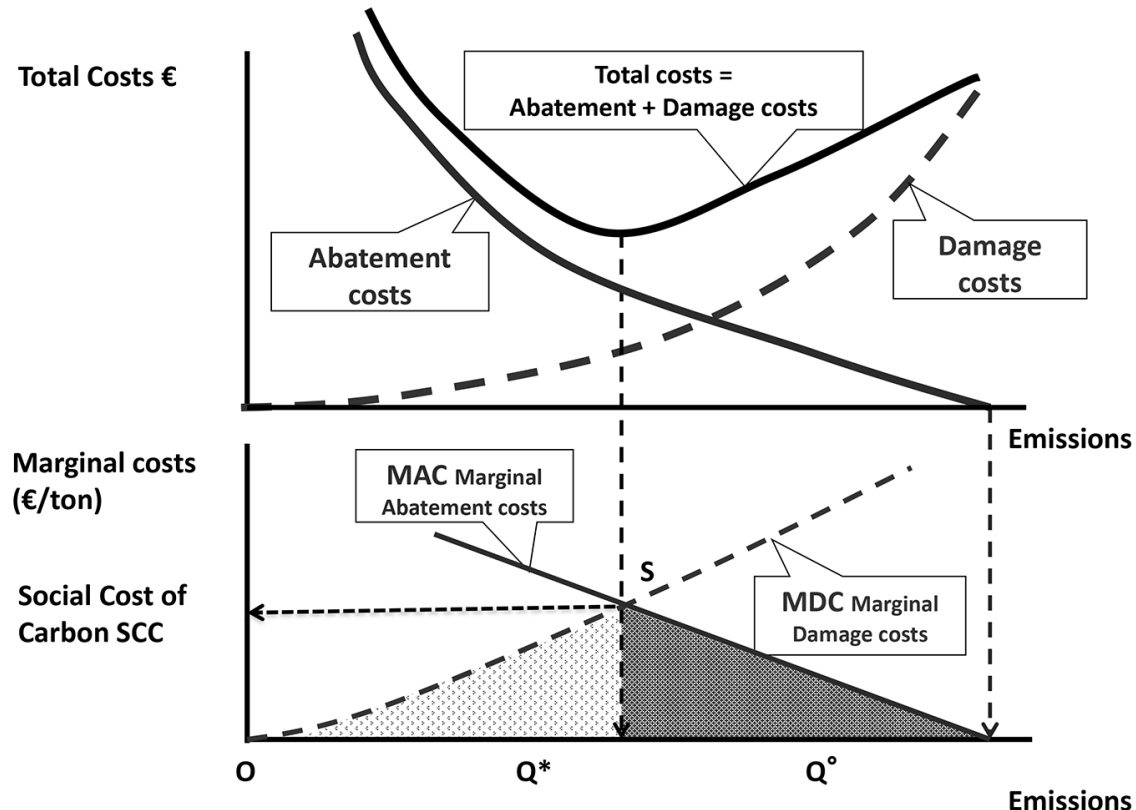

Figure B.1 Simple cost-benefit framing of environmental economics textbooks

- Precise identification of subject, spatial and temporal scope of the application.

- Proper estimation and aggregation of the (marginal) abatement costs of the scoped emissions sources.

- Proper estimation and aggregation of the (marginal) damage costs of the scoped impact factors in the area covered.

Applied on climate change, neoclassical economists advocate the global and very long-term scope, including all emission sources. Because the global scope is tremendously wide (billions of sources with trillions of emission batches daily (Nordhaus 2007)), even economists step down to a regional (EU) or a big nations (USA) spatial scope, and/or to a limited selection of large emission sources. The difficulties in estimating proper functions (curves) of abatement and damage costs are immense, especially for the damage costs (Mayumi 2019).

\section{B.2 Climate change framed in VDPSI@R}

The study of environmental problems in a societal and policy context started about half a century ago. The OECD (2003) introduced environmental indicators in causal frames. Systematic state-of-the-environment reporting uses a Driving forces - Pressures - State - Impacts - Responses (DPSIR) frame. 
Private sphere: causes, triggers, activities Mitigation - Abatement

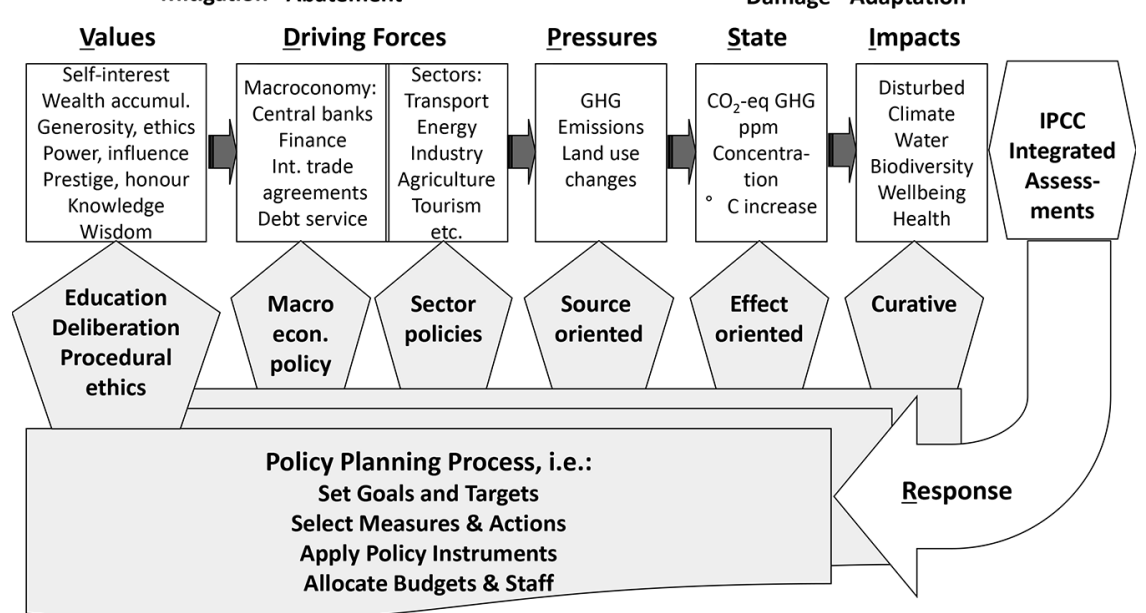

Figure B.2 VDPSI@R framework addressing climate change

Causal sequence Values $\rightarrow$ Driving Forces $\rightarrow$ Pressures $\rightarrow$ State $\rightarrow$ Impacts (a) Response, structured as a Policy Planning Process addressing all components of the causal sequence.

Attention for societal embedment adds upfront Values highly influential on how people organize their societies, and emphasizes the inclusive role of policy responses at the end, giving VDPSI@R. The mentioned values are inspired by the Kant-Ricoeur triptych 'Avoir - Pouvoir - Valoir', completed with 'Savoir' because knowledge and wisdom are esteemed high, pursued by many (Hardy 2014). Figure B.2 shows the VDPDI@R framework, with clarifying words for the various components.

A few meta-comments more:

The Value component refers to personal values and motives, ensuing activities deployed in communities, societies, national states, and international settings. For global climate policy, the full diverse people's world is streamlined in a causal sequence up to Pressures on nature and environment. Reducing the pressures requests initiatives of people, changing activities causing efforts and expenses to progress in mitigation - abatement. Emissions and emission reductions own the attributes of private goods.

The state of the environment is the result of the various pressures changing the natural course of nature, being the cause of multiple impacts. For CC the usual state indicators are global GHG ppm concentrations in the atmosphere, and temperature increase compared to pre-industrial times. Impacts are predominantly negative, often classified as adverse changes in environmental and natural capital and services, in human health, amenities and life conditions, and in economic wellbeing.

The causal chain is followed by assessments of the impacts and their preceding phases. IPCC publishes integrated assessments since 1990, the sixth one 
expected by 2021. The assessments are the scientific basis for structuring the Response as a consistent policy planning process, which addresses all VDPSI components in a specific, appropriate way. Early environmental policies started with curative measures. The upstream policy crawling to address consistently and comprehensively the societal Pressures, Driving forces up to Values has still a long way to go.

Pinpointing in the VDPSI@R framework the coverage of climate change issues by IPCC's Working Groups (WG) shows: WG1 focuses on State, WG2 on Impacts and adaptations, WG3 on Driving forces and Pressures, and also on Integrated Assessments and policies (in a descriptive way). The contributions of the world's knowledge about the components is almost $100 \%$ for WG1, nearing 50\% for WG2, presumably less than $10 \%$ for WG3. The low integration of knowledge by WG3 is due to the huge abundance and diversity of Driving forces, Pressures and Responses, and by WG3's fixation on neoclassical economics and neoliberal paradigms.

A climate change CBA assumes to encompass the full VDPSI reality, the private and public spheres. This merits at least an improved textbook scheme (shown in Section B.3) opening a wider window, when introducing freshmen to climate change CBA concepts.

\section{B.3 Climate change CBA connecting the private and public worlds}

The envisaged global climate policy CBA is shown as stylized trade-off scheme between abatement and damage costs in Figure B.3. An overlay of the private mitigation - abatement sphere and public damage sphere [Figure B.2] reveals the distinct character of both. The time slot of such trade-off is mostly not identified; one could think of one year (bypassing the difficulties of dynamics) for fixing the amounts of emissions reduction to impose on the aggregate emission sources.

Linking emissions and concentration is scientifically challenging, although climate scientists have made considerable progress on this relation. Aggregating the marginal abatement cost curves of all emitting points is problematic, given the knowledge about single abatement cases is shaky. Even when separate case information would be perfect, the amalgamation of heterogeneous cases is doubtful practice. Nonetheless, aggregate MACs are widely used in climate CBA included in Integrated Assessment Models (IAM). Although the approach of the various IAM versions is similar, their results reveal wide numeric differences (IPCC, WG3 reports).

By the public good character of damage (or the reverse: benefits from less damage), the aggregate MDC curve is the vertical sum of the monetized values of numerous types and intensities of damages experienced by all the exposed people within the scoped area, in principle the globe for CC. The methods for assessing damage values are several. Nonetheless, their results remain very contentious, because the studies employ ad-hoc bypasses, rule of thumb estimates, transfers from other studies, etc. In Figure B.3, the slope of the aggregate MDC is shallow 


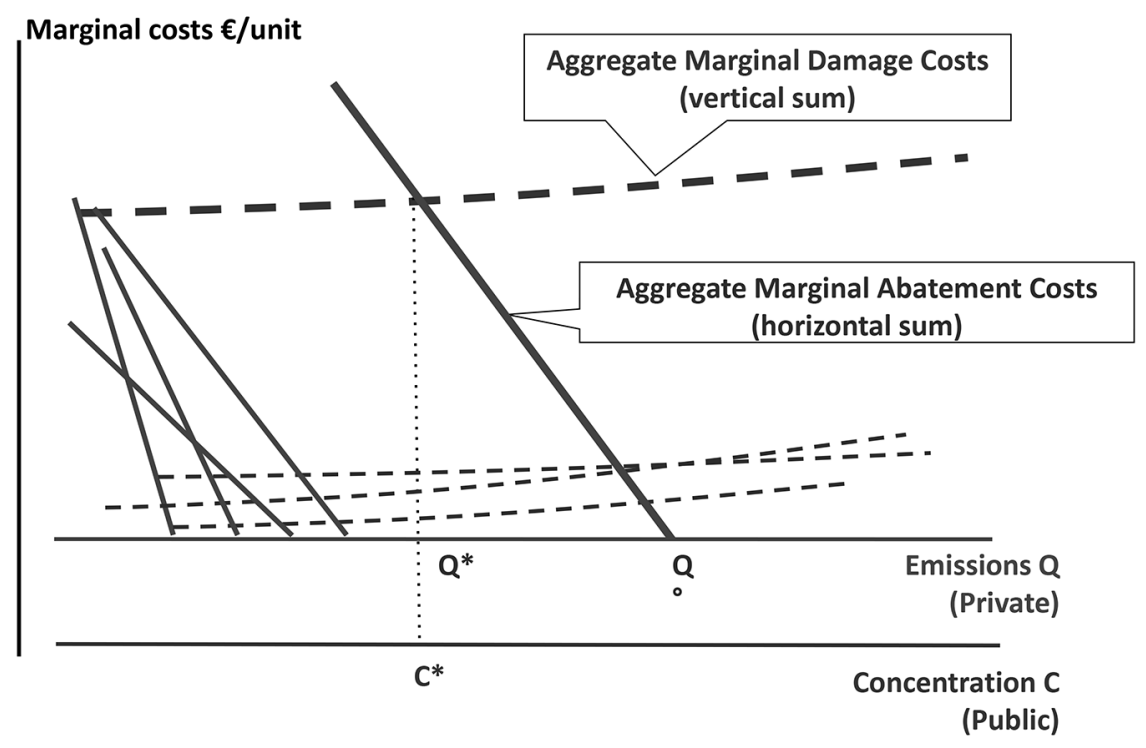

Figure B.3 Cost Benefit Analysis applied to climate change

because it is only valid for the trade-off during a single year. As argued in Chapter 3, the structure of the MDC over time is like mounting a stair: every following year a higher step, with every step being (almost) flat.

Private Abatement costs for reducing emissions trade-off against Public Damage costs related to GHG concentrations requires proper linking of emissions Q (Pressures) with concentration C (State).

\section{B.4 Assessing the impacts of climate change}

The short, non-exhaustive list of impact categories in Figure B.2 announces the difficulties in assessing all impacts in a reliable way. The enumeration and description of all major impacts and their likely evolution over time are challenging tasks (IPCC WG2 Reports). The further step of quantifying the identified impacts in monetary values is neither evident, because observable market prices are lacking (Arrow 1974). The willingness-to-pay by constituencies (the global constituency) for un-priced goods \& services is indirectly assessed. However, the results are always partial and often of poor quality.

Figure B.4 shows a catalogue of environmental values, some mentioned before, for example Turner et al. (1994); Vilkka (1997). Tietenberg and Lewis (2015) provide an introduction to the valuation methods used by environmental economists, including an overview of the provisioning, regulating, cultural, and supporting ecosystems services (their loss or degradation being one of the impact categories).

Figure B.4 sets relevant values in a frame built with one bifurcation and three dialectic relations. Short descriptions are included. The overview 
Annex B: Cost-benefit analysis in the context of climate change 171 Bifurcation of perspectives

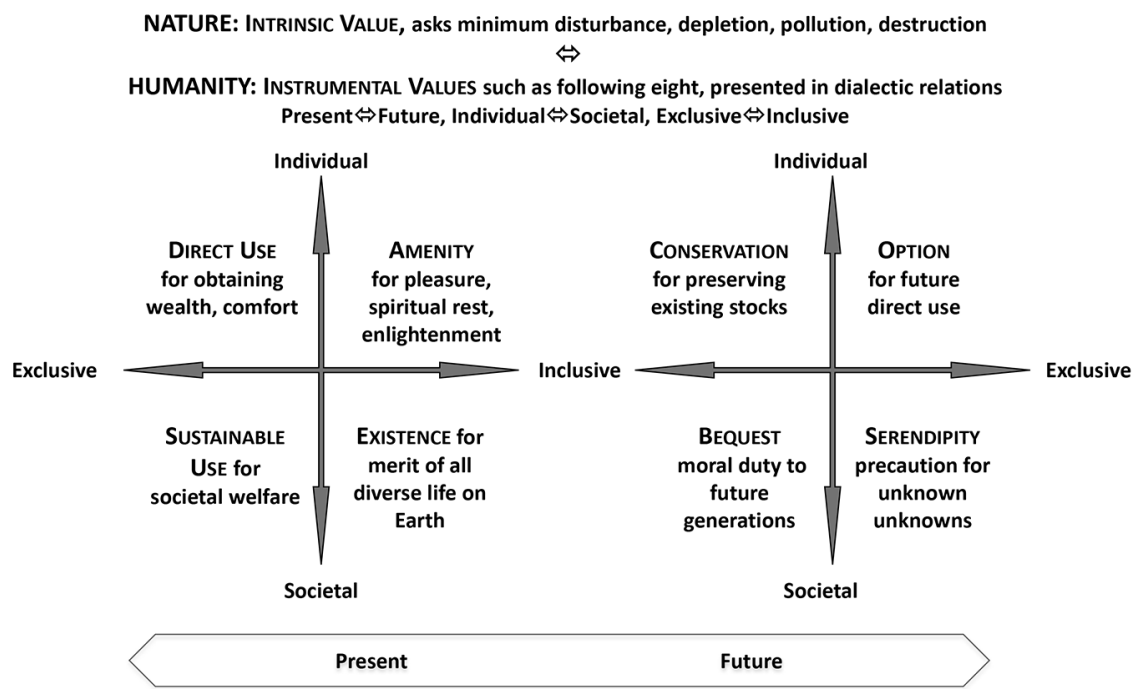

Figure B. 4 Valuing impacts on nature and environment: catalog of values

highlights the unlikelihood of identifying and measuring in monetary terms most of the values, with perhaps the exception of direct use value. Nevertheless, the values are real and important. Rather than pursuing numerical quantification, binary coding of their availability (Yes/No) and assignment of weight on an interval scale may advance the attention for the bypassed values. The specificity of the investigations implies decentralized set-ups, taking into account the diversity of people, societies and natural environments.

At present, IAMs are the main tools used for assessing mitigation and damage costs of climate change, and influencing the official global climate policy process.

\section{B.5 The limited applicability of CBA for climate policy}

The climate CBA scheme is an overlay of two worlds: the private world of driving forces \& pressures, mitigation-abatement, and the public world of state \& impact, damage-adaptation. CBA takes an important place in climate policy by their incorporation in the Integrated Assessment Models (IAMs) delivering the scenario outcomes in the Assessment Reports of IPCC WG3. Ackerman et al. $(2009$, p. 309, 312) argued that

most IAMs rely on an analytical framework that privileges immediate, individual consumption over future-oriented concerns; that the benefits, or avoided damages, from climate mitigation are both unpredictable in detail and intrinsically non-monetizable; and that the conventional economic view of technology misrepresents the dynamic, socially determined 


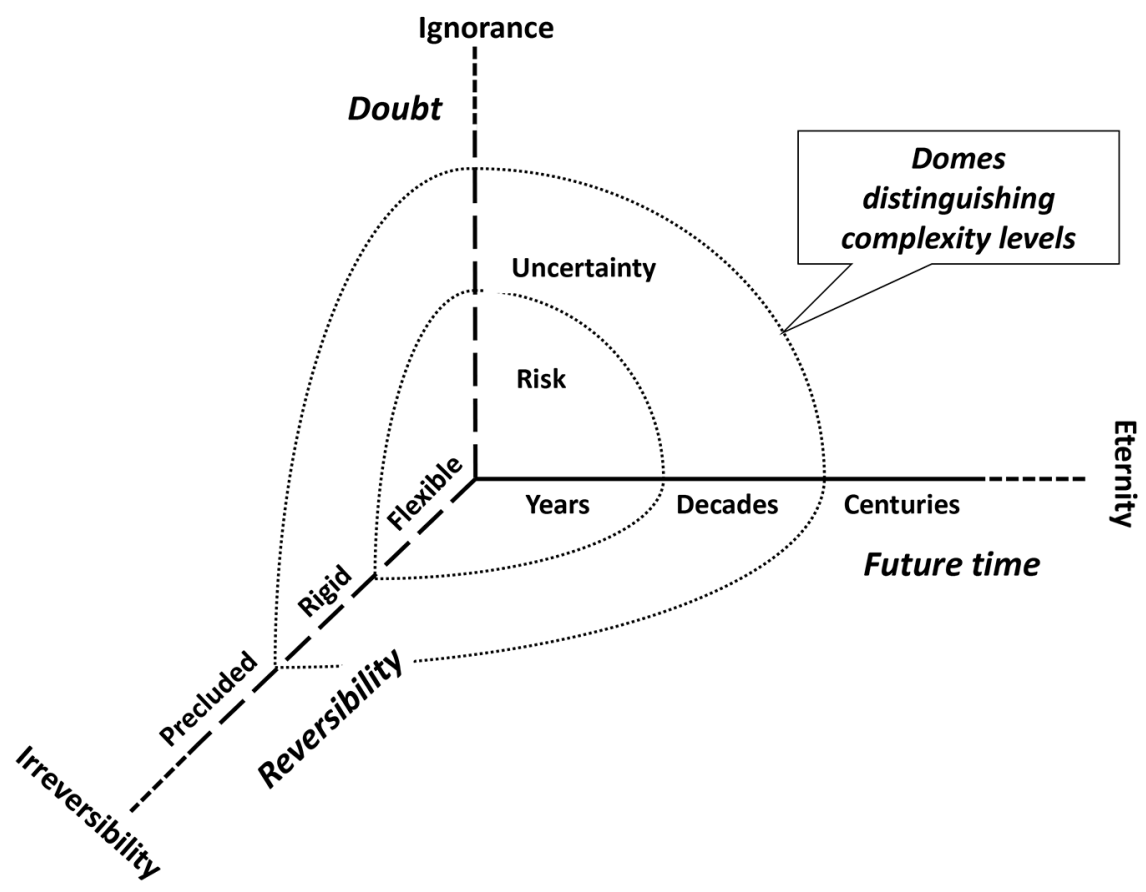

Figure B.5 Decision-making context of future time, doubt, and reversibility

nature of technical change ... [and] do not embody the state of the art in the economic theory of uncertainty.

Comprehensive assessment of public damage costs faces very long spans in future time (Cline 1992), doubts expressed as risks, uncertainty, ignorance, and the looming danger of irreversibility. This challenging context is shown in Figure B.5 for distinguishing various levels of complexity. Near the origin of the three-dimensional space, the context is standard and manageable. Doubt in terms of risk, a future time span counted in years, and flexible reversibility, together make CBA feasible, practical, and helpful.

The situation between the two domes is grading towards complexity: under uncertainty probabilities are subjective, the time span runs in the decades and rigidity reduces degrees of freedom in reverting failing systems, weakening their resilience. This makes CBA problematic and the results contingent on many assumptions. When performed carefully with explicit attention for the contentious issues, CBA still can play a subservient role in decision-making. Beyond the outer dome, complexity dominates because uncertainty turns in ignorance, very long time spans eye eternity, and precluded reversibility nears irreversibility. Under such circumstances, CBA is counter-productive because it presents opinions and guesses as knowledge. This is economics in Utopia. 


\section{Annex C: Cost-effectiveness and diversity of emitting sources}

Because assessed climate damage costs are of dubious quality, economists and policymakers tend to focus on the mitigation-abatement section of the climate changeVDPSI@R [Figure B.2]. They set targets for emission reductions in one or more future years and select policy instruments to command or to provide financial incentives to individual polluters to reduce their emissions.

Annex C holds four sections. Section C.1 describes the behaviour of the economic rational polluter when submitted to environmental policy. Section C.2 broadens the perspective beyond the single representative polluter. In Section C.3 several sources under a Cap and Trade regulation are considered. The basic idea of emissions trading is graphically explained in Section C.4.

\section{C.1 Behaviour of the economic rational polluter}

The economic logic is documented with an average, assumed 'representative', polluter [Figure C.1]. Whatever policy instrument - tax or standard - is applied, an economic rational polluter minimizes the abatement (mitigation, compliance) expenditures.

Let

$\mathrm{q}=$ quantity of emissions by the polluter

$\mathrm{q}^{\circ}=$ quantity emitted before new policy is applied, minimizing AC to $€ 0$

$\mathrm{q}^{\#}=$ emissions level targeted by the new policy via a policy instrument

$\mathrm{q}^{\circ}-\mathrm{q}^{\#}=$ emissions reduction for reaching the target from position $\mathrm{q}^{\circ}$

The regulator may command $\mathrm{q}^{\#}$ as standard (= maximum emitted volume) the emitter should reach by reducing a quantity of $\left(q^{\circ}-q^{\#}\right)$ tons emissions, given $\mathrm{q}^{\circ}$ as initial least-expense position. Obeying the standard asks $€$ area $<\mathrm{q}^{\circ}-\mathrm{q}^{\#}-\mathrm{S}>$ abatement expenses, paid by the polluter, according to the light version of the Polluter Pays Principle. ${ }^{1}$

This 'command and control' $(\mathrm{CaC})$ regulation was, and still is, common in environmental policy. Then, polluters should get $\mathrm{q}^{\#}$ free permits to emit. In practice, the number of free assigned permits is constrained by 'Best Available 
174 Annex C: Cost-effectiveness and diversity of emitting sources

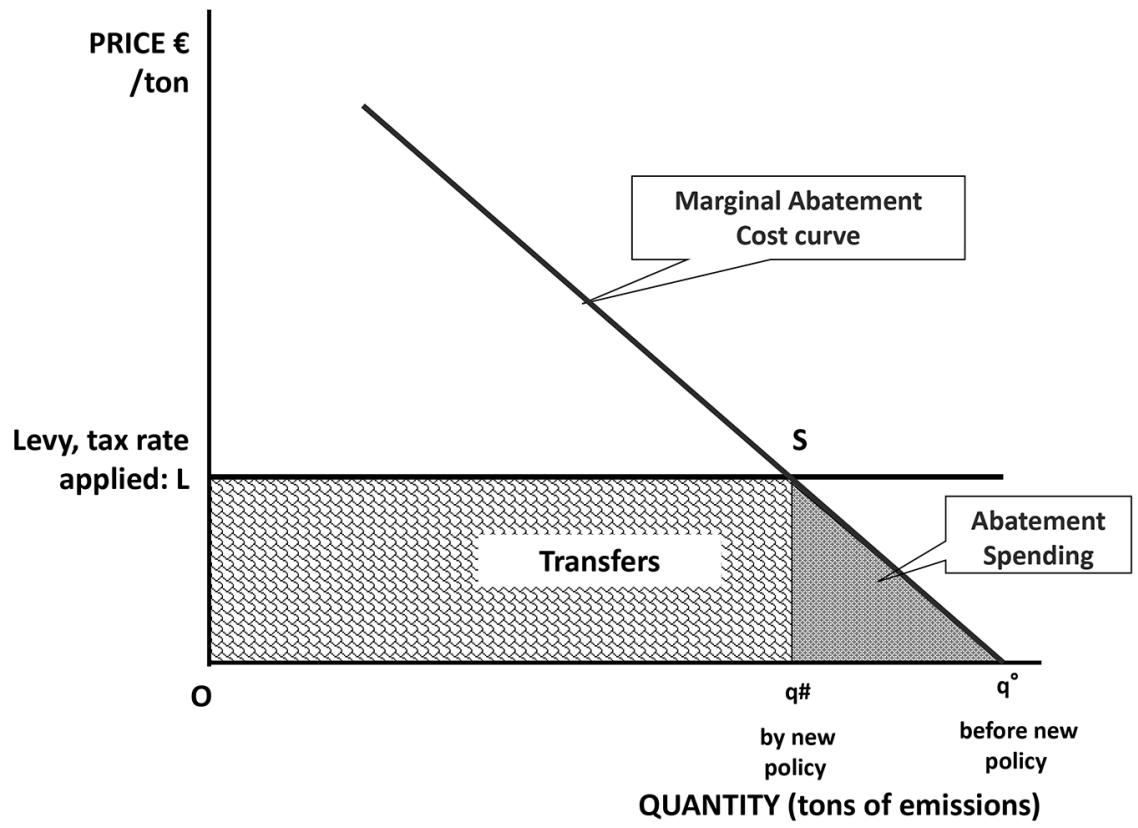

Figure C.1 Rational polluters reduce emission level from $\mathrm{q}^{\circ}$ to $\mathrm{q} \#$ in reaction to a permit $\mathrm{q}^{\#}$ or an imposed levy $\mathrm{L}$ per ton emitted

Technology' (BAT) references, with $\mathrm{q}^{\#}$ assignments ample enough for not unduly hampering business activities. At the end of the regulatory control periods expire permits that remained unused (for example because of a sudden economic downturn).

Asymmetric information among polluters and regulators may erode the stringency of standards. Uniform $\mathrm{CaC}$ instruments as top-down, rigid one-way commands, cause efficiency losses when applied on heterogeneous sources. However, $\mathrm{CaC}$ instruments have variants of specific designed optimization paths for innovation in deliberation between regulator and large emitters, allowing flexibility and technological creativity. Such approach generates more benefits than MBIs assumed to function in a frictionless world.

When a $€ \mathrm{~L}$ levy per ton emitted is installed, an economic rational emitter reacts by finding the level of emissions causing the least expenses for him. The expenses are the sum of a levy bill and abatement outlays, minimized as:

Min.! $\left\{\mathrm{L} . \mathrm{q}+\mathrm{AC}\left(\mathrm{q}^{\circ}-\mathrm{q}\right)\right\}$, with first order condition:

$\mathrm{L}-\operatorname{MAC}(\mathrm{q})=0$, or MAC $(\mathrm{q})=\mathrm{L}$, which solves for $\mathrm{q}=\mathrm{q}^{\#}[$ Figure C.1]

When the polluter's emissions equal $\mathrm{q}^{\#}$, expenditures are: $€ \mathrm{~L} . \mathrm{q}^{\#}$ (area rectangle with diagonal $\mathrm{O}-\mathrm{S})$ as transfers to the public treasury $+€$ area $\left.<\mathrm{q}^{\circ}-\mathrm{q}^{\#}-\mathrm{S}\right\rangle$ 
abatement expenses. Transfers are not costs because money is only moved from a debit to a credit account. However, transfers are (considerable) financial expenses for regulated emitters, explaining why they (fiercely) oppose levies and taxes as policy instrument. They also distrust schemes that organize rebates for their $€$ transferred to the treasury, because rebating mostly is not full and the redistribution mechanisms may turn out negative for the accounts of individual polluters. Anti-tax coalitions are swiftly founded and attract large parts of the constituency. Politically, levies are difficult to pass, except when the bill can be rolled on other constituencies, as is the case for most severance taxes in U.S. oil winning states (Rabe 2018).

\section{C.2 Consider two (groups of) polluters}

The analysis is extended to a case with two polluters [Figure C.2], 'representative' for two different groups. After explaining the standard economic view, we discuss two interpretations of the differences.

A uniform levy L per ton emitted is charged, and every polluter minimizes the own expenses by fixing their emission levels such that the MAC equals $\mathrm{L}$, or:

$\operatorname{MAC}^{\mathrm{x}}\left(\mathrm{q}^{\mathrm{x}}\right)=\mathrm{L}$ and $\operatorname{MAC}^{\mathrm{y}}\left(\mathrm{q}^{\mathrm{y}}\right)=\mathrm{L}$. Hence: $\operatorname{MAC}^{\mathrm{x}}\left(\mathrm{q}^{\mathrm{x}}\right)=\operatorname{MAC}^{\mathrm{y}}\left(\mathrm{q}^{\mathrm{y}}\right)=\mathrm{L}$.

Equalized MAC by selecting the appropriate pollution quantities means that the aggregate abatement expenses are minimum, making a uniform levy effective and efficient. This result would not be obtained by a uniform

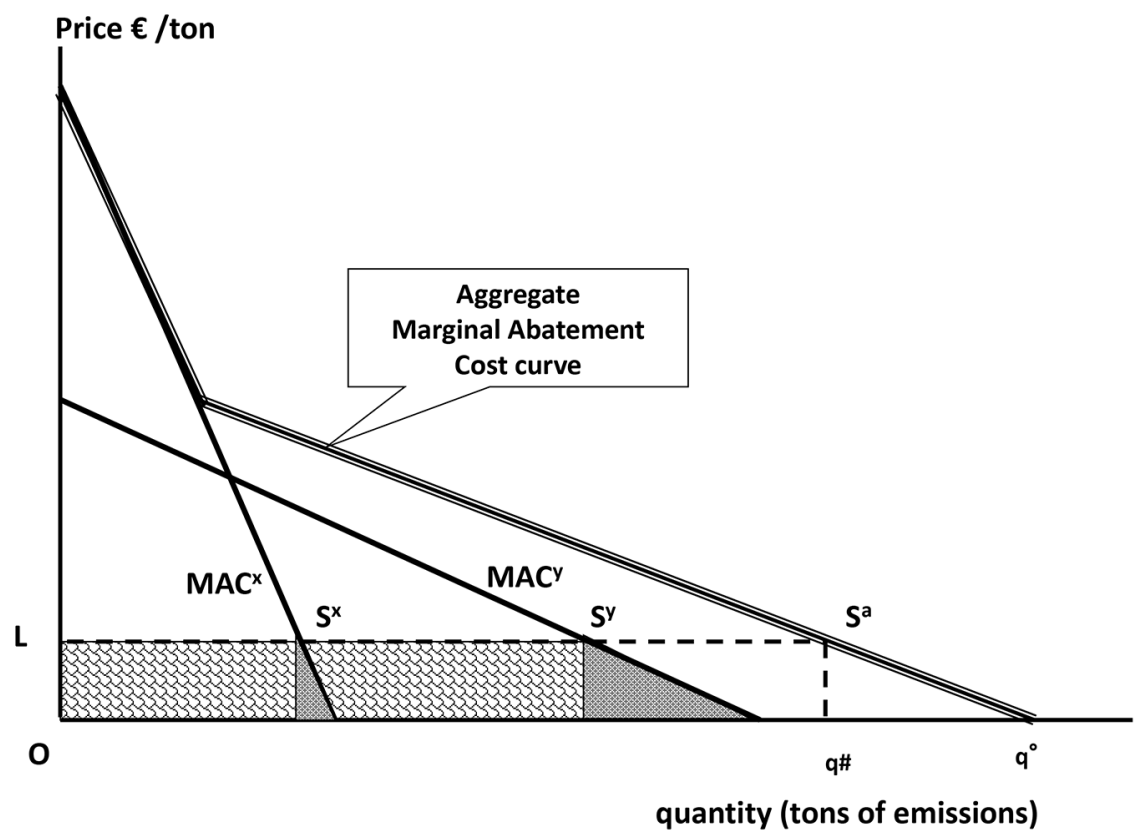

Figure C.2 Aggregate MAC of steep $\mathrm{MAC}^{\mathrm{x}}$ and shallow $\mathrm{MAC}^{\mathrm{y}}$ 
standard like 'all sources reduce by $20 \%$ '. This would disadvantage polluter $\mathrm{x}$ (steep MAC) and advantage polluter y (shallow MAC). Nonetheless, all polluters, also $\mathrm{x}$, will prefer the standard, for avoiding the significant tax money transfers to the public treasury.

Going beyond the first-hand mathematical optimization brings the question: What cause and mean the differences between $\mathrm{x}$ and $\mathrm{y}$ ? Are the activities $\mathrm{X}$ and $\mathrm{Y}$, their embedded technologies, material flows for performing the activities, regulatory and economic contexts, homogeneous or heterogeneous?

When homogeneous, main causes of differences may be entrepreneurial capability, advantageous circumstances (like the ones explaining Ricardo rents), or another position on the pioneer-laggard innovation scale (Schumpeterian rents). Pioneer companies will likely face steeper (short-run) MAC curves, and laggard companies shallower curves because the latter can still harvest low-hanging fruit.

Homogeneous activities are best submitted to equal (uniform, common) regulation to obtain the static economic first optimum. A flat levy (tax) is recommendable for cutting the emissions of homogeneous sources. A tradable permit system may hold some stimuli for further innovation, the source of dynamic efficiency. In a homogeneous situation it is unlikely that the differences among the MAC of the sources will be significant, and regulation by appropriate standards would neither cause large efficiency losses.

When the activities $\mathrm{X}$ and $\mathrm{Y}$ are heterogeneous, significant differences in the MAC of the heterogeneous sources may exist. Handling such heterogeneity diverges: Either one partitions the heterogeneous total in separate homogeneous parts, each part receiving specific regulation, or one applies neoclassical economics theory across the heterogeneous cases. For example, climate policy for the industrial activities is either developed by sector, or uniform over the amalgamated sectors. On paper, the latter approach will announce huge gains by applying uniform levies or a single emissions trading system. In practice, heterogeneous sources are better approached with specific regulation per sufficiently homogeneous category [Chapter 2].

\section{C.3 Emissions of many sources restricted by a quota}

The case of two emitters is extended to several groups of many emitters. When a quota $Q$ restricts the sum of their emissions, the Lagrange theorem finds the most efficient sharing of the reduction burden over all emitters.

Minimizing the abatement expenses of $\mathrm{N}$ emission sources, with the sum of their emissions capped by a quota $\mathrm{Q}$, runs as follows:

$\operatorname{Min} ! \Sigma i \operatorname{ACi}(q i)$, subject to $\Sigma \mathrm{i}$ qi $=\mathrm{Q}$, or:

$\operatorname{Min} !\{\Sigma$ i ACi(qi) $-\lambda[\Sigma$ i qi $-Q]\}$

The $\mathrm{N}$ emission quantities qi $(\mathrm{i}=1 \ldots \mathrm{N})$ and the introduced multiplier $\lambda$ are unknown variables. The solution holds $\mathrm{N}$ first order conditions, here 


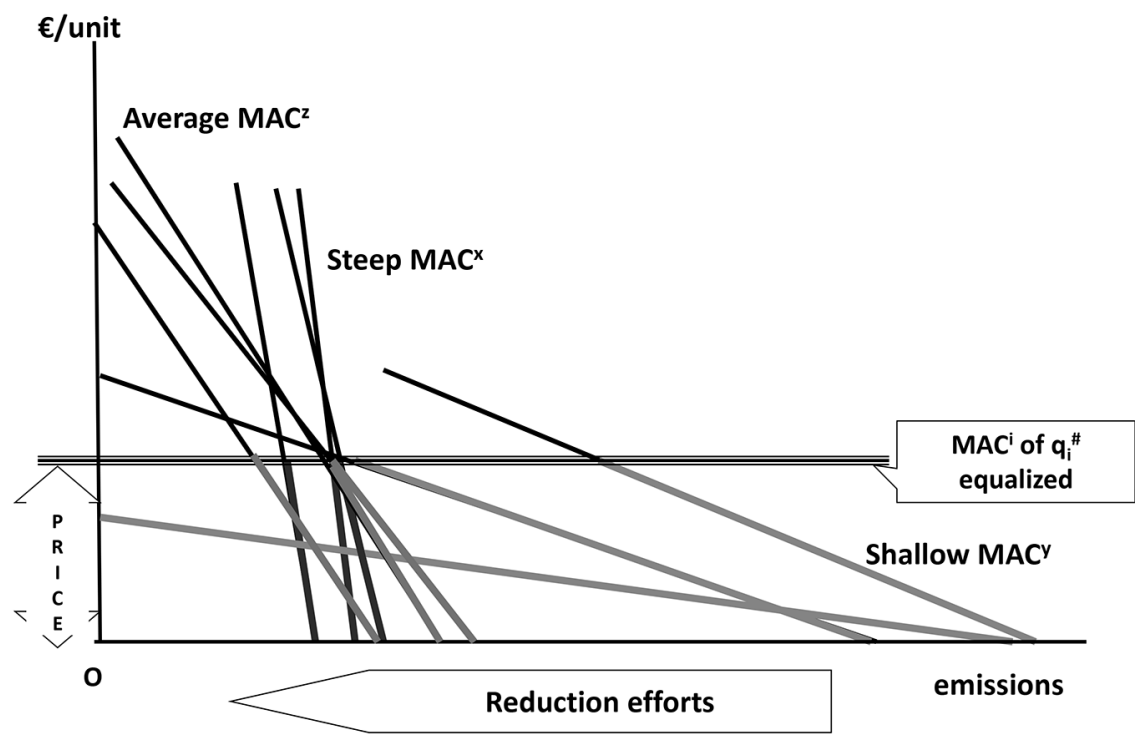

Figure C.3 Minimizing the sum of abatement expenses of three categories of emitters

summarized as: $\mathrm{MAC}^{1}=\ldots=\mathrm{MAC}^{\mathrm{i}}=\mathrm{MAC}^{\mathrm{j}}=\ldots=\mathrm{MAC}^{\mathrm{N}}=\lambda$. The $(\mathrm{N}+1)$ condition is respecting the constraint $\Sigma \mathrm{i} q \mathrm{i}=\mathrm{Q}$.

The $\mathrm{N}$ emission quantities are optimal when the marginal abatement costs of all $\mathrm{N}$ sources are equal and equal to $\lambda$, with $\lambda=\partial \mathrm{AC} \# / \partial \mathrm{Q}$ (the marginal change in the minimum abatement costs when quota $Q$ is changed marginally).

Figure C.3 is a graphical representation of the Lagrange theorem applied on three groups of emissions sources $\mathrm{X}$ (steep MAC curves), Y (shallow MAC curves), and $Z$ (average MAC curves). A uniform price (levy, tax) on all emitted tons will incentivize the emitting sources to reduce their emissions up to emission levels where their MAC equals $\lambda$. The sum of the abatement costs of all emitters would be minimum.

The Lagrange theorem is equally valid for sets of polluters belonging to a homogeneous group and for amalgamated sets of heterogeneous groups. Mathematical theorems are impartial for specific or amalgamated coverage. Hence, they do not provide a scientific ground for arguing in favour of amalgamated approaches of heterogeneous cases.

\section{C.4 Establishing the uniform price via emissions trading}

Instead of calling in the visible hand of public authorities to set the uniform levy on carbon emissions, economics favour the 'invisible hand' of the market. Emission permits or allowances (licenses to emit) are distributed among the participants in a scoped market. How this allocation may happen is discussed in Chapter 3. The MAC $\mathrm{M}^{\mathrm{i}}$ of the many sources are the actual demand curves of 


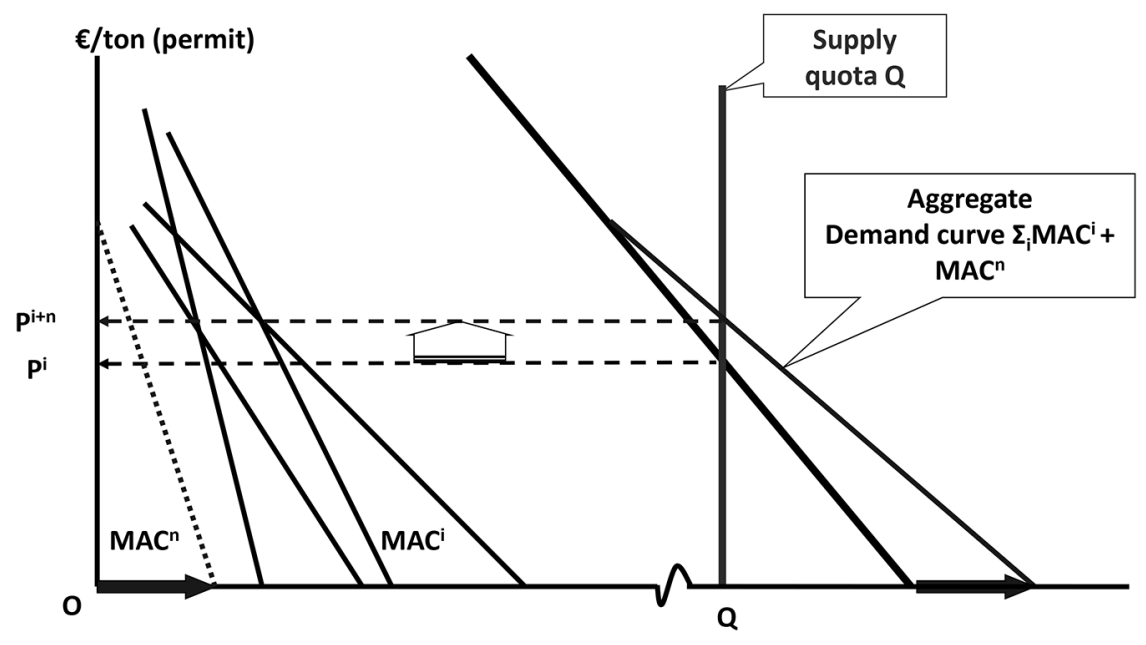

Tons of emissions

Figure C. 4 Market of tradable permits

Supply curve is a fixed quota Q - Demand curve is the aggregate of MAC of covered sources (adding a new source with $\mathrm{MAC}^{\mathrm{n}}$ shifts the demand curve, generating a higher price per permit).

emitters $i$, expressing their willingness-to-pay for permits. The market demand is the horizontal sum of all MAC $\mathrm{MArves}^{\mathrm{i}}$ [Figure C.4].

The supply is the vertical line at the quota $Q$, mostly called the 'cap'. The supply is inelastic and decided by a public authority that offers the licenses to emit. At the crossing of the supply and aggregate demand curves, the equilibrium price is set, valid for all market participants. In addition to fulfil the Lagrange optimization conditions [Section C.3], the market mechanism is flexible. When emitting sources are added, the appropriate higher price is settled to distribute the increased scarcity in permits over all sources [Figure C.4]. A decreasing price is established when the demand for permits shrinks, for example because of economic recession.

Neoclassical economics favours amalgamation of a maximum of heterogeneous sources in one market and announces huge efficiency gains by trade among heterogeneous sources. The more heterogeneous the participants would be the higher are the announced gains. In the amalgamated version, a maximum of heterogeneous sources is covered, such as the EU ETS is doing. In the homogeneous version a specific ETS is limited to a single sector, such as the RGGI covers only the electricity generation companies in North-eastern USA.

The choice depends on valuing or ignoring diversity as productive, structural factor. Covering incompatibility, non-substitutability, disparate technologies, distinct disciplinary specialisms, etc. causes considerable transaction costs, and excessive transaction costs make transact non-optimal. "If some transactions did not appear, it was because it was optimal not to transact" (Demsetz quoted by Vatn 2005, p. 89). 
Indeed, massive exchanges across different industrial sectors are doubtful. Companies anyhow are unwilling to transfer Ebillions to other sectors, endowed with cheap abatement opportunities. Buying relevant technology within the own sector, even from competitors, is observed practice in industry (for example, the common rail injection system on diesel engines). Joint development of sector-relevant low-carbon technology, products, and practices is possible (Verbeke et al. 2017), and likely preferable as most effective and efficient pathway.

To avoid climate collapse all carbon emissions need reduction to zero, as soon as possible. This mission means all emphasis on innovation, changing activities and technologies to zero-carbon versions. Hence, the crucial question: is the mission best served by specific or by uniform financial incentives? Is amalgamated ETS preferable above homogeneous sector ETS? These questions cannot be answered by referring to the Lagrange method, because mathematical theorems are only formal, not substantial.

\section{Note}

1 This is the 'Polluter Pays Principle' in the narrow sense. In its broader sense, polluters should additionally pay for the damage caused by their residual pollution. 


\section{Annex D: The German feed-in-tariff (FIT): Successful financial incentive}

In climate policy, two externality issues are coupled (Jaffe at al. 2005). Goulder and Parry (2008, p. 152) "consider policies that address pollution externalities and policies that deal with market failures associated with efforts to invent or deploy new technologies".

Climate pollution externalities are negative as too much GHG emissions litter the atmosphere and wreck climate stability. It is in the public interest to reduce the negative externalities by penalizing emissions, for example by carbon taxes. Invention of, innovation in, low-carbon technologies create positive externalities beyond the inventors and innovators efforts. Other firms and citizens benefit from the inventions by copying, imitating, or otherwise use of the better knowledge. When inventors cannot appropriate the exclusive or major part of the benefits, not enough invention will take place. Hence, public research institutes and subsidies for private inventors and innovators are warranted. Goulder and Parry (2008, p. 167) conclude: "No single instrument can effectively correct market failures from both emissions externalities and the knowledge appropriability problem".

The German (and Danish) policies accelerated inventions and innovations in renewable energy technologies and deployment since the 1970 s by a 'market pull' instrument creating markets for premature technologies, such as wind and PV. The market creation was realized with the financial incentive instrument FIT (feed-in-tariff). Thorough evaluation makes a scholar lyric about FIT's attributes and results and suspicious about nasty comments on FIT because it disrupts neoclassical economics' doctrine.

Annex D introduces briefly some financial algebra to spell out the meaning of LCp, the 'levelized cost price' of electricity generation projects [Section D.1]. The LCp method is the basis for the assessment of proper FIT numbers for a specific RE technology, illustrated with numerical examples in Section D.2. The problem context for RE development and deployment over the last decades is discussed in Section D.3. Section D.4 evaluates FIT as a financial incentivizing instrument on the standard set of criteria used by environmental economics [Chapter 1, Table 1.2]. In Section D.5 additional evaluative aspects are discussed, with a comment on the shortcomings in the vested economics literature for obtaining a correct view on what FIT is and what it realized. 


\section{D1 Introductory financial algebra}

The following notes are based on a paper prepared by Verbruggen and Nyboer (2009) for the IPCC-SRREN, to standardize reporting of expenses and revenues of RE-supplies. A few points are adapted for this Annex D.

\section{D.1.1 Discounting and net present value (NPV)}

Private people assign less value to things in the future than to things in the present because of 'time preference for consumption' or because of 'return on investment (= non-consumption)'. Therefore, people discount future money amounts. Discounting itself is a mathematical operator: dividing future cash flows by a number $>1$. By discounting to the base year, numbers are converted in the common financial metric of the base year. Discounting a series of net cash flows (= revenues - expenses) over time and adding the results (permitted now because they all are stated in the same reference year - point 0 of the analysis), the NPV is obtained:

$$
N P V=\sum_{j=0}^{n} \frac{\text { Net cash flows }(j)}{(1+i)^{j}}
$$

The value of NPV depends on the yearly net cash flows and on two parameters: the lifetime $n$ of the project and the discount rate $i$. In principle, project results are fully comparable when their NPVs are calculated with the same parameters $n$ and $i$.

\section{D.1.2 Levelized Cost price (LCp)}

Levelized costs are used in the appraisal of conventional power generation investments, where the outputs are quantifiable MWh generated during the lifetime of the investment. The Levelized Cost price is the unique break-even price - constant during the full lifetime of the project - that sets discounted revenues equal to the discounted expenses. Hence it is solved from the following identity:

$$
\sum_{j=0}^{n} \frac{\operatorname{Revenues}(j)}{(1+i)^{j}}=\sum_{j=0}^{n} \frac{\operatorname{Expenses}(j)}{(1+i)^{j}}
$$

or:

$$
\sum_{j=0}^{n} \frac{L C_{p} * \operatorname{Quantities}(j)}{(1+i)^{j}}=\sum_{j=0}^{n} \frac{\operatorname{Expenses}(j)}{(1+i)^{j}}
$$


Because LCp is a constant non-dependent on the year index $\mathrm{j}$, it can be placed before the $\Sigma$ sign, or:

$$
L C_{p}=\sum_{j=0}^{n} \frac{\text { Expenses }(j)}{(1+i)^{j}} / \sum_{j=0}^{n} \frac{\text { Quantities }(j)}{(1+i)^{j}}
$$

This definition of LCp discounts expenses and revenues in the same way. 'Discounting quantities' may seem strange, but considered is the value of the revenues even though they are not in euro but in MWh (i.e., a MWh today is worth more to you than a MWh in the future - we assume the same time value can be applied here as we apply to the expenses).

\section{D.1.3 Annuities and the annuity factor}

A very common practice is the conversion of a given sum of money at moment 0 into a number $n$ of constant annual amounts of money over the coming $n$ future years. This is what households experience as annual (or monthly) mortgage payments for the cash check they received from the bank to pay the house they bought. This is a clear example of what discounting means:

Let $\mathrm{A}=$ annual constant amount in mortgage payments over $n$ years

Let $\mathrm{B}=$ cash amount to pay for the house in year 0

How does the bank derive A from B? The answer: the bank wants to receive $\mathrm{B}$ back at the interest rate $i$. The NPV of $n$ future mortgages A must equal B:

$$
\sum_{j=1}^{n} \frac{A}{(1+i)^{j}}=B, \text { or }: A \sum_{j=1}^{n} \frac{1}{(1+i)^{j}}=B
$$

A can be put before the $\Sigma$ because it is a constant (not dependent on $j$ ).

The sum of the discount factors (a finite geometrical series) is deductible as a particular number (dependent on the parameters $n$ and $i$ ). When this number is calculated, one finds A by dividing B by this number, known as the Capital Recovery Factor or the annuity factor $\delta$ :

$$
\delta=\frac{i \times(1+i)^{n}}{(1+i)^{n}-1}
$$

\section{D.1.4. Shortcut assessment of LCp with the annuity factor}

In small projects and in back-of-the-envelop assessments one can assume there is only capital investment B as expenses in year 0 and an expected constant amount of MWh generated during all years of the lifetime (= $\mathrm{Q}$ during years $1 \ldots \mathrm{n}$ ). 
The basic expression of the break-even price is reduced to:

$$
\sum_{j=1}^{n} \frac{L C_{p} * Q}{(1+i)^{j}}=B, \text { or }:\left\{L C_{p} * Q\right\} \sum_{j=1}^{n} \frac{1}{(1+i)^{j}}=B
$$

Or:

$$
L C_{p} * Q=B * \delta, \text { or }: L C_{p}=(B * \delta) / Q
$$

This shortcut is only useful when simple projects are considered, such as a rooftop PV installation.

\section{D.2 FIT calculation for rooftop PV panels}

The standard financial algebra of Section D.1 is the basis for assessing FIT values for various immature RE technologies. Using PV as example is simple and clarifying (I start with the 2004 numbers of my own rooftop PV installation).

In 2004, a $2.4 \mathrm{~kW}$ polycrystalline PV installation came at an investment price of $€ 8000 / \mathrm{kW}$. Insolation conditions and panel efficiency deliver a capacity factor of $10.3 \%$, i.e. one $\mathrm{kW}$ capacity delivers yearly $902 \mathrm{kWh}$. With a project span of 20 years $(n=20)$ and a financial return rate $i$ of $5 \%$, the annuity factor $\delta=0.0802$. Applying the shortcut formula, the break-even price LCp $=$ $€ c t 71.2 / \mathrm{kWh}$. In 2014, this was a reasonable FIT level, because of the infant status of the PV technology.

At 2020 prices of PV of $€ 1500 / \mathrm{kW}$ and a capacity factor of $13.7 \%$ (due to higher conversion efficiency), the LCp is $€ c t 10 / \mathrm{kWh}$ (with a $5 \%$ financial return rate over 20 years; when halving the rate to $2.5 \%$, the LCp equals $€$ ct8/ $\mathrm{kWh}$. To receive $€ \mathrm{ct} 10$ per $\mathrm{kWh}$ delivered to the grid and then buy $\mathrm{kWh}$ from the grid at ca. €ct28 is not a good deal for the private investor.

This means: FIT finished the job in bringing the investment price down and the conversion efficiency up, putting rooftop PV in a winning competitive position vis-à-vis delivered grid power. And PV is but writing the first page of its success story (www.irena.org; Belton 2020). However, a decreasing LCp of variable RE supplies is not ending the power play in the electric power market [Annex E; Chapters 7 and 8]. This Annex D continues the topic of FIT as a financial instrument.

\section{D.3 Context for developing and deploying RE technologies}

Electricity generated is a combination of an energy source and a technology to convert the energy in power. The sustainable renewable sources of the future are the currents of wind, waves of light, and flows of water available in the ambient environment. They are not available on command but follow nature's 
laws. Compared to fossil fuels and nuclear fission, the energy available in nature's currents is more diffuse, variable and stochastic. The technologies for their harvesting must be advanced to keep the price of the generated power affordable. Affordable is a relative concept, anchored at customary situations and conditions, or affordable is what deviates little from the usual.

A competitive power price of RE is one equal or lower than the regular prices households, firms, and organizations pay. Considered from a public, sustainability and a true economic point of view all supplies from competitors should include all costs, inclusive the external costs (Fouquet and Johansson, 2008). This full-cost rule would significantly raise the price of power from fossil fuels and from nuclear fission, given the enormous costs of climate change, of nuclear risks and waste until eternity. The reality is quite different: non-sustainable activities and options receive significant subsidies (Coady et al. 2019; Haas et al. 2019). Energy and climate politics is talking about sustainability and climate, but walking the opposite direction. Progressive politics in Germany and Denmark could not reset this kind of imbalanced behaviour of incumbent interests, partly because the financial and industrial economies are globalized.

When you cannot take the fortress by the front door, try the back door. Skip the imbalanced, true economics negating energy sector, but develop and deploy the sustainable solutions of the future (Scheer 1993; 2001). Such plan of persistent advancing embryonic - nascent - immature RE technologies cannot succeed without lean and effective mechanisms working step by step, in interaction with and supported by civil society, citizens, grassroots, scientists, future oriented entrepreneurs. Because of intense interactions with civil society, 'lean and effective' is not sufficient: the policy should also be diverse, realistic, and transparent, attributes of all good policies.

Another important context factor is the general evolution of the science \& technology world since the 1970s (Rosenberg 1976; Grübler 1998). Almost all technological clusters seen as highly promising for the future in the 1990s have delivered and revolutionized production, consumption, travel, education, leisure, science itself, for example: semiconductors, microelectronics, ICT (the internet, big data, AI), robotics, composite materials, bioengineering, etc. This technological progress largely spilled over on RE technologies, with PV and wind as evident cases. They became part of the future technologies club.

The third context element is the electric power generation sector: the physical laws governing the phenomenon electric power, the technical-economicsocial-political attributes inherited from the past, and the due transformations into sustainable future systems. Some aspects of the sector are discussed in Annex E and in Chapter 7 [Sections 7.2.4 and 7.4.4]. Here, only aspects relevant for FIT as policy instrument are highlighted.

The German FIT system addressed new RE investors: households, cooperatives, communities, SMEs, farmers, etc. It was necessary to create a policy adapted to the new investors, shielding them from the intricacies of integrated electric power systems (monopolistic or oligopolistic competitive in EU's 
IEM). Negotiating with experts of the power companies, requests specialized knowledge, experience and punching resilience. In particular, the interaction of IGOPs with the power grid is an endless fountain of problems and headaches. This was cut short by the FIT design in the EEG, with as key features (www.futurepolicy.org):

- Priority access to the power grid for RE supplies.

- A fixed price for every RE $\mathrm{kWh}$ produced for a fixed period (generally 20 years), ensuring a return on investment [Sections D.1 and D.2].

- All different types of RE are considered and tariffs are differentiated by source and size of the plant and the year the installation was put into operation.

- The extra cost is shared among all energy users by the EEG surcharge; consumers of energy expect to pay a specific amount for each $\mathrm{kWh}$ used.

- The fixed tariff is decreased based on technology and market developments.

Latest details on German FIT are available on the www, for example res-legal.eu and bmwi.de.

\section{D.4 Evaluation of FIT as financial incentivizing instrument}

The set of criteria commonly used by environmental economics [Chapter 1, Table 1.2] is the canvas for evaluating FIT as a financial incentivizing instrument.

\section{D.4.1 Effectiveness}

The goal of FIT is to pull invention and innovation of a range of diverse RE technologies, with focus on the most sustainable, least mature technologies such as wind turbines and PV panels at the end of the $20^{\text {th }}$ century.

As market pull instrument FIT has been exceptionally effective for the most essential technologies: the learning curves of wind and PV reveal significant market growth correlated to improving technical performance, conversion efficiency, and cost decreases (ISE 2020; IRENA 2020). Germany's share of $\mathrm{RE}$ in the electricity mix increased from 6\% in 2000 to $43-45 \%$ in 2019 (Agora, Fraunhofer). The development success of wind and PV technology is unprecedented measured by speed, by volume/scale, by fall in LCp.

Without FIT, this success would not have been realized. Assume, Germany in 1999 had not stand strong against the EC pressure to adopt the pan-EU TGC system, and all MS had fared as Flanders did [Chapter 5]. The consequences would have been disastrous for the decarbonizing transformation in Europe and for the rest of the world.

By FIT, private actors have received incentives to effectively invest and effectively operate the installations. 
The FIT mechanism proved robust and was not halted by circumstantial events such as the financial crisis of 2008. Only Magritte lobbyism and dubious changes in EU's state aid guidelines (EC, 2014b) disturbed the FIT process (Verbruggen et al. 2015) [Chapters 5 and 7]. The disturbance slowed the RE growth in 2015 and 2016, and was digested (Agora Energiewende and Sandbag 2020, Figure 3.1), because in 2014 crucial RE technologies already had passed 'the innovation valley of death' (IPCC 2012, pp. 884-885; Murphy and Edwards 2003).

\section{D.4.2 Efficiency}

For obtaining the above unprecedented effectiveness is a mechanism, more efficient than FIT, not described in the literature and also difficult to imagine. The least cost support of FIT is the result of policy specificity and regular updating of the LCp values per RE segment: "All different types of RE are considered and tariffs are differentiated by source and size of the plant and the year the installation was put into operation" (www.futurep olicy.org).

As 'nobody is perfect', the FIT administrators were overrun by the fast success: in 2008, the LCp of PV kinked down, mocking expectations based on smoothly decreasing experience or learning curves. FIT reductions had to come earlier and more frequently (not yearly, but quarterly, then monthly), an adaptation that took too long in the administrative process. The investors at that time interval of too high FIT benefited from the 'opportunity window' and sealed 20-year advantageous FIT for their relatively cheap PV panels. After this 2008 experience, PV-FIT was adapted faster in Germany.

The dynamic efficiency of the FIT instrument can be measured by the declining learning curves of the various technologies supported. For PV and wind, the dynamics are spectacular (IRENA 2020).

The macroeconomic effects are the creation of innovative industrial activities, employment in future-oriented activities, cheaper electricity generation, less pollution related to fossil fuel combustion, and paving the road to sustainable development.

\section{D.4.3 Equity (fairness)}

Does FIT, a subsidizing instrument, obey the 'Polluter Pays Principle', important to verify fairness (Heyward 2007)? There is a weak argument that polluting brown-kWh users pay a fee for RE via the surcharge on consumed electricity. However, EITE industrial companies (BMWI mentions 2000 in Germany) are exempted from surcharge contributions. Moreover, the distribution of surcharges over electricity consumers is regressive, given RE investors were predominantly middle- or higher-income households, firms or other institutes; they benefit from guaranteed return on investment (Többen 2017; Winter and Schlesewsky 2019). 
Nonetheless, FIT opened the choice for households, cooperatives, communities, farmers, SMEs, organizations, etc. to become RE producer.

Triggering a decentralized, bottom-up mobilization, this policy gave people the chance to invest in renewable energy projects. This communitybased approach fosters widespread citizen participation demonstrated by the fact that most RE infrastructure in Germany is owned by private individuals and cooperatives.

(www.Futurepolicy.org)

The transparent financial mechanism resonated familiar to mortgage lending, what many economic actors understand, mostly when they acquired some real estate property financed with an annuity loan.

The German FIT has most advanced the most sustainable RE technologies (PV and wind). The technological knowledge spilled over to China and other industrializing nations. The Chinese mass production made wind and PV more affordable for the poor in developing countries, and increasingly applied. In global equity terms, this technological-economic transfer overcomes pockets of poverty, because electricity access is a crucial factor of development. The impact will be deep and robust, beating top-down financial aid for large-scale conventional electricity generation.

\section{D.4.4 Administrative and political feasibility}

Clear political decision-making in touch with civil society empowers a competent administration, helped by scientific institutions (for example Fraunhofer). The performance of FIT is correlated to proper, detailed classification and qualification of all RE sources and technologies (Verbruggen and Lauber 2009). Calculating the related, dynamically changing LCp values is repetitive, easy duty, and done more frequently when technological development is successful. The 2008 experience shows that fast response to changes in the decisive parameters is due, and could have been prepared better.

The German FIT experiment is a proof that democratic decision-making is necessary for selecting the right technologies humanity needs for sustainable development. Talk of 'markets solve the problems and pick the winners' is unfounded and clearly exposed by the failing TGC experience [Chapter 5]. Diligent public policy selects the winners beneficial for society, not the market has done this, i.e. the financial-economic interests controlling the market fetish (they were building coal plants at that time).

MRV of FIT regulation piggybacks on established information channels in the electric power sector, and benefits from easy and accurate measurement of electricity flows. Assessing the merits of the variety of biomass is contentious.

FIT is transparent and enforceable. 


\section{D.5 Additional evaluative aspects of FIT}

FIT is based on solid financial economic concepts and practices, common in capital budgeting and investment appraisals [Section D.1]. Many households, institutes, and entrepreneurs are familiar with mortgage loans and annuity payments. FIT is similar, but also different. FIT assigns to RE investors the role of bank, providing money for financing research, development and deployment of sustainable technologies. Repayment is guaranteed in 20-year reimbursements on delivered $\mathrm{kWh}$ at the contracted, fixed FIT. Keeping the $\mathrm{RE}$ installations running remains the duty of investors; no $\mathrm{kWh}$ generation means no FIT reimbursement. Such provision is effective to prevent abuse of subsidy money, often observed in capital financed R\&D projects without output assurances.

The FIT regulation assigns RE priority access to the electric grid. This priority is crucial, especially when RE is generated from natural currents, waves, or flows, irrevocably foregone if not harvested when available. The priority assignment can be argued with sustainability attributes of the RE supplies. It concurs also with the least-cost logic of merit order loading of electric power generation capacities [Annex E]: given the zero or very low short-run marginal cost of PV, wind and other RE, they should be used first in meeting the demand of grid customers.

Since the restoration of 2014 (Verbruggen et al. 2015), the relevance of FIT is decreasing, as is the impact of public policy. Market based mechanisms (such as tendering) have regained terrain. New built wind and PV come at LCp below the low-voltage consumer prices for electricity and participate in the electricity business as prosumers or Independent Generators of Own Power (IGOP). This is also the case for older RE installations after their 20-year FIT period ends. New challenges for public authorities and regulators arise to protect the rights of the small-scale RE in a new constellation of power supply [Chapter 8]. The intricacies of integrated electric power systems imply huge informational, administrative burdens, too heavy for RE smallholders. FIT and priority access have been so successful because they alleviated the informational load on would-be small-scale RE investors.

A review of literature on FIT by mainstream economics finds mainly FIT criticizing and rejecting articles, such as Frondel et al. (2010), Marcantonini and Ellerman (2014), Böhringer et al. (2014), Többen (2017), Winter and Schlesewsky (2019). They have in common that they focus on (understandably) the German FIT and prioritize analysis of the surcharges and their distributional aspects, however with little attention to the exemptions for large industry. Many studies are cross-sectional, mostly one year in the past, for example: "The year of analysis is 2011" in Többen (2017, p. 196), otherwise being the most comprehensive and informative study of the broader economic impacts.

The paper by Böhringer et al. (2014) is discussed in Section 5.6. Frondel et al. (2010) made longitudinal projections, exposing the Ebillions surcharges 
due to FIT, stretching in the future. With the hindsight in 2020, their estimates are comparable with factual data, for example: Frondel et al. (2010, Table 7) forecasted surcharges for PV and onshore wind at $€ c t / \mathrm{kWh}$ : years 2017/ 2018/ 2019 respectively: 7.49/ 7.80/ 8.13; BMWI has published for all EEG surcharges in the same years: 6.88/ 6.79/6.40.

Notwithstanding the EEG reforms of 2014 pushing up the surcharges, the technological progress in RE technologies went faster than Frondel et al. assumed. More problematic are the authors' conclusions (pp. 4055-4056), like: "FIT, in fact, imposes high costs without any of the alleged positive impacts on emissions reductions, employment, energy security, or technological innovation". Then they refer to the EU ETS as the solution: "Nevertheless, government intervention can serve to support renewable energy technologies through other mechanisms that harness market incentives or correct for market failures. The European Trading Scheme, under which emissions certificates are traded, is one obvious example". The authors are mainly harsh on PV, pulled by FIT from embryonic to mature in a decade, with an accumulated budget of Ebillion 79.2 at the end of 2010 (p. 4051).

Billions of euros are big chunks of money and should be governed well, as the FIT administrators did. The PV Ebillions are peanuts compared to the Etrillions in damage and risks fossil fuels and nuclear power have loaded, are loading and will load on peoples' lives. Moreover, these obsolete options continue to absorb public subsidies (Coady et al. 2019).

At every occasion, as a scientist and a citizen, I like to express sincere thanks to the German people (and Danish and other) who did invest in the political, financial adventure of pulling PV, wind, and other RE technologies over the stranding 'valleys of death' they faced. Hence, around 2018 the world crossed the watershed from the fossil fuel and nuclear energy era into the RE era, fostering realistic hope humankind can escape climate collapse and can attain global sustainable development. 


\section{Annex E: Ageing electricity economics: Marginal cost pricing $\leftrightarrow$ fringe pricing}

'Ageing' in the title is a teaser. It reflects the electric power systems transitions from thermal generation plants (capacities), predominantly operated at command of human operators, toward renewable electricity (RE) generation plants (capacities) mainly at command of nature's currents wind, light, and water. Since the 1970s I studied the ageing systems now ready for pass on. Theory and practice of the new systems are developing [Chapter 8]. This annex deals with the science about the - still dominant in 2020 - ageing systems and concludes with hints to science dealing with 100\% RE electric supplies, mostly not on command.

For non-technical trained readers, first come some introductory concepts about what electricity is. Electricity is secondary energy converted from energy sources, e.g., via mechanical energy in an alternator driven by a steam or gas turbine [Chapter 7, Figure 7.5], a water turbine or a wind turbine. Electricity is also generated by direct conversion of light waves (photo-voltaic cell) and of chemical energy (battery, fuel cell). Direct electricity from nature (lightening, static) is hazardous, not useful.

KWh electric energy is the amount of electric power $(\mathrm{kW})$ used over an interval of one hour (h). Electric power in Watt (Joule/second) is a transient current running over copper cables. Alternating current respects standards on frequency $(50 \mathrm{~Hz}$ or $60 \mathrm{~Hz})$ and on Voltage (high, medium, low, depending on the various levels applied in integrated grids). Obeying the technical standards during every second of the year is necessary for delivering reliable, goodquality electricity to end-users. Being a current, power is not storable, i.e., electricity storage includes two conversions: 1) electricity in another energy outfit (chemical, potential) and 2) this outfit back in electricity.

The momentary demands for power constitute fluctuating load curves, with peaks when aggregate use is high. Every second of the day and of the year meeting the fluctuating loads, is a considerable task for the set of generation units, operating in interconnected grids. The grids are instrumental in regionwide exchanges of variable RE supplies from different places. Power delivery can be complemented by load management (rearranging loads of some enduses), and by storage facilities (water pumped-storage; batteries; hydrogen; flywheels; compressed air). Shortage of power causes brownouts and blackouts, 
regularly occurring for short periods in small parts of the grids in industrialized countries. However, developing countries with poor resources face frequent blackouts for significant shares of the service area during several hours of the day. The number of people with no access to electricity is now less than one billion (UNDP 2019).

\section{E.1 Electricity economics with plants generating electricity on command}

The second half of the $20^{\text {th }}$ century witnessed a tenfold growth of global electricity use. More rivers were dammed for harnessing hydropower. Nuclear power was named backstop technology for substituting fossil fired power, with belief in breeder reactors and fusion to be available before the year 2000 (Nordhaus 1973). Thermal power units scaled up from tens of MW to above thousand MW; their conversion efficiency improved to physical limits. Pollution, waste, and risks are largely rolled off on nature, society, and the future.

The large-scale systems are top-down designed and operated. Generation and transmission are continuously monitored, functioning on command by central system and plant operators, with distributed generation languishing. Engineering-economic models govern investments in capacities, operations and pricing of electric power. The interlinked models answer the major engineering-economic questions on reliably meeting the demand for the nonstorable electric current. When to build which capacities? How should they be operated? Who should pay which costs?

The stylized version of the investment theory assumes a continuous range of capacity options, from high fixed / low variable costs (base-load) to low fixed/ high variable costs (peak-load). In an optimally composed generation system, installed capacities each run their number of hours as least cost generator in the range.

All plants function on command and 'in real time'. Over brief time spans (e.g., 15 minutes) available generation capacities are ranked in merit-order of their variable generation costs (OPEX). The OPEX of the marginally loaded plant equals the short-run marginal cost (SRMC) of the integrated generation system, this being the theoretical proper $\mathrm{kWh}$ price of generation for all end-uses during that brief time span.

When the sequence - investment, operations, pricing - fits, the major issues of power supply achieve neat solutions: all end-users during the real time interval are treated equally via a SRMC-price, signalling the momentary opportunity cost of generated power. In an optimally composed and operated production park, revenues obtained via SRMC-pricing cover full CAPEX and OPEX.

\section{E.2 Economics on Marginal cost pricing}

In neoclassical economics, 'marginal cost pricing' is the golden rule for reaching maximum efficiency. Producers minimize their expenses in providing 
goods \& services. Hence, a neoclassical 'cost' function $\mathrm{C}(a)$, with a being amount of output, implies minimum expenses. The truth of this assumption is questionable for several reasons: one being the phenomenon of $\mathrm{X}$-inefficiency (Leibenstein 1966); a more important reason is the omitting of external costs, also making strict application of the terminological difference between costs and expenses recommendable (Verbruggen et al. 2011).

Goods and services are supplied in markets where the aggregated demand $\mathrm{D}(\mathrm{a})$ expresses consumers' propensity to buy or willingness-to-pay for amounts $a$. In competitive markets, a producer cannot influence the selling conditions: $\mathrm{S} /$ he must accept the market price as a given, when setting the quantity s/he offers. A rational producer offers the quantity $a^{\star}$ which maximizes profits (= revenues - expenses), or: Max.! $\{\mathrm{P} . a-\mathrm{C}(a)\}$. Via the first order condition $\{\mathrm{P}-\mathrm{MC}(a)=0\} a^{\star}$ is fixed such that price $=$ marginal cost $\left\{\mathrm{P}=\mathrm{MC}\left(a^{\star}\right)\right\}$.

As simple the textbook theory is, as messy are real pricing practices (Phlips 1983; Dorward 1987). Marginal cost pricing is little observed in real businesses. Generation of electricity is the economic activity where marginal cost pricing has been explicitly proposed and pursued (Nelson 1964; Turvey 1968; Rees 1976; Turvey and Anderson 1977; Vanlommel 1992). The electricity generation case is most suited to introduce and clarify marginal cost pricing. And electricity is the pivot of today's energy transitions [Chapter 7].

Accountancy is the specialized branch of economics dealing with firms' expenses and revenues. A distinction between fixed and variable expenses is made; capital expenses (CAPEX) are depreciated over a number of years, while operational expenses (OPEX) are processed within one year. The neoclassical distinction between fixed and variable costs is not strictly obeying accounting rules but depends on adopted time frames from short run (SR) to long run (LR).

In the LR, all is changeable. In the SR fixed costs are a given, beyond discretionary impact; only variable costs are affected by the producer's quantity choice. It follows, that MC-pricing equals SRMC-pricing, or the neoclassical optimal prices are derived from variable costs only.

This property is the source of misunderstanding and contention between neoclassical theorists and practitioners such as engineers, marketing staff, sales staff, etc. about how fixed costs are covered by a price only based on variable costs. Neoclassical economics assumes the mathematical cost functions are 'well-behaving' (convex, differentiable) and aggregates are decomposable in countless infinitesimal small parts. However, the cliff between mathematical theorems and practice is not easily bridged.

\section{E.3 Marginal cost pricing of electricity supplies}

The case of electric power generation is helpful in concretizing the theoretical assumptions and their impact on the validity of SRMC-pricing. The case is specified as follows: 
- An electricity generation company owns numerous $(\Omega)$ power plants with differing weights of fixed and of variable costs, adapted to their expected number of activity hours during the year (holding 365 days $=8760$ hours). Commonly, the many plants are classified by intended number of production hours h/year, for example: base-load (high fixed \& low variable costs, $\mathrm{h}>8000$ ); intermediate-load (moderate fixed \& variable costs, $2500<\mathrm{h}<8000$ ); peak-load (low fixed \& high variable costs, $\mathrm{h}<2500$ ).

- Electric current is non-storable. Fluctuating loading of the various plants in real-time covers the fluctuating demands for electric power. Leaving technical and operational details aside, we adopt hourly as sufficient real-time and only the barest essentials to explain the principle of SRMC-pricing.

- It is assumed that the generation system of the company is optimally composed, i.e. the right capacities $(\mathrm{kW})$ of base, intermediate and peak load plants are available for being loaded to generate electricity e (kWh). The $\Omega$ plants are ranked in a merit order stack from least to highest OPEX for generating electricity, thus base-load plants come first, followed by intermediate load, with peak-load plants at the tail.

During every hour of the year the company will meet the total demanded quantity of $\mathrm{E} \mathrm{kWh}$ for avoiding blackout. For minimizing operating expenses $\Sigma_{\mathrm{i}} \mathrm{C}_{\mathrm{i}}\left(\mathrm{e}_{\mathrm{i}}\right)$, the proper quantities of electricity generated by the various plants $(1, \ldots, \Omega) \mathrm{e}_{1}, \ldots, \mathrm{e}_{\mathrm{k}}, \mathrm{e}_{\mathrm{m}}(\mathrm{m} \leq \Omega)$ are identified. Formally:

Min.! $\Sigma_{\mathrm{i}} \mathrm{C}_{\mathrm{i}}\left(\mathrm{e}_{\mathrm{i}}\right)$

Subject to: $\Sigma_{\mathrm{i}} \mathrm{e}_{\mathrm{i}}=\mathrm{E}$ [total demand is covered]

$\mathrm{e}_{\mathrm{i}} \leq \mathrm{e}_{\mathrm{i}, \mathrm{max}}, \forall \mathrm{i}$ [no plant can generate more than its available capacity]

The Lagrange function: $\mathrm{L}=\Sigma_{\mathrm{i}} \mathrm{C}_{\mathrm{i}}\left(\mathrm{e}_{\mathrm{i}}\right)-\lambda\left\{\Sigma_{\mathrm{i}} \mathrm{e}_{\mathrm{i}}-\mathrm{E}\right\}-\Sigma_{\mathrm{i}} \mu_{\mathrm{i}}\left\{\mathrm{e}_{\mathrm{i}, \max }-\mathrm{e}_{\mathrm{i}}\right\}$

First order conditions for minimizing $\mathrm{L}$ are the first derivatives to the unknown variables set equal to zero and the complementary slackness condition for the inequality constraints, or:

$\forall \mathrm{i} \mid \mathrm{MC}_{\mathrm{i}}\left(\mathrm{e}_{\mathrm{i}}\right)=\lambda-\mu_{\mathrm{i}}$

$\Sigma_{\mathrm{i}} \mathrm{e}_{\mathrm{i}}=\mathrm{E}$

$\forall \mathrm{i} \mid \mu_{\mathrm{i}}\left\{\mathrm{e}_{\mathrm{i} \text { max }}-\mathrm{e}_{\mathrm{i}}\right\}=0$ [i.e.: $\mu_{\mathrm{i}}=0$ when $\mathrm{e}_{\mathrm{i}}<\mathrm{e}_{\mathrm{i}, \max }$; otherwise $\mu_{\mathrm{i}} \neq 0$ ]

The last loaded generation plant of the stack is partly loaded $\left\{\mathrm{e}_{\mathrm{m}}<\mathrm{e}_{\mathrm{m}, \max }\right\}$, at marginal generation cost $\lambda$, called 'system lambda $\lambda$ ' of the considered hour. It is the company's system marginal cost for producing one $\mathrm{kWh}$ extra, and this value $\lambda$ will be charged for all $E \mathrm{kWh}$ supplied to end-users during the considered hour. Hence, the returns of MC pricing equal $\lambda \star \mathrm{E}$.

However, other active plants are fully loaded $\left\{\mathrm{e}_{\mathrm{i}}=\mathrm{e}_{\mathrm{i}, \max }\right\}$, delivering $\mathrm{kWh}$ at their lower specific marginal cost-price $\left\{\lambda-\mu_{\mathrm{i}}\right\}$, with $\mu_{\mathrm{i}} \neq 0$. This implies that the company earns $\mu_{i}$ per kWh generated by plant $i$, or in the aggregate $\Sigma_{i}$ $\mathrm{q}_{\mathrm{i}} \star \mu_{\mathrm{i}}$ on top of the OPEX of these units. When the company's generation system is optimally composed, this aggregate $\Sigma_{i} q_{i} \star \mu_{i}$ (summed over the 8760 hours of the year, and over the lifetime of the plants) suffices for covering the fixed costs of the plants. 
194 Annex E: Ageing electricity economics: Marginal cost pricing $\leftrightarrow$ fringe pricing Fully loaded generation units from 1 ... k
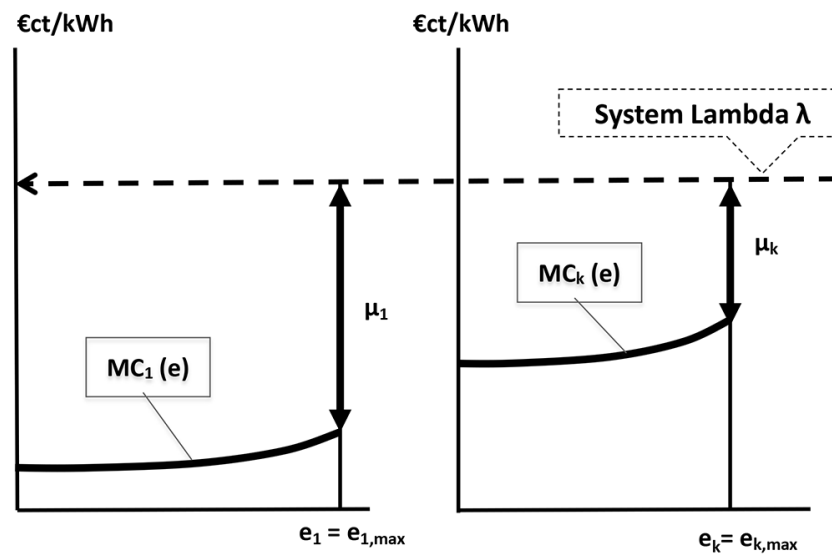

$€ c t / k W h$

Generated kWh $\mathrm{e}_{1} \ldots \mathrm{e}_{\mathrm{k}}, \mathrm{e}_{\mathrm{m}}$

Figure E. 1 Marginal cost curves of three generation units: $\mathrm{n}^{\circ} 1$ of the merit order; the penultimate loaded $\mathrm{n}^{\circ} \mathrm{k}$ and the marginal loaded unit $\mathrm{n}^{\circ} \mathrm{m}$, visualizing the Lagrange results

\section{E.4 Fringe pricing is 'the tail wags the dog' economics}

The analysis shows the important difference between marginal cost pricing and fringe pricing. Fringe pricing returns are only $\lambda \star \mathrm{e}_{\mathrm{m}}$ for the full output $\mathrm{E}$ of the company's system during the hour. In this case, it is unlikely that rational economic actors (the core agents in neoclassical economics) would continue to run $m$ units in an operational set of $\Omega$ plants to supply electric power, and think of building electric power generation plants for the future. Fringe pricing can only have some ephemeral effect on fringes.

\section{E.5 Recalcitrant realities preclude theoretical optimality}

The above description of the functioning of centrally controlled electric power generation systems with all units on command is a single hour snapshot to explain marginal cost pricing and expose the distinction to fringe pricing. Actually, costing and pricing of electric power is more complicated. Consecutive hours are interdependent, because thermal power plants have start-up costs, and technical constraints limit ramping capacity rates of various units. Reserve capacities are spinning for the requested reliability of supply. Shipping power from the generation plants to end-use points add network costs, while congested lines may have an impact on the optimization of generation systems.

The multiple technical, economic, and practical factors challenge the stylized theory. Economies of scale, discrete sized generation units, sunk costs of longliving assets, and changing input factor prices destabilize perfectly optimal 
compositions of electricity production systems. In addition, some 'must run' or inflexible units claim priority over cheaper plants in the merit order. External costs related to placement, functioning, emissions and waste of power plants are mostly not comprised in the accounts and in the prices of power delivered by particular units. The theoretical models provide guidance in economic decision-making but not a simple cookbook.

\section{E.6 From centrally planned and operated to market based power supply systems}

Unbundling of generation, transmission, system monitoring and control, distribution and delivery through the IEM (EC 1997; Verbruggen 1997) deconstructed most centralized, vertically integrated electricity monopolies in the EU. In theory, a perfect competitive market would deliver the same MCprices as a perfectly planned and operated centralized system. The IEM created power exchanges, such as EEX (now also trading carbon emission permits), and Independent System Operators (ISO) took over operational dispatching of generation units and supervision over transmission operations in the ISO service area. Year-by-year electricity generation became more competitive, with growing shares of real-time transactions (hourly and 1/4 hourly). The hourly spot prices on the exchanges are proxies of SRMC prices, however not applied on all power delivered, because bilateral contracts with large customers and established tariffs for small customers prevail.

For applying MC-based electricity prices, time resolution in hours (or finer) is recommended. Smart metering and ICT significantly extend the ability to monitor real time operations, governed by many factors (Stoft 2002). But how practical is it for most end-users to process themselves the information overload? The majority of end-users react on monthly or annual €invoices from their electricity supply company, not on detailed hourly swinging SRMC pointers.

\section{E.7 Evolving transformation of the electricity sector}

Electricity sector liberalization intends to substitute free market principles for vertically integrated supply structures. However, realizing workable competition in such tightly managed systems is contingent on a logical sequence of prerequisites, viz. proper harmonization of rules and conditions for participants in the to become 'competitive' markets, transparency of the institutions and activities, unbundling of the main functions (generation, transmission, distribution), and firm guidance and supervision by excelling public regulators (Verbruggen 1997; 2017).

The three EU regulatory packages (1997; 2003; 2009) could not fully impose the prerequisites on the MS, and competition remains incomplete with influential oligopolies and remaining state-owned companies (e.g., EDF, Vattenfall $\mathrm{AB})$. 
Figure E.2 shows an unbundled structure of power generation activities, the high-voltage grid transmitting power to bulk demand nodes, one kind of nodes being distribution networks serving the retail markets. Liberalization forced unbundling of the entities processing physical power flows, and added several new entities, such as power exchanges, bilateral trade brokers, power sales companies (also called: suppliers), embroiled as intermediaries in contracting electric power transactions.

The new institutions function on legal and financial terms, not intensely interfering in physical electricity flows (hexagons with dashed borders in Figure E.2). The national regulatory authority, supervising the electricity sector, stays at the top of the chart. System operators function independently of physical power supply activities. In Europe they mostly are merged with grid owners and operators, and named transmission system operators (TSO), also balancing power generation with demand for power. In large service areas, TSO decentralize to subdivisions and to distribution network operators (DNO).

Power generators are classified according to specific purposes, with terms and definitions often unsettled, for example: central versus distributed; independent versus incumbent; (variable) renewable energies versus (on command) plants; small-scale versus large-scale. Figure E.2 identifies two main classes. 'Commanded Generation Plants' guarantee dispatching capacity contracts with

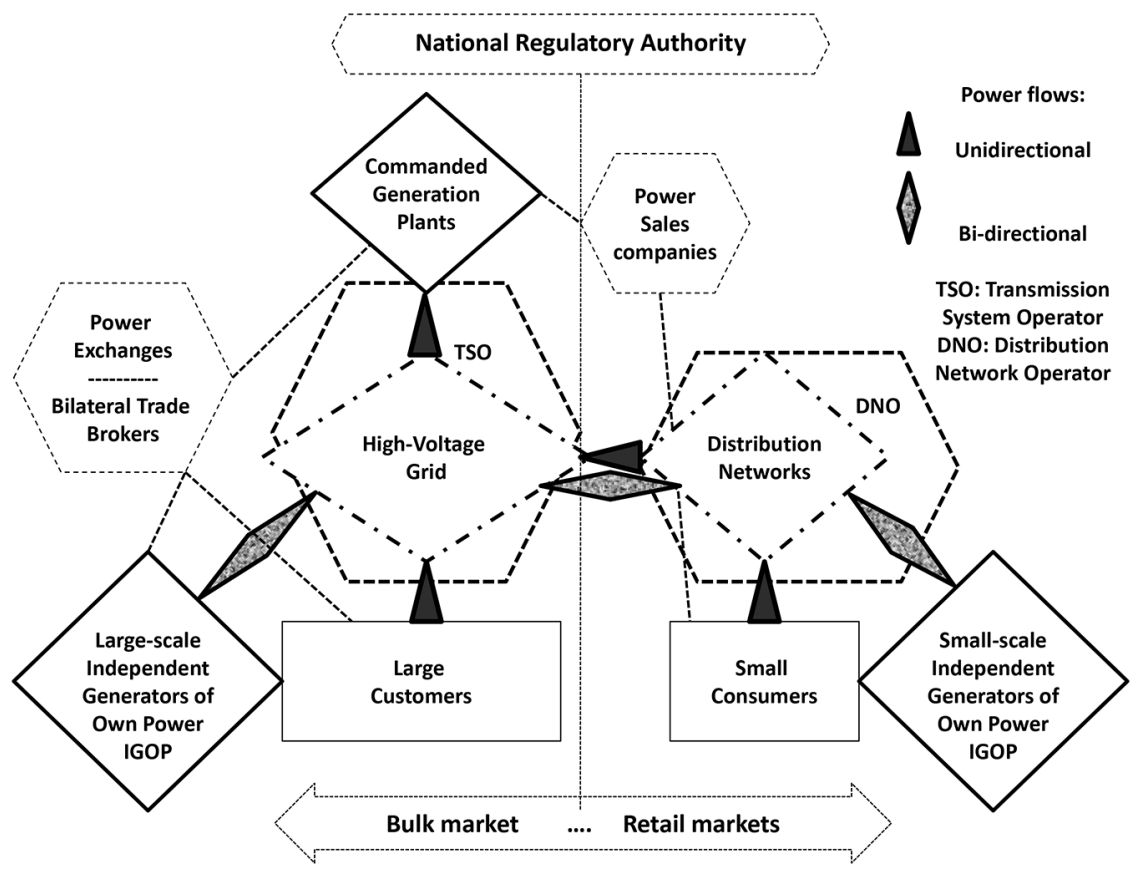

Figure E.2 Components and relationships in liberalized electric power supply systems 
the TSO, i.e., on request deliver power or withhold generation. Most production facilities of incumbent power companies belong to this class, as do plants of independent power producers exclusively generating power for selling to customers.

The other class of power generators consists of - large and small - 'Independent Generators of Own Power (IGOP) ${ }^{1}$. They are often named 'on site' generation because they are placed at the premises of large customers (industrial plants, commercial sites) or of households and small businesses (PV at building roofs, small-scale cogeneration). IGOP use fossil fuels (often in cogeneration units) or renewable sources and technologies. They build and run power plants to serve primarily the own loads but in interaction with the high-voltage or low-voltage - power grids. Grid connection is preferable for attaining the best reliability/cost ratio, because of electric power being non-storable.

Commanded (incumbent or independent; central or distributed) generation plants are single-directionally linked to the power system: they only deliver power. IGOP (large-scale and small-scale) are bi-directionally linked [Figure E.2]. IGOP mostly switch roles from (net) supplier to (net) consumer of electricity. This aspect created the name 'prosumer'. When technically feasible and financially opportune IGOP first serve the own loads and eventually send surplus power to the grid. When the own demand exceeds the power output of the IGOP plant, electricity is imported from the grid as 'make-up' or as 'back-up' (in case of IGOP plant failure).

\section{E8 RE from disturbing inroad to sustainable solution}

Surplus power from IGOP delivered to the grid is disturbing power system balancing when overall low load is already challenging TSO in keeping commanded, inflexible (often large-scale), generation capacities on line. The short-run price of the $\mathrm{kWh}$ may then fall to zero, or become negative when payment is needed to purge superfluous power. Structurally, the system is too heavily locked in large-scale fossil and nuclear production plants resisting to be reduced in output. The system is also short in buffering facilities where surplus power can be converted in storable energy, later reconverted in electricity. Technically, spiky fluctuations are wearing and tearing electricity supply equipment. Financially, longer periods of running below planned capacity factors erode the bottom-line financial accounts of generation plants (Verbruggen and Yurchenko 2019).

The growing role of IGOP will increase the size of surplus power deliveries to the grid. Houses and other buildings with well-oriented roof surfaces may yearly generate double or more PV electricity than the own activities absorb. In a completed transition to $100 \%$ renewable power systems, IGOP should be the most common and predominant type of power supplies. Growing importance of IGOP is inevitable, and regulation must play a stimulating role not a choking one. Gawel and Purkus (2013, p. 608) express "doubts whether the 
current electricity market design is suitable at all for integrating large scales of RES."

This quote and several other positions in their analysis, reveal that they look at the transition challenges from the present, incumbent perspective, however concluding another view is necessary. Geelen et al. (2013, p. 152) sympathize an active role as co-providers for end-users connected to smart grids but observe "little is known yet on how to shape active participation of residential end-users in smart grids and thus how to support them in achieving the role of co-provider." Nykamp et al. (2012) investigate various regulation designs on effectively stimulating DNO investment in innovative smart grid solutions (local storage, voltage regulation).

When electricity generation depends more and more on renewable energy currents (wind, light, water), nature is commanding the supply, and new pricing concepts and rules are due. For example, regulators could rule that DNO are hold liable for all cases where small-scale IGOP investments or activity are curtailed; TSO assume similar liability for large-scale IGOP. Penalties paid by DNO and TSO (anyhow charged on electricity consumers) for such shortcomings are redirected to fund innovative smart grid investments, storage facilities, dedicated fast ramping, decentralized generation units, optimization of IGOP activities and their power grid interactions, etc. In this way, remedying problems is directly linked to penalizing their symptoms.

Chapter 8 discusses the future of electric power systems.

\section{Note}

1 IGOP as general and neutral term (Verbruggen 1997) is preferred above e.g. 'prosumers' (Schleicher-Tappeser 2012) or 'co-providers' (Geelen et al. 2013). The adjective independent is added to distinguish from joint ventures between incumbent power companies and industries that house on site the shared (often cogeneration) power plant. 


\section{References}

Ackerman, B.A., Stewart, R.B. (1988). Reforming environmental law: The democratic case for market incentives. Columbia Journal of Environmental Law (13): 171-199.

Ackerman, F., DeCanio, S.J., Howarth, R.B., Sheeran, K. (2009). Limitations of integrated assessment models of climate change. Climatic Change 95: 297-315.

Agora Energiewende (2013). 12 Insights on Germany's Energiewende. www.agora -energiewende.de.

Agora Energiewende, Sandbag (2018). The European power sector in 2017. State of affairs and review of current developments. www.agora-energiewende.de.

Agora Energiewende and Sandbag (2020). The European power sector in 2019: Up-todate analysis on the electricity transition. www.agora-energiewende.de.

Aldy, J.E., Stavins, R.N., eds. (2007). Architectures for Agreement. Addressing Global Climate Change in the Post-Kyoto World. Cambridge: Cambridge University Press.

Aldy, J.E., Krupnick, A.J., Newell, R.G., Parry, I.W.H., Pizer, W.A. (2010). Designing climate mitigation policy. Journal of Economic Literature 48 (4): 903-934.

Arrow, K.J. (1974). The Limits of Organization. The Fells Lectures on Public Policy Analysis. New York: W.W. Norton \& Company,

Ayres, R., Ayres., L. (2002). Handbook of Industrial Ecology. Cheltenham, UK: Edward Elgar Publishing Ltd.

Baker, S. (2012). Climate change: The common good and the promotion of sustainable development, in Meadowcroft, J., Langhelle, O., Ruud, A., eds., Governance, Democracy, and Sustainable Development. UK: Edward Elgar, pp. 249-271.

Baldwin, R. (2008). Regulation lite: The rise of emissions trading. law, society and economy. London School of Economics and Political Science, Law Department. www.lse.ac.uk/collections/law/wps/wps.htm.

Banks, J.S., Hanushek, E.A., eds. (1997). Modern Political Economy. Cambridge University Press.

Baranzini, A., van den Bergh, J.C.J.M., Carattini, S., Howarth, R.B., Padilla, E., Roca, J. (2017). Carbon pricing in climate policy: Seven reasons, complementary instruments, and political economy considerations. WIREs Clim Change 2017, e462. doi:10.1002/wcc.462.

Baron, D.P. (1997). The economics and politics of regulation: perspectives, agenda, and approaches, in Banks, J.S., Hanushek, E.A., eds., Modern Political Economy. Cambridge University Press, pp.10-62.

Baron, R., Serret, Y. (2002). Renewable energy certificates: Trading instruments for the promotion of renewable energy, in OECD, Implementing Domestic Tradeable Permits. Proceedings Workshop Paris, 6-7 September 2001, pp. 105-140. 


\section{References}

Bataille, C., Guivarch, C., Hallegatte, S., Rogelj, J., Waisman, H. (2018). Carbon prices across countries. Nature Climate Change 8: 648-659.

Baumol, W.J., Oates, W.E. (1975). The theory of environmental policy. Prentice-Hall, Inc. Becker, G.S. (1971). Economic Theory. New York: Alfred A. Knopf.

Belton, P. (2020, May 1). A breakthrough approaches for solar power. BBC.

Bierman, H., Smidt, S. (2006). The Capital Budgeting Decision. Economic Analysis of Investment Projects. Taylor \& Francis Group.

Böhringer, C., Balistreri, E., Rutherford, T.F. (2012). The role of border carbon adjustment in unilateral climate policy: Overview of an Energy Modeling Forum study (EMF 29). Energy Economics 34 (2): 97-110.

Böhringer, C., Cuntz, A., Harhoff, D., Asane-Otoo, E. (2014). The Impact of the German Feed-in Tariff Scheme on Innovations: Evidence Based on Patent Filings in Renewable Energy Technologies. Department of Economics, University of Oldenburg.

Bode, S. (2004). Equal emissions per capita over time - a proposal to combine responsibility and equity of rights for post-2012 GHG emission entitlement allocation. European Environment 14: 300-316.

Bohm, P., Russell, C.S. (1985). Comparative analysis of alternative policy instruments, in Kneese, A.V., Sweeney, J.L., Handbook of Natural Resources. Elsevier, pp. 395-460.

Boulding, K. (1964). The Meaning of the Twentieth Century. Harper\&Row.

Brink, C., Vollebergh, H.R.J., van der Werf, E. (2016). Carbon pricing in the EU: Evaluation of different EU ETS reform options. Energy Policy 97: 603-617.

Bromley, D.W. ed. (1986). Natural Resource Economics. Boston: Kluwer Nijhoff Publishing.

Bromley, D.W. (1986). Markets and externalities, in Bromley, D.W., ed., Natural Resource Economics. Boston: Kluwer Nijhoff Publishing, pp. 37-68.

Bromley, D.W. (1990). The ideology of efficiency. Journal of Environmental Economics and Management 19, 86-107.

Bromley, D.W. (2006). Sufficient Reason: Volitional Pragmatism and the Meaning of Economic Institutions. Princeton University Press.

Brown, D. (2010). Ethical issues raised by carbon trading. https://ethicsandclimate.org/ 2010/06/15/ethical_issues_raised_by_carbon_cap_and_trade_regimes/.

Bryant, G. (2016). Carbon markets and the production of climate change. Appropriating, commodifying and capitalizing nature. $\mathrm{PhD}$ thesis Department of Political Economy, School of Social and Political Sciences, University of Sydney.

Bryner, G.C. (1999). New Tools for Improving Government Regulation: An Assessment of Emissions Trading and Other Market-Based Regulatory Tools. The PriceWaterhouseCoopers Endowment for The Business of Government. University of Colorado, School of Law.

BP (2019). Statistical Review of World Energy. www.bp.com.

Burtraw, D., Szambelan, S.J. (2009). U.S. Emissions Trading Markets for $\mathrm{SO}_{2}$ and NOx. Resources for the Future DP 09-40.

Calel, R., Dechezleprêtre, A. (2016). Environmental policy and directed technological change: Evidence from the European carbon market. Review of Economics and Statistics 98 (1): 173-191.

Callen, T. (2007). PPP versus the market: Which weight matters? IMF Finance and Development 44 (1).

CAN (2018). European Fat Cats. EU Energy Intensive Industries: Paid to Pollute, not to Decarbonize. Climate Action Network Europe.

Caney, S., Hepburn, C. (2011). Carbon trading: Unethical, unjust and ineffective? Centre for Climate Change Economics and Policy Working Paper 59, www.lse.ac. 
uk/GranthamInstitute/wp-content/uploads/2011/06/WP49_carbon-trading-caneyhepburn.pdf.

Carattini, S., Kallbekken, S., Orlov, A. (2019). How to win public support for a global carbon tax. Nature 565: 289-291.

Carbon Trust (2006). Allocation and Competitiveness in the EU Emissions Trading Scheme. Options for Phase II and beyond. London, UK.

Carlson, A.E., Fri, R.W. (2013). Designing a durable energy policy. Daedalus 142 (1): 119-128.

Carlson, C., Burtraw, D., Cooper, M., Palmer, K.L. (2000). Sulfur dioxide control by electric utilities: What are the gains from trade? Journal of Political Economy 108 (6): 1292-1326.

CE Delft (2016). Calculation of additional profits of sectors and firms from the EU ETS. www.cedelft.eu.

CEO (2009). Putting the fox in charge of the henhouse: How BP's emissions trading scheme was sold to the EU. A case study. Corporate Europe Observatory and PLATFORM. www.archive.corporateeurope.org.

CEO (2013). EU ETS myth busting: Why it can't be reformed and shouldn't be replicated. Corporate Europe Observatory and PLATFORM. www.archive.corpora teeurope.org.

Chan, H.R, Chupp, B.A., Cropper, M.L., Muller, N.Z. (2017). The impact of trading on the costs and benefits of the Acid Rain Program. Journal of Environmental Economics and Management 88: 180-209.

Chao, H. (1983). Peak load pricing and capacity planning with demand and supply uncertainty. The Bell Journal of Economics 14 (1): 179-190.

Christiansen, A.C., Wettestad, J. (2003). The EU as a frontrunner on greenhouse gas emissions trading: how did it happen and will the EU succeed? Climate Policy 3: 3-18.

Cline, W.R. (1992). The Economics of Global Warming. Peterson Institute for International Economics.

Cludius, J. (2018). Winners and losers of the EU ETS. Economics of Energy \& Environmental Policy 7 (2): 93-110.

Cludius, J., Duscha, V., Friedrichsen, N., Schumacher, K. (2019). Cost-efficiency of the EU Emissions Trading System: An evaluation of the second trading period. Economics of Energy \& Environmental Policy 8 (1): 145-161.

CMW (2019, September). Avoiding a carbon crash. How to phase out coal and strengthen the EU ETS. Policy Briefing.

Coady, D., Parry, I., Le, N.P., Shang, B. (2019). Global Fossil Fuel Subsidies Remain Large: An Update Based on Country-Level Estimates. Fiscal Affairs Department WP/19/89. International Monetary Fund.

Coase, R.H. (1960). The Problem of Social Cost. Journal of Law and Economics 3: 1-44.

Coelho, R.S. (2015). The high cost of cost efficiency: A critique of carbon trading. $\mathrm{PhD}$ thesis, Universidade de Coimbra.

COM (2012). Communication from the Commission Guidelines on Certain State Aid Measures in the Context of the Greenhouse Gas Emission Allowance Trading Scheme Post 2012, 2012 / C 158/4 of 5.6.2012.

Connolly, D., Mathiesen, B.V. (2014). A technical and economic analysis of one potential pathway to a $100 \%$ renewable energy system. International Journal of Sustainable Energy Planning and Management 1 (1): 7-28.

Cooper, R. (1998). Toward a Real Treaty on Global Warming. Foreign Affairs 77 (2): $66-79$. 


\section{References}

Cooper, R. (2005). Alternatives to Kyoto. The case for a Carbon Tax. Harvard University.

Cooper, R.N. (2007). Alternatives to Kyoto: The case for a carbon tax, in Aldy, J.E., Stavins, R.N., eds, Architectures for Agreement. Addressing Global Climate Change in the Post-Kyoto World. Cambridge: Cambridge University Press, pp. 105-115.

Corfee-Morlot, J., Kamal-Chaoui, L., Donovan, M.G., Cochran, I., Robert, A., Teasdale, P.J. (2009). Cities, Climate Change and Multilevel Governance. OECD Environmental Working Papers $\mathrm{N}^{\circ} 14$.

Cox, E., Johnstone, Ph., Stirling, A. (2016). Understanding the Intensity of UK Policy Commitments to Nuclear Power. SPRU, Working Paper Series SWPS 2016-2016.

Cramton, P., Ockenfels, A., Stoft, S. (2015). An International Carbon-Price Commitment Promotes Cooperation. Economics of Energy \& Environmental Policy 4 (2): 51-64.

Cummings, Mary L. (2006). Integrating Ethics in Design through the Value-Sensitive Design Approach. Science and Engineering Ethics 12 (4): 701-715. https://doi.org/10. 1007/s11948-006-0065-0.

Dales, J.H. (1968). Pollution, Property and Prices. University of Toronto Press.

Daly, H.E., ed. (1980). Economics, Ecology, Ethics. Essays toward a Steady-State Economy. San Francisco: W.H. Freeman and Company.

Daly, H.E. (1988). On sustainable development and national accounts in Collard, D., Pearce, D., Ulph, D. eds., Economics, Growth and Sustainable Environments, Macmillan Press, pp. 41-56

DDPP (2015). Pathways to Deep Decarbonization. Executive Summary 2015 Report. Deep Decarbonization Pathways Project. Sustainable Development Solutions Network (SDSN) and the Institute for Sustainable Development and International Relations (IDDRI). www.deepdecarbonization.org.

Debreu, G. (1959). Theory of Value: An Axiomatic Analysis of Economic Equilibrium. Cowles Foundation Monograph Series.

De Cendra, J. (2008). Too much harmonization? An analysis of the Commission's proposal to amend the EU ETS from the perspective of legal principles, in Faure, M., Peeters, M. eds., Climate Change and European Emissions Trading. Lessons for Theory and Practice. New Horizons in Environmental Law. Cheltenham: Edward Elgar, pp. 53-87.

Dechezleprêtre, A., Gennaioli, C., Martin, R., Muûls, M. (2014). Searching for Carbon Leaks in Multinational Companies, GRI Working Papers 165, Grantham Research Institute on Climate Change and the Environment. London: London School of Economics (LSE).

Dietz, S., Fruitiere, C., Garcia-Manas, C., Irwin, W., Rauis, B., Sullivan, R. (2018). An assessment of climate action by high-carbon global corporations. Nature Climate Change 8: 1072-1075.

Dixit, A.K., Pindyck, R.S. (1994). Investment under Uncertainty. Princeton University.

Dorward, N. (1987). The Pricing Decision: Economic Theory and Business Practice. London: Harper \& Row.

DTI (2000). New \& Renewable Energy Prospects for the $21^{\text {st }}$ Century. Department of Trade and Industry. The Renewables Obligation Preliminary Consultation. London: HMSO.

DTI (2007). Meeting the Energy Challenge - A White Paper on Energy. Department of Trade and Industry. London: The Stationary Office.

EC (1996). Directive 96/61/EC of 24.09.1996 concerning integrated pollution prevention and control. 
EC (1997). Directive 96/92/EG of the European Parliament and of the Council of 19 December 1996 concerning the common rules for the internal market in Electricity. Official Journal of the European Communities L27.

EC (1999). Electricity from renewable energy sources and the internal electricity market. Commission Working Document. SE(1999) 470 final.

EC (2000). Green Paper on greenhouse gas emissions trading within the European Union. Commission of the European Communities. COM(2000) 87 final.

EC (2001). Directive 2001/77/EC of the European Parliament and of the Council of 27 September 2001 on the promotion of electricity produced from renewable energy sources in the internal electricity market. Official Journal of the European Communities L 283/33.

EC (2003). Directive 2003/87/EC of the European Parliament and of the Council of 13 October 2003 establishing a scheme for greenhouse gas emission allowance trading within the Community and amending Council Directive 96/61/EC.

EC (2004). Directive 2004/8/EC of the European Parliament and of the Council of 11 February 2004 on the promotion of cogeneration based on a useful heat demand in the internal energy market and amending Directive 92/42/EEC. Official Journal of the European Union L 52/50.

EC (2005). Communication from the Commission. The support of electricity from renewable energy sources. Commission of the European Communities. COM(2005) 627 final.

EC (2009). Directive 2009/28/EC of the European Parliament and of the Council of 23 April 2009 on the promotion of the use of energy from renewable sources and amending and subsequently repealing Directives 2001/77/EC and 2003/30/EC. Official Journal of the European Union L 140/16.

EC (2012). The state of the European carbon market in 2012. COM(2012) 652 final.

EC (2014a). A policy framework for climate and energy in the period from 2020 to 2030. European Commission COM(2014) 15 final.

EC (2014b). Guidelines on State aid for environmental and energy 2014-2020. European Commission. Official Journal of EU 57 2014/C 200/01.

Edenhofer, O., Flachsland, C., Wolff, C., Schmid, L.K., Leipprand, A., Koch, N., Kornek, U., Pahle, M. (2017). Decarbonization and EU ETS Reform: Introducing a Price Floor to Drive Low-Carbon Investments. Mercator Research Institute on Global Commons and Climate Change.

Ehrlich, P. (1968). The Population Bomb. New York, Ballatine Books.

Ekins, P., Speck, S., eds. (2011). Environmental Tax Reform (ETR). A Policy for Green Growth. Oxford University Press.

Ellerman, A.D., Buchner, B.K. (2007). The European Union emissions trading scheme: Origins, allocation, and early results. Review of Environmental Economics and Policy 1 (1): 66-87.

Ellerman, A.D., Joskow, P. (2008). The European Union's Emissions Trading System in Perspective. Pew Center on Global Climate Change.

Ellerman, A.D., Convery, F.J., De Perthuis, C. (2010). Pricing Carbon: The European Union Emissions Trading Scheme. Cambridge University Press.

Ellerman, A.D., Joskow, P.L., Schmalensee, R., Montero, J.-P., Bailey, E.M. (2000). Markets for Clean Air: The U.S. Acid Rain Program. New York, Cambridge University Press.

EPA (2001). The United States Experience with Economic Incentives for Protecting the Environment. Washington, DC: National Center for Environmental Economics, U.S. Environmental Protection Agency.

Etminan, M., Myhre, G., Highwood, E.J., Shine, K.P. (2016). Radiative forcing of carbon dioxide, methane, and nitrous oxide: A significant revision of the methane radiative forcing. Geophysical Research Letters. AGU Publications - Wiley Online Library. 


\section{References}

EU (2003). Directive 2003/87/EC of the European Parliament and of the Council of 13 October 2003 establishing a scheme for greenhouse gas emission allowance trading within the Community and amending Council Directive 96/61/EC. Official Journal of the European Union L 275/32-46.

EU (2012). Directive 2012/27/EU of the European Parliament and of the Council of 25 October 2012 on energy efficiency, amending Directives 2009/125/EC and 2010/30/EU and repealing Directives 2004/8/EC and 2006/32/EC.

EU (2018a). Directive (EU) 2018/410 of the European Parliament and of the Council of 14 March 2018 amending Directive 2003/87/EC to enhance cost-effective emission reductions and low-carbon investments, and Decision (EU) 2015/1814. Official Journal of the European Union L76/3-27.

EU (2018b). Directive (EU) 2018/2001 of the European Parliament and of the Council of 11 December 2018 on the promotion of the use of energy from renewable sources (recast). Official Journal of the European Union L 328/82 (21.12.2018).

EUROSTAT (2010). Taxation Trends in the European Union. Data for the EU MS and Norway. Luxembourg: Publications Office of the European Union.

Faure, M., Peeters, M. eds. (2008). Climate Change and European Emissions Trading. Lessons for Theory and Practice. New Horizons in Environmental Law. Cheltenham: Edward Elgar.

Ferguson, S., Sanctuary, M. (2018). Why is carbon leakage for energy-intensive industry hard to find? Environmental Economics and Policy Studies. doi:10.1007/s1001810018-0219-0218

Fischer, C., Newell, R.G. (2008). Environmental and technology policies for climate mitigation. Journal of Environmental Economics and Management 55: 142-162.

Fisher, A.C. (1981). Resource and Environmental Economics. Cambridge: Cambridge University Press.

Fouquet, D. (2019). Nuclear policy in the EU from a legal and institutional point-ofview, in Haas, R., Mez, L., Ajanovic, A., eds., The Technological and Economic Future of Nuclear Power. Energy Policy and Climate Protection series. Springer VS, pp. 169-209.

Fouquet, D., Johansson, T.B. (2008). European renewable energy policy at cross-roads. Focus on electricity support mechanisms. Energy Policy 36 (11): 4079-4092.

Freeman, D., dir. (1974). A Time to Choose: America's Energy Future. Energy Policy Project of the Ford Foundation. Ballinger Publishing.

French Council of Economic Analysis \& German Council of Economic Experts (2019, July 16). A Uniform Carbon Price for Europe. Paris, Wiesbaden.

Fri, R.W. (2003). The role of knowledge: Technological innovation in the energy system. The Energy Journal 24 (4): 51-74.

Fri, R.W. (2013). The alternative energy future: The scope of the transition. Daedalus 142 (1): 5-7.

Friedrichs, J. (2010). Global energy crunch: How different parts of the world would react to a peak oil scenario. Energy Policy 38 (8): 4562-4569.

Friends of the Earth Europe (2013, 19 February). Dangerous over-reliance on failing carbon trading scheme. Press note.

Frondel, M., Ritter, N., Schmidt, C.M., Vance, C. (2010). Economic impacts from the promotion of renewable energy technologies: The German experience. Energy Policy 38: 4048-4056.

Fuchs, D. (2007). Business Power in Global Governance. Boulder, USA: Lynne Riener.

Gamson, W.A., Modigliani, A. (1989). Media discourse and public opinion on nuclear power: A constructionist approach. American Journal of Sociology 95 (1): 1-37. 
Gawel, E., Purkus, A. (2013). Promoting the market and system integration of renewable energies through premium schemes - a case study of the German market premium. Energy Policy 61: 599-609.

Geelen, D., Reinders, A., Keyson, D. (2013). Empowering the end-user in smart grids: Recommendations for the design of products and services. Energy Policy 61: 151-161.

Gillon, L. (1986). De kwestie kernenergie. Antwerpen: Standaard Uitgeverij.

Goldstein, A., Turner, W.R., Gladstone, J., Hole, D.G. (2019). The private sector's climate change risk and adaptation blind spots. Nature Climate Change 9, 18-25.

Gollier, C., Tirole, J. (2015). Negotiating effective institutions against climate change. Economics of Energy \& Environmental Policy 4 (2): 5-27.

Goulder, L.H., Parry, I.W.H. (2008). Instrument choice in environmental policy. Review of Environmental Economics and Policy 2 (2), 152-174.

Goulder, L.H., Schneider, S.H. (1999). Induced technological change and the attractiveness of $\mathrm{CO}_{2}$ abatement policies. Resource and Energy Economics 21 (3-4): 211-253.

Goulder, L.H., Parry, I.W.H., WilliamsIII, R.C., Burtraw, D. (1999). The cost-effectiveness of alternative instruments for environmental protection in a second-best setting. Journal of Public Economics 72: 329-360.

Green, D. (2016). How Change Happens. Oxford University Press.

Grubb, M. (2007). The European Emissions Trading Scheme: An Overview of Operation and Lessons. Forum CESifo DICE Report 4, pp. 17-25.

Grübler, A. (1998). Technology and Global Change. Cambridge University Press.

Gullì, F. ed. (2008). Markets for Carbon and Power Pricing in Europe: Theoretical Issues and Empirical Analyses. Cheltenham-Northampton: Edward Elgar.

Gupta, S., Tripak, D.A. et al. (2007). Policies, Instruments and Co-operative Arrangements, in IPCC, Intergovernmental Panel on Climate Change: Climate Change 2007. Assessment Report 4, pp. 745-807. www.ippc.ch.

Haas, R., Mez, L., Ajanovic, A. eds. (2019). The Technological and Economic Future of Nuclear Power. Energy Policy and Climate Protection series. Springer VS.

Haas, R, Thomas, S., Ajanovic, A. (2019). The historical development of the costs of nuclear power, in Haas, R., Mez, L., Ajanovic, A. eds., The Technological and Economic Future of Nuclear Power. Energy Policy and Climate Protection series. Springer VS, pp. 97-115.

Haas, R., Lettner, G., Auer, H., Duic, N. (2013). The looming revolution: How photovoltaics will change electricity markets in Europe fundamentally. Energy 57: 38-43.

Haas, R., Eichhammer, W., Huber, C., Langniss, O., Lorenzoni, A., Madlener, R., Menanteau, P., Morthorst, P.E., Martins, A., Oniszk, A., Schleich, J., Smith, A., Vass, Z., Verbruggen, A. (2004). How to promote renewable energy systems successfully and effectively? Energy Policy 32 (6): 833-839.

Haas, T. (2019). Struggles in EU energy politics: A Gramscian perspective on power in energy transitions. Energy Research \& Social Science 48: 66-74.

Hache, F. (2019). 50 Shades of Green. The rise of natural capital markets and sustainable finance. Part I Carbon. Policy Report. Green Finance Observatory.

Hahn, R., Ulph, A. eds. (2012). Climate Change and Common Sense. Essays in Honour of Tom Schelling. Oxford University Press.

Hahn, R.W., Stavins, R.N. (2011). The effect of allowance allocations on cap-and-trade system performance. Journal of Law and Economics 54: S267-S294.

Hardin, G. (1968). The tragedy of the commons. Science 162: 1243-1248. 


\section{References}

Hardy, J.S. (2014). Linéaments d'une phenomenology des passions chez Ricoeur. Philosophiques 41 (2), 313-332.

Healy, N., Stephens, J.C., Malin, S.A. (2019). Embodied energy injustices: Unveiling and politicizing the transboundary harms of fossil fuel extractivism and fossil fuel supply chains. Energy Research \& Social Science 48: 219-234.

Heilmayr, R., Bradbury, J.A. (2011). Effective, efficient or equitable: Using allowance allocations to mitigate emissions leakage. Climate Policy 11, 1113-1130.

Heinberg, R. (2011). The End of Growth. Gabriola Island, BC, Canada: New Society Publishers,

Heiskanen, E., Apajalahti, E.-L., Matschoss, K., Lovio, R. (2018). Incumbent energy companies navigating energy transitions: Strategic action or bricolage? Environmental Innovation and Societal Transitions 28: 57-69.

Held, A., Haas, R., Ragwitz, M. (2006). On the success of policy strategies for the promotion of electricity from renewable energy sources in the EU. Energy \& Environment 17 (6), 849-868.

Helm, D., Hepburn, C. (2005). Carbon Contracts and Energy Policy: An Outline Proposal. Oxford University mimeo.

Henderson, J.M., Quandt, R.E (1971). Microeconomic Theory. A Mathematical Approach, 2nd ed. New York: McGraw-Hill.

Hennicke, P., Johnson, J.P, Kohler, S., Seifried, D. (1985). Die Energiewende ist möglich. Frankfurt am Main: S. Fischer Verlag.

Hepburn, C. (2006). Regulation by prices, quantities, or both: A review of instrument choice. Oxford Review of Economic Policy 22 (2): 226-247.

Hepburn, C., Grubb, M., Neuhoff, K., Matthes, F., Tse, M. (2006). Auctioning of EU ETS Phase ii allowances: How and why? Climate Policy 6: 137-160.

Heyward, M. (2007). Equity and international climate change negotiations: A matter of perspective. Climate Policy 7, 518-534.

Homer-Dixon, T.F. (1991). On the threshold: Environmental changes as causes of acute conflict. International Security 16 (2): 76-116.

Howard, P.H., Sterner, T. (2017). Few and not so far between: A meta-analysis of climate damage estimates. Environmental and Resource Economics 68 (1): 197-225.

Howard, W.W. (2008). Electricity Market Design: Coordination, Pricing and Incentives. ERCOT Energized Conference, Austin, Texas.

IEA (2012). Energy Technology Perspectives 2012. Pathways to a clean energy system. Paris: International Energy Agency.

IEA (2019, December 2). The IEA at COP25. Newsletter. www.iea.org.

IEA (2019b). World Energy Outlook.

IEA (2020). Global Energy Review 2020. The Impacts of the Covid-19 Crisis on Global Energy Demand and $\mathrm{CO}_{2}$ Emissions. www.iea.org.

IPCC (2007). Intergovernmental Panel on Climate Change: Climate Change 2007. Assessment Report 4. www.ippc.ch.

IPCC (2012). Special Report on Renewable Energy Sources and Climate Change Mitigation. Cambridge University Press, www.ipcc.ch.

IPCC (2014). Intergovernmental Panel on Climate Change, Fifth Assessment Report, WG3, Mitigation of Climate Change. www.ipcc.ch.

IPCC (2018). Global warming of $1.5^{\circ} \mathrm{C}$. An IPCC Special Report on the Impacts of Global Warming of $1.5^{\circ} \mathrm{C}$ above Pre-Industrial Levels and Related Global Greenhouse Gas Emission Pathways. www.ipcc.ch.

IRENA (2018). Renewable Power Generation Costs in 2017. www.irena.org. 
IRENA (2019). Innovation Landscape for a Renewable-Powered Future: Solutions to Integrate Variable Renewables. www.irena.org.

IRENA (2020). Renewable Power Generation Costs in 2019. www.irena.org.

ISE (2020). Photovoltaics report. Freiburg: Fraunhofer Institute for Solar Energy Systems. www.ise.fraunhofer.de.

Jacques, P.J, Dunlap, R.E., Freeman, M. (2008). The organization of denial: Conservative think tanks and environmental skepticism. Environmental Politics 17 (3): 349-385.

Jaffe, A.B., Stavins, R.N. (1995). Dynamic incentives of environmental regulations: The effects of alternative policy instruments on technology diffusion. Journal of Environmental Economics and Management 29 (3), 43-63.

Jaffe, A.B., Newell, R.G., Stavins, R.N. (2005). A tale of two market failures: Technology and environmental policy. Ecological Economics 54: 164-174.

Jardon, A.J., Huitema, D., Hildén, M., van Asselt, H., Rayner, T.J., Schoenefeld, J.J., Tosun, J., Forster, J., Boasson, E.L. (2015). Emergence of polycentric climate governance and its future prospects. Nature Climate Change 5: 977-982.

Jenkins, K., McCauley, D., Heffron, R., Stephan, H., Rehner, R. (2016). Energy justice: A conceptual review. Energy Research \& Social Science 11: 174-182.

Johnstone, P., Stirling, A., Sovacool, B. (2017). Policy mixes for incumbency: Exploring the destructive recreation of renewable energy, shale gas "fracking," and nuclear power in the United Kingdom. Energy Research \& Social Science, Policy Mixes for Energy Transitions 33: 147-162.

Joltreau, E., Sommerfeld, K. (2019). Why does emissions trading under the EU emissions trading system (ETS) not affect firms' competitiveness? Empirical findings from the literature. Climate Policy 19 (4): 453-471.

Jones, J.M. (1977). Introduction to Decision Theory. Illinois: Richard D. Irwin Inc.

Jong, M.A.P. (2018). Energy and Carbon Markets: Empirical Law and Economics Studies. $\mathrm{PhD}$-thesis, University of Groningen

Joskow, P.L., Schmalensee, R. (1985). Markets for Power. An Analysis of Electric Utility Deregulation. Cambridge, Massachusetts: The MIT Press,

Juergens, I., Barreiro-Hurlé, J., Vasa, A. (2013). Identifying carbon leakage sectors in the EU ETS and implication of results. Climate Policy 13: 89-109.

Kemp, R., Pontoglio, S. (2011). The innovation effects of environmental policy instruments - a typical case of the blind men and the elephant? Ecological Economics 72: $28-36$.

Klare, M., (2004). Blood and Oil: The Dangers and Consequences of America's Growing Dependency on Imported Petroleum. Metropolitan Books.

Klare, M., (2008). Rising Powers, Shrinking Planet: The New Geopolitics of Energy. Metropolitan Books.

Klare, M., (2012). The Race for What's Left: The Global Scramble for the World's Last Resources. Metropolitan Books.

Klenert, D., Mattauch, L., Combet, E., Edenhofer, O., Hepburn, C., Rafaty, R., Stern, N. (2018). making carbon pricing work for citizens. Nature Climate Change 8: 669-677.

Kolstad, C.D. (1996). Fundamental irreversibilities in stock externalities. Journal of Public Economics 60: 211-231.

Komanoff, C. (1981). Power Plant Cost Escalation. New York: Komanoff Energy Associates. Kungl, G. (2015). Stewards or sticklers for change? Incumbent energy providers and the politics of the German energy transition. Energy Research \& Social Science 8: 13-23. 


\section{References}

Kupers, R. (2018). Resilience in complex organizations, in World Economic Forum, The Global Risks Report, pp. 54-55.

Lakoff, G. (2010). Why it matters how we frame the environment. Environmental Communication 4 (1): 70-81.

Lancaster, K. (1971). Consumer Demand. A New Approach. Columbia University Press.

Lancaster, K. (1979). Variety, Equity, and Efficiency. Product Variety in an Industrial Society. Columbia University Press.

Lane, R., Newell, P. (2016). The Political Economy of Carbon Markets, in Van de Graaf, T. et al., The Palgrave Handbook of the International Political Economy of Energy, pp. 247-267.

Lauber, V., Mez, L. (2006). Renewable electricity policy in Germany, 1974 to 2005. Bulletin of Science, Technology and Society 26 (2), 105-120.

Lawson, T. (1997). Economics and Reality. Economics as Social Theory. London: Routledge. Laybourn-Langton, L., and Jacobs, M. (2017). Moving beyond Neoliberalism: An Assessment of the Economic Systems Change Movement in the UK. Friends Provident Foundation. www.friendsprovidentfoundation.org/wp-content/uploads/2017/11/ Michael-Jacobs-LLL-Moving-Beyond-Neoliberalism-Report-5-Oct-2017.pdf.

Lehtonen, M. (2019). Framing of nuclear megaproject pathologies by the OECD-NEA. 23rd Reform Group Meeting, Salzburg.

Leibenstein, H. (1966). Allocative efficiency vs. x-efficiency. American Economic Review 56 (3): 392-415.

Lesourne, J. (1975). Cost-Benefit Analysis and Economic Theory. Amsterdam: North-Holland Publishing Company.

Löfgren, A., Burtraw, D., Wrake, M., Malinovskaya, A. (2018). Distribution of emissions allowances and the use of auction revenues in the European Union emissions trading system. Review of Environmental Economics and Policy 12 (2): 284-303.

Löfgren, A., Wrake, M., Hagberg, T., Roth, S. (2013). Why the EU ETS needs reforming: An empirical analysis of the impact on company investments. Climate Policy 14 (5), 537-558.

Lohmann L. ed. (2006). Carbon Trading: A Critical Conversation On Climate Change, Privatization and Power, Dag Hammarskjöld development dialogue, 48.

Lovins, A.B. (1976). Energy strategy: The road not taken? Foreign Affairs 55 (1): 65-96.

LSE (2019). What is a Carbon Price and Why Do we Need One?London: The London School of Economics and Political Science.

Lundy, D. (2017). Lobby Planet Brussels. The Corporate Europe Observatory guide to the murky world of EU lobbying. www.corporateeurope.org.

Luta, A.P. (2014). The current state of the EU ETS. European Parliament lecture. www.sa nbag.be.

Marcantonini, C., Ellerman, A.D. (2014). The Implicit Carbon Price of Renewable Energy Incentives in Germany. European University Institute.

Marcu, A., Alberola, E., Caneill, J.Y., Mazzoni, M., Schleicher, S., Stoefs, W., Vailles, Ch. (2017). 2017 State of the EU ETS Report. International Centre for Trade and Sustainable Development. www.ictsd.org.

Marcu, A., Alberola, E., Caneill, J.Y., Mazzoni, M., Schleicher, S., Vailles, Ch., Stoefs, W., Vangenechten, D., Cecchetti, F. (2019). 2019 State of the EU ETS Report. International Centre for Trade and Sustainable Development. www.i4ce.org/wp -core/wp-content/uploads/2019/05/2019-State-of-the-EU-ETS-Report-1.pdf.

Markussen, P., Svendsen, G.T. (2005). Industry lobbying and the political economy of GHG trade in the European Union. Energy Policy 33: 245-255. 
Marten, M., van Dender, K. (2019). The Use of Revenues from Carbon Pricing. OECD Taxation Working Papers No. 43.

Mayumi, K. (2019). Can the social cost of carbon be calculated? No: there are fundamental problems with cost-benefit analysis when applied to climate change, in Hulme, M. ed., Climate Change Debates: A Student Primer. London: Routledge.

Meadowcroft, J. (2012). Pushing the boundaries: governance for sustainable development and a politics of limits, in Meadowcroft, J., Langhelle, O., Ruud, A., eds., Governance, Democracy, and Sustainable Development. UK: Edward Elgar, pp. 272-296.

Meadowcroft, J., Langhelle, O., Ruud, A., eds. (2012). Governance, Democracy, and Sustainable Development. UK: Edward Elgar.

Meadows, D.H., et al. (1972). The Limits to Growth. New York: Universe Books.

Mehling, M., van Asselt, H., Das, K., Droege, S. (2018). Beat protectionism and emissions at a stroke. Nature 559: 321-324.

Meckling, J. (2011). Carbon Coalitions. Business, Climate Politics, and the Rise of Emissions Trading. Cambridge, MA: The MIT Press.

Meckling, J. (2014). The future of emissions trading, Opinion. WIREs Clim Change 2014, 5: 569-576. doi:10.1002/wcc.293.

Metcalf, G.E. (2009). Market-based policy options to control US greenhouse gas emissions. Journal of Economic Perspectives 23: 5-27.

Meyer, A. (1998). The Kyoto Protocol and the emergence of "contraction and convergence" as a framework for an international political solution to greenhouse gas emissions abatement, in Hohmeyer, O., Rennings, K., eds., Man-Made Climate Change. Economic Aspects and Policy Options. ZEW, Springer Verlag, pp. 291-326.

Meyer, N.I. (2003). European schemes for promoting renewables in liberalized markets. Energy Policy 31: 665-676.

Montgomery, W.D. (1972). Markets in licenses and efficient pollution control programs. Journal of Economic Theory 5: 395-418.

Moomaw, W., Burgherr, P., Heath, G., Lenzen, M., Nyboer, J., Verbruggen, A. (2011). Annex II. Methodology, in IPCC Special Report on Renewable Energy Sources and Climate Change Mitigation, Cambridge University Press, pp. 973-1000.

Morthorst, P.E. (2000). The development of a green certificate market. Energy Policy 28: 1085-1094.

Munasinghe, M. (1993). Environmental Economics and Sustainable Development. World Bank.

Murphy, L.M., Edwards, P.L. (2003). Bridging the Valley of Death: Transitioning from Public to Private Sector Financing. Golden, USA: National Renewable Energy Laboratory.

Narassimhan, E., Gallagher, K.S., Koester, S., Rivero Alejo, J. (2018). Carbon pricing in practice: A review of existing emissions trading systems. Climate Policy 18 (8): 967-991.

Nazifi, F. (2016). The pass-through rates of carbon costs on to electricity prices within the australian national electricity market. Environmental Economics and Policy Studies 18: 41-62.

Nelson, J.A. (2013). Ethics and the economist: What climate change demands of us. Ecological Economics 85: 145-154.

Nelson, J.R. ed. (1964). Marginal Cost Pricing in Practice. Englewood Cliffs, NJ: Prentice-Hall.

Nemetz, P.N. (2015). Reconstructing the sustainability narrative, in Kopnina, H., Shoreman-Ouimet, E. (2015). Sustainability. Key Issues. Earthscan, pp. 40-69. 
Neuhoff, K. (2008). Tackling Carbon. How to Price Carbon for Climate Policy. University of Cambridge, Faculty of Economics.

Newell, P., Johnstone, P. (2018). The Political Economy of Incumbency Fossil Fuel Subsidies in Global and Historical Context, in Skovgaard, J. and Van Asselt, H. eds., The Politics of Fossil Fuel Subsidies and Their Reform. Cambridge: Cambridge University Press, pp. 66-80.

Newell, P., Paterson, M. (2010). Climate Capitalism: Global Warming and the Transformation of the Global Economy. Cambridge University Press.

Nordhaus, W. (1973). The allocation of energy resources. Brookings Papers on Economic Activity 3: 529-576.

Nordhaus, W. (2007). To tax or not to tax: Alternative approaches to slowing global warming. Review of Environmental Economics and Policy 1: 26-44.

Nordhaus, W.D. (2018, December 8). Climate Change: The Ultimate Challenge for Economics. Nobel Lecture in Economic Sciences. Stockholm University.

Nykamp, S., Andor, M., Hurink, J.L. (2012). "Standard" incentive regulation hinders the integration of renewable energy generation. Energy Policy 47: 222-237.

Oates, W.E. (2011). Fiscal Federalism. Cheltenham: Edward Elgar.

OECD (1972). Guiding Principles Concerning International Economic Aspects of Environmental Policies. Paris: OECD.

OECD (2003). OECD Environmental Indicators. Development, Measurement and Use. www.oecd.org/env/.

Oosterlaken, I. (2015). Applying value sensitive design (VSD) to wind turbines and wind parks: An exploration. Science and Engineering Ethics 21 (2): 359-379. https:// doi.org/10.1007/s11948-014-9536-x.

Ostrom, E. (1990). Governing the Commons. The Evolution of Institutions for Collective Action. Cambridge University Press.

Ostrom, E. (1992). The rudiments of a theory of the origins, survival, and performance of common-property institutions, in Bromley, D.W., ed., Making the Commons Work, pp. 293-318.

Ostrom, E. (2005). Understanding Institutional Diversity. Princeton University Press.

Ostrom, E. (2014). A polycentric approach for coping with climate change. Annals of Economics and Finance 15 (1): 97-134.

Page, E.A. (2012). The hidden costs of carbon commodification: Emissions trading, political legitimacy and procedural justice. Democratization 19 (5): 932-950.

Parry, I., Pizer, W. (2007). Combating Global Warming: Is taxation or cap-and-trade the better strategy for reducing greenhouse emissions? Regulation, Fall: 18-22.

Parry, I., Williams III, R.C. (2012). Moving US climate policy forward: Are carbon taxes the only good alternative? in Hahn, R., Ulph, A. eds., Climate Change and Common Sense. Essays in Honour of Tom Schelling. Oxford University Press, pp. 173-202.

Parry, I., Williams III, R.C., Goulder, L.H. (1999). When can carbon abatement policies increase welfare? The fundamental role of distorted factor markets. Journal of Environmental Economics and Management 37 (1): 52-84.

Passey, R., Bailey, I., Twomey, P., MacGill, I. (2012). The inevitability of "flotilla policies" as complements or alternatives to flagship emissions trading schemes. Energy Policy 48: 551-561.

Pearce, D.W., Turner, R.K. (1990). Economics of Natural Resources and the Environment. Harvester Wheatsheaf.

Pearse, R., Böhm, S. (2014). Ten reasons why carbon markets will not bring about radical emissions reduction. Carbon Management, Taylor \& Francis. 
Peeters, M. (2008). Legislative choices and legal values: considerations on the further design of the European greenhouse gas Emissions Trading Scheme from a viewpoint of democratic accountability, in Faure, M., Peeters, M. eds., Climate Change and European Emissions Trading. Lessons for Theory and Practice. New Horizons in Environmental Law. Cheltenham: Edward Elgar, pp. 17-52.

Pellegrini-Masini, G., Pirni, A., and Maran S. (2020). Energy justice revisited: a critical review on the philosophical and political origins of equality. Energy Research E Social Science 59 (January): 101310. https://doi.org/10.1016/j.erss.2019.101310.

Peltzman, S. (1976). Towards a more general theory of regulation. Journal of Law $\mathcal{E}$ Economics 19 (2): 211-240.

Perino, G., Willner, M. (2016). Procrastinating reform: The impact of the stability reserve on the EU ETS. Journal of Environmental Economics and Management 80: 37-52.

Peters, S., (2004). Coercive western energy security strategies: 'Resource wars' as a new threat to global security. Geopolitics 9 (1): 187-212.

Phlips, L. (1983). The Economics of Price Discrimination. Cambridge University Press.

Pindyck, R.S. (2000). Irreversibilities and the timing of environmental policy. Resource and Energy Economics 22: 233-259.

Pindyck, R.S. (2013). Climate change policy: What do the models tell us? Journal of Economic Literature 51 (3): 860-872.

Pindyck, R.S. (2017a). Coase lecture: Taxes, targets and the social cost of carbon. Economica 84: 345-364.

Pindyck, R.S. (2017b). The use and misuse of models for climate policy. Review of Environmental Economics and Policy 11 (1): 100-114.

Pizer, W., Adler, M., Aldy, J., Anthoff, D., Cropper, M., Gillingham, K., Greenstone, M., Murray, B., Newell, R., Richels, R., Rowell, A., Waldhoff, S., Wiener, J. (2014). Using and improving the social cost of carbon. Science 346 (6214): 1189-1190.

Point Carbon (2008). EU ETS Phase II: The Potential and Scale of Windfall Profits In the Power Sector. A report for WWF by Point Carbon Advisory Services.

Porter, M.E. (1985). Competitive Strategy. New York: The Free Press, Simon \& Schuster Inc.

Prins, G., Rayner, S. (2007). The Wrong Trousers: Radically Rethinking Climate Policy. Discussion Paper. University of Oxford and London School of Economics.

Rabe, B.G. (2018). Can We Price Carbon? Cambridge, MA: The MIT Press.

Raymond, L. (2003). Private Rights in Public Resources: Equity and Property Allocation in Market-Based Environmental Policy. Washington DC: Resources for the Future Press.

Rees, R. (1976). Public Enterprise Economics. London School of Economics handbooks in economic analysis. London: Weidenfeld and Nicolson.

Reynolds W., Perkins H. (1977). Engineering Thermodynamics. New York: McGraw Hill.

Richardson, N., Fraas, A.G. (2013). Comparing the Clean Air Act and a Carbon Prize. Discussion Paper RFF DP 13-13. Resources for the Future.

Roelfsema, M., Fekete, H., Höhne, N., den Elzen, M., Forsell, N., Kuramochi, T. (2018). Reducing global GHG emissions by replicating successful sector examples: The "good practice policies" scenario. Climate Policy 18 (9): 1103-1113.

Rogge, K.S., Schneider, M., Hoffmann, V.H. (2011). The innovation impact of the EU emission trading system: Findings of company case studies in the German power sector. Ecological Economics 70: 513-523.

Rosenberg, N. (1976). Perspectives on Technology. Cambridge University Press. 


\section{References}

Rosenbloom, D., Markard, J., Geels, F.W., Fuenfschilling, L. (2020). Why carbon pricing is not sufficient to mitigate climate change - and how "sustainability transition policy" can help. Opinion. doi:10.1073/pnas.2004093117.

Roser, M. (2020). Economic Growth. https://ourworldindata.org/economic-growth.

Saltelli, A., Benini, L., Funtowicz, S., Giampietro, M., Kaiser, M., Reinert, E., van der Sluijs, J.P. (2020). The technique is never neutral. How methodological choices condition the generation of narratives for sustainability. Environmental Science and Policy 106: 87-98.

Samuelson, P.A. (1948). Foundations of Economic Analysis. Cambridge, MA: Harvard University.

Schapper, A. (2018). Climate justice and human rights. International Relations 32 (3): 275-295. https://doi.org/10.1177/0047117818782595.

Scheer, H. (1993, 2001). A Solar Manifesto. UK: James \& James.

Schleicher-Tappeser, R., (2012). How renewables will change electricity markets in the next five years. Energy Policy 48: 64-75.

Schmalensee, R., Stavins, R.N. (2013). The $\mathrm{SO}_{2}$ allowance trading system: The ironic history of a grand policy experiment. Journal of Economic Perspectives 27 (1): 103-122.

Schmalensee, R., Stavins, R.N. (2017). The design of environmental markets: What have we learned from experience with cap and trade? Oxford Review of Economic Policy 33 (4): 572-588.

Schneider, M. (2019). The World Nuclear Industry Status Report 2019. www.WorldNu clearReport.org.

Schnellenbach, J. (2005). The Dahrendorf Hypothesis and its implications for (the theory of) economic policy-making. Cambridge Journal of Economics 29 (6): 997-1009.

Schoemaker, P.J.H. (1990). Strategy, complexity and economic rent. Management Science 36: $1178-1192$.

Shannon, C.E. (1948). A mathematical theory of communication. The Bell System Technical Journal 27: 379-423 and 623-656.

Sijm, J., Neuhoff, K., Chen, Y. (2006). $\mathrm{CO}_{2}$ cost pass-through and windfall profits in the power sector. Climate Policy 6: 49-72.

Simmons, I.G. (1989). Changing the Face of the Earth. Culture, Environment, History. Oxford: Basil Blackwell.

Skjaerseth, J.B, Wettestad, J. (2010). Making the EU emissions trading system: The European Commission as an entrepreneurial epistemic leader. Global Environmental Change 20: 314-321.

Smil, V. (2017). Energy and Civilization: A History. Cambridge, MA: The MIT Press.

Smith, S. (2002). Ex-post evaluations of tradeable permits programmes, in OECD, Implementing Domestic Tradeable Permits. Proceedings Workshop Paris, 6-7 September 2001, pp. 29-66.

Spash, C. (2010). The brave new world of carbon trading. New Political Economy 15 (2): 169-195.

Stavins, R.N. (1995). Transaction costs and tradable permits. Journal of Environmental Economics and Management 29: 133-148.

Steiner, P.O. (1957). Peak loads and efficient pricing . The Quarterly Journal of Economics 71 (4): 585-610.

Stenqvist, C., Ahman, M. (2014). Free allocation in the 3rd EU ETS period: Assessing two manufacturing sectors. Climate Policy 16 (2): 125-144.

Stephan, B., Paterson, M. (2012). The politics of carbon markets: An introduction. Environmental Politics 21 (4): 545-562. 
Stern, N. (2006). Stern Review: The Economics of Climate Change, Executive Summary.

Stigler, G. (1971). The theory of economic regulation. Bell Journal of Economics and Management Science 2 (1): 3-21.

Stiglitz, J. (2015). Overcoming the Copenhagen failure with flexible commitments. Economics of Energy \& Environmental Policy 4 (2): 29-36.

Stiglitz, J, Stern, N. (2017). Report of the High-Level Commission on Carbon Prices. World Bank Group initiative. Carbon Pricing Leadership Coalition.

Stirling, A. (1998). On the Economics and Analysis of Diversity. SPRU Electronic Working Papers Series, No. 28. Brighton, UK: University of Sussex.

Stirling, A. (1999). On Science and Precaution in the Management of Technological Risk. SPRU. Brighton, UK: University of Sussex.

Stirling, A. (2007). A general framework for analysing diversity in science, technology and society. Journal of the Royal Society Interface 4 (15): 707-719.

Stoft, S. (2002). Power System Economics. Designing Markets for Electricity. IEEE Press, Wiley-Interscience.

Tanwar, R. (2013). Porter's generic competitive strategies. IOSR Journal of Business and Management 15 (1): 11-17.

Tapia Granados, J.A., Spash, C.L. (2019). Policies to reduce $\mathrm{CO}_{2}$ emissions: Fallacies and evidence from the United States and California. Environmental Science and Policy 94: 262-266.

Thiel, A., Blomquist, W.A., Garrick, D.E. eds. (2019). Governing Complexity. Analyzing and Applying Polycentricity. Cambridge University Press.

Tietenberg T.H. (2000). Tradable Permits and the Control of Air Pollution in the United States. $10^{\text {th }}$ anniversary jubilee edition of the Zeitschrift für Angewandte Umweltforschung.

Tietenberg T.H. (2006). Emissions Trading. Principles and Practice. Washington, DC: RFF.

Tietenberg, T., Lewis, L. (2015). Environmental \& Natural Resource Economics, $10^{\text {th }} \mathrm{ed}$. England: Pearson Education Limited.

Tiebout, C.M. (1956). a pure theory of local expenditures. Journal of Political Economy 64: 416-424.

Tinbergen J. (1952). On the Theory of Economic Policy, 2nd ed. Amsterdam: North Holland.

Többen, J. (2017). Regional net impacts and social distribution effects of promoting renewable energies in Germany. Ecological Economics 135: 195-208.

Toke, D. (2008). Trading schemes, risks, and costs: The cases of the European Union emissions trading scheme and the renewables obligation. Environment and Planning C: Government and Policy 26: 938-953.

Töpfer, K., et al. (2011). Germany's Energy Turnaround: A Collective Effort for the Future. Berlin: Ethics Commission on a Safe Energy Supply.

Tormos, F., Garcia-Lopez, G.A. (2018). Polycentric Struggles: The experience of the global climate justice movement. Environmental Policy and Governance. Wileyonlinelibrary.com/journal/eet.

Turmes, C. (2000). REPORT on Electricity from Renewable Sources and the Internal Electricity Market. Committee on Industry, External Trade, Research and Energy. European Parliament. FINAL A5-0078/2000.

Turner, R.K., Pearce, D., Bateman, I. (1994). Environmental Economics. New York: Harvester Wheatsheaf.

Turvey, R. (1968). Optimal Pricing and Investment in Electricity Supply. London: G. Allen and Unwin. 


\section{References}

Turvey, R., Anderson, D. (1977). Electricity Economics. Essays and Case Studies. A World Bank Research Publication. The John Hopkins University Press, Baltimore.

Twidell, J., Weir, T. (2006). Renewable Energy Resources. Taylor \& Francis.

UN (1992). United Nations Framework Convention on Climate Change. GE.05-62220 (E) 200705.

UN (2015). Paris Agreement. UNFCCC.

UNDP (2019). Annual Report 2018. www.undp.org.

Vailles, Ch., Berghmans, N. (2020, May 15). Re-shaping the EU ETS as a safety net, not a driver. Energypost.eu.

Van de Graaf, T., Laes, E., Verbruggen, A. (2019). Energy Governance in Belgium, in Knodt, M., Kemmerzell, J., eds, Handbook of Energy Governance in Europe, Springer, pp. 1-22.

Van den Bergh, J.C.J.M. (2008). Optimal diversity: Increasing returns versus recombinant innovation. Journal of Economic Behavior \& Organization 68: 565-580.

Van den Bergh, J.C.J.M., Angelsen, A., Baranzini, A., Wouter Botzen, W.J., Carattini, S., Drews, S., Dunlop, T., Galbraith, E., Gsottbauer, E., Howarth, R.B., Padilla, E., Roca, J., Schmidt, R. (2018). Parallel Tracks towards a Global Treaty on Carbon Pricing. IEB Working Paper 2018/12.

Van de Poel, I. (2013). Translating Values into Design Requirements, in Michelfelder, D. P., McCarthy, N., Goldberg, D.E., eds., Philosophy and Engineering: Reflections on Practice, Principles and Process, Dordrecht: Springer Netherlands, pp. 253-266. http s://doi.org/10.1007/978-94-007-7762-0_20.

Van de Poel, I., Royakkers, L.M.M. (2011). Ethics, Technology, and Engineering: An Introduction. Wiley.com. www.wiley.com/en-be/Ethics\%2C+Technology $\% 2 \mathrm{C}+$ and +Engineering\%3A+An+Introduction-p-9781444330953.

Vanlommel, G. (1992). Cost Analysis and Pricing Policies of Electricity Generation and Transmission with an Application to Belgium. Ph.D thesis. University of Antwerp.

Varian, H.R. (1978). Microeconomic Analysis. New York: W.W. Norton \& Company.

Vatn, A. (2005). Institutions and the Environment. Cheltenham, UK: Edward Elgar.

Vatn, A. (2018). Environmental governance: From public to private? Ecological Economics 148: $170-177$.

Venmans, F. (2013). A Multi-Criteria Analysis of the European Union Emission Trading Scheme. PhD thesis, Faculté Waroqué d'Economie et de Gestion, UMons, Belgium.

Verbeke, A., Osiyevskyy, O., Backman, C.A. (2017). Strategic responses to imposed innovation projects: The case of carbon capture and storage in the Alberta oil sands industry. Long Range Planning 50: 684-698.

Verbruggen, A. (1990). Pricing independent power production. International Journal of Global Energy Issues 2 (1): 41-49.

Verbruggen, A. (1997). A normative structure for the European electricity market. Energy Policy 25 (3): 281-292.

Verbruggen, A. (2004). Tradable green certificates in Flanders (Belgium). Energy Policy 32: $165-176$.

Verbruggen, A. (2008a). Windfalls and other profits. Energy Policy 36: 3249-3251.

Verbruggen, A. (2008b). The merit of cogeneration: Measuring and rewarding performance. Energy Policy 36 (8): 3069-3076.

Verbruggen, A. (2008c). Economische Benadering van Milieu en Milieubehoud. AntwerpenApeldoorn: Garant.

Verbruggen, A. (2009a). Performance evaluation of renewable energy support policies, applied on Flanders' tradable certificates system. Energy Policy 37: 1385-1394. 
Verbruggen, A. (2009b). Beyond Kyoto, Plan B: A climate policy master plan based on transparent metrics. Ecological Economics 68: 2930-2937.

Verbruggen, A. (2013). Revocability and reversibility in societal decision-making. Ecological Economics 85: 20-27.

Verbruggen, A. (2014). Could it be that stock-stakeholders rule transition arenas? in Brunnengräber, A., Di Nucci, M.R., eds., Im Hürdenlauf zur Energiewende. Wiesbaden: Springer VS, pp. 119-131.

Verbruggen, A. (2015). Self-Governance in Global Climate Policy: An Essay. University of Antwerp. www.avielverbruggen.be.

Verbruggen, A. (2017). Electric power system transition and the "polluter pays principle", in Uyar, T.S. ed., Towards 100\% Renewable Energy. Springer, pp. 419-434.

Verbruggen, A., Al Marchohi, M., (2010). Views on peak oil and its relation to climate change policy. Energy Policy 38:5572-5581.

Verbruggen, A., Brauers, H. (2020). diversity disqualifies global uniform carbon pricing for effective climate policy. Environmental Science \& Policy 112: 282-292.

Verbruggen, A., Gijsbrechts, E. (1988). Estimating the sales potential of a new heating system. An "inverted" Lancaster approach. International Journal of Research in Marketing 5: 289-302.

Verbruggen, A., Laes, E. (2015). Sustainability assessment of nuclear power: Discourse analysis of IAEA and IPCC frameworks. Environmental Science \& Policy 51: 170-180.

Verbruggen, A., Laes, E. (2021). Early European experience with tradable green certificates neglected by EU ETS architects. Environmental Science \& Policy 119: 66-71.

Verbruggen, A., Lauber, V. (2009). Basic concepts for designing renewable electricity support aiming at full-scale transition by 2050. Energy Policy 37: 5732-5743.

Verbruggen, A., Nyboer, J. (2009). Reporting Expenses and Revenues of RE-supplies: Net Present Value and Levelized Costs. IPCC-SSREN. Preparatory document.

Verbruggen, A., Van de Graaf, T. (2013). Peak oil supply or oil not for sale? Futures 53: $74-85$.

Verbruggen, A., Vanderstappen, E. (1999). Electricity sector restructuring in Belgium during the 90's. Utilities Policy 8: 159-171.

Verbruggen, A., Yurchenko, Y. (2017). Positioning nuclear power in the low-carbon electricity transition. Sustainability 9 (163). doi:10.3390/su9010163.

Verbruggen, A., Yurchenko, Y. (2019). The collision of atomic and flow renewable power in decarbonization of electricity supply, in Haas, R., Mez, L., Ajanovic, A. eds, The Technological and Economic Future of Nuclear Power. Energy Policy and Climate Protection series. Springer VS, pp. 77-95.

Verbruggen, A., Klemes, J.J., Rosen, M.A. (2016). Assessing cogeneration activity in extraction-condensing steam turbines: Dissolving the issues by applied thermodynamics. Journal of Energy Resources Technology 158 (5).

Verbruggen, A., Laes, E., Lemmens, S. (2014). Assessment of the actual sustainability of nuclear fission power. Renewable and Sustainable Energy Reviews 32: 16-28.

Verbruggen, A., Laes, E., Woerdman, E. (2019). anatomy of emissions trading systems: what is the eu ets? Environmental Science \& Policy 98: 11-19.

Verbruggen, A., Borghys, A., De Jonghe, L., Vanderstappen, E., Verheyen, H., Verheyen, S. (2001). Organisation and regulation of the electricity supply industry in Belgium, in De Paoli, L., ed. The Electricity Industry in Transition. Organization, Regulation and Ownership in EU Member States. Milano: FrancoAngeli, pp. 71-121. 


\section{References}

Verbruggen, A., Fischedick, M., Moomaw, W., Weir, T., Nadai, A., Nilsson, L.J., Nyboer, J., Sathaye, J. (2011). Renewable energy costs, potentials, barriers: Conceptual issues. Energy Policy 38: 850-861.

Verbruggen, A., Di Nucci, M.R., Fischedick, M., Haas, R., Hvelplund, F., Lauber, V., Lorenzoni, A., Mez, L., Nilsson, L.J., del Rio Gonzalez, P. Schleich, J., Toke, D. (2015). Europe's electricity regime: Restoration or thorough transition. International Journal of Sustainable Energy Planning and Management 5: 57-68.

Vilkka, L. (1997). The Intrinsic Value of Nature. VIBS 59. Amsterdam: Editions Rodopi B.V.

Volberda, H.W., Morgan, R.E., Reinmoeller, P., Hitt, M.A., Ireland, R.D., Hoskissen, R.E. (2011). Strategic Management: Competitiveness and Globalization (Concepts and Cases). Cengage Learning EMEA.

Voss, J-P., Simons, A. (2014). Instrument constituencies and the supply side of policy innovation: The social life of emissions trading. Environmental Politics 23 (5): 735-754.

Wagner, G., Kaberger, T., Olai, S., Oppenheimer, M., Rittenhouse, K., Sterner, T. (2015). Energy policy: Push renewables to spur carbon pricing. Nature 525 (7567): $27-29$.

Waisman, H., Bataille, C., Winkler, H., Jotzo, F., Shukla, P., et al. (2019). A pathway design framework for national low greenhouse gas emission development strategies. Nature Climate Change 9 (4): 261-268.

Walker, G. (2012). Environmental Justice: Concepts, Evidence and Politics, 1 st ed. Routledge.

Wang, T., Watson, J. (2007). Who Owns China's Carbon Emissions? Tyndall Centre for Climate Research. Briefing Note $\mathrm{N}^{\circ} 23$.

Wara, M. (2007). Is the global carbon market working? Nature 445: 595-596.

Watkiss, P. (2005). The Social Cost of Carbon. UK: Department for Environment, Food and Rural Affairs.

WCED (1987). Our Common Future. Oxford University Press.

WEF (2019). The Global Risks Report 2019, $14^{\text {th }}$ edition. Insight Report. World Economic Forum, in partnership with Marsh \& McLennan Companies and Zurich Insurance Group.

Weitzman, M.L. (1974). Prices vs. quantities. Review of Economic Studies 16: 477-491.

Weitzman, M.L. (1992). On diversity. The Quarterly Journal of Economics (May): 363-405.

Weitzman, M.L. (2013). Tail-hedge discounting and the social cost of carbon. Journal of Economic Literature 51 (3): 873-882.

Weitzman, M.L. (2015). Internalizing the climate externality: Can a uniform price commitment help? Economics of Energy \& Environmental Policy 4 (2): 37-50.

Wettestad, J., Gulbrandsen, L.H., eds. (2018). The Evolution of Carbon Markets. Design and Diffusion. Transforming Environmental Politics and Policy. London \& New York: Routledge, Taylor \& Francis Group.

White, L.A. (1943). Energy and the evolution of culture. American Anthropology 45: 335-356.

Winter, S., Schlesewsky, L. (2019). The German feed-in tariff revisited: An empirical investigation on its distributional effects. Energy Policy 132: 344-356.

Woerdman, E. (2019). Energietransitie en klimaatbeleid: tussen marktwerking en overregulering [Energy Transition and Climate Policy: Between Market Formation and Overregulation], Inaugural lecture, https://ssrn.com/abstract $=3361527$. 
Woerdman, E., Nentjes, A. (2019). Emissions trading hybrids: The case of the EU ETS. Review of Law and Economics 15 (1): 1-32.

Wolin, S.S. (2008). Democracy Incorporated. Managed Democracy and the Specter of Inverted Totalitarianism. Princeton University Press.

Wood, P.J., Jotzo, F. (2011). Price floors for emissions trading. Energy Policy 39 (3): 1746-1753.

World Bank (2016). What Are the Options for Using Carbon Pricing Revenues? Executive Briefing, Carbon Pricing Leadership Coalition.

World Bank (2019). State and Trends of Carbon Pricing. Washington, DC. doi:10.1596/ 978-971-4648-1435-8.

Yandle, B. (1999). Bootleggers and Baptists in retrospect. Regulation 22 (3): 5-7.

Zaccai, E. (2012). Over two decades in pursuit of sustainable development: Influence, transformations, limits. Environmental Development 1: 79-90.

Zapfel, P. (2019, June 19). The European carbon market. A practitioner's perspective. Energy \& Climate, University of Antwerp.

Zeng, Y., Weishaar, S.E., Vedder, H.H.B. (2018). Electricity regulation in the Chinese national trading scheme (ETS): Lessons for carbon leakage and linkage with the EU ETS. Climate Policy. doi:10.1080/14693062.2018.1426553. 


\section{Index}

A-goal (policy for atmospheric cleanness) 33-4, 41, 44, 46

abatement 24, 32, 38, 40-1, 77, 85, 128, $163,166-9,173$; cost savings 55 ; efforts 82, 121; greenhouse gas emissions 209; lower costs 41; minimizing 166

abatement expenses 14, 24, 32-3, 36, 38, 40-1, 52, 76-7, 82, 166-7, 173, 175-7; aggregate 175 ; carbon emissions 23 ; declining 163; for EITE activities 44; equal marginal overall 44; lower 32; marginal 125; minimising the sum of 177; and price-induced innovation 42; skyrocketing 42; total 166

academics 3, 6, 46, 63, 139, 143, 157 acidification 51

Ackerman, F. 2, 8, 24, 79, 171 activities $12-14,26-8,33-4,36-7,43-5$, 52-3, 56-7, 74-6, 119-21, 128-31, 138-42, 149-51, 161-3, 176, 195-8; carbon-intensive 130; changing 158 , 168, 179; economic 30, 36, 93-4, 100, 110, 145, 192; exchange 129;

heterogeneous 24, 27; industrial xix; socio-economic 28

Acts and Regulations: Clean Air Act Amendments 1990 49; European Securities and Markets Authority 116 adaptation budgets 40

administrations xxii, 6, 32, 63, 115, 156-7, 187

administrative interventions 40, 133 advocacy 14, 95-6, 111; activities 87; centres 109 ; early emissions trading 8 ; functions 88 ; networks 87 ; plans 96 agencies $\mathrm{xx}, 51-2,54,203,206$; executive 113; regulatory 115,121 Agora Energiewende 41, 71-2, 81, 134, 186 agreements 7, 25, 63, 108-9, 125, 144, 199, 202, 214; high 108-9; international 25

agriculture 7,72

Aldy, J.E. 6, 17, 24, 33, 36-9, 42, 73, 117, 157

Al Marchohi, M. 94, 104-5

alliances 35, 105; anti-taxation 35; of polluters minimizing expenditures by obtaining free or low-priced licences 82

allocations $7,32,34-5,40,50,52,57$, 81-2, 127, 137, 177, 201, 203, 210; adjustments 129; administrative 36 ; allowance 82, 205-6; auctions 37; cost based economic 36; distorted initial 36; efficient 85; free 9; mechanisms 8; options, available 34

allowances 3, 7, 50, 52, 55, 81, 86, 117, 137, 177, 206; allocations 82, 205-6; emission 7, 37; free allocation of 3, 36, $55,74,79,81,83,86,117,212$; quota 44

Almunia, Joaquín 70, 135, 142

alternators 103

amortization 12,76

analysis xvii-xviii, 1-2, 13, 17-19, 25-6, $29,31-2,86-8,122-3,143-5,157$, 165-72, 198-202, 206-9, 211-15; academic 73 ; comparative 72,200 ; counterfactual 87; documented 143; economic xviii, 7, 13, 148, 200-1, 211-12; empirical 208; political 17; theoretical 78

analysts $10,111,140$

annuity $182-3,187-8$; factors $182-3$;

loans 187; payments 188

anti-nuclear protests 91

anti-tax coalitions xix-xx, 78, 175 
anti-taxation $\mathrm{xx}, 73,99-100,123$

applied carbon pricing xxii

arbitrage (among polluters) xix, 125, 130

architects 50, 55, 62, 113

architecture 61

arguments xix, xxii, 2, 14-16, 25, 32, 100, 107-9, 114, 121, 125, 149, 156, 163, 166; compelling xxii, 123, 125; economic 73; fake 121; ideological 74; invalid 14; negative 49; theoretical 148

Arrow, K.J. 12, 13,18, 19, 24, 125, 160, 170

artificial markets 4, 40, 44, 61, 65, 71; permit trading in 88,137 ; systems 68 ;

for trading atmospheric pollution space 34; trials 147

assessment 16, 38, 52, 70, 108, 156, $168-9,180,202,215$; costs 57 ; feasibility 96; integrated 168-9; IPCC 51 ; official 68

assets 76, 131; endowed 19; financial 12, 76, 161; long-living 194; obtained in several countries 115; stranded 115 , 132

assumptions 13, 21, 23; adopted 1; discount rate 38 ; economics textbook 31 ; major 82; special 18; theoretical 192; unrealistic 147; unverified 148 atomic power energy companies 75 Atoms for Peace xx, 93-4 attributes 23, 49-51, 60, 65, 72, 96-7, 122, 125, 163, 168, 184; low-carbon 107 ; physical 16; technical-economicsocial-political 184; uniform 17 ; of the US $\mathrm{SO}_{2}$ and $\mathrm{NOx}$ emissions reduction programs (1995-2005) and of the emerging $\mathrm{EU} \mathrm{CO}_{2}$ emissions trading system (2000-2007) $\mathbf{5 1}$

auctions 7-8, 10, 44, 47, 52, 56, 76, 79, $81,83,111,116,128,136,138$; prices 9; revenue 27,52

authorities $6,10,17,36,40,63,65,74$, 115, 117, 126-7, 131-2, 150, 157, 177; exclusive 63; local 150, 157; national regulatory 196; responsible 147

Baldwin, R. 2, 127, 140

banking 35-6, 52, 54-5, 83

bankruptcy 42, 106-7

banks 111, 182, 188

Baranzini, A. 17, 22, 24, 28, 58, 73, 130

Baron, D.P. 61, 63
Baron, R. 127

barriers 48, 62, 65, 108-9, 115, 151, 153, 216; emotional 141; to an increasing use of nuclear energy 108; raised by power monopolies for IGOP's grid access 131; removing vested interest xxii

BAT see best available technologies

$\mathrm{BaU}$ see Business-as-Usual

Belgian 68, 90, 114-15; electricity companies 115; politicians and regulators 63

Belgium 29, 63, 91, 99, 114, 214-15

benefits xviii, 21, 56, 69, 80, 97, 114, 152, 163, 165-6, 169, 171, 174, 180, 186-7; environmental 1; public 38, 165 ; source of 21

bequests (regulatory) 50, 54

best available technologies $8,36,57$

bills $9,37,43,45,47,64,67,77-9$, 84-5, 114-15, 117, 150, 153, 162, 175; auction 136; electricity 10,27 , 37, 84, 115, 133, 135-6; fossil fuel 43; permit 79; pollution 77

biodiversity 165

bioenergy 67

biomass 66, 68, 72, 187

Böhm, S. 2-3, 31, 36, 83, 86, 144, 162

Böhringer, C. 34, 71-2, 149, 188

Boulding, Kenneth 89

BP see British Petroleum

British Petroleum xxi, 48, 78, 93-4, 97, 104, 120, 128; emissions trading scheme 201; launching internal carbon trading among $\mathrm{CO}_{2}$ emitting activities in its facilities: 128

Bromley, D.W. 5, 21, 23-4, 82, 117, 125, 156, 200, 210

Bryant, G. 87, 113

Bryner, G.C. 58, 71

budgets 12, 78-9, 91, 97, 162, 189; adaptation 40; luxurious 108; public 26; R\&D 97

bureaucracy 125, 129, 143-4

Burtraw, D. 50, 53-5, 60

Business-as-Usual xxi, 10, 102, 104, 120-1, 123, 131-2, 136-7, 139, 141, 150-1; activities 121, 141; of the fossil fuel companies 102; maintaining with the corresponding emissions 100, 119; in nuclear power and fossil fuels 88 , 110 ; reconciling profitmaking with climate goals $\mathrm{xxi}$

business models 10, 20, 119, 133 
businesses xviii, 34, 58, 60, 74, 76, 84, 117, 120, 126, 131, 142, 200, 209, 213 ; core 138 ; intensive 75 ; maintaining 100; nuclear fuel xxi; privileged 134; protracting 157; small 152, 197; standard 53

buyers 52, 116, 138

Calel, R. 41, 43, 78

Callen, T. 90

campaigns 48, 73; around the import of emissions trading to Europe 48; organized on the EU State aid guidelines 72

Canada 17, 163

Cap and Trade xxii-xxiii, 6, 8, 10, 26-8, $31,46,52,55-6,59-60,82,86,88$, 119, 124-31; concept 128; discourse 136; economists at the front line of 132; efficiency 128; emissions 36 ; narrative 128, 131, 140; powerful companies wanting and advocating 125 capabilities xxii, 45, 51, 57, 63, 75-6, 87, 122; entrepreneurial 176; human 38 ; paralyzing hostile oil production 105; public 54; respective 19

capacity xx, xxiii, $25,27,51,54-5,57-8$, $68,70,100,104,134,190-1,193-4$, 196-7; availability of 193; computing 110; existing competitive power 70 , 134; expanding supply 100 ; factors 183, 197; infinitesimal 80; installing renewable 134, 191; options 191; planning 201; rates 194; recently built coal 84; reserve 194; solar 107; two-part tariffs charging 15

CAPEX see capital expenses

capital 4, 94, 96, 141, 152, 160, 188; accumulation 87,148 ; budgeting 165 , 188; expenses 191-2; human 150; invested 72; investments 182; markets 205; natural 168

carbon 13, 33-4, 78, 87, 98, 100, 109-10, 144, 161-2, 165-6, 200, 202, 209-11, 214, 216; bills 150; capture and storage $\mathrm{xxi}, 88,110$; charges 27 , 133; coalitions $35,86,123,143,209$; economy 111; emitted xxi, 117, 156, 160; energy-related 97

carbon dioxide xix, 7, 117, 160, 203; emissions 16, 103, 117; fixed point sources of 7

carbon emissions xvii, xix, 13-14, 32-3, $36,39,42,44-5,116-17,118,120$,
139-42, 144, 177, 179; abatement programs 148, 163; cost-effectiveness 163; marginal abatement costs 23 ; mitigating 132; pricing xvii-xxiv, 1-38, 39, 40-217; trading schemes 3, 14, 31, 35, 43-4, 46, 195

'carbon emissions price stair' 39, 44 carbon-free energy supplies 97 carbon-free energy transmitters 113 carbon fuels 94

carbon leakage $34,37,44,78,121,128$, 150, 204, 217; avoiding 149; fears of 84

carbon markets $2-5,9,37,86-90,100$, 119, 140, 143-4, 200, 207-8, 210, 212,216 ; design 87, 143; fraud in the years 2008-2010 116; global 216; and limited jurisdictions 148; measures adopted 49; single largest 2

carbon pricing xvii-xix, 1-3, 4, 12-14, 16-17, 23-4, 27-8, 30-1, 37, 42-4, 76-7, 124, 126-8, 146-51, 159-64, 212-14; advertised xvii; applied xxii; discourse on 29; global uniform 15, 24, 215; increasing xix; juxtaposing reality and discourse on 85; practices 17; results 147; setting 126; study of 3 ; and trading 4; uniform xviii, 1, 17, 29, 138,204

carbon taxes xxii, 35, 49, 117, 120-1, 131, 148, 150, 163, 180, 202, 210; brutal 150; charging 121; payments 139; proposals 6; uniform 23

carbon trading 3, 6, 22, 36; BP launches internal 128; global 22

Carlson, C. 49, 53-4, 58, 60

cases xviii-xix, 14, 19, 21, 38, 117, 141, 143-4, 151, 161, 175, 184, 198; environmental 82; equal xviii, 19, 151, 163; exemplary 14, 18, 87, 111, 114; fringe price 80 ; non-interacting 147 ; rare 43; single abatement 169 ; unequal xviii, 19, 163

cash $24,119,121,133,136,182$

cash drain 69

cash flow 11-12, 15, 76, 84-5, 165, 181

CaT see Cap and Trade

CBA see cost-benefit analysis

CCE see Control Committee for Electricity

CCEG see Control Committee for Electricity and Gas

CCS see carbon capture and storage 
CDM see Clean Development

Mechanism

CE Delft 8, 43, 81, 83

certificates 61, 63-4, 66, 68-9; greenpower 60,72 ; supply of 64 ; yearly average 72

chemicals xxi, 57, 95, 116-17, 119-20; see also petrochemicals

Chinese 89, 107, 130, 187; mass production making wind and PV more affordable for the poor in developing countries 187; 'one child' policy 89

choices xxii, 55, 83, 145, 178, 187, 206; preferred climate policy 31 ; producer's quantity 192

CHP see 62, 120, 131, 132

civil nuclear activity 106

civil society $60,123,126,131,149,184$, 187

Clean Air Act Amendments 199049

Clean Development Fund 6

Clean Development Mechanism 6, 125, 133; of COP3, Kyoto 1997 164; credits resulting in more than 2 billion surplus permits by end of 2012. 8 climate $24,27,29,47,52,88,92,98$, 100, 106, 108, 117, 119, 154, 156; activists xxii, 100, 112, 145; benefits xxii; economics xxiii, 1, 13, 144, 148; and energy 3; and energy policy 4; escaping collapse 110, 152, 157, 189; justice 27; policy-making resources 143; politics xxi, 29, 146, 184, 209; stability 38,40 ; sustainable action 25 , 202

climate change xvii, 5-6, 12-14, 15, 27, 38-9, 93-4, 97, 99-101, 154-5, 165-7, 170-1, 199-200, 202-3, 205-6, 208-10; addressing 3, 168; context of 13, 165-72; damage costs 39; detrimental 25; impacts of 16, 170; irreversible 18, 29, 94, 118, 122, 136; mitigating $\mathrm{xx}, 18,59,212$; responses 16

climate collapse 145; escaping xxiii, 103 , 150; evading 145; irreversible xvii, $\mathrm{xx}$, 143-4, 155

climate policy xvii-xxi, xxiii, 2-3, 11-13, 18-19, 23-9, 33-4, 84, 88, 150-1, 156-7, 162-3, 165-6, 206-12, 216-17; debates 24, 28-9, 31, 37, 120; designs 33; failure 123; global xix, 6, $25,157,168,215$; goals 60 ; instruments $49,51,84,120$; international
25; practitioners 14; preferences 116 ; unilateral 200

Cludius, J. 79, 84

$\mathrm{CO}_{2}$ 50-3, 56, 74, 94, 97, 128, 140, 154, 159; Emissions Trading System 58, 60; energy-related carbon emissions 48 , 51-2, 93, 100, 110, 113, 119, 206, 213; EU emissions permit markets 49 coal 53, 60, 93-4, 100, 103-4, 118, 120, 144, 159, 201; high-sulphur 49, 53; plants $68,78,83$; substituting low-sulphur 49; transportation costs 54

'Coal Phase-Out' 112

coalitions xix-xx, 6, 35-6, 46, 78, 82, 86-7, 112-13, 123, 143, 175, 209, 213, 217; anti-tax xix-xx, 78, 175; carbon trade 36; global pro-trading 112

Coady, D. 25, 94, 184, 189

Coase, R.H. 82, 159

'comitology' 127, 136, 141-4

common pool resources 11,157

companies xix, xxi, 7-8, 43-4, 75-6, 78-81, 91-2, 98, 114-15, 117-19, 121-2, 127-9, 131, 141-2, 193; controlled 114, 119; emitting 87; energy 114, 119; giant 91, 119-20, 135; incumbent 33, 139; large xxi, 78, 111, 116, 130-1, 138; regulated xix, 10, 42, 139-40; triumvirate of 8,122 , 127-8, 136, 142

competition 7, 52, 56, 60, 117, 195

competitive markets 12-13, 80, 192, 195

competitiveness 134-5, 201, 207, 216

conflicts xxiii, 31, 105, 116, 153;

diplomatic 105; geopolitical 94, 104; militarized 104; value 32

consumers $12,21,28,66-8,160,185$, 192, 197; demand curves 21; non-ETS 9; rational 79; small 69

corporate stakeholders 124

corporations 6, 73-6, 79, 83, 90-1, 113, $115,119,121-3,133,137,139$, 148-50, 154; electric power 86; fossil fuel 148; giant 73, 87, 137; global 150; industrial 6, 78, 149; major 44; multinational 20,112 ; power 81 ; private 143; transnational xxii, 157; triumvirate of $121,143,150$

cost-benefit analysis 1, 13, 165-72, 208-9; applied to climate change 166 , 170; constituency 166; envisaged global climate policy 169; global 13; schemes 165-6; tool evolves from 
practical over problematic to counterproductive 13; widened to address climate change globally 13

cost coverage $66,72,80,159$

cost-effectiveness $14,24,40,64,81-2$, 163 ; in abating carbon emissions 163 ; and diversity of emitting sources 173-9 costs xviii-xix, 7, 9, 11-12, 21, 38, 41, $80,83,86,163,165-6,184-5,191-2$, 194; fixed 192-3; real 66, 80, 83; social 1, 13, 17, 201, 209, 211, 216; total $24,135,166$

countries $17,25-6,30,56,61-3,68,85$, 89-90, 95, 101, 103-8, 114-15, 122,

154, 161-2; developing 6, 90, 103, 125, 130, 187, 191; exporting 98-9, 105, 148; industrialized 48, 90, 101, 191; performance, in applying financial incentive instruments 26

CP see carbon pricing

CP Symbol 128, 140-1, 147

CPR see common pool resources

Cramton, P. 13, 17, 22, 24, 31, 37, 42

customers $64,79,81,83,115,117,150$, 195, 197; high-voltage direct 15; lowvoltage 15,133 ; medium voltage 114 ; non-ETS 37, 47, 74, 84, 150; small 134, 195

Dales, J.H. 52-3, 138, 143, 159

Daly, Herman 89-90

damage costs $38-9,51,82,141,163$, 166-7, 169, 171; assessed climate 173; charged on the emitters 39; climate change 39; comprehensive assessment of public 172; estimates 51; long-term 38; public 38, 170, 172; total 166

damages 13-14, 38, 40-1, 51, 94, 163, $166,169,171,179,189$

dangers 16, 68, 71, 121, 128, 155, 172, 207

Danish 85, 102, 132, 189; and German Feed-in-Tariff support 85; inventions and innovations in renewable energy technologies 180; and the non-confused policies salvaged in the 1980s 148 de-carbonization 9, 43-4, 75, 78, 102, 120, 131, 138, 147, 203, 215; deferral agenda 127; delaying 120, 131; goal 151; innovative xvii; missions 61; success 103; technologies 46

decarbonizing 2, 58, 72, 74-6, 81, 85, 136, 139, 141-2, 145, 151, 157; commitment 74 ; facilitating industry's 151 ; goals xxii; innovations xix, xxii, 34, 41, 85, 132, 150; investments xxi, 119; obligations 121, 143; options xix; progress 150; solutions xix, 85; technologies 10, 129; transformations 121, 185; triptych 155-6

Dechezleprêtre, A. 34, 41, 43, 78

decisions 12, 74-5, 79, 81, 84-5, 204; difficult 7; human 76; logical 107; political 82; rational 86, 119

decommissioning (of plants) 107

democracy 91

deregulation 54

design 32, 47, 49, 51, 55-6, 119, 121, 140, 143, 164-5, 199, 202, 205, 211-12, 216; choices 47, 50; features 126; flawed 62; guidelines 160-1; options 35; planned 58; process 123; requirements 32-4, 37, 214

discursive power $\mathrm{xx}-\mathrm{xxii}, 4,119,122-4$, 127-8, 139-40, 156

distribution network operators 196, 198 diversity xviii, xxiii, 14, 17-22, 24, 26-30, 45, 53, 123, 131, 138, 169, 173-9, 213, 216; ambivalent treatment of xviii; degrees of xviii, 18 ; disqualifies global uniform CP 18-30; economic analysis neglecting xviii; exante 23, 27-8; framework with three dimensions 21; grades of 19; and heterogeneity 17, 20,138, 148; ignoring 178; institutional 21; natural 18, 72; optimal 21, 214; of people with various disciplines 145, 171; role of 18 , 28; societal 18

DNO see distribution network operators domes 172

Donations of Permits 3, 10, 127-8, 132, 136-8, 149

DoP see Donations of Permits

Dorward, N. 80, 192

DPSI Driving forces, Pressures, State, Impacts frame 14,15

earnings xxi, 12, 66, 76

earth 11, 14, 19, 94, 112, 118, 137, 144, 212

EC see European Commission

ecological 94, 101, 103; and economics icon Kenneth Boulding 89; economists 89,147

economic analysis xviii, 7, 13, 200-1, 211-12; experience based 29; modern 159; standard xvii-xviii 
economics xvii-xviii, 1, 3, 13-15, 18, 20, 23-4, 121, 125, 127, 151, 199-202, 204-5, 208-13, 215-17; concepts 1-2, 10; discourse 25, 74; logics 5, 28-9; mainstream 29-30, 188; profession xx, 11, 54, 148; scholars 58, 73-4, 78; theory xviii, xxii-xxiii, 1, 20, 28-9, $32,64,81,172,200,202,208-9$

economies xix, 17, 104, 128, 154-6, 194, 199, 214; industrialized market 113; low-carbon 14, 59; real xviii, 20, 22-3, 30,81

economists xvii-xviii, $\mathrm{xx}$, xxiii, 11 , 13-14, 21, 23-5, 32, 34, 42, 44, 82, $84,147,149$

ecosystems $5,27,104$

Edenhofer, O. 46, 74

Ehrlich, P. 89

Ekins, P. 23, 84

EITE see Emissions Intensive Trade Exposed

electric power xix, xxiii, 14, 67, 75, 89, 133, 184, 190-1, 193-4, 197; companies xvii, xxi, 8, 78-9, 83, 103, 111, 113-14, 116, 120, 131-3, 135, 138, 162; corporations 86; generation 37 ; industry 118 ; supply systems 196

electricity xviii, xxi, xxiii, 62, 64, 80-1, 101-2, 110, 113-14, 152, 188, 190-3, 197, 203, 213; bills 10, 27, 37, 84, 115, 133, 135-6; companies 8, 119, 132, 150; consumers 9-10, 42, 65, 67-8, 71, 85, 133, 136, 141, 186, 198; consumption 62-3; generation companies xxi, 43, 80, 110, 178, 187, 192-3, 198, 214; markets 60, 62, 120, 132, 154, 185, 195, 203, 213; non-ETS customers $37,74,84$, 150; pricing xix, xxiii, 14-15, 132, 147, 151, 154, 209; promotion of $62,203,206$; sector 47 , $62,74,78,83,110,117,119,195-6$, 215; storage 110, 190; supplies 63, 65, 80, 107, 134, 190, 192, 213, 215;

systems xxiii, 96, 152

electronics 65, 101

Ellerman, A.D. 2, 22, 34, 36, 48-9, 53, $56,58,60,188$

emission allowances 7, 37

emission levels 174-5, 177

emission licenses 4, 54, 81

emission permit markets 58,73

emission sources 7-8, 16, 23, 36, 41, 45, 53-4, 56, 82, 143, 147, 167, 176-7; aggregate 169; capped 26; diverse 51; large-scale $\mathrm{CO}_{2}$ 52, 167; major 40; priced xviii; regulated 41; scoped 167 emissions xix, 27-8, 34-5, 37-9, 41-2, $44-5,51-7,75-7,81-2,128-30$, 138-40, 160-1, 166, 173-4, 176-7; carbon 34, 37, 141; costs 37; electric power generation 10; energy-related 100, 103; fringe 43, 119; global xvii, 14 ; heavy taxing carbon 128; historical 8, 36; industrial 150; low carbon 97; markets 53, 59; mitigating carbondioxide 105; permits $34,41,46,78$; 'no price on carbon' 117; prices 25 , 38,76 ; reducing carbon $10,14,33,38$, 41-4, 51-2, 81, 85, 105, 146, 148, 156, 161, 168-70, 173; tax carbon 17; tradable 32, 34-5; zero-carbon 41, 100

Emissions Intensive Trade Exposed (industrial activities) 8, 10, 26-7, 34, $37,44-5,47,56-7,79,83-4,128$, 149, 186

emissions trading $2,4,6-7,48-50$, 111-13, 116, 119, 121, 123, 125-8, 130, 138-9, 199-200, 209-10, 216-17; amalgamated 33; CaT discourse 123 ; community 7 ; complements and compatible with other policies 7, 48; defending 2; economists advocating xix; experiments 49; global 125, 140; greenhouse gas 201, 203; hybrid 156; international GHG 48; performance 7; program 50, 81; proponents 112; proposals 49; schemes 7 , 201

emissions trading systems xvii-xxiii, 1-6, 8-20, 22-65, 67-74, 76, 78-145, 147-51, 156-9, 161-2, 176-81, 187, 194-6, 200-3, 205-17; anatomy of 31-47, 215; bills 74, 84-5; companies $44,52,136$; consisting of four components and their relations 45 ; discourse xxiii, 125, 127, 140; exemplar 32-3, 44, 46-7, 138; existing 209; permit prices $9,40,83,117-18,124$, 127, 147; Reports 6, 9

emitters 14, 23, 35-9, 55, 76, 82, 124, 173, 176-8; categories of 177; economic rational 174; GHG 57, 82; incentive prices for 37; largest 10, 113, 121, 174; major 20, 74; regulated 175; single 130; sources $14,173-9$

energy 5-7, 15, 19, 75, 88, 93-4, 101, $135,138,145-9,183-5,202-5$, 207-8, 212-13, 216-17; alternative 91, 


\section{Index}

204; atomic power companies 75; carriers 133; chemical 190; climate policy designs xviii; and climate politics 184; companies 70; economics 1 , 3; electric 190; fossil fuel xxi, 98, 110; intensive industries 34, 47, 72, 111, 116, 204; justice 27, 207, 211; kinetic 103; lowcarbon supply xxi, 109-10; markets 114-15, 132, 203; mechanical 190; non-sustainable 110; safeguarding Europe's 134; secondary 190; sector 93, 113 , 129; sources 62, 183, 190; storable 197; and technology 145-6; thermal 123; transformations xxi-xxii, 89, 101, 145, 155; transitions 142, 192, 205, 207, 216; use and GHG emissions 93

energy efficiency xxi, 94, 97-9, 101, 106, 132, 162, 204; budding 148; buildings 132 ; equipment 98 ; extra 153 ; frustrated 98; improving 93; measures 51 , 100; modern 97; path (opportunity missed) 99; pioneering 132

energy policy 2, 4, 63, 70, 134, 217;

Belgian patchwork of authorities in 63; developed to an open scientific platform 135; German renewable 41; including carbon pricing and emissions trading 2; nexus 88

environmental 58, 68-9, 153; carbon pricing 159-64; economics $1,23,125$, 180, 185, 213; effectiveness 34, 40, 58, $62,82,106,124,163$; justice 27, 216; negative externalities 99 ; policy 58 , 161, 173, 200, 205, 207, 211, 213

Environmental Protection Agency 50-4, 203

EPA see Environmental Protection Agency

ESMA see European Securities and Markets Authority

ETR see Environmental Tax Reform ETS see emissions trading system

EU ETS 10, 25, 33 , 44, 46-7, 49-50, 52, $56,74,78,80,82-3,112,118$; carbon emissions $\mathrm{CaT}$ concept 128 ; $\mathrm{CO}_{2}$ emissions permit markets $49 ; \mathrm{CO}_{2}$ emissions trading system $50-1$; emissions trading system 72; observed performance of the 141; permit prices 9

Europe xvii, 8, 25, 48, 60, 107, 113-14, 120, 124, 126, 130-1, 135, 196, 204-5, 214; carbon markets 200, 203; climate politics 6
European Commission 3, 5-10, 31-2, 36-7, 40, 48-50, 52-3, 56-7, 60-5, $70-3,111-14,118,121-4,129$, 132-5, 202-3

European electricity companies 131-2, 199

European energy companies 70

European industrial activities 34, 57

European Parliament 61

European pro-trading business coalition of oil and power companies 6

European Securities and Markets Authority 116, 138

European Union 203-4, 208, 213; Climate Change Unit's intentions and visions 6; Emission Trading 214; excess profits 65, 66, 67, 69-71, 132

false narratives xxi

feed-in tariffs $61,68,71,133-4$

financial departments 43, 116, 138

financial incentives $1,3,11,18,23,26$, 28-9, 136, 140-1, 148, 151, 156-8, 160-1, 162, 180-9; applying 84; and cash flows 11; common 160; designated 161; designed 102; differentiated 23 ; instruments 26 ; uniform 179; used in environmental policy making 161 financial instruments 18, 23, 25, 100, $152,161,183$

financial products $116,137-8$

financial resources 97, 121-2, 129

financial return rate 183

financial revenues 165

financial support $64-5,97$

financial transfers $43,62,65-7,71-2$, 161

FIT see German feed-in-tariff

Flanders 62, 63, 67-72, 185, 214

fossil fuel xxi, xxii, 52, 88, 93-4, 97-8, 102-3, 105, 113, 119-20, 123, 133, 136, 142, 144-5, 149-52, 154-5, 184,189 ; and atomic power energy companies 75 ; bills 43; cheap 156 ; combustion 78, 113, 155, 186; companies 102, 113, 117, 120; corporations 148 ; data 52 ; dense 146 ; expansion 89, 93; industry 118-19; prices 98, 106; reserves 94, 101; substituting 191; use 51, 93-4, 149, 151

free allocation of allowances 3, 36, 55, $74,79,81,83,86,117,212$

free emission permits 44, 82, 149

Fri, R.W. 61, 97 
fringe pricing xviii-xix, xxii, 47, 73-85, $128,133,138,140,149,190-8$; charged by some power corporations on the invoices of captive customers 81; EU ETS 128; idiosyncratic xix; and price-induced-technological-innovation 74-85

Frondel, M. 42, 71, 137, 149, 188-9

Fuchs, D. xxii, 113, 122-4, 127, 142

fuels 93, 103-4, 116, 150, 152

gas xxi, 86, 104, 113-14, 120; companies 113, 119; natural 55, 93, 100, 103-4, 120

GDP see Gross Domestic Product generated power xxiii, 68-9, 80, 111, 158, 184, 191

generation plants 110, 190, 194, 197

generation systems 152, 190, 193-5; company's 193; composed 191; controlled electric power 194; integrated 191

generators $\mathrm{xx}, 64,66-7,71$

Germany xvii-xviii, 42, 61, 68-9, 78, 81, 99, 120, 132, 134, 149, 184-7, 208, 213; feed-in-tariffs 180-9; industrial companies 134

global carbon trading 22

global corporations 150

global electricity generation 94, 108-9

global greenhouse warming 15

global oil rents (volume) 98

global uniform 30; carbon price xvii, 1 , $14,17,22-5,27-30,125,147-8$, 150-1, 157, 164; levy 11, 24; pricing 2, 16; tax 22

Gollier, C. 13, 24, 31, 33, 56, 73, 84, 131, 192

Goulder, L.H. 20, 24, 29, 76, 119-20, 125,180

greenhouse gas 11, 13, 16, 20, 24, 29, 31, $38,44,51-2,55,57,59,150,154$; atmospheric concentration 38-9, 51, 58,170 ; emissions mitigation efforts 14; emitters 57,82

greenhouse gas emissions 11, 14, 22, 24, $34,37,41,45,53,56-8,72-4,84-5$, 97, 99, 165-6; abatement 43, 57, 76; global 142, 211; of industrial activities 151; mitigating 48, 130, 143; problems and regulatory capacity 58 ; reducing 40, 61, 146, 166; sources 56; trading system 51-3, 58

grid customers 188
Gross Domestic Product 26, 89-90, 94, 98, 142

growth $10,14,36,64,69,89,93-4,99$, 103, 152-3, 186, 206, 209; economic 92,212 ; population and material throughput 89

GUCP see global uniform carbon price

Gupta, S. 17, 24, 159, 164

Haas, R. 61, 62, 70, 107, 134

Haas, T. 149

Hahn, R. 2, 47, 80-2, 86, 117, 149, 205

Heilmayr, R. 20, 34, 45, 57

Held, A. 62, 70

heterogeneity xviii, 17, 19-23, 130, 138, 147-8, 176; disentangling 22; and diversity 17, 20, 138, 148; ex-ante 138; requests specific approaches 138 ; and transaction costs 130

heterogeneous xxi, 16-17, 19-20, 26, 56, 143, 176, 178; cases xviii, 22, 169, 176-7; emission activities 147; emission sources xviii, 22, 65, 138-9, 174, 176, 178

homogeneous 14, 19, 28, 139, 176; activities 176; parts 17, 19, 22-3, 176

IAEA see International Atomic Energy Agency

IAMs see Integrated Assessment Models

IEM see Internal Electricity Market

IGOP see Independent Generators of Own Power

incentives xix, 1, 12, 40, 45, 47, 61, 76, 82, 126, 147, 161, 185, 206, 208; economic 41, 203; financial 1; market 189, 199; see also financial incentives

'independence property' 47, 74, 80-3, 85-6, 149

Independent Generators of Own Power 84, 131, 135, 154, 185, 188, 197-8; activities 131, 198; distributed 135; grid access 131; ineradicable 134; large batches 154, 198; plant failure 132, 197; use of fossil fuels 197

Independent System Operators 152, 195 indispensable energy technology $\mathrm{xx}, 3,5$, $88,90,101,107,110,120,133,155$

induced technological innovation 32, 43, 73-85, 138

industrial activities xix, xxii, 8, 10, 33-4, $37,41,43-5,56-7,64,78,81,136$, 138, 150-1; innovative 186; intensive 22, 119; neutral 74 


\section{Index}

industrial sectors xxi, 8-9, 29, 37, 43, 52, $78,103,118,136,179$

industries $8,10,20,46,48,78-9,84-5$, 113-14, 116, 128-9, 135-6, 155, 157, 160,202

infrastructures xvii, xxiii, 3, 5, 88, 90, 93, $101,131,146,155,157,187$

innovations 40-4, 46, 65-6, 69, 72, 77-9, 99, 125, 128, 130-2, 139, 141, 174, 176, 179-80; shifts 77; subsidies 131

installations $8,10,29,50,73-4,77,103$, 141, 154, 185-6, 188; amortized 154; emitting 10, 52; industrial 51, 74, 79; power sector 129; rooftop PV 183 institutes 5, 38, 90, 116, 146, 155-7, 186, 188; EU 142; excelling 90; financial 85 ; nuclear 108; public governance 11 ; research 180

institutions xvii-xviii, $\mathrm{xx}$, xxiii, $3,5,11$, $28,88,91,101,126-7,135,141,210$, 214

instruments $11,17-18,25,29,33-4,41$, 46-8, 61, 64, 121, 140, 150-1, 161, 163, 205-6; economic 1, 12, 23, 111; emissions permit market 50, 54; financial incentivizing 146, 180, 185; supreme GHG emissions reduction 122

Integrated Assessment Models xix, 13, 78-9, 110-11, 148, 159, 169, 171, 199

Intergovernmental Panel on Climate Change xix-xx, 16-17, 65, 69, 79, 97, $100,108-11,117,119,124,126$, 152-3, 168-70, 205-6

internal electricity markets $60,62,120$, 132, 185, 195, 203, 213

International Atomic Energy Agency xx, 96, 108, 144

International Monetary Fund 26, 90, 201 inventions $41-3,57,64,85,98,133$, $139,161,165,180$

inventors 180

investments 12, 21, 38, 76, 92, 114, 136, 139, 141, 152-3, 160, 162, 181, 185-6, 191

investors 76, 98, 184, 186, 188

IPCC see Intergovernmental Panel on Climate Change

IRENA 10, 43, 47, 69, 71, 78, 97, 102, $133,136,152-3,155,185-6$

ISIC see International Standard Industrial Classification

ISOs see Independent System Operators
Jaffe, A.B. 180

Johnstone, P. 25, 28

Jong, M.A.P. 83-4, 129

Juergens, I. 83

justice xxii, 27, 29, 37, 150, 206-7, 210-13, 216; climate 27; distributive 37 ; environmental 27, 216

Kemp, R. 61, 78-9

Lagrange theorem 176-7, 194

Lakoff, G. 3, 156

Lancaster, K. 20-1

language xxiii, 3, 6, 9, 16, 53, 92, 103, 117, 155-6; biased 3; euphemistic 117; flawed 117; fuzzy 1; plain 108

Lauber, V. 23, 41, 61, 187

laws 5, 154, 161, 184, 199-201, 205, 211,217

LCp see levelized cost price

learning 18, 41, 43, 49, 58-9, 62, 71-2, 128; curves 71, 143, 149, 186; opportunities 72, 128; sources 60

legislation $8,51,122,131,144,150$

legislators 113

lessons 50, 55, 60, 65, 151, 202, 204-5, 211; clear 62; early 62

levelized cost price 15, 71, 180-3, 185, 188; decreasing 183; discounting expenses and revenues 182; of electricity 15; values per RE segment 186 levies 12, 14, 35, 40-1, 43-4, 159, 161, 174-5, 177; environmental 161; flat 176; harmonized carbon 73; high 41-2, 78

licenses 5, 48, 81, 89, 91, 177-8, 209; emission $4,54,81$; low-priced 82 ; to pollute 137; transferable birth 89

life-support systems 101, 146, 154

local politicians 114-15; see also politicians

Löfgren, A. 9, 78-9, 81, 83-4

London ICE exchange 9

London School of Economics 17, 24, 28, 199, 202, 208, 211

Lovins, A.B. 94, 100

low-carbon technologies 43, 47, 180

low-cost abatement options 50, 53, 57

LSE see London School of Economics

MAC see marginal abatement costs

MAR see Market Abuse Regulations

Marcu, A. 2, 6, 9, 27, 31, 34, 72, 74, 78-9, 81, 84, 136 
marginal abatement costs $22,27,36,38$, 41-4, 54, 76-8, 129-30, 141, 166, 174-7; curves MACi(q) of the aggregate of installations, with innovation shifts over three decades 77 ; and price-induced innovation 42 marginal cost pricing (of electricity supplies) xix, 190, 192-3

marginal costs xix, xxiii, 12, 14, 41, 45, 54, 66, 80, 111, 152-4, 166, 188, 191-4, 209; and fringe pricing 80; increasing 66; low short-run xxiii, 188 ; prices xviii, 79, 195; pricing xix, 3 , 47, 74, 79-80, 84-5, 128, 138, 149, 190-8; short-run 80, 191

Market Abuse Regulations 116, 138

market-based instruments xix, 6, 10, 13, $16,33,55,73,82,125-6,142,174$; discourse 84; new 48; particular (CP or ETS) 16; requesting intensive research 16; supremacy in general 125

market creation 41, 60, 180; failed xviii; with FIT financial support mechanism adopted in Denmark and Germany 132; purest textbook blend 63; shelved and replaced by ad-hoc rulings per band of RE supplies 68

Market Stability Reserve 9-10, 27, 40, $46,83,128,133,141$

markets xvii-xviii, 3-5, 9-13, 20-1, 64-5, 71, 73, 116, 128-9, 132, 137-8, 143, 177-8, 187-8, 200; advertising 129; bubble 52, 54; constructed 72 ; environmental 212; failures 64, 180, 189 ; forces $55,105,129,143$; incentives 189, 199; internal 203; liberalizing 120, 209; mechanisms 52, 54, 64, 178; pan-European 61; parties 56, 160 ; perfect 57-8, 159; prices 66, 170, 192; pull initiatives 61, 65, 69; regular 70, 134; retail 196; scoped 177; segmentation $50,53,56,62,72$; segments 53 , 56; vending 120

Markets in Financial Instruments Directive 116, 138

Markussen, P. 36, 44, 78, 208

mathematical theorems xx, 3, 11, 14, 29, 177, 179, 192; applying 24; solid 29; standard 3

mathematical treatises xix, 25, 81, 149

mathematics 18, 147

MBIs see market-based instruments

MC see marginal costs

Meadowcroft, J. 91-2, 104, 199
Meckling, J. 2, 6, 27, 31, 35, 36, 44, 48, $55,73,82,87-7,112,113,122-3$, 138,143

media $22,85,96-7,108,110,124,126$, 142-3, 156

member states 6-7, 25, 27, 37, 48-9, 51-2, 61-3, 65, 69-70, 83-4, 112-13, $131,133,142,144 \mathrm{n} 5$

metrics 16, 18-19, 71, 161-2

microeconomics 1, 21, 32, 76, 125

MiFID see Markets in Financial

Instruments Directive

mitigation 12, 33, 38, 40-1, 100, 111, 141, 155, 163, 166, 168, 171, 173; abatement activities 163, 171, 173; environmental 162; options 53, 104; precautionary 103 ; private 169 ; technologies $23,125,131$

money 1, 4-5, 12, 16, 67, 69, 76, 84-5, 117, 122, 124, 139, 175, 182, 188-9; circuits 10, 133, 136; losing 139, 147; pressures 147; skimming 37; sources 141; spending xix; subsidy 188

money flows xxii, 12, 16, 25, 160; $\$$ billions 100; cashed 76; effective 1; potential 12; quantified 16

Monitoring, Reporting and Verification of emissions 47, 147, 163, 187

Montgomery, W.D. 149

moral philosophers 10, 151

mortgage 182, 187-8; lending 187; loans 188; payments 182

MRV see Monitoring, Reporting and Verification of emissions

MS see member states

Narassimhan, E. 31, 34, 47, 79

narratives 3, 108, 117, 119, 127, 142, 155-6, 212; causality 87; false xxi; fueled anti-tax 148; imaginary 95

national accounts 25-6, 202

nationalization 113

NATO 105

natural gas 55, 93, 100, 103-4, 120

natural resources 90

natural sources xxiii, 146

nature 5, 84, 94, 101, 155, 157, 163, 168, 171-2, 183, 190-1, 198, 201, 209, 216; capitalizing 200; and the environment 168; hybrid 33 negative externalities 99, 129, 180 neoclassical economics $\mathrm{xx}, 1,3,12,14$, 28, 32, 44, 58, 86, 162, 169, 178, 191-2, 194; assumptive 151; cash flows 


\section{Index}

181; commandments 125; conceptions 32 ; core models 23; cornerstone paradigm 21; dependents 125; discourse $12,23,25$; disrupting the doctrine of 119, 180; mainstream 1; paradigm 111, 126; position on CP and GUCP 17; theory $17,21-5,27-8,30,39,94$, 125, 129-31, 138, 142, 165, 176, 181, 197, 215

neoliberal 6, 86, 92, 142; anti-tax narratives 148; economy 103; growth model 91; interests 137, 149, 155; paradigm $\mathrm{xx}, 4,148,169$; regimes 145 ; worldviews 111, 156

Nelson, J.R. 27, 80, 192

NET see Neoclassical Economics Theory net present value 181-2

Netherlands xvii, 78, 81, 113, 132

networks xxii, 15, 107, 116, 122; advocacy 87; lobbyism 142

new technologies 57, 65, 69, 141, 180

New York 93

NGOs see non-government organizations nitrogen oxides 50-4; catalysts 51; diverse 53; diverse emitting activities 53; emissions market experiments 54 ; emissions reduction programs 51-2; markets 52 ; trading programs 50

nitrous acids 51

nodes 108, 123, 154, 196

non-ETS electricity consumers 10,42 , $85,133,141$

non-government organizations 31,40 , 44, 112, 121, 123, 129; environmental 48, 74, 130; specialized 127

Nordhaus, W. 38, 167, 191

Nordstream2 (Russia-Germany gas connection project) 105

NOx see nitrogen oxides

NP see nuclear power

NPV see net present value

nuclear energy xxi, 94, 107-10, 189

nuclear fission 96, 135, 184, 215

nuclear fleet 106

nuclear fuels 145

nuclear interests 95, 97, 107, 109

nuclear power xx-xxii, 88, 93-4, 96-7, 100-1, 106-11, 133, 136, 155-6, 189, 191, 202, 204-5, 207, 215; advocacy xxi; cases 141; Hinkley Point project 135; necessity of 96 ; production plants 197; risks of 106, 108-9, 184

nuclear power reactors 119

nuclear reactors 91, 107 nuclear renaissance $95,132-3$

nuclear technology xx, 96-7, 107-9, 133

Nykamp, S. 198

OECD 38, 112, 167, 199, 209-10, 212

OECD-NEA 96, 108, 208

officials $31,44,57-8,60,62-3,78,143$

oil xxi, 6, 86, 98-9, 103-5, 113, 119-20,

144, 148, 207, 215; addictions to 104; crisis 100; crude 89, 104; demand 105; depletion 94; and electricity 113; end-use prices 105; exporters $\mathrm{xx}, 98$, 148; and gas 113; gluts 105; markets 105; palm 68; peaking supply 104 , 144, 215; prices 97, 104-5, 148; resources 104

OPEX 191-3

Ostrom, E. 21, 29, 157

"Our Common Future" - Sustainable Development 90-1, 92, 145, 155; essence 93; exposed to falsification and abuse 91; flattening the radical mission 91; non-sustainable pathways 155; paradigm 101, 149, 155; radical goals 91; renewable power based 145

Paris Agreement 125, 144, 214

Parry, I. 2, 23-4, 125, 180

parties 12, 16, 26, 75, 82, 129-30, 144, 160; controlled 115, 142; market 56, 160; non-expert 152; political 114; UNFCCC 18

patent filings 71-2

Paterson, Matthew 138

Pearse, R. 3, 31, 36, 83, 86, 144

Peeters, M. 127

penalties 12, 34, 55, 64, 69, 72, 161, 198

permit 45, 83, 85, 136-7, 174, 178; allocations $8,36-7,52$; bills 79 ; trading $83,88,151$

permit prices $37,40-1,44,76,80,147$; emissions 34, 41, 46, 78; ETS 9, 40, 83, 117-18, 124, 127, 147; high 34, 42, 46, 139; increasing 35

petrochemicals 104

photovoltaic processes xxi, 69, 71, 97, 101-2, 132-3, 135, 146, 149, 151, $154,180,183-9,197$; prices 70,183 ; technologies 71, 132-3, 136, 183, 185

Pindyck, R.S. 12-13, 24, 38-9, 73, 76, 79, 165

Pigouvian tax 159, 160, 161

PITI see price-induced-technologicalinnovation 
Pizer, W.13, 125

policies xvii-xviii, 7, 22, 29, 46-9, 51, 61, 123, 157, 163-4, 180, 184, 203, 205, 210-13; energy-climate xviii; flawed 157; goals 32-3, 64, 139; instruments 48, 58, 60-1, 63, 111, 124, 126, 129-30, 137, 159, 162, 163, $173,175,184$; performance $28-9,162$; price collar 83

political economy $\mathrm{xx}, 86-144,157$, 200-1, 208, 210, 213; analysis xvii, xxiii, 88, 135, 150; and carbon markets 2-5, 9, 37, 86-90, 100, 119, 140, 143-4, 200, 207-8, 210, 212, 216; and emissions trading $2,4,6-7,48-50,86$, 111-13, 116, 119, 121, 123, 125-8, 138-9, 199-200, 209-10, 216-17; study of EU ETS 111

political parties 5, 111, 114; ChristianDemocrat Party 114; Liberal Party 114; Socialist Party 114

political scientists 5,111

politicians xxiii, 4, 25, 31, 67-8, 89, 99, 102, 114-15, 122, 125, 132, 150, 157

politics $\mathrm{xx}$, xxii, 23-4, 87, 91-2, 136, 149-50, 155-7, 163, 199, 207, 209, 212, 216

pollutants 50

polluters $17,38,40,42,74,77,79,81-2$, $85,125,131,173,174,175-7,179$; reduce emission level from $\mathrm{q}^{\circ}$ to $\mathrm{q} \#$ 174 ; wealthy 86

pollution $38,77,151,186,191,202$

population 89-90

power xx-xxi, xxiii, 86-8, 122, 129, 131, 148, 150, 152-5, 157, 183-4, 190, 195-7, 204-5, 207-8; exchanges 153 , 195-6; supplies 136, 153, 188, 191, 197

power companies $6,10,27,37,49,53$, 95, 113-15, 132-3, 136, 141, 185; charging permit bills on captive customers 79; European 131-2; giant 115, 120, 133, 136; incumbent 133, 136, 197-8; major 8, 113, 134; private 91

power generation $80,102,110,131,136$; activities 196; capacities 120, 188; centralized xxiii, 152; coal-fired 53, 83; companies 8, 56, 119-20, 135; decarbonizing benefits 57 ; decentralized 149; distributed renewable xxiv, 155; electric 10, 36-7, 52, 57, 113, 192; emissions 10; expenses 102; investments 181; minimized on-site
114; nuclear 95, 115, 136; oligopolies 148; plants 53, 78, 194; small-scale renewable 103

power systems xxiii, 15, 152, 154, 156, 197; commanded 153; disturbing 197; electric 152, 198; existing 153; integrated electric 107, 184, 188; planned 80; renewable 197

pressures 14-15, 25, 43, 158, 165,

167-71; environmental 99; innovation 79; societal 169; tax 161

price control 9, 27, 128, 133, 141

price discrimination 13, 211

price floors 46, 203

Price-Induced-Technological-Innovation xviii-xix, 9, 32, 42, 45-7, 73, 77, 79, $83,85,131,139,141,148,150$; and fringe pricing $74-85$; in real carbon emissions abatement programs 148 prices xviii, 1, 3, 5, 13-18, 37, 42-5, 52, 69, 73-85, 124-9, 135-6, 166, 184, 192; higher 45, 74, 83, 105, 118, 178; incentive 38,40 ; investment 183 ; low 40, 154; observed 40, 55; optimal 153, 192; positive 35, 43; posted 27, 83 , 128; quoted 40; volatile 40, 83, 117 pricing xvii, xxii, 12, 32-3, 40, 73, 80, 84, 105, 120, 152, 191, 194, 206, 214; efficient 212; idiosyncratic 140 ; mechanisms 105; optimal 23; peak load 201; policies 32,214 ; public 65 ; theory 154; uniform xviii, 13-15, 22, 28, 138-9

processes 43, 75, 78, 87, 92, 97, 144, 195, 214; biomass conversion 66; carbon substitution xix; decision-making 88 , 108; emissions permit assignment 54; improved combustion 53; industrial 57, 78, 104; photovoltaic 69; policy-making 61; policy-planning 169; political 82, 86; societal 90; strategic management 75 ; trade 125 production technologies 50, 53, 56 profits $10,12,65,66,67,69-71,76,79$, $81,85,92,114-15,117,119,121$ programs 41, 49-51, 53-5, 128, 155 protests, anti-nuclear 91

public authorities 5, 10, 35-6, 40, 74, 115, 117, 126-7, 129, 131-2, 150, $177-8,188$

public offices 121

public regulation xxiii, 132; deficient 117; direct 73; shielding small power producers and end-users 152 


\section{Index}

public treasury xix, 12, 77-9, 139, 159,

174, 176

PV see photovoltaic processes

quadrant areas 76

quantitative targets $61-2$

quantities $11,16,67,74,166,173,192$,

206, 216; emitted 41, 77; equilibrium

12; optimal emissions 38 ; total 111 ,

193; yearly 111

quasi taxes 115,162

quota $24,65-6,72,176-8$; fixed 178; numeric 68 ; reducing a given 1 ; targets 67 ; yearly 35,64

Rabe, B.G. 2, 11, 17, 21-4, 27-8, 31, 99, 113, 143, 150, 164, 175

rational polluters reduce emission level from $\mathrm{q}^{\circ}$ to $\mathrm{q} \# 174$

Raymond, L. 137

reactor technologies 108-9

recycling 24, 67-8, 163

redundancy xxiii, 110, 153-4

reforms $9,40,84,144,210$

regulation $113-14,117,121,125,129$, 143-4, 147, 154, 173, 176, 197, 199, 210-11, 215, 217; ad-hoc patchwork 84; economic 213; electricity 217 ; emissions permit assignment 36 ; environmental 17, 207; flawed 67; formal 115; gas market 62; governmental 138; independent 136, 152; prescriptive command-and-control 126; public 84; stringent 44,115 ; US acid rain program $50,55,58-9$; voltage 198

regulators $53-4,63-4,69,115,173-4$, 188, 198; alert 69; authoritative 54; diligent 121; formal public 123 regulatory $5-7,50-1,54,57-8,63$, $66,68-9,82-3$; arrangements 6; capabilities 51, 57; capacity 58; constructions 115 , control periods 174 , risks 109

renewable energy $28,62-3,70,72,94$, $97,99,106,132,135,145,196,203$, 205, 206, 207-9, 213

renewable power 101, 103, 107, 110, 134, 145, 156, 215; advanced technology 78; decentralized 103; deployment xxii, 71, 134; future oriented 76; generators 107; growth 135; harvesting xxi; innovations 47; new 78; support 135 rents xix-xx, 12, 66, 72, 76, 79, 83, 85, $105,117,120,136$

revenues $7,52,80,105-6,117,131,159$, 164, 181-2, 191-2, 209, 215; see also financial revenues

risks $11,51,76,89,94-5,101,103,107$, 109, 135-6, 172, 191, 213; hydrogen explosion 95; fossil fuels 189; major global 155; nuclear power 106, 108-9, 184; operational 109; regulatory 108-9, 113; uranium mining 109

Roelfsema, M. 23

Rogge, K.S. 45, 61, 79

royalties 72,76

rules xvii, 5, 63, 110, 129, 138, 152, 161, 164, 169, 195, 198; administrative 40; equal-marginal cost 45; financial market 116; regulatory 154; supplydemand proximity xxiii; tax 114 ; technocratic 122

sales $20,69,76,80,105,131,215$

Sandbag 40, 44, 71-2, 81, 126, 134, 144, 186, 199

SCC see social cost of carbon

Scheer, H. 102, 104

Schmalensee, R. 24, 31, 33, 49-50, 53-5, $58,61,73,79,149,151$

Schneider, S.H. 109

scholars 31, 38, 40, 70, 78-9, 86-8, 113, $125,129,140,150,165$; confusing irrevocability of investments with intractable irreversibility of losses 38; not criticizing NET 23; economics 58 , 73-4, 78; neglecting one panel truncates the understanding of the other 3

SD see sustainable development self-interest xvii, xxiii, 1, 3, 11, 157 short-run marginal costs $12,80,153,188$, 191; applied on all infra marginal generated $\mathrm{kWh} 80$; pricing 80 , 191-3; system 80

sink flabs 102

SM see stakeholder masterminding smart grids 154, 198, 205

Smith, Adam 10, 151, 157

$\mathrm{SO}_{2}$ 49-55, 200; markets 50, 52-3; and NOx emissions 49, 52, 54

social cost of carbon 13, 17, 38-9, 165-6

social sciences xxiii, 21, 24, 29, 151, 163

societal transformations xxii, 5 
societies 3-6, 11-13, 90-1, 140, 145, 149, 152, 155-7, 166, 168, 171, 187, 191, 208, 213; democratic 107; industrial 93, 103, 208; low-carbon 102; modern 5; neoliberal 142; revolutionizing 89, 101-2; unequal 145

solar panels 69

Spash, C. 89, 140-1

stakeholders xxii, 16, 32, 67, 115, 122, 129, 144, 156; corporate xxii, 124, 142; engaged 46; informing 75; masterminding $\mathrm{xx}$-xxiii, 91, 119, 122-3, 126-8, 139-40, 142, 150; multiple 76

Stavins, R.N. 2, 24, 27, 31, 33, 36, 41, 47, 49-50, 53-5, 58, 61, 73, 79, 81, $82,86,117,149$

steam electricity generation source 102 Stiglitz, J. 8, 13, 17, 24, 28

Stirling, A. 21

storage xxi, 109-10, 135, 154, 214; and carbon capture xxi, 88, 110; electricity 110, 190; facilities 153, 190, 198; local 153-4, 198

subsidies xx, xxii, 11, 25, 61, 64, 68, 147, 180, 184; biomass technology 71 ; project-by-project 68; public 189 ; unjustified xxii, 150

supplies 3, 5, 40, 64-5, 68, 73, 133-4, 152-4, 157, 178, 183-5, 188, 190,

194, 198; electricity $63,65,80,107$, 134, 190, 192, 213, 215; oil 105; power 136, 153, 188, 191, 197; renewable 76,111

surcharges $84,115,150,162,186,188-9$ sustainability 92, 134, 156, 184, 209, 212, 215; assessments 96, 107, 155; attributes of the RE supplies 188; claims 97; options xxiii, 156; solutions xxiv; technology 145

sustainable development $\mathrm{xx}$, xxiii, 75 , 89-92, 93, 144-5, 155-6, 186-7, 189, 199, 202, 208-9, 217

systems $4,7,10,18-19,59,61,63,67$, $86-7,125-7,140-1,143,152-3,156$, 197; ageing 190; central 191; circulatory 145; company's 193-4; electric 103; independent 136; large-scale 103, 191; managed 195; multinational 50; neural 123; new 190; premium 70; regulatory 83,115 ; trading $13,22,24$, 176; transmission 152

Szambelan, S.J. 50, 53-5, 60 tariffs xviii, 114, 185-6, 195

tax transfers 131, 159, 176

taxes xix, xxii, 12, 14, 23, 25, 28, 73, 84-5, 118-20, 139, 159-60, 173, 175-7, 210-11

technological 92, 154, 187; price-induced innovation 46, 139; problem-solvers xxi; progress 184, 189; transfers 187; transformations 5, 88, 90, 133

technological innovation xviii, 61-2, 64-5, 69, 71-2, 77, 163, 189, 204

technologies xviii-xix, 44-5, 56-7, 61-2, 64, 66, 68-9, 71, 97, 101-2, 132, 146, 149, 179-80, 183-7; best available 8, $36,51,57,174$; indispensable energy $\mathrm{xx}, 3,5,88,90,101,107,110,120$, 133, 155; low-carbon 43, 47, 180

TGC see tradable green certificates theory xvii, xix, $12,14,80,123,125$, 127, 131, 190, 195, 200, 202, 204, 210-13; electricity economics $152-3$; microeconomic 73, 79, 206

thermal power xxi, 103, 110, 119, 142, 152-3; units 191

Three Miles Island 95, 106

Tietenberg, T. 3, 6, 24, 49-50, 53, 59, 73, 119, 125, 165-6, 170

TMI see Three Miles Island

tradable emissions permits, allocation of 35

tradable green certificates 60-72, 132, 147, 214-15

tradable permits 178

trade $22,26,36,44,52-4,75,82,116$, 121, 129-30, 141, 178, 200-2; boards 40; brokers 196; inter-firm 129; zero-sum 81-2

tradeable green certificates $60,62,71-2$; assigning 65 ; concept 70 ; failing experience of 187; market 61-4, 67, 69-70, 141; market regime on all MS 61 ; mechanisms 70; predecessors 72 ; regulations 66

trading 4, 36, 55, 60, 63, 78, 119, 121, 127, 137, 201; atmospheric pollution space 34; carbon pricing and emissions 2, 4, 111; emissions 76, 130; experiences 76, 116; greenhouse gas emission allowance 203-4; instruments for the promotion of renewable energy 61 ; systems 13, 22, 24, 176; unrestricted 55

transfers xix, 66-7, 77-8, 169, 174-5, 179; financial 43, 62, 65-7, 71-2, 161; 


\section{Index}

tax 131, 159, 176; technological 187; wealth 37

transformations xix, xxiii, 91, 101-3, 110, 113, 145-6, 149, 151, 153, 156-7, 184, 195, 210, 217; creative 156; energy xxi-xxii, 89, 101, 145, 155; millennium revolutionizing 101 ; radical 157; societal xxii, 5; voluntary 101

transmission system operators $196-8$ treasury xix, 24, 85, 128, 131, 161, 175

TSO see transmission system operators turbines 103

Turner, R.K. 165-6

Turvey, R. 80, 192

UK see United Kingdom

UNFCCC see United Nations Framework Convention on Climate Change

uniform price xviii, 14, 22-3, 25-7, 44, 66, 69, 73, 177, 216

United Kingdom 63, 66, 70, 120, 136, 216; emissions trading system 128; financial support package for the planned nuclear station Hinkley Point 70, 135; initial trading program 52

United Nations Framework Convention on Climate Change 26, 30, 51, 93, 99, 120, 155, 214

United Nations International Standard Industrial Classification 30

United States 48-50, 57, 155, 213; acid rain programs 50, 55, 58-9; Cap and Trade system 49 ; low-cost abatement options for meeting the emissions reduction caps 53; markets in $\mathrm{NOx}$ emissions 50

US see United States

US $\mathrm{SO}_{2}$ 49-50, 58; Cap and Trade system 49, 52, 56; emissions permit trade 48-50, 53-9; and NOx emissions reduction programs $50, \mathbf{5 1}, 52$

values $5,12,28,32,50,69,90,95,165$, 168-71, 181-2, 193, 202, 215; assigning numerical 40 ; causal sequence 15 , 168; conflicts 32 ; direct use 171 ; environmental 165, 170; influential 32; legal 211; monetary 65, 169-70; moral 32-3, 37; numerical 1, 14; personal 168; positive 2 ; sales 69 ; sensitive design 210; stock 76

van den Bergh, J.C.J.M. 21, 24-5, 28 variable xxiii, $39,76,87,110,152-3$, 166, 183-4, 190, 196; ambient energy currents 107; financial 26; reduction effort 166

Vatn, A. 5, 122, 142, 147, 178

VDPSI@R framework addressing climate change 168, 169

vested interests 90-2, 102, 108, 149, 156

visions $6,9,41,52,74-6,90,116-17$; corporate's 75, 85; and EUs Climate Change Unit's intentions 6; strategic 65,69

Volberda, H.W. 12, 74-6, 119, 139

Voss, J-P. 60, 127, 129

VSD see value sensitive design

water $\mathrm{xx}, 102,110-11,134,137,183$, 190, 198; currents 10, 107, 110; flows xxiii, 153; policy instrument reconciling fire and 122

WCED see World Commission on Environment and Development

wealth transfers 37

Weitzman, M.L. 13, 20, 24, 38-9, 73, 119, 159

Wettestad, J. 3, 6, 24, 31, 40, 48-9, 53, $60,71,73,78,82$

WG see Working Groups

wind turbines xx, 65, 71, 136, 146, 149 , 152-4, 185, 190

Woerdman, E. 31, 37, 42, 45, 83

Wolin, S.S. 90, 105, 113, 129, 142

World War II 89, 93, 114, 122, 154

Working Groups 169; 1 97, 111, 119, 169; 2 97, 100, 111, 169; 3 108, 111, 124, 169, 206

World Bank 17, 23-4, 79, 90, 98, 112, 209, 217

World Commission on Environment and Development 89-90, 92, 101, 155, 216 